DOE/ET/29196--T1

\title{
DE83 017479
}

\section{Final Report}

on

DOE Contract No. EC-7-S-01-5102
An Efficient Technique for Calculating
Multiple Solutions
of Electric-Field Problems
Part I

ASOI-7HET 24196

$\begin{aligned} \text { Principal Investigator: T. S. Lauber } & \text { S. B. Crary Professor of Engineering }\end{aligned}$

NOTICE

PORTIONS OF THIS REPORT ARE ILLEGIBLE.

It has been reproduced from the best available copy to permit the broadest possible availability.

Rensselaer Polytechnic Institute

Troy, New York

December 1980

\section{DISCLAIMER}

This report was prepared as an account of work sponsored by an agency of the United States C Ient. Neither the United States Government nor any agency thereof, nor any of their e es, makes any warranty, express or implied, or assumes any legal liability or responsibunty ior the accuracy, completeness, or usefulness of any information, apparatus, product, or process disclosed, or represents that its use would not infringe privately owned rights. Reference herein to any specific commercial product, process, or service by trade name, trademark, manufacturer, or otherwise does not necessarily constitute or imply its endorsement, recommendation, or favoring by the United States Government or any agency thereof. The views and opinions of authors expressed herein do not necessarily state or reflect those of the United States Government or any agency thereof.

\section{MASTER}




\section{DISCLAIMER}

This report was prepared as an account of work sponsored by an agency of the United States Government. Neither the United States Government nor any agency Thereof, nor any of their employees, makes any warranty, express or implied, or assumes any legal liability or responsibility for the accuracy, completeness, or usefulness of any information, apparatus, product, or process disclosed, or represents that its use would not infringe privately owned rights. Reference herein to any specific commercial product, process, or service by trade name, trademark, manufacturer, or otherwise does not necessarily constitute or imply its endorsement, recommendation, or favoring by the United States Government or any agency thereof. The views and opinions of authors expressed herein do not necessarily state or reflect those of the United States Government or any agency thereof. 


\section{DISCLAIMER}

Portions of this document may be illegible in electronic image products. Images are produced from the best available original document. 


\section{Foreword to Part I}

The computer program described herein was written for the PRIME 500 system then in existence at the RPI Engineering Center. It will not work on the IBM 3033 system also in existence at RPI.

The problem of translation from the PRIME to the IBM System, as well as the correction of a few errors, were undertaken as a master's project in electric power engineering by George G. Theodossiou. His project report is issued as Part II of this final report on this contract.

Prospective users of either program are advised to study both parts of the report.

The principal investigator on this project has some reservation regarding how universal this program version is with regard to geometry. That is, although the program ran successfully on the Prime system for the three examples given in the report, he does not think that it will run properly for some geometric situations on all Prime installations. Errors discovered in the translation to the TBM system are the cause of this lack of certitude.

On the other hand, the IBM system version presented in Part II is believed to be of much more general applicability. 
I. Purpose. . . . . . . . . . . . . . . . . . . . . 1

A. Calculation in practical configurations. . . . . . . . . 1

B. What is now available?................... 1

c. Improvements possible. . . . . . . . . . . . . 2

D. Summary. . . . . . . . . . . . . . . . . . 2

II. Theory . . . . . . . . . . . . . . . . . . . 4 4

A. The Finite Element Method. . . . . . . . . . . . 4

1. The variational formulation. . . . . . . . . . . 4

2. Division into small elements . . . . . . . . . . . 4

3. Choice of element shape. . . . . . . . . . . . 5

4. Choice of potential variation within elements. . . . . . 5

B. Results of Choices . . . . . . . . . . . . . 6

C. Equivalent Electric Network. . . . . . . . . . . . . 8

D. Specialization to Rectangular Grids. . . . . . . . . . 9

1. Two dimensions . . . . . . . . . . . . . . 9

2. Two dimensions with axial symmetry . . . . . . . . . . 11

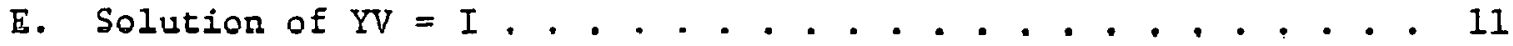

1. Relation of boundary conditions to the network equations . 11

2. Matrix expression. ................ 13

F. Splitting the Problem. . . . . . . . . . . . . . . . . 14

1. Reduction of matrix size . . . . . . . . . . . 14

2. H. E. Brown's technique. . . . . . . . . . . 14

G. Solution of the combined matrices. . . . . . . . . . 16 
The Program. . . . . . . . . . . . . . . . . 17

A. Program Philosophy . . . . . . . . . . . . . . . 17

1. Two-pass program . . . . . . . . . . . . . . 17

2. The "window" terminology . . . . . . . . . . . . . . 17

3. Subroutine CODING. . . . . . . . . . . . . 17

4. Subroutine EQUIV . . . . . . . . . . . . . . 22

5. Subroutine SOLUTN. . . . . . . . . . . . . . 24

6. Subroutine PLOTY . . . . . . . . . . . . . . 26

B. Program Organization ..................... 27

1. Division into sub-programs . . . . . . . . . . . . 27

2. Sub-Program MAIN . . . . . . . . . . . . . . . 27

3. Sub-Program CODING . . . . . . . . . . . . . . . 29

4. Sub-Program EQUIV. . . . . . . . . . . . . . . . 31

5. Sub-Program SOLUTN . . . . . . . . . . . . 37

6. Sub-Program PLOTY. . . . . . . . . . . . . . . . 44

7. Sub-Program PERTRI . . . . . . . . . . . . . 45

8. Sub-Program FSTR . . . . . . . . . . . . . . 45

9. Sub-Program SUBD ................. 45

10. Sub-Program INTER. . . . . . . . . . . . . . . . 46

11. Sub-Program DIGIT. . . . . . . . . . . . . . 46

12. Function NODFT . . . . . . . . . . . . . . 46

13. Function NBOUfT. . . . . . . . . . . . . . 4 46

Descriptions of Arrays. . . . . . . . . . . . . . . 48

List of Varlables . . . . . . . . . . . . . . . 51

C. Users' Manual. . . . . . . . . . . . . . . 53

1. Introduction ................... 53 
2. Input Data. ............... 53

3. Run identification and over-all geometry

(IDENT, FLAXI, RMIN, SORIG) .......... 54

Glossary. . . . . . . . . . . . 55

4. EQLIN, EPSO, WITHN, NOLIN ........... 56

5. Window location (for equivalent formation runs only)

(HLF, HLL, VLF, VLL).............. 57

6. Grid definition

$(\operatorname{PCHV}(16)$, DIGLN, PCHH (16), DIGLN) ........ 57

7. Contour specification

(PNTS, EPS, POT, CODE, DIGLN) ............. 59

8. Computation of the equitralent.............. 62

9. Computation of field strengths. . . . . . . . . 62

10. Input and Output files. . . . . . . . . . . . . . 64

11. Error messages. . . . . . . . . . . . . 64

12. Compiling, loading and running the program. . . . . . . 65

13. Example . . . . . . . . . . . . . . 66

IV. Program Verification. . . . . . . . . . . . . . . 73

A. Summary . . . . . . . . . . . . . . . . . . 73

1. A Cable Splice. . . . . . . . . . . . . . 73

2. Circuit Breaker Bushing Throat Shield . . . . . . . . 75

3. Transformer Turns . . . . . . . . . . . . 75

B. Cost Comparisons. . . . . . . . . . . . . . . 76

V. Program Limitations . . . . . . . . . . . . . . . . 88

Appendtx 1 a $b$ c Constants for Triangles . . . . . . . . . . . . A.1

Appendix 2 Minimization of the Functional . . . . . . . . . . A.2

Appendix 3 Program Listing . . . . . . . . . . . . . . . A,4

Lppendix 4. Flow Charts . . . . . . . . . . . . . . A. 37 


\section{LIST OF FIGURES}

Figure

Page

2.1 Regular Rectangular Grid in Two Dimensions. . . . . . . . 10

2.2 Triangle I from the Regular Grid. . . . . . . . . . 10

2.3 Admittance Network Representing Triangle. . . . . . . . 10

2.4 Regular Rectangular Grid in Axi-Symetric Two Dimensions. . 12

2.5 Trlangle I from the Axi-Symmetric Grid. . . . . . . . . . . 12

2.6 Admittance Network Representing Axi-Symmetric Triangle, . . 12

III.A.1 Decomposition into Two Regions. . . . . . . . . . . 19

III.B.3.1 Vertical and Horizontal Zones.............. 30

III.B.4.1 Box Definitions . . . . . . . . . . . . . . . 33

III.B.4.2 Illustration of Matrix Rearrangement. . . . . . . . . . . 36

III.B.5.1 Illustration of Pointer Arrangement . . . . . . . . . . 40

III.B.5.2 Orientation of Triangles. . . . . . . . . . . . 4 42

III.B.5.3 Correlation Between Additional Admittances and Boundary

Nodes . . . . . . . . . . . . . . 43

III.C.1 Input Data Sample... . . . . . . . . . . . 61

III.C.2 Cable Splice. . . . . . . . . . . . . . 68

III.C. 3 Schematic of the Problem. . . . . . . . ... 69

III.C.4 Lines Indicating Grid Density Changes and the Window. . . 70

III.C.5.a Equivalent Input Data . . . . . . . . . . . . . 71

III.C.5.b Window Input Data . . . . . . . . . . . . . . 71

ITT.C.6 Window solution of Cable Joint. . . . . . . . . . . . 72

IV.1 Cable Splice. . . . . . . . . . . . . . . 74

IV. 2 Andersen Solution of Cable Joint. . . . . . . . . 77

IV. 3 Window Solution of Cable Joint. . . . . . . . . . . 77

IV.4 Enlargement of Andersen Solution in Window Region of

Cable Splice. . . . . . . . . . . . . 78 
V.5.a Window Solution for Square-Cut End. . . . . . . . . . 79

IV.5.b Window Solution for Ramp-Cut End. . . . . . . . . . , 79

IV. 6 Interrupter Tank Assembly . . . . . . . . . . . . 80

IV.7 Circuit Breaker Bushing Throat Detail . . . . . . . . . 81

IV. 8 Andersen Solution of Circuit Breaker Bushing Throat . . . . 82

IV.9 Window Solution of Circuit Breaker Bushing Throat . . . . 82

IV.10 Enlargement of Andersen Solution In Window Region of Circuit Breaker Shield. . . . . . . . . . . 83

IV.11 Shield Variations . . . . . . . . . . . . 84

IV.12 Transformer Winding . . . . . . . . . . . . 85

IV.13 Andersen Solution for Transformer Winding . . . . . . . . 86

IV.14 Window Solution for Transformer Winding End . . . . . . 86

IV.15 Enlargement of Andersen Solution in End Region of Transformer Winding . . . . . . . . . . . . 87 


\section{LIST OF TABLES}

Table Page

III.I Division into Sub-Programs. . . . . . . . . . . . 27

III. 2 Location of Sub-Program Calls . . . . . . . . . . 28

III.3 Information Requested by PRIME Subroutine SRCH\$. . . . . . 38

III.3.5.1 Logic Arrangement of the Pointers . . . . . . . . . . . 4 42

III.B.6.1 Array Concordance Between ELB and PLOTY . . . . . . . . . . . 44

III.B.7.1 Logic Table for Array IVERT . . . . . . . . . . . . . 45

III.C.1 FLAXI and RMIN. . . . . . . . . . . . . . . . 54

III.C. 2 Grid Co-ordinate Data . . . . . . . . . . . . . . 58

III.C. 3 Contour Parameters. . . . . . . . . . . . . . 62 


\section{LIST OF FLOW CHARTS}

Page

III.A. 1

MAIN Program

18

III.A. 2

Subroutine CODING

21

III.A. 3

Subroutine EQUIV

23

III.A. 4

Subroutine SOLUTN

25 


\section{Purpose}

The purpose of this report is to present a digital computer program capable of calculating the electrostatic field in an arbitrary two-dimensional configuration. The program was developed as a preliminary result in a project aimed at producing a three-dimensional program. Thus, this report represents an interim report on the entire project.

\section{A. Calculation in practical configurations}

The electrostatic field is known to satisfy Laplace' equation in chargefree regions.

$$
\nabla^{2} \phi=0
$$

The partial differential equation is solved numerically, on a digital computer, in the dielectrics of a given system, subject to given or known boundary conditions. The boundary conditions, given by the operator, will consist of the geometry of the problem surfaces. That is, he will give the location and shape of conducting electrodes, dielectric interfaces and bounding surfaces. He will also give known potentials of electrodes. Among the boundary conditions known from theory to require satisfaction are that a conductor will have a single potential, that cut bounding surfaces have no potential gradient normal to them, and at the interface between two different dielectrics, that the normal components of displacement field are equal and the tangential components of electric field are equal.

It was the aim of the project that no geometric restrictions would be placed on the configuration. This was imperfectly realized. For instance, it was found that boundaries involving small acute angles cause problems. Such restrictions will be discussed in a later part of this report.

\section{B. What is now available?}

Several, maybe many, digltal programs have been developed to perform this calculation. Some are available comercially. For example, a program written by Prof. 0. W. Andersen of Norway is available from him. Other commercial versions of such programs are available from organizations such as Swanson Analysis Systems, Inc. and the General Electric Company Research and Development Center.

The limitations of these programs are in the number of simultaneous equations which can be solved for an acceptable cost. Greater accuracy through smaller divisions (finer grids) results in a larger system of equations. Therefore run costs are greater.

Acceptable costs are defined by the user. Many near-repetitive runs in a trial-and-error deslgn process would require a much lower cost per run than a final design check run. 
Run costs depend strongly on the programmer's skill and inventiveness as well as the innovations in large scale computer hardware. It is not unusual to get run costs in the $\$ 5$ to $\$ 20$ range for grids with 200 to 600 nodes. Although the programs cited can accommodate more than 2000 nodes in reasonably large hardware configurations, the run costs escalate and can be a few hundred dollars for grid sizes around 3000 nodes.

\section{Improvements possible}

The set of simultaneous equations, resulting from the finite element formulation of a problem, which must be solved, bear a strong resemblance to the equations of large electrical networks. Such networks have been studied extensively and efficient techniques for solving their systems of equations have been developed.

One such technique is used when a system is too large to be solved in one run. The concept is to separate the system into two sub-systems: one sub-system, call it $A$, is to be solved in detail because solution values are crltical in its region; the other sub-system, called $B$, must be considered in its effect on the A solution, but its detailed internal solution need not be considered. The equations for the nodes in $B$ are solved in terms of variables at those nodes interconnecting $B$ with $A$, i.e. an "equivalent" of $B$ as viewed from $A$ is formed. This equivalent is much smaller than the total B system. Then the equivalent can be combined with a system for $A$ and solved for the variables in $A$.

Use of this technique permits separation of a large problem containing many thousand nodes into a "window" and a "discardable" region. The window would correspond to region $A$ and region $B$ is discardable.

For design variations only within the window, region $B$ need be computed only once. Thus the repetitive design runs are limited to the number of equations contained in the window. The result is a lowering of run costs for the repetitive runs, but requires a larger run to establish the equivalent initially.

It should be noted that equivalents, or partial solutions, of parts of complex structures can be formed and retained for future use.

Therefore, it is expected that larger systems can be solved with this technique than can be economically solved by considering the entire region at one time. This permits finer grid subdivisions and therefore greater accuracy if run costs are held constant. On the other hand, if grid size is constant, run costs should decrease for multiple runs.

\section{Summary}

The program described herein is used to solve Laplace' equation in two dimensions through use of the finite element method. The set of equations 
formed by use of this method is seen to be analogous to that of an extensive electrical network of resistive branches. Such networks can be divided into several regions by the method of "diakoptics" as enunciated by G. Kron. Representation of each sub-region in terms of variables at its boundaries with other regions has been described by H. E. Brown. These equivalents at sub-region boundaries permlt placing a "window" on a very large problem.

Solution within the window is done for a much smaller set of equations than if the total problem were attempted in one computer run. 
- Theory

A. The Finite Element Method

1. The variational formulation

We are seeking a technique of calculating the electric field in a given geometry. It is known that an electric field is described by Laplace' equation in a charge-free region:

$$
\nabla^{2} v=0
$$

The solution of this partial differential equation is known to satisfy a minimization of a functional described by the Euler-Lagrange equation. Texts on variational methods are common. One adequate description of the statement above is found in The Variational Method in Engineering by R. S. Schechter; published by McGraw-Hill 1967.

J. Heuser, in NASA Tochniral. Note D-7274, November 1973, has given the variational form which applies to heat conduction problems in two and three dimensions. Heat conduction is also described by Laplace' equation in regions where no internal heat generation is present. The equations below are Heuser's results with temperature replaced by potential; conductivity replaced by permittivity; boundary conditions simplified to allow only fixed potentials and considerations of Internal generation, surface flux, radiation, convection and heat storage are omitted.

In two dimensions Laplace' equation is

$$
\frac{\partial}{\partial x}\left(\varepsilon \frac{\partial V}{x x}\right)+\frac{\partial}{\partial y}\left(\varepsilon \frac{\partial V}{\partial y}\right)=0
$$

where $\varepsilon$ is the dielectric permittivity which is allowed to be non-isotropic in the most general case.

The functional, the minimization of which constitutes the solution sought is

$$
U=\iint_{A}\left[\frac{\varepsilon}{2}\left(\frac{\partial V}{\partial x}\right)^{2}+\frac{\varepsilon}{2}\left(\frac{\partial V}{\partial y}\right)^{2}\right] d A
$$

\section{Division into small elements}

The process will then be to divide the entire range of the problem into smaller elements. In each small element, there will be assumed a variation of potential. This variation will be introduced into the functional expression (2.3). The functional will be minimized with respect to the assumed variational parameters. The result is a relation among the assumed variational parameters which represents the solution to Laplace' equation. 


\section{Choice of element shape}

The most popular choice of element shape has been the triangle in two dimensions. One advantage of such a choice is that it is easy to automate division of a problem domain into such elements. For example, 0 . W. Andersen uses such a technique in "Laplacian Electrostatic Field Calculations by Finite Elements with Automat1c Grid Generation," IEEE Transactions on Power Apparatus and Systems, vol. PAS-92, no. 5, Sept./Oct. 1973, pages 1485-1492.

Another advantage of choosing triangles is that each element has a minimum number of nodes, thus simplifying algebraic results.

However, elements may be chosen to be of any shape which fills the problem space. Of course, shapes with larger numbers of nodes per element require more algebra per calculation. The advantage may be that elements with more nodes can be larger than simpler elements, and therefore use fewer elements to fill the field.

In that which follows the two-dimensional triangles were chosen for the following reasons:

1. the literature shows greater familiarity with manipulating the simpler elements;

2. results using these shapes are available in several studies;

3. accuracy of the results of such studies has been evaluated and published.

\section{Choice of potential variation within elements}

The analytical technique is to divide the entire region of the problem into small elements in which the potential variation can be approximately described. For example, it is desirable for simplicity of calculation that, within each element, the potential be assumed to vary linearly with each dimension. This is not necessary, but it makes the calculation of an element easier.

The accuracy of the result depends directly upon how well the assumption of linearity corresponds to the actual field. In this respect, intuition suggests that smaller elements give better approximations to linearity and thus more accurate results.

Some investigators have suggested larger elements with more complex potential variations, such as quadratic, cubic or even higher order polynomials, with distance. The advantage would appear to be that more complicated variational assumptions would permit larger, and therefore fewer, elements within the problem range. Even though more nodes per element might be required, it is possible that the total calculation required might be less than that required with simpler, smaller, more numerous elements.

In that which follows, the linear potential variation is assumed in the smaller elements. This was done because: 
1. more familiar results are available and

2. it was easily seen that admittance matrix techniques apply.

B. Results of Choices

1. The results of choosing linear potential variation in a triangular element are given by Heuser(I) to be:

a. $\quad v=a+b x+c y$

b. Using subscripts to denote quantities at the nodes

\begin{tabular}{|c|c|c|c|}
\hline$v_{i}$ \\
\hline$v_{j}$ \\
\hline$v_{k}$
\end{tabular}$\quad=$\begin{tabular}{|c|c|c}
\hline 1 & $x_{i}$ & $y_{i}$ \\
\hline 1 & $x_{j}$ & $y_{j}$ \\
\hline 1 & $x_{k}$ & $y_{k}$ \\
\hline
\end{tabular}

c. Inversion of (2.6) gives abc in terms of the node potentials

\begin{tabular}{|l|l|l|l|}
\hline$a$ \\
\hline$b$ \\
\hline$c$
\end{tabular}$\quad$\begin{tabular}{|c|c|c|}
\hline 1 & $x_{i}$ & $y_{i}$ \\
\hline 1 & $x_{j}$ & $y_{j}$ \\
\hline 1 & $x_{k}$ & $y_{k}$ \\
\hline$v_{j}$ \\
\hline$v_{k}$ \\
\hline
\end{tabular}

$=\frac{1}{2 \mathrm{~A}}$

\begin{tabular}{|c|c|c|}
\hline$a_{1}$ & $a_{j}$ & $a_{k}$ \\
\hline$b_{i}$ & $b_{j}$ & $b_{k}$ \\
\hline$c_{i}$ & $c_{j}$ & $c_{k}$ \\
\hline
\end{tabular}

$\frac{v_{i}}{v_{j}}$

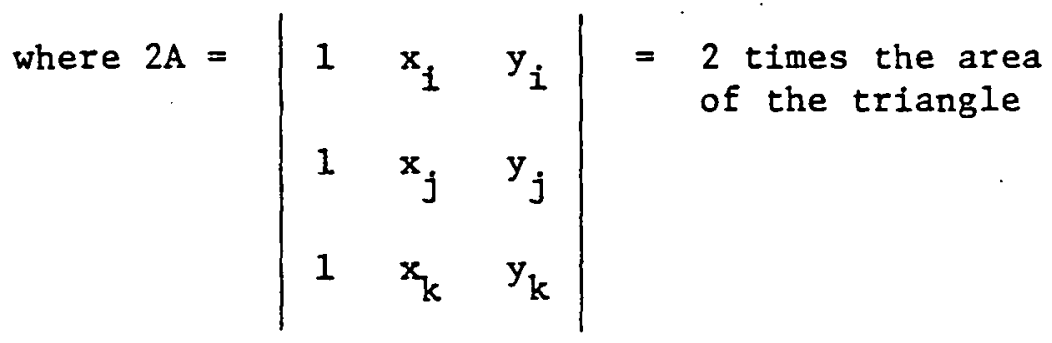




$$
a_{i}=+\left|\begin{array}{ll}
x_{j} & y_{j} \\
x_{k} & y_{k}
\end{array}\right|
$$

etc.

Expressions for all the abc values for the subscripts $i, j$ and $k$ are given in appendix 1 . Note that the results in some cases have signs differing from Heuser's results.

d. Since equation (2.5) may be written in the matrix form

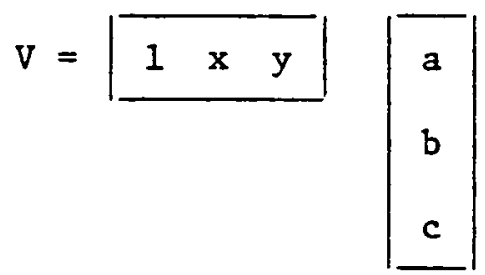

equation (2.7) may be used in this to give

$$
V=\frac{1}{2 \mathrm{~A}} \quad \mathbf{1} \quad \mathrm{x} \quad \mathrm{y}
$$

\begin{tabular}{|cc|c|}
$a_{i}$ & $a_{j}$ & $a_{k}$ \\
$b_{i}$ & $b_{j}$ & $b_{k}$ \\
$c_{i}$ & $c_{j}$ & $c_{k}$ \\
\hline
\end{tabular}

Equation (2.10) expresses the potential at any location ( $x, y$ ) within the triangle in terms of the potentials at the vertices of the triangle.

The method now requires use of equation (2.10) in the functional expression, equation (2.3), and then minimization of (2.3) with respect to each of the node potentials. This process is carried out in appendix 2 . The result, in matrix form is, when $\varepsilon_{x}=\varepsilon_{y}=\varepsilon_{z}=\varepsilon$ :

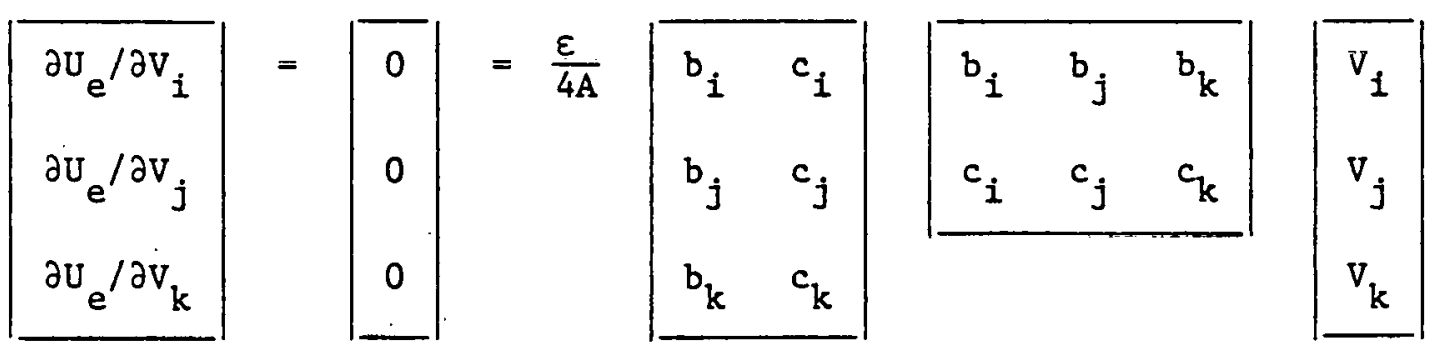


e. Equation (2.11) is seen to be of the form

$$
Y=0
$$

in which $\mathrm{V}$ is a ( $3 \times 1)$ column of vertex potentials, 0 is a ( $3 \times 1)$ null matrix and $Y$ is a ( $3 \times 3)$ matrix whose elements are given by

$$
Y(r, s)=\frac{\varepsilon}{4 A}\left(b_{r} b_{s}+c_{r} c_{s}{ }^{2}\right.
$$

where $r$ and $s$ take on the values of $1, j$ and $k$. This is seen to be symetric, that is $Y(r, s)=Y(s, r)$.

It is easily established, by direct computation from the expressions in appendix 1 , that

$$
\begin{aligned}
& b_{i}+b_{j}+b_{k}=0 \\
& c_{i}+c_{j}+c_{k}=0
\end{aligned}
$$

As a consequence, the sum of the elements in any row of (2.12) is zero.

Thus, minimization of the functional in the tetrahedron has resulted in a relation among the vertex potentials given by equation (2.12). The elements of the $Y$ matrix are given by (2.13). The matrix is symmetric and any row, or column, sums to zero.

\section{Equivalent Electric Network}

Thus far there has been obtained the matrix relation

$$
\mathrm{YV}=0
$$

Where the matrix elements are functions of geometry alone, they are symetric and the sum of any row, or column, is zero. The $Y$ matrix is $(3 \times 3)$ for the triangular, two-dimensional element. The $V$ matrix is a column of three vertex potentials in two dimensions.

The result was obtained by considering the triangular element with known vertex locations. Within each element, a linear variation of potential with distance was assumed. Introduction of this assumption into the Euler-Lagrange functional and minimizing it with respect to the vertex potentials produced the relation among vertex potentials which satisfied Laplace' equation within the element subject to the assumption of linear variation.

Equation (2.15) must be written for every element into which the field has been divided, euitable boundary potentials assigned to certain vertices and then the entire assemblage of equations must be solved for the unknown potentials. 
But equation (2.15) also is characteristic of an electrical network in wich nodes located at the element vertices are interconnected by admittance given by

$$
y(r, s)=-Y(r, s)
$$

Since the sum of elements in any row, or column, is zero, no admittance is connected node to ground at any vertex.

The electric network representation is valuable because network analysis has been so widely studied in the past. For instance, the network representing one element is easily combined with the network of an adjacent element merely by adding matrix elements between common nodes. Also, the imposition of fixed potentials from external sources to boundary nodes is easily accomplished and solution for the unknown node potentials is illustrated by

$$
\begin{array}{|ll|l|l|}
\hline \mathrm{UU} & \mathrm{UK} \\
\mathrm{KU} & \mathrm{KK} & 0 \\
\mathrm{~V}_{\mathrm{u}} & \mathrm{I}_{\mathrm{u}} \\
\hline
\end{array}
$$

In this equation $u$ means unknown, $k$ means known, $V$ means node potential and I means current required from the external source required to produce the known potentials. Normally $I_{u}$ is not required in the field problem. Thus only the upper partition of $(2.17)$ is required

$$
\begin{aligned}
& \text { UU } v_{u}+U K v_{k}=0 \\
& v_{u}=-U U^{-1} U K v_{k}
\end{aligned}
$$

Solutions of this type are a common procedure in network analysis.

Further, the clectric network analog farilitates treatment of equipotential nodes, i.e., those nodes on conductor surfaces not connected to fixed potentials ("floating"). In the electric net, all such nodes are combined and treated as one node. Admittances from any node not on the surface to any surface node are combined into one admittance by addition.

D. Speclalization to Rectangular Grids

1. Two dimensions

Figure 2.1 illustrates a uniform rectangular grid. Node numbers have been assigned arbitrarily and the six triangles surrounding node 7 have been designated by Roman numerals. It is desired to determine the admittance branches within the elementary triangles. Triangle $I$ in flgure 2.1 is re-drawn in figure 2.2. Direct calculation of the relations in appendix 1 and their use in equation (2.13) give the results 


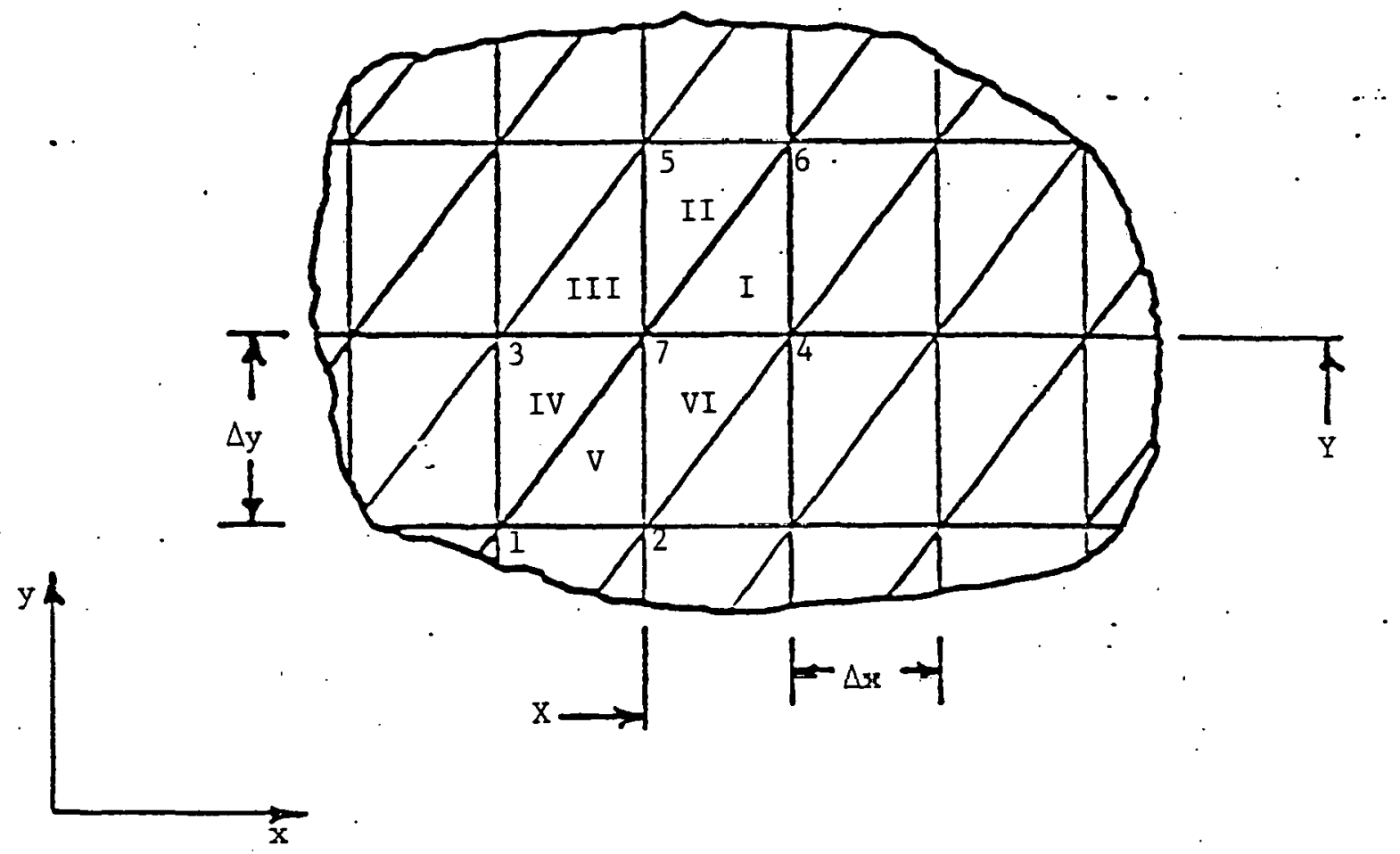

Figure 2.1 Regular Rectangular Grid in Two Dimensions

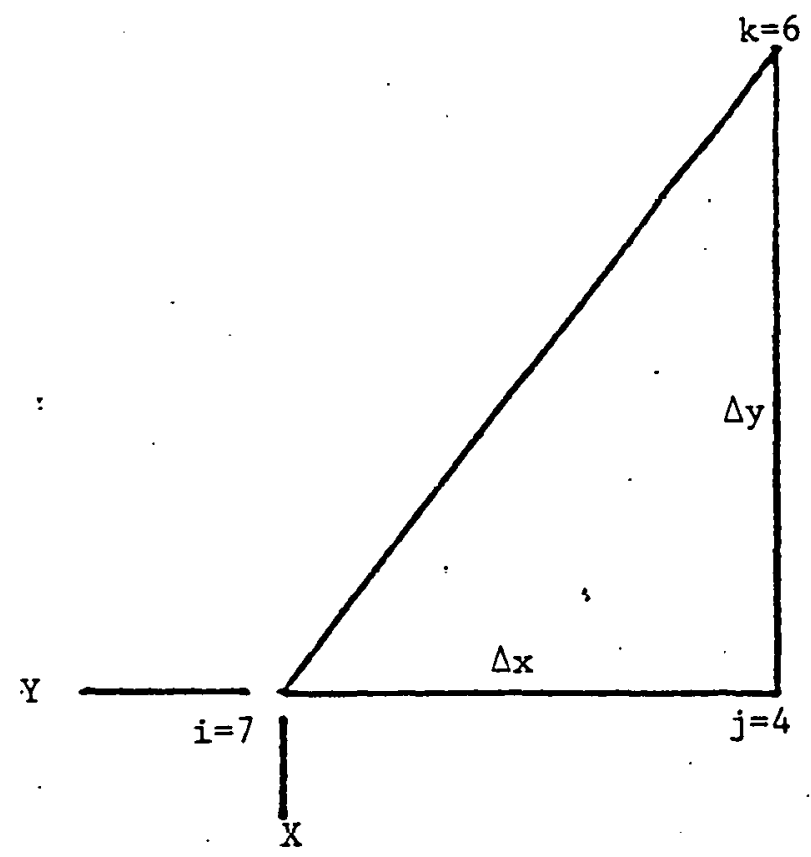

Figure 2.2 Triangle I from the Regular Grid

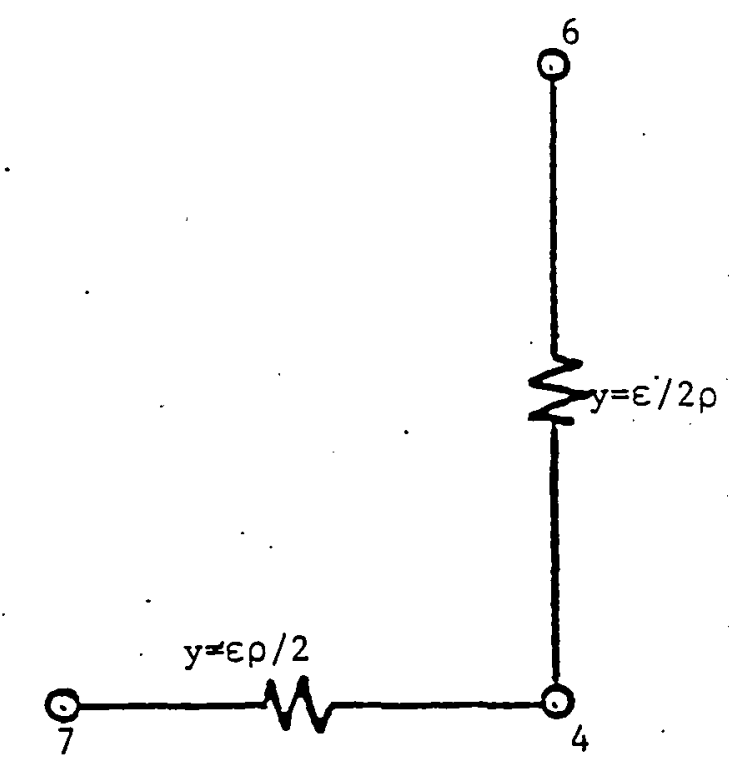

Figure'2.3 Admittance Network Representing Triangle 


$$
\begin{aligned}
Y(7,4) & =-\varepsilon \rho / 2 \quad Y(7,6)=0 \quad Y(4,6)=-\varepsilon / 2 \rho \\
\text { where } \rho & =\Delta y / \Delta x
\end{aligned}
$$

This means that triangle I can be represented by the electrical network of admittances shown in figure 2.3 .

It is intuitively evident, and proved by calculation, that every triangle in figure 2.1 has an admittance network similar to figure 2,3. That is, there is admittance $\varepsilon \rho / 2$ from the right-angle vertex horizontally and admittance $\varepsilon / 2 p$ vertically. No admittance is connected diagonally.

2. Two dimensions with axial symetry

Figure 2.4 shows the regular, rectangular, two-dimensional grid with axial symmetry in which the axis of symmetry is horizontal and the radius from that axis is shown vertical. Again, nodes are numbered arbitrarily and six triangles surrounding node 7 are given Roman numeral names.

Figure 2.5 shows triangle $I$ with $i=7, j=4$ and $k=6$. The two-dimensional relations in appendix 1 are applicable provided that results for each triangle are weighted by the radius of the centroid of the triangle. The centroid has the radius

$$
r_{c}=\left(r_{i}+r_{j}+r_{k}\right) / 3
$$

Therefore the modified results of appendix 1 for triangle I in figure 2.6 are

$$
\begin{aligned}
& Y(7,4)=-\left(R+\frac{\Delta r}{3}\right) \varepsilon \rho / 2 \\
& Y(4,6)=-\left(R+\frac{\Delta r}{3}\right) \varepsilon / 2 \rho \quad Y(7,6)=0 \\
& \text { where } \rho=\Delta r / \Delta z
\end{aligned}
$$

Matrix elements with these values are represented by the electrical network in figure 2.6 .

\section{E. Solution of $\mathrm{YV}=\mathrm{I}$}

1. Kelation of boundary conditions to the network equations

It has been shown that the field problem has been transformed by use of the finite element method to an equivalent, lumped parameter network problem. The network is specified in terms of its admittance matrix,

Thus the problem is now to solve YV = I subject to the existing boundary conditions: 


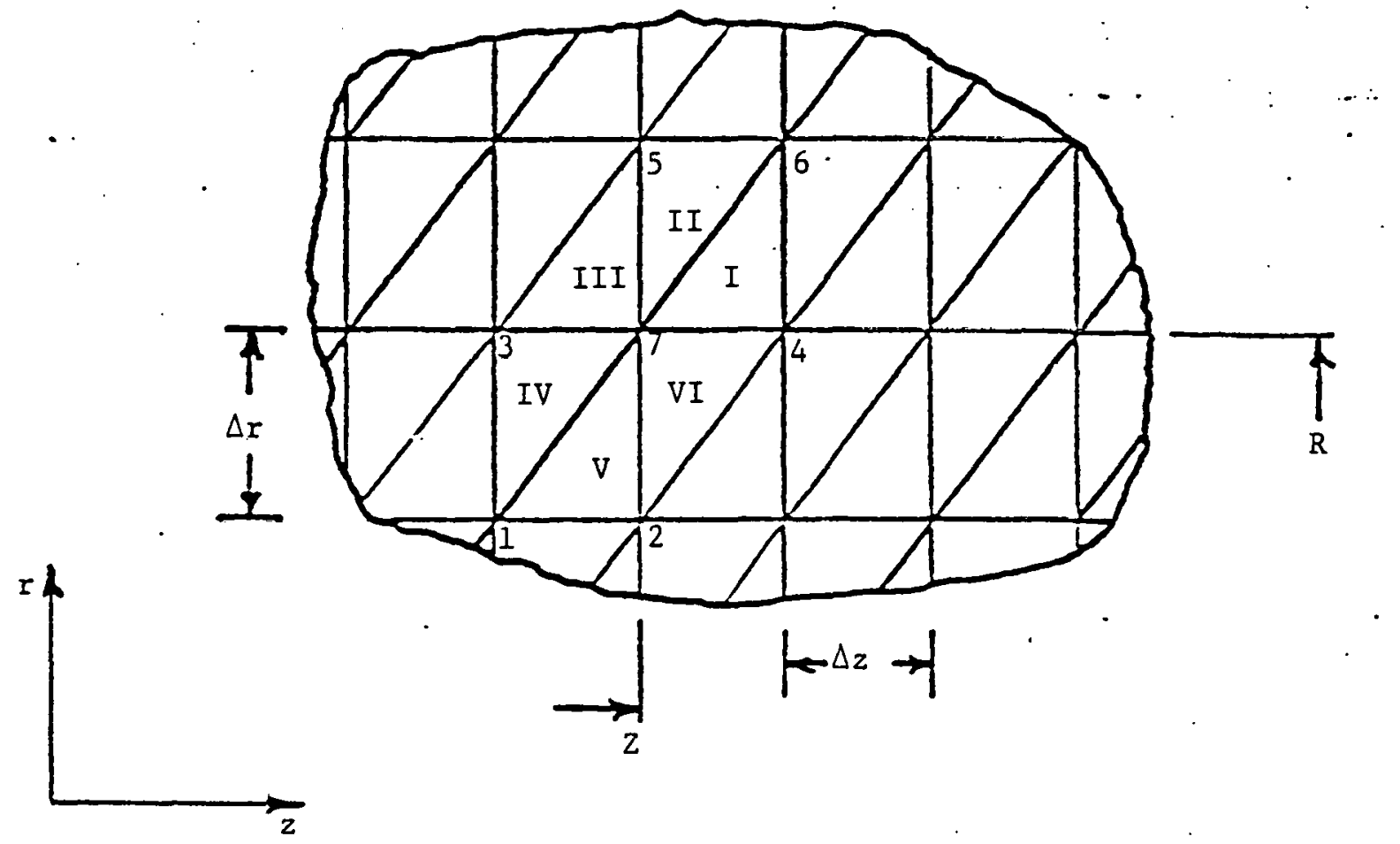

Figure 2.4 Regular Rectangular Grid in Axi-Symmetric Two Dimensions

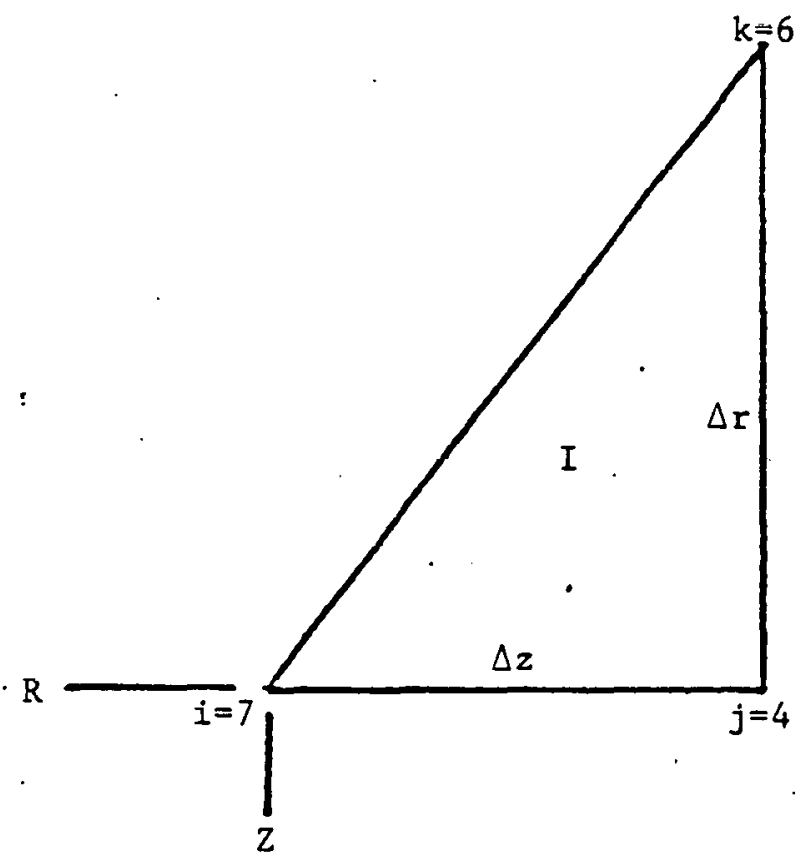

Figure 2.5 Triangle I from the Axi-Symmetric Grid

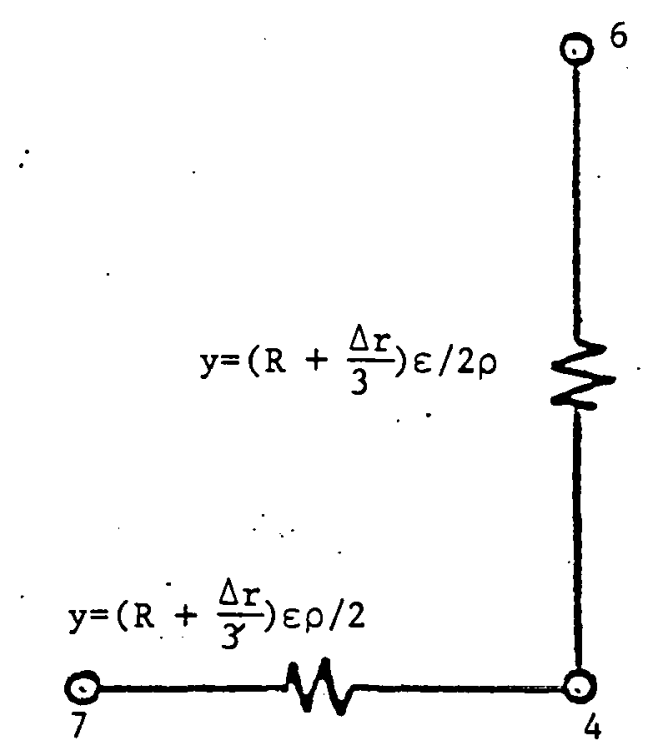

Figure 2.6 Admittance Network Representing AxiSymmetric Triangle 
a. Electrodes with known potentials are represented in the matrix by external sources which apply the known voltages from reference to the nodes. The resulting current which flows in these external sources is unknown.

b. Cut surfaces, due to limitations on problem extent or due to symmetry in the geometry, are represented by non-connection of the network across the cut surfaces.

c. Floating electrodes, with constant but unknown potential, are represented by one network node to which are connected all network branches of all element nodes located on the electrode surface.

d. Changes in permittivity are automatically included in the branch admittance values. It is important that each element consist of only one material, that is, that no element extend across a material boundary.

2. Matrix expression

The problem is now expressed as

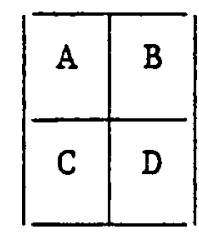

Y

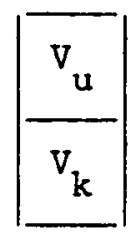

$\mathrm{V}$

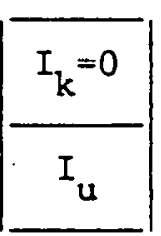

I

The matrix equation has been partitioned between the known and unknown voltages. As stated above, the currents are unknown into nodes with known voltages. On the other hand, the unknown voltages to be determined by solution are known to have zero current being injected into them by external sources.

The solution desired is seen to be

$$
\mathrm{AV}_{\mathrm{u}}=-\mathrm{BV}_{\mathrm{k}}
$$

since the unknown source currents are not required. The actual solution process will be postponed until further characteristics of the partitioned matrix, $A$, are described.

The main limitation on such problems is the size of the A matrix which can be contained in existing hardware and run costs. 


\section{F. Splitting the problem}

\section{Reduction of matrix size}

In order to accommodate larger matrices, the problem (network) can be split into two parts. In one part (b) total solution is not necessary. It is. not necessary to know the unknown potentials within this part. Thus the matrix equation can be partitioned further to separate the a and $b$ regions.

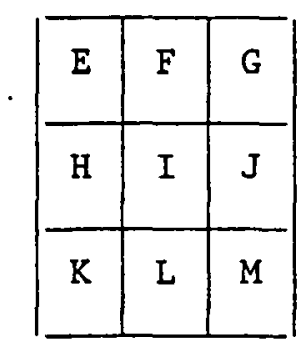

$$
\begin{array}{|l|}
\hline V_{u a} \\
\hline V_{u b} \\
\hline V_{k} \\
\hline I_{b}=0 \\
\hline I_{u} \\
\hline
\end{array}
$$

Since $I_{u}$ is not required, the bottom partition is ignored. The top two partitions become

$$
\begin{aligned}
& \mathrm{EV}_{\mathrm{ua}}+\mathrm{FV_{ub }}+\mathrm{GV}_{\mathrm{k}}=0 \\
& \mathrm{HV} \mathrm{ua}_{\mathrm{ua}}+\mathrm{IV_{ub }}+\mathrm{JV_{ \textrm {k } }}=0
\end{aligned}
$$

Elimination of $\mathrm{V}_{\mathrm{ub}}$ between these two equations gives the result

$$
\left(E-F I^{-1} H\right) V_{u a}+\left(G-F I^{-1} J\right) V_{k}=0
$$

The solution of this equation for $V_{\text {a }}$ is desired. It is seen to be reduced. That is, it is of order $E$ which is much smaller than $E, F, H$ and I together. This is referred to as a Kron reduction.

One price to be paid for reducing the problem size is the necessity for inverting the matrix I. Another cost is that the matrix started out sparse and banded but in the reduction process it becomes full.

2. H. E. Brown's technique

H. E. Brown in Solutions of Large Networks by Matrix Methods, Wiley 1975 has described a technique for developing the equivalent matrix one step at a time. This is in contrast to the implied method given above where the entire matrix was formed and then reduced. Brown's technique is illustrated for an impedance matrix rather than for an admittance matrix. The transition is trivial. 
The procedure is as follows:

a. Form the admittance matrix for partial networks, one branch at a time, for nodes lying in region $b$ (discardable) of the problem. This is easily done. For any branch being added to the net, the admittance of the branch is added to the diagonal positions in the matrix corresponding to the nodes at the ends of the branch; and the branch admittance is also subtracted from the off-diagonal positions in the matrix corresponding to the intersections of the branch end nodes.

b. When all branches connected to one specific node, $n$, are incorporated in the network, the result is

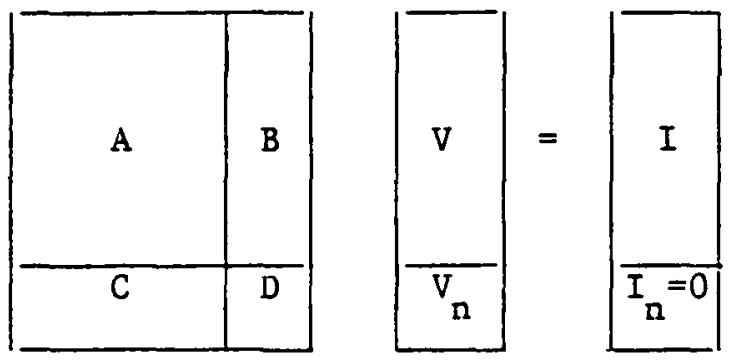

In this expression, it is assumed that node $\mathrm{n}$ is the node to which all admittance branches have been completely assembled. It is further assumed that $\mathfrak{n}$ is not on an electrode.

c. Since it is in the discardable region of the problem, the partitioned equations can be written

$$
\begin{aligned}
& A V+B V_{n}=I \\
& C V+D V_{n}=0
\end{aligned}
$$

$V_{n}$ can be eliminated from these two equations

$$
\left(A-B D^{-1} C\right) V=I
$$

This is seen to be a single-axis Kron reduction. It is easily performed because $\mathrm{D}$ is one element only.

d. The process is continued, adding admittance branches one-by-one and eliminating unwanted nodes in the discardable region as their incorporation in the $Y$-matrix is completed. Only nodes which are on electrodes are retained. 
e. It should be noted that nodes connecting region b (discardable) to region a (the window), i.e. nodes on the window boundary, are not fully connected to the $Y$-matrix by admittance branches in $b$ only. Therefore they are not discarded.

f. Completion of this process in region b, produces a matrix which contains only nodes which are on electrodes or on the surface separating $b$ from the window region, $a$. Thus, it is an "equivalent" matrix which represents $b$ as seen from $a$. The effect of the nodes discarded are still present in the matrix. However, it is not possible to solve for potentials at those discarded nodes directly from the equivalent matrix.

The advantage of the building process is that the matrix increases in size only to a certain limit which is considerably smaller than if all nodes in the discardable region were incorporated before any reduction is performed. The final equivalent matrix is somewhat smaller than the working matrix limit.

The dioadvantage of the process is that the reduction fills up the matrix. That is, the sparse character of typical admittance matrices is eliminated.

Once the equivalent matrix has been formed, it can be stored for future use in combination with solutions of various configurations within the window. One restriction is that conditions within the window must agree with conditions in the discardable region at the separation surface between them.

Thus, when desired, an admittance matrix for the interior of the window is formed with no reductions. Then it is combined with the equivalent matrix to give the final problem formulation.

G. Solution of the combined matrices

The solution can be accomplished by some form of iteration or relaxation; or alternatively and directly by some form of elimination. Specifically, in this program, successive over relaxation is the technique employed. 
I. The Program

A listing of the program is included as appendix 3.

\section{A. Program Philosophy \\ 1. Two-pass program}

It was decided to write a "two-pass" program rather than to write two separate programs. That is, it was decided to write a program which, under proper input data control, was capable of being run:
a. to form an equivalent admittance matrix at the "window" boundaries for a region outside the window; or
b. to form the admittance matrix within the window, combine it with an equivalent, if present, and solve the resulting equation set.

This was done because there are large areas of the same programming in the two program parts, equivalent formation and window solution.

The common areas are those in which a regular grid is defined, body contours are described, the grid is distorted to match the contours and admittance branch values are calculated.

The result is illustrated in Flow Chart III.A.1. The subroutines indicated there are described briefly below and in more detail in section III.B.

\section{The "window" terminology}

Because of its appearance, the region to be retained for final solution is called the "window". See Figure III.A.1. in which Region I is the window. Also in the figure Region II is part of the overall problem, the influence of which on final solution is required, but in which detailed results are not necessary.

It is important to note that the grid definitions specified by data Input in Section 3. below must be consistent for the equivalent Y-matrix of Region II and for the window Y-matrix of Region I. That is, the positions of the regular grid lines must be the same for the two runs: pass 1 - equivalent formation and pass 2 = window solution.

\section{Subroutine CODING}

This subroutine is comon to both the formation of the equivalent and to the solution of the window.

a. The function of the subroutine is to read enough control data so that the proper first pass or second pass run is performed. It also 


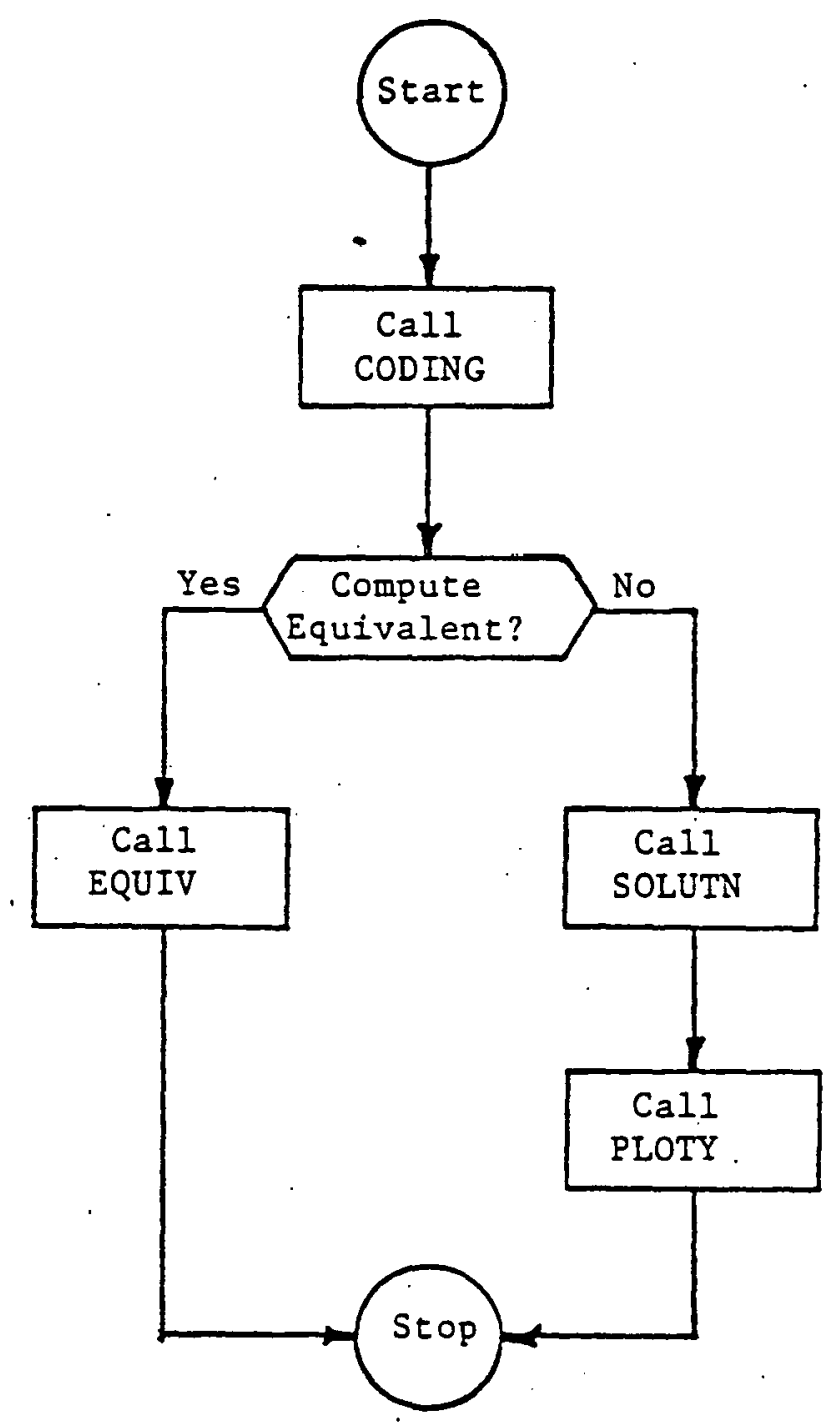

Flow Chart III.A.1

MAIN Program 


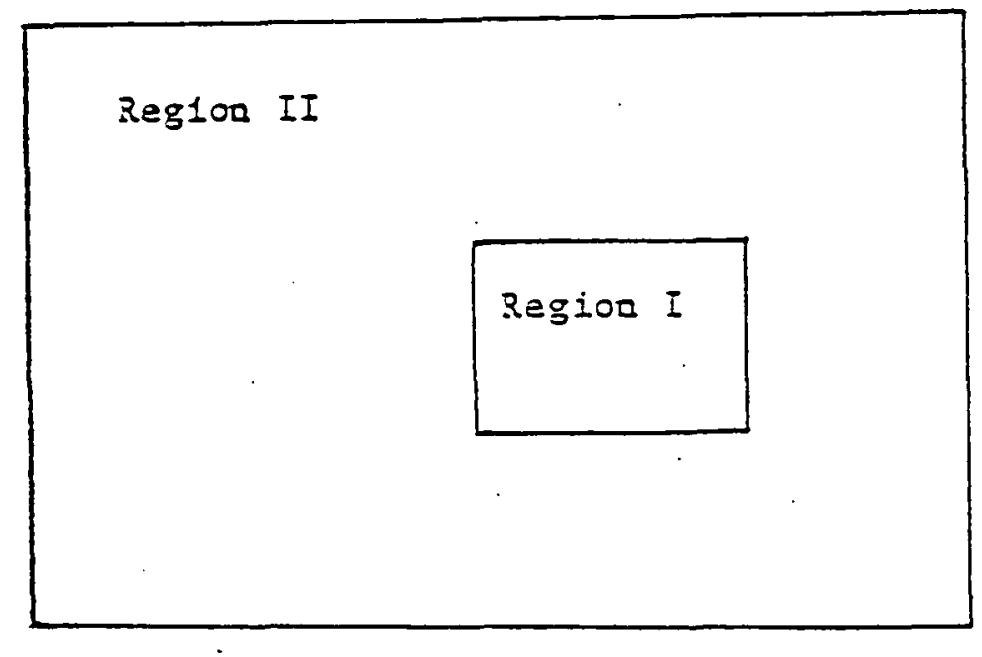

Decomposition into Two Regions

Figure III.A.I 
reads data which are used commonly for the two passes. These data are the regular grid definitions and the geometric descriptions of the problem bodies (contours).

Flow chart III.A.2. shows the basic organization.

The data input format used is that existing in a program (FLD6) left at RPI by Prof. O. W. Andersen in the 1970's. First, a regular grid definition is entered by specifying, along each of the two axes, locations at which grid spacing changes and also the sequence number of the grid line at that location. Thus, on each axis, there are specified a number of zones and how many equal spaces are in each zone. Second the shapes of the bodies in the problem are described by closed polygons composed of straight line segments connected at vertices. The input data for these contours are a series of $(x, y)$ co-ordinates for the vertex locations in the order met as the contour is traversed. Closed contours are entered by entering the last vertex equal to the first. In addition to the vertices, each contour (body) has entered for it the value of permittivity if it is a dielectric body, or the voltage value for a fixed potential electrode, or the fact that the electrode is "floating".

b. After problem definition data entry, the subroutine moves grid nodes (as defined by the regular grid definition) in the vicinity of the body contours to the contours. That is, the regular grid is distorted to the given geometric contours.

First, regular grid nodes closest to the vertices are moved to the vertex locations for all vertices entered. Then, for each line segment between successive vertices, the regular grid nodes closest to the lines are moved perpendicular to the line until they lie on the line.

c. As the regular grid nodes are being moved to their distorted positions, a code value is assigned to each node position. The node is designated by its undistorted position in the regular grid. To each of these' positions is assigned a value in the MVERT array.

Each value in NIVERT has 5 digits, call them $a \underline{b} \underline{c} \underline{d} \underline{e}$. Poslllon $a$ is used to indicate whether the node (vertex) can be eliminated during computation of the equivalent. It can take two values: 0 for reduceable, and 1 for not reduceable. Only electrodes will have $\underline{a}=1$ assigned.

Positions $\underline{b} c$ indicate the contour (body). to which the node belongs. Contours are numbered in sequence as they are read.

Position $\mathrm{d}$ is the irregularity code and indicates whether the node has been moved during grid distortion. Two values are possible: 0 for not moved and 1 for a moved node.

Position $e$ is the availability code, as originally used in the FLD6 program. It is used in the line fitting stages - 0 for avallable, 1 for unavailahle in some program parts, and 2 for absolutely unavailable. 


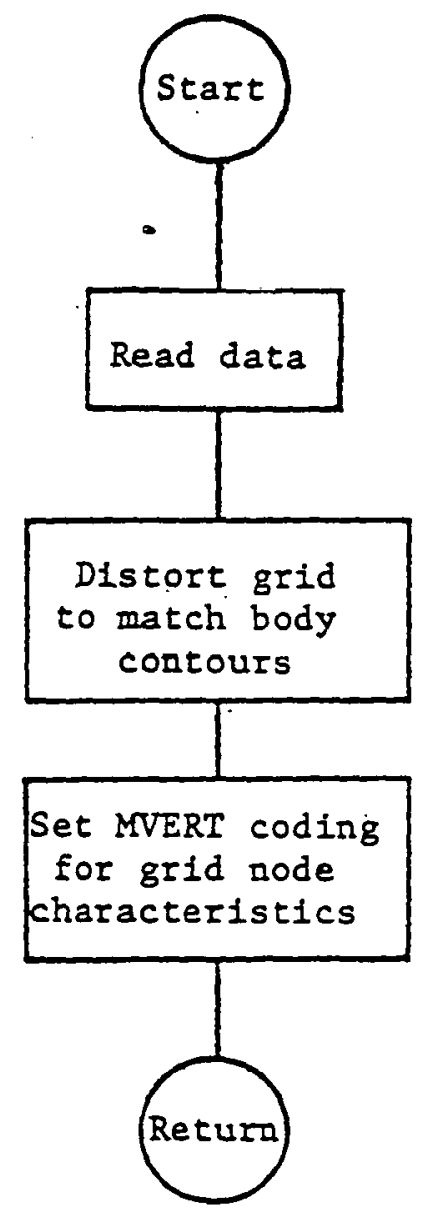

Flow Chart III.A.2

Subroutine CODING 
d. It is shown in the theory part of this report that the admittance branches for any triangular element depend on the permittivity and the geometry of the element. In an element where none of the three triangle vertices have been moved from their regular grid positions, it is found by direct computation that the $y$-branch representing the hypotenuse of the right triangle has a zero value. Furthermore, the other two branches retain their values no matter how the element is rotated, and also even if the element is reversed as by reflection in a mirror.

Therefore, for regular elements, the y-branches need be computed only once for each regular zone in both axes. This is done in the coDING subroutine and the geometric factors of the $y$-branches are retained for future use during Y-matrix formation.

\section{Subroutine EQUIV}

The purpose of this subroutine is to form the admittance matrix representing the discardable area of the problem (Region II in Figure III.A.1) as an equivalent matrix at its common nodes interconnecting it with the window. That is, it is an equivalent $Y$-matrix representing Region II as seen from Region I.

Flow chart III.A.3. shows the basic organization. The process is as follows :

a. The grid is considered block by block for the entire program area. The start is at the block closest to the origin. Next block is closest along the $\mathrm{x}$-axis until an $\mathrm{x}$-row is formed. Then $\mathrm{y}$ is incremented, $\mathrm{x}$ is reduced to initial value and the second row is formed. This proceeds until all rows have been included.

b. As each block is considered in turn, it must be divided into triangles. This is done either by a diagonal from upper left to lower right (UL-LR) or from lower left to upper right (LL-UR). The choice of which diagonal is used is on the basis of which divides the block into triangles of most nearly equal area.

c. When the triangles for a block have been specified, the admittance branch values are calculated for the geometric locations of the triangle vertices by using the expressions for the $b$ and $c$ variables derived in the theory section of this report. If a triangle is regular, in the sense that none of its vertices have been distorted from their regular grid positions, it is only necessary to recall the standard admittance branch geometric factors from storage.

The permittivity of a triangle is determined by finding within which body the centroid of the triangle is located. Once determined, the y-branches are modified by this factor.

d. When the $y$-branches for a block have been calculated, they are added to the total Y-matrix of the equivalent. This is done by standard 


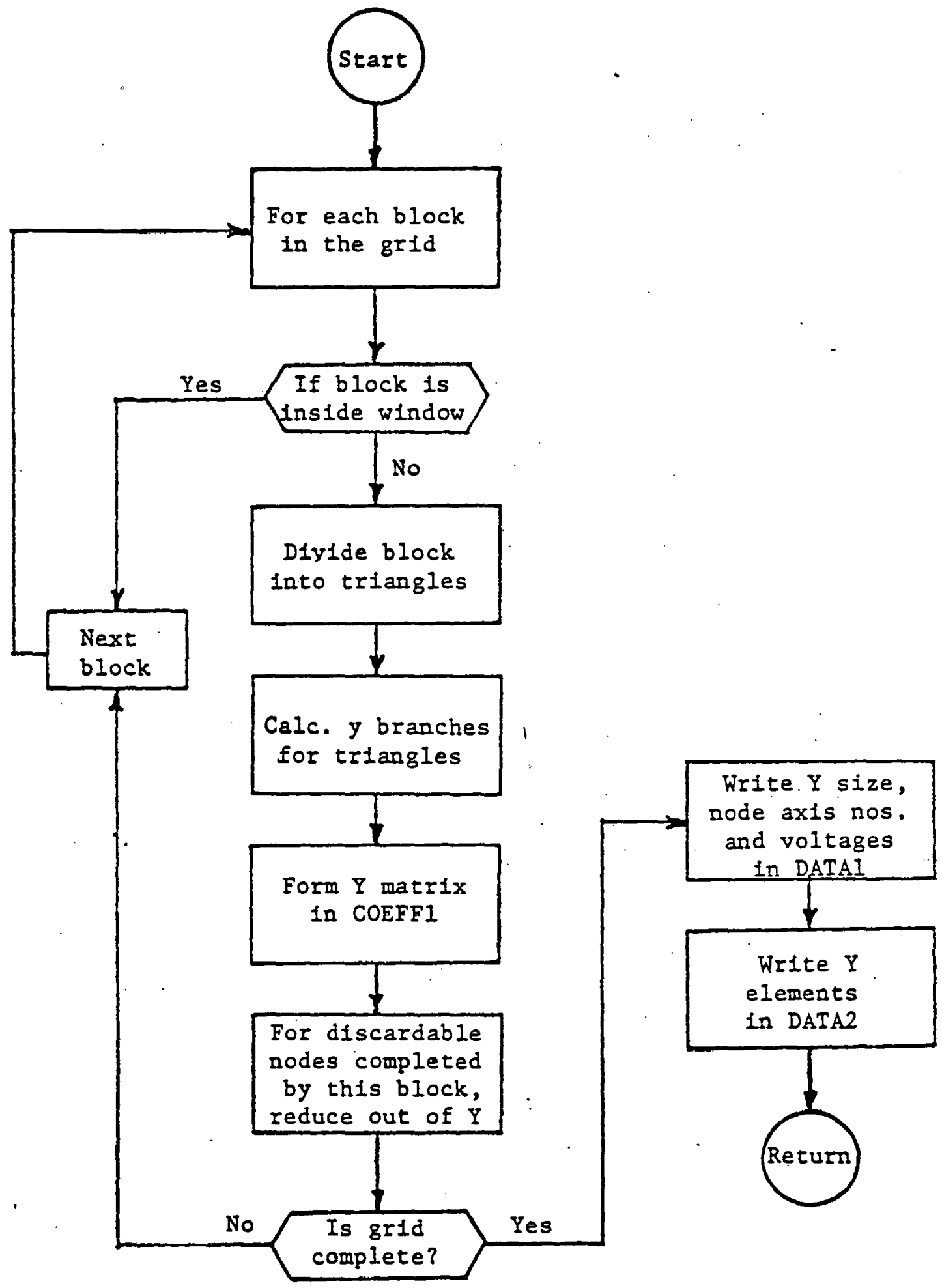

Flow Chart III.A.3

Subroutine EQUIV 
-modification algorithms for adding branches and nodes to a network. The - ssulting $Y$ elements are stored in array COEFFl. Since $Y$ is symmetric, it is only necessary to retain the lower triangle and principal diagonal terms. Therefore, COEFFl is a linear array representation of those elements of the Y-matrix.

e. When the branches of a block have been added to $Y$ in this manner, it is frequently found that one or more of the block corners are now complete in the sense that all y-branches connecting them to the remainder of the network have been included in $Y$.

When this occurs, if the node is not important for the final window solution, the $Y$-axis corresponding to that node can be "reduced out" of $Y$ by a Kron reduction as explained in the theory section of this report.

All internal dielectric nodes in the discardable region fall in this category of "not important for final window solution". The only nodes which must be retained are those on the window boundary and those which are on olectrodes.

f. The final result of this process is a multi-port Norton equivalent Y-matrix for the discardable region as seen from the window. Its elements are stored in the linear array COEFF1. These are read out to a data file, DATA2.

Data required to combine the equivalent $Y$ with a future window $Y$ are read out to a data file, DATAl. Such data are:

the size of the matrix (number of window boundary nodes plus number of electrodes in the discardable region);

the node number associated with each axis in the Y-equivalent (the axis identifications);

the voltages known for each of the electrode nodes.

\section{Subroutine SOLUTN}

The purposes of this subroutine are to form the admittance matrix for the window area of the problem, to combine it with the Y-matrix equivalent of the discardable area of the problem and to solve the resultant combination for potentials at nodes where voltages are not specified.

Flow chart III.A.4, shows the basic organization. The process is as follows :

a. Window blocks are considered one by one in a scheme similar to that used in EQUIV. That is, the block considered first is the one closest to the origin. Then blocks along the $x$-direction are considered until a row is formed. Then an adjacent row in the y-direction is considered block by block in the $x$-direction until all window blocks have been included. 


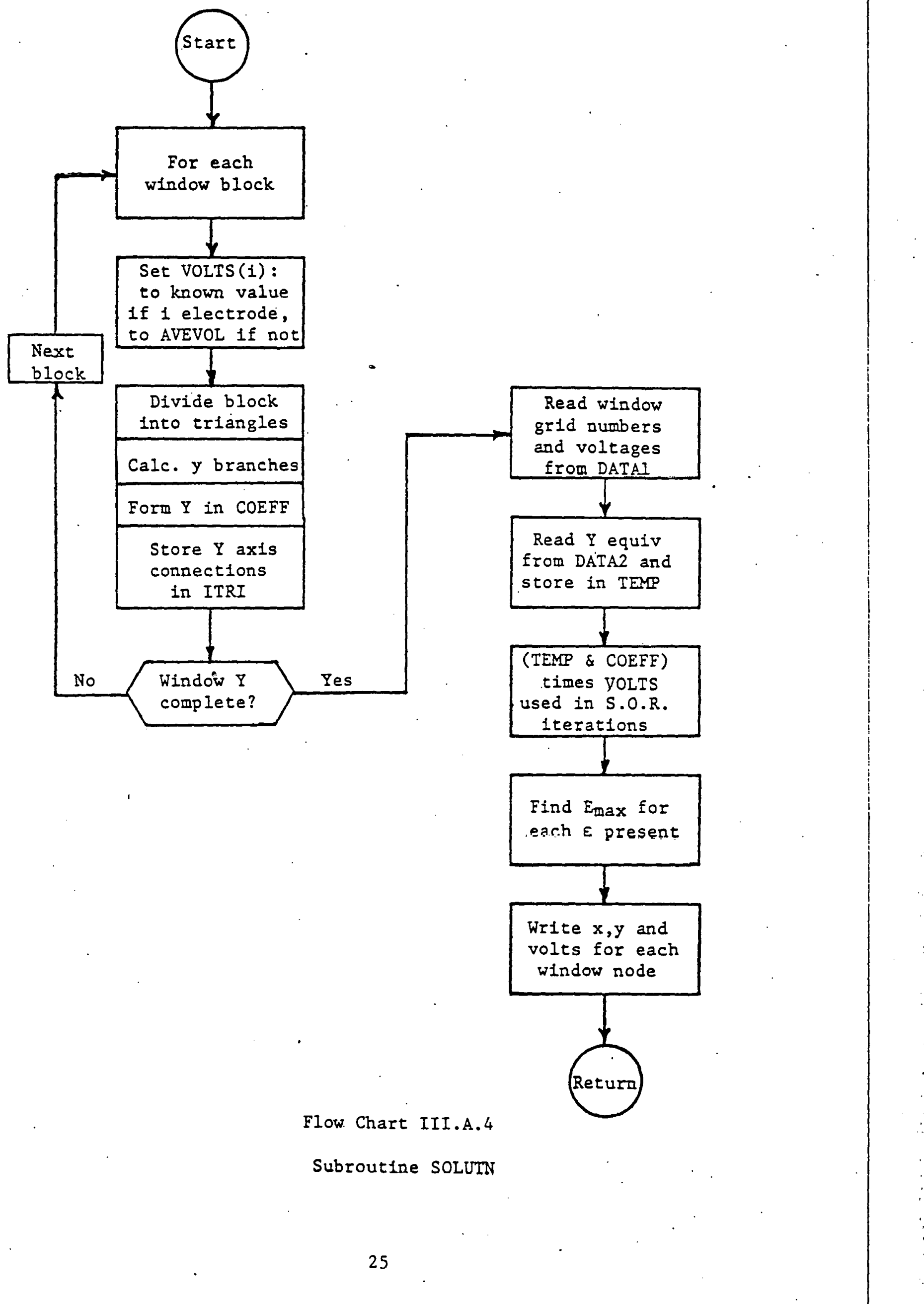


b. As each block is considered, the grid nodes at its corners have assigned to them a voltage which is the node's known voltage, if specified by the problem boundary conditions, or an initial guess at the node's final solution value. Since the solution is iterative, solution time is shortened by more accurate guesses at final values. In the absence of other values, the program assigns the input value of AVEVOL to every node having an unknown voltage value. This is the starting point for the iterative solution.

c. Then, for each block, the steps described for EQUIV in Sections 4.b, $c$ and $d$ are performed. That is, the block is divided into triangles, the admittance branch values are computed for both triangles and the Y-matrix elements are formed.

d. In this case, the Y-matrix elements are stored in the twodimensional array, COEFF. Although the Y-matrix for the equivalent is very full as a result of the reduction process, the Y-matrix for the window elements alone is sparse and tightly banded. Since any window node can be connected only to the eight surrounding nodes, there are possible only nine distinct Y-elements in each row of the matrix: the diagonal term and eight off-diagonal terms in the lower triangle. Therefore only these nine possible values are stored in COEFF. An array, ITRI, is used to indicate which other nodes are connected to the diagonal node in question.

e. When the window Y-matrix is complete, the Y-matrix of the equivalent is read back from DATAI and DATA2 with the Y-elements stored in TEMP.

f. Solution of the combined system is by successive over relaxation (S.O.R.) for potentials at nodes where the voltages have not been fixed by boundary conditions of the problem.

g. When node potentials have been found, it is seen that each triangular element has a uniform electric field value, due to the assumption of linear space variation of potential in an element. Therefore, each triangle in the window is examined, its electric field strength calculated, and the maximum fipld for each different dielectric is retained along with the location of the maximum field.

h. Finally, the $(x, y)$ co-ordinates and potential at each window node are written as output.

\section{Subroutine PLOTY}

The purpose of this subroutine is to use the output of section $3 . \mathrm{h}$. dild geometric input information to plot the problem body contours and equi-potential lines. This subroutine is hardware dependent on the specific computer installation and must be re-written for any given computer configuration. The program given is for a Prime 500 installation using a Dynagraphics plot package. 


\section{B. Program Organization}

1. Division into sub-programs

There are twelve sub-programs as indicated in the table below. Also indicated are the number of lines in the listing, the page of listing on which the sub-program begins and the page of listing on which the sub-program ends.

\begin{tabular}{cccc}
$\begin{array}{c}\text { Sub-Program } \\
\text { Name }\end{array}$ & $\begin{array}{c}\text { Number } \\
\text { of Lines }\end{array}$ & $\begin{array}{c}\text { Starts } \\
\text { on Page }\end{array}$ & $\begin{array}{c}\text { Ends } \\
\text { on Page }\end{array}$ \\
\cline { 3 - 4 } MAIN & 30 & 1 & 1 \\
CODING & 608 & 1 & 12 \\
EQUIV & 333 & 12 & 18 \\
SOLUTN & 409 & 18 & 25 \\
PINTTY & 221 & 25 & 29 \\
PERTRI & 30 & 29 & 30 \\
FSTR & 20 & 30 & 30 \\
INTER & 33 & 30 & 31 \\
DIGIT & 82 & 31 & 32 \\
SUBD & 4 & 32 & 32 \\
NODFT & 5 & 32 & 32 \\
NBOUFT & 11 & 32 & 32
\end{tabular}

The listing includes only those sub-programs written for this program. Other sub-program calls, e.g. for plotting purposes, which are device dependent are not included here.

Table III.2 Indicates the location in the program and from which sub-program the various sub-programs are called.

\section{Sub-Program MAIN}

Flow chart III.A.1 gives details.

This contains only calls to the major subroutines, CODING, SOLUTN, EQUIV, and PLOTY. No executeable instructions are included in it.

Subroutine CODING reads the input data, fits the grids to the contours, and assigns the codes to the vertices on the grid.

Subroutine EQUIV computes the equivalent at the boundary of the window. 


$$
\begin{aligned}
& \text { MAIN (p.1) } \\
& \text { p.I - CODING (p.1). } \\
& \text { p.2 - DIGIT (p.3I) } \\
& \text { p.3 - DIGIT (p.31) } \\
& \text { p.4 - DIGIT (p.31) } \\
& \text { p.11 - INTER (p.30) } \\
& \text { p.1 - EQUIV (p.12) } \\
& \text { p.13- NBOUFT (p.32) } \\
& \text { p.15 - INTER (p.30) } \\
& \text { p.16 - NODFT (p.32) } 6 \text { times } \\
& \text { p.16 - NBOUFT (p.32) } 3 \text { times } \\
& \text { p.17 - NODFT (p.32) } 5 \text { times } \\
& \text { p.18- NODFT (p.32) } \\
& \text { p.1 - SOLUTN (p.18) } \\
& \text { p.21 - INTER (p.30) } \\
& \text { p.21 - PERTRI (p.29) } \\
& \text { p.24 - FSTR (p.30) } \\
& \longrightarrow \quad \text { p.30 - SUBD (p.32) } \\
& \text { p.1 - PLOTY (p.25) }
\end{aligned}
$$

Table III.2

Location of Sub-Program Calls 
Subroutine SOLUTN computes the potential at every grid point of the window, and the maximum field strength for every permittivity present. terminal.

Subroutine PLOTY draws the equipotential lines on the screen of the

\section{Sub-Program CODING}

Flow chart III.A.2 gives an over all picture of the process.

a. This subroutine performs five basic duties. The following is a description of those duties.

1) Reads all of the input data for the program, except the coordinates of the regular grid points. This is done by subroutine DIGIT, and will be explained later.

2) Positions each one of the grid lines.

3) Computes the standard admittances for each one of the different grid densities.

4) Adds the minimum radius to all the input points.

5) Fits the grid to the contours, and assigns the proper code to each one of the vertices in the grid. This is performed in four steps:

a) When a point used in the definition of a contour lies in the path of a straight segment joining two points used in definition of a second contour, the first point is made part of the set of points defining the second contour, thus the segment to which reference was made will be broken down into two segments.

b) The contours are taken one at a time, and the grid is made to coincide with the points defining the contours.

c) Once all the defining points have been fitted, they are joined by imaginary segments, then the grid nodes closest to these segments are forced to lie on the path of the segments.

d) In stages $b$ and $c$, all the vertices involved are coded properly; the fourth stage assigns the proper codes to the vertices internal to the closed contours.

b. This subroutine was originally developed by 0 . W. Andersen, and used in the FLD6 program. All the algorithms and most of the 
variables are still the same. Changes were made to accommodate a new coding system and to include the computation of the standard admittances. These changes are explained rext. Their locations in the final program are indicated.

c. Computation of the standard admittances

Referring to F1g. III.B.3.1, there are different spacings in both directions defining the equally spaced zones indicated by the parentheses. At the intersection of each zone a special type of rectangle is defined. For each type of rectangle standard admittances are computed.

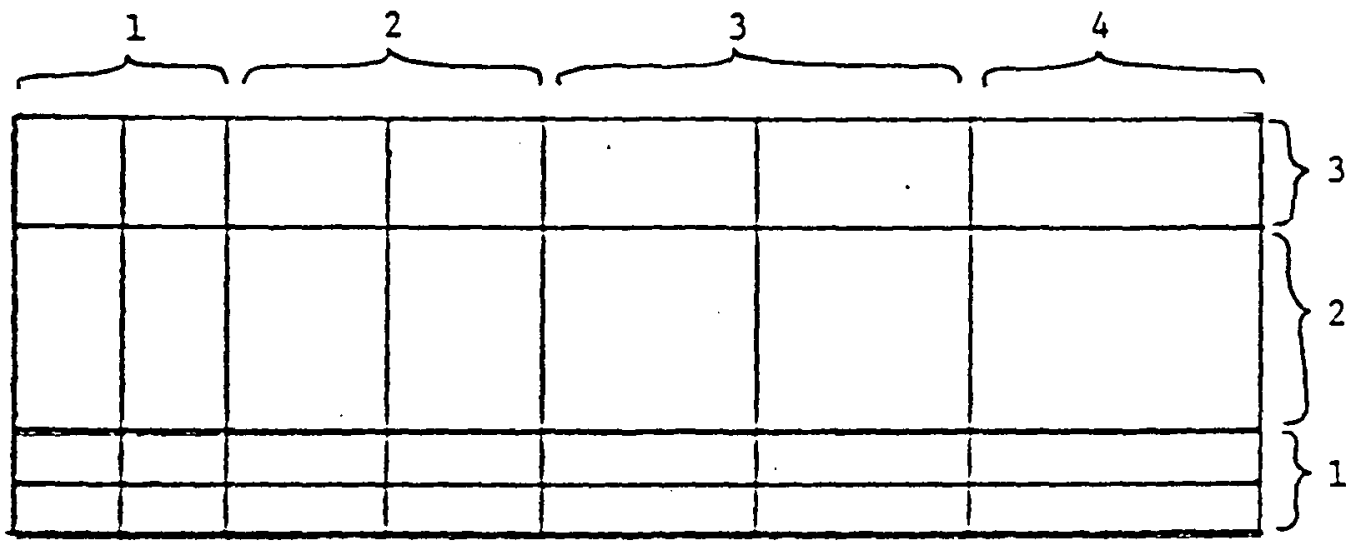

Figure III.B.3.1

Vertical and Horizontal Zones

For a given vertical zone, all the horizontal zones are scanned, and the corresponding admittances computad. (See Flow chart III.B.3.1)

\section{d. Vertex Coding}

The array IVERT contains a code for each grid node. The array 1s two dimensional; the first subscript indicates the horizontal line number; the second indicates the vertical line number. Thus each vertex is specified as the intersection of two lines of the regular grid as if the vertex had not been moved (even though it may have been moved). 
The contents of each code entry is a five digit number in which the various digits have meanings as specified in section III.A.3.c.

\section{e. Irregular points}

The position of the vertical lines is defined by their $\mathrm{X}$ co-ordinate, and the position of the horizontal lines is defined by their $Y$ co-ordinate. The arrays storing those positions are XPOS and YPOS respectively.

A point, defined by the intersection of two lines will have the same $X$ co-ordinate as the vertical line, and the same $Y$ co-ordinate as the horizontal line. Therefore the storage of the co-ordinates for every vertex in the grid is unnecessary. Only the co-ordinates of those vertices moved from their original positions during the contour fitting process have to be stored, along with a code that relates them to the storage position.

Arrays AUX and MAUX contain the (X,Y) co-ordinates and the grid vertex number, as calculated from

$$
\text { NVM }=(N-1) * \text { LNVER }+M
$$

where $\mathrm{N}$ is the horizontal line number

and $M$ is the vertical line number of the vertex that has been moved.

\section{Sub-Program EQUIV}

Flow chart III.A.3 gives an overall picture of the process.

When computing the equivalent the grid is processed from left to right and from the bottom up; rectangles are considered one at a time.

Three major blocks can be identified in this subroutine:

a. computation of the admittances inside the rectangle;

b. location of the admittances in their proper matrix places;

c. elimination of those nodes that need not be retained.

Each one of these blocks is subdivided into several "action" blocks.

a.1) Code decompositions for each one of the four vertices in the rectangle;

a.2) Assignment of electric network node number;

a.3) Divioion of the block into triangles;

a.4) Assignment of the proper permittivity to each one of the resulting triangles;

a.5) Computation of the admittances inside the triangles.

b.1) Identification of the proper matrix position for the electric nodes involved;

b.2) Summation of the six sub-matrix elements involved. 


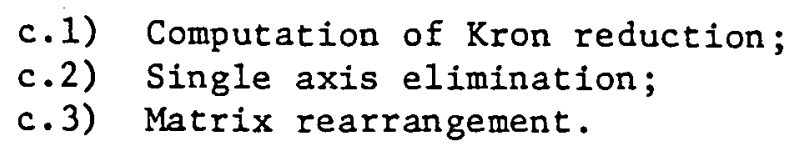

d. Finally, two files are created: DATAl and DATA2.

DATA1 contains the information necessary for the proper connection of the equivalent to the window.

DATA2 contains the matrix elements representing the network connections of the equivalent.

Each of these action blocks will be explained in detail and a flow chart will be shown for each one of them. The arrays and variables to which reference is made appear in the proper lists.

\section{a.1) Code decomposition}

Fig. III.B.4.1 shows two "boxes." A) is regular and B) is irregular. Both have the corners numerated counterclockwise. A four cycle "Do" loop finds the grid position $(M, N)$, the contours to which it belongs, and whether it has the original co-ordinates or not, for each vertex.

Whenever a box is inside the window, the program skips it.

\section{a.2) Assignment of the electric network node number}

Each subindex of the array NODE is an electric node number and the variable stored is the grid node position to which the electric node was assigned.

If the vertex is on the window boundary its grid position in the window with a minus sign is used to establish the correspondence.

If the vertex is on or in a contour that is an equipotential the electric node assigned to it will be the same as that of the first vertex encountered on the contour.

After the electric node is assigned, the co-ordinates of the vertex are found. If the vertex has not been moved they are obtained from the lines positions, otherwise a search through the moved points is conducted until the proper one is found.

\section{a.3) Division of the block into triangles}

The boxes are divided into two triangles by a diagonal. The diagonal is systematically drawn from bottom to top and from left to right (LI-UR). However when a box is irregular the diagonal is drawn in such a way that the resulting areas are as close in magnitude as possible. 


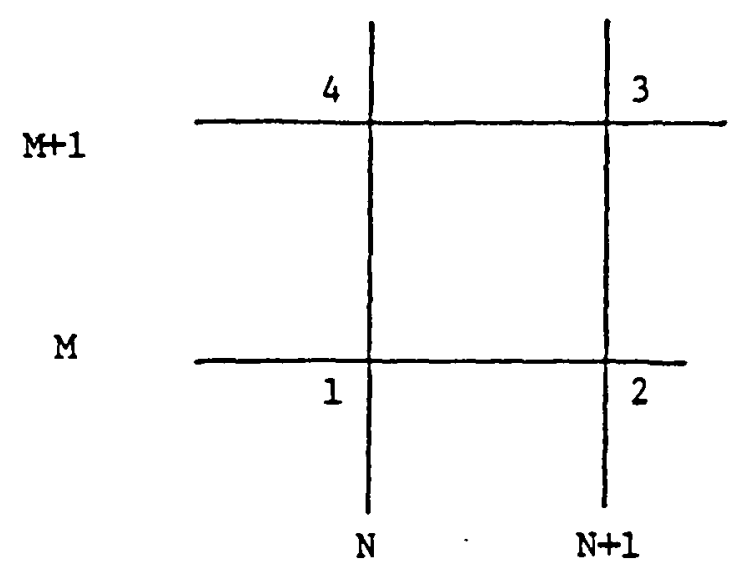

REGULAR BOX

A)

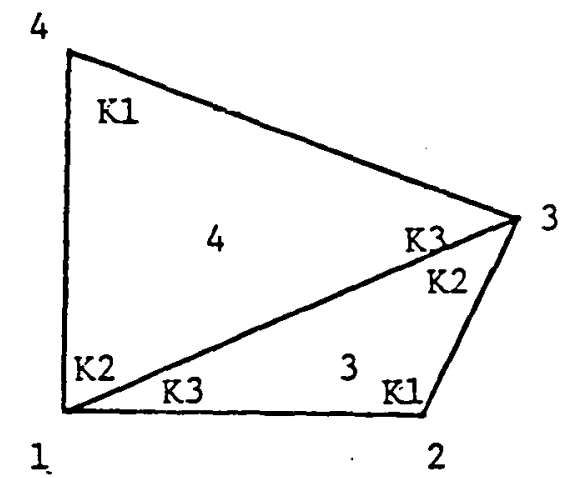

DIAGONAI TYPE 1

C)

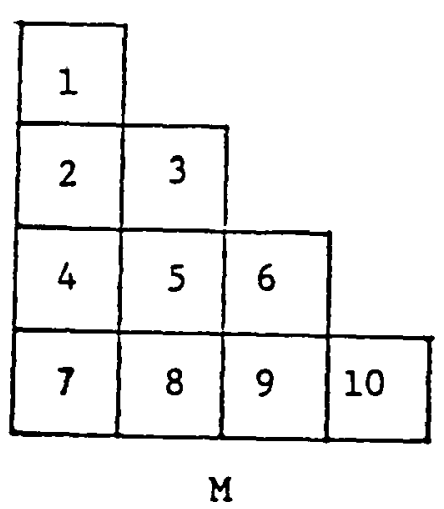

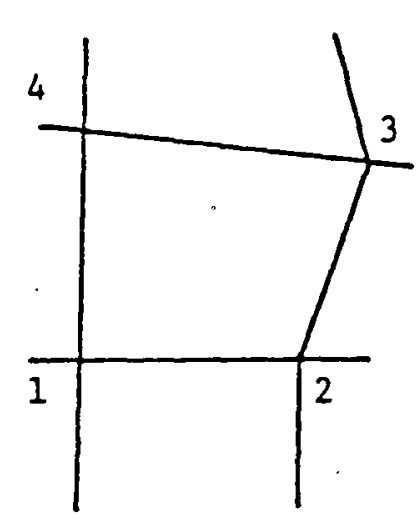

IRREGLLAR BOX

B)

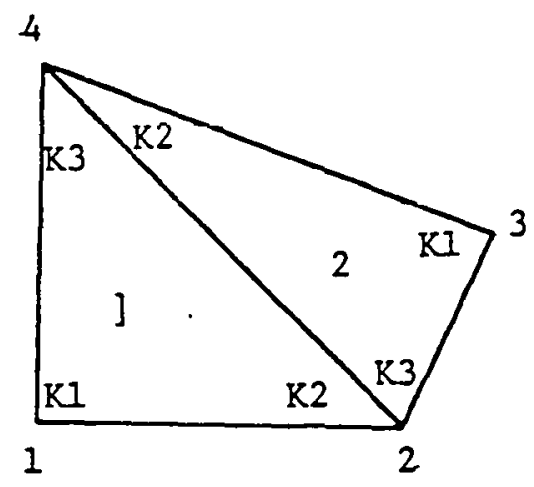

DIAGONAL TYPE 2

D)
E) STORAGE OF EQUIVALENT ADMITTANCES

Figure III.B.4.1

Box Definitions 
Referring to Fig. III.B.4.1 C,D, the two possible diagonals are shown and the four possible areas also.

In the example shown, areas 1 and 2 give a difference of areas smaller than 3 and 4.

The choice of diagonal is overridden when the diagonal is part of contour definition in which case, it is forced to follow the contour.

\section{a.4) Permittivity assignation}

After the triangles are defined, the centroid of the triangle is found. Codes $K 1, K 2$ and $K 3$ are filled with the proper comer that defines the lower triangle so the co-ordinates are accordingly chosen.

$$
\begin{aligned}
& \bar{X}=(K(K 1)+X(K 2)+X(K 3)) / 3 \\
& \bar{Y}=(Y(K 1)+Y(K 2)+Y(K 3)) / 3
\end{aligned}
$$

The codes $\mathrm{K} 1, \mathrm{~K} 2$ and $\mathrm{K} 3$ are not necessarily coincident with corners 1,2 , 3 and 4. All their possible values are shown in Fig. III,B,4.1 C,D.

The co-ordinates of the centroid are given to subroutine INTER which tells what contour they are internal to, if any, and from that information the permittivity is obtained.

\section{a.5) Computation of the admittances}

If the box is regular we search for the precalculated admittances of the grid zone where the box is. Admittance $\mathrm{AB}$ connects corners $\mathrm{K} 1$ and $\mathrm{K} 2$; admittance $\mathrm{AD}$ connects corners $\mathrm{K} 1$ and $\mathrm{K} 3$, and admittance $\mathrm{BD}$ connects corners $\mathrm{K} 2$ and $\mathrm{K} 3$. If the diagonal is from bottom left (LL-UR), then YAB and YAD are the vertical and horizontal admittance branches respectively. When the diagonal is reversed (UL-LR), $Y A B$ and $Y A D$ are the horizontal and vertical admittance branches respectively.

The irregular box requires a calculation of YAB, YAD and YBD. However, these values are obtained directly from expressions given in the theory section from the appropriate $b$ and $c$ values which are dependent only on the vertex locations.

Codes NOD1, NOD2, NOD3 are the electric nodes associated with each corner of the triangle. They correspond one to one with $\mathrm{K} 1, \mathrm{~K} 2, \mathrm{~K} 3$. If any of these nodes is the same, the admittance connected across the corresponding corners is made equal to zero.

If there is axial symmetry, FLAXI > 1.0, the admittances are multiplied by the distance from the center of the triangle to the axis of symmetry. 


\section{c.1) Computation of KRON reduction code (NRED)}

After a box is processed the node on corner 1 l has all of its electrical connections completed, unless it is an electrode or a floating conductor, in which case that assertion is not necessarily true.

Such a node is normally reduced out of the matrix unless one or more of the following conditions is present:

i) it is on the window boundary;

ii) it is an electrode;

iii) it has not completed all of its electrical connections.

Each time one of these conditions is encountered, a code, NRED, is increased by one. So whenever NRED is greater than zero, the node is not reduced.

If the box that has been processed is on the right hand side boundary of the grid, the reduction logic is repeated for the node on corner $\$ 2$.

If the box is on the top boundary of the grid, the reduction logic is repeated for the node on corner $\$ 4$.

If the box is the last on the grid, the reduction logic is performed for all the nodes in the box.

\section{c.2) Single axis elimination}

The algorithm for the elimination of the axis $K$ from a $M \times M$ matrix is :

$$
\begin{aligned}
& \text { for } J=I, M \\
& \text { for } I=I, M \\
&\text { (but } J \neq K \text { and } I \neq K) \\
& Y(J, I)=Y(J, I)-\frac{Y(J, K) \star Y(K, I)}{Y(K, K)}
\end{aligned}
$$

However, due to the symmetry of the matrix, it is only necessary to modify up to the diagonal element of each row.

\section{c.3) Matrix re-arrangement}

Once a node is eliminated, the nodes of the matrix whose order is greater than that of the reduced, are decreased by one, the elements of the matrix below the reduced row are shifted one position upward and the elements to the right of the reduced column are shifted one position to the left.

Fig. III.B.4.2 explains the procedures graphically. 


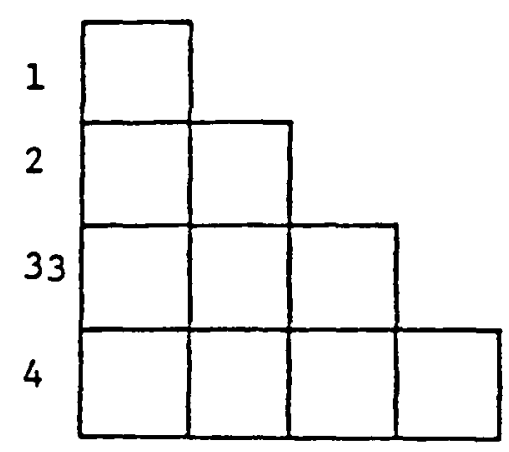

Matrix before elimination of node 2

1

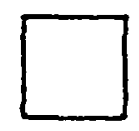

3

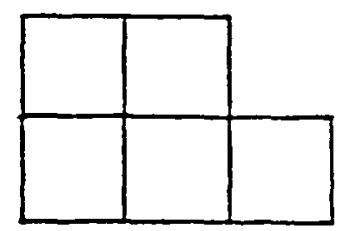

Elements to the right are relocated

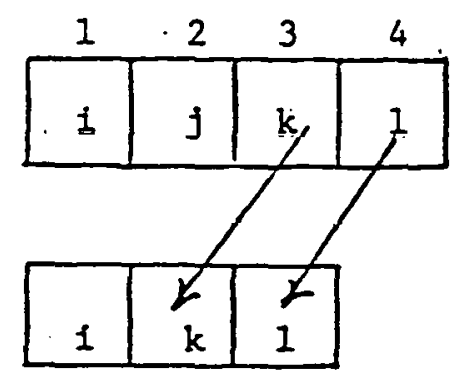

Re-assignment of the grid position to the nodes.
1
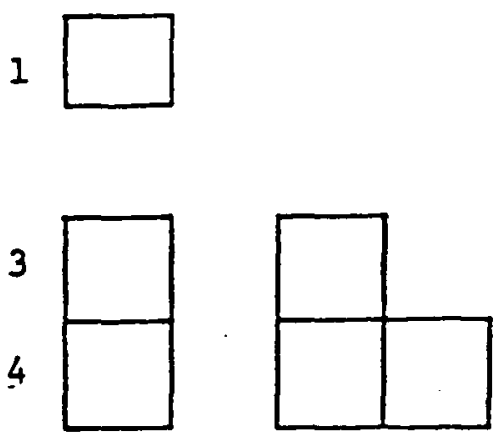

Matrix after elimination of node 2

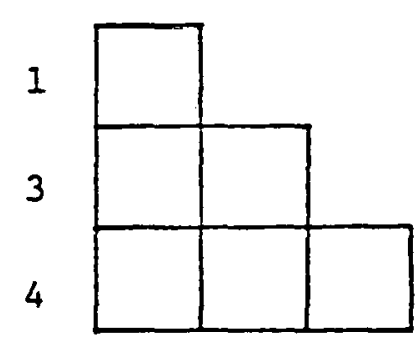

Elements from below are relocated

\author{
ILLUSTRATION OF \\ MATRIX REARRAIIGEI-ENT
}


d) Writing of the equivalent matrix and the information needed by the subroutine SOLUTN

Two files are created, DATAl and DATA2.

\section{DATA1:}

This contains the information necessary for the subroutine SOLUTN to use the equivalent properly. It contains the total number of nodes in the equivalent (JFIN) and the negative of the grid position that the node will have in the window. If the node is one that does not appear in the window then a fictitious position is assigned to it. This fictitious position starts with the total number of grid points (vertices) in the window plus one, and it is increased by one every time a similar node appears. SOLUTN understands this node as being associated with an imposed potential, in fact they are nodes representing electrodes outside the window, and the potential associated with them is provided next in the program.

\section{DATA2:}

Contains the elements of the final equivalent matrix, they are written as a linear array following a convention indicated in Figure III.B.4.1.E).

Ths user has nothing to do with these files; his only duties are to make sure that they belong to the right equivalent. These files appear by subroutine SRCH\$\$, which is a PRIME system low level subroutine. The information listed in Table III. 3 is requested by the subroutine.

5. Sub-Program SOLUTN

Flow chart III.A.4 shows the overall process.

a) Summary of differences from EQUIV

The same general procedure of EQUIV is followed here. The main differences are pointed out next.

1) Electric network node numbers and grid vertex numbers are one and the same for all the grid points, so no special resemblance between node number and grid position is necessary. The only code assigned is to indicate whether a node (grid point or vertex) is an electrode or not.

2) The admittances are computed as in EQUIV. They are stored In the two dimensional array $\operatorname{COEFF}(900,9)$, one row for every node and up to nine elements per row.

3) The resultant system of equations is solved by an iterative technique (S.O.R. = successive over relaxation). 
Action key: $\quad k \$$ WRIT for writing

$\mathrm{k} \$$ CLOS. for closing the file

File name: DATA1, DATA2

Length of the name: 5

File Utility Unit: 4,5 (this is equal to FORTRAN logic unit - 4)

Type of file: sequential (0) (numbers are written one after another in sequence)

NCUV: error code in the use of the subroutine

(See PRIME FTN Manual, Sec. 20, for more detailed explanation.)

Table III. 3

Information requested by PRIME subroutine SRCH\$\$ 
4) Maximum field strength for every permittivity present in the problem is computed.

\section{b. Potential code assignation}

Array NODE(904) contains a code for the 900 possible vertices in the grid plus four (4) electrodes outside of the window. 0 is assigned to a vertex if it is not an electrode and 1 if it is. There is a special code NCOD(4) assigned to each vertex in a box. This code is the negative of the corner number if it is not on a code 3.0 (floating conductor) contour, otherwise the contour number is assigned to it. This code makes possible the handling of floating conductors that are an open contour. (See flow chart III.B.5.1.)

c. Storage of permittivity for the triangles and triangle vertex

This is done for two reasons:

1) field strength is computed for each individual triangle, and storing that information speeds up the process;

2) equipotential lines are plotted by interpolation on each one of the trlangles (see subroutine PLOTY).

d. Computation of admittances for open floating conductors

A special code (NCOD, see Sec. III.B.5.b) is assigned at the beginning of the subroutine to each corner of the box. These codes are compared, and if they match, a permittivity of 9000 is assigned to the admittance connecting the matching nodes.

e. Assignation of the pointers, and storage of matrix elements

In an admittance matrix, the element $Y(i, j)$ for $i \neq j$ is the negative of the branch admittance between $i$ and $j$.

In the electric network representation of the field problem as derived from the finite element method, each grid node can be connected by branches to a maximum of eight other nodes. See figure III.B.5.I.A) which shows a central point $E$ surrounded by the eight nodes $A$ to $D$ and $F$ to $I$. These are the only nodes to which $\mathrm{E}$ can be connected by an admittance branch.

Therefore in the matrix row corresponding to node $E$, there will be only eight, non-zero, off-diagonal elements. The diagonal element is the selfadmittance of the node.

In order to conserve storage space, only the nine possible non-zero elements are stored in a row of the array $\operatorname{COEFF}(900,9)$. The Y-matrix elements corresponding to the connections of node $E$ to grid nodes $A$ to $D$ and $F$ to $I$ are stored in array positions 1 to 8 which correspond to the numbered locations in figure III.B.5.1.A). The ninth position stores the diagonal element value.

See figure III.B.5.1.B). 


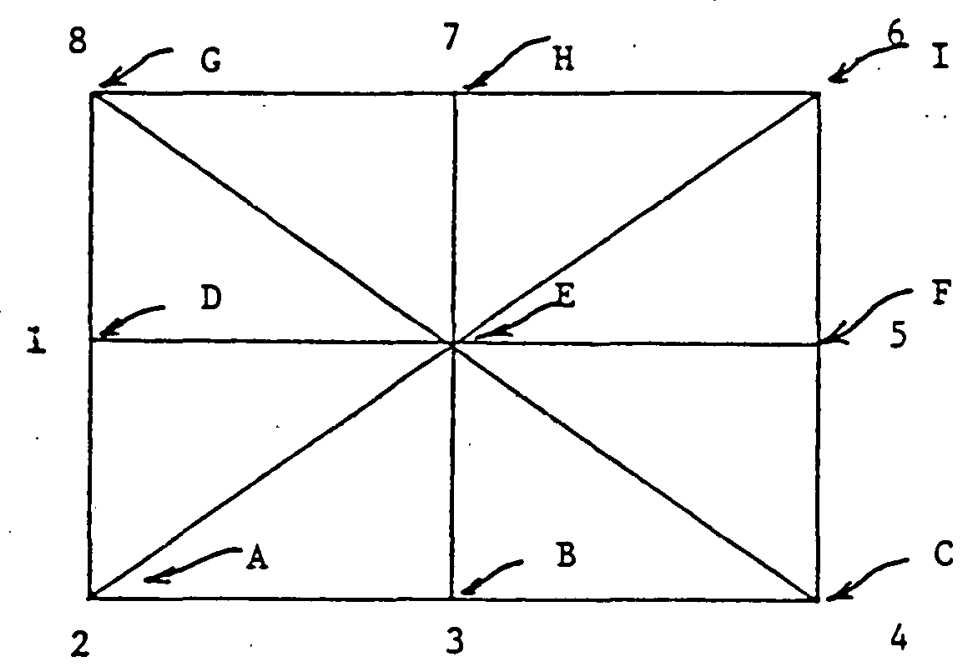

Possible connections to node "E"

A)

\begin{tabular}{|c|c|c|c|c|c|c|c|c|c|}
\hline \multirow{3}{*}{ ITRI } & 1 & 2 & 3 & 4 & 5 & 6 & 7 & 8 & \multirow[b]{3}{*}{9} \\
\hline & D & A & B & C & $E$ & I & $\mathrm{H}$ & G & \\
\hline & 1 & 2 & 3 & 4 & 5 & 6 & 7 & 8 & \\
\hline COEFF & YED & YEA & YEB & YEC & YEF & YEJ & YEH & YEG & YEE \\
\hline
\end{tabular}

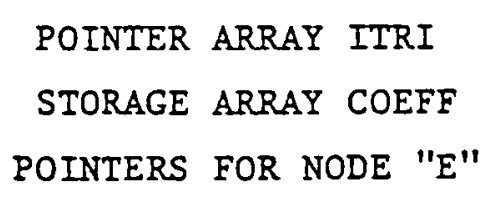

B)

Figure III.B.5.1 
But now a pointer must be stored to indicate that position $I$ for node $E$ contains the element connection to node $D$. Similar values for the remaining seven surrounding nodes are also required. This is done in array $\operatorname{ITRI}(900,8)$. See figure III.B.5.1.B).

The pointer and storage arrays are organized by means of a logic table. The nodes interconnected within a triangle are a function of the kind of diagonal drawn in the box. Table III.B.5.1 shows the organization of the pointers, and Fig. III.B.5.2 shows the four possible triangles.

\section{f. Reading of the equivalent matrix}

The first file open is DATAl, the total number of nodes in the equivalent (JFIN) is read; next the grid position of these nodes (NODE4). After the nodes are read their polarity is requested.

Negative polarity means that the node is on the boundary and positive polarity that it is outside the window.

Whenever a node is on the boundary and has a potential assigned to it (NODE = 1), its grid position is changed to positive. Otherwise its code (NODE) is set equal to 2. This is the way of knowing that the node has other connections (to the equivalent) than those inside the window.

If the node is outside the window, the total number of nodes present is increased by 1 and the voltage assigned to it is read.

The second file opened is DATA2, from JFIN, the total number of elements is computed

$$
\text { NODE } 3=(\mathrm{JFIN}+1) * \mathrm{JFIN} / 2
$$

and then the elements are read from the file.

\section{g. Solution of the system of equations}

The array TEMP contains the equivalent elements, and the array COEFF contains the window elements.

As many iterations as specifled by NMAX are done unless the tolerance wanted is reached first.

The nodes on the boundary are questioned, the ones that are electrodes are skipped over, otherwise the admittances connected to the node are multiplied by the corresponding potential and accumulated. The storage of the equivalent elements resembles that of Fig. III.B.5.3.A). The admittances are located 1 by 1 using the following process. The subscript of the array NODE4(J) indicates the node number in the equivalent matrix of the window node indicated by NODE $4(\mathrm{~J})$, i.e., if window node number $1 \mathrm{~s} 10$ and corresponding equivalent node number is 3 , then $\operatorname{NODE} 4(3)=10$. This makes possible locating the admittances 


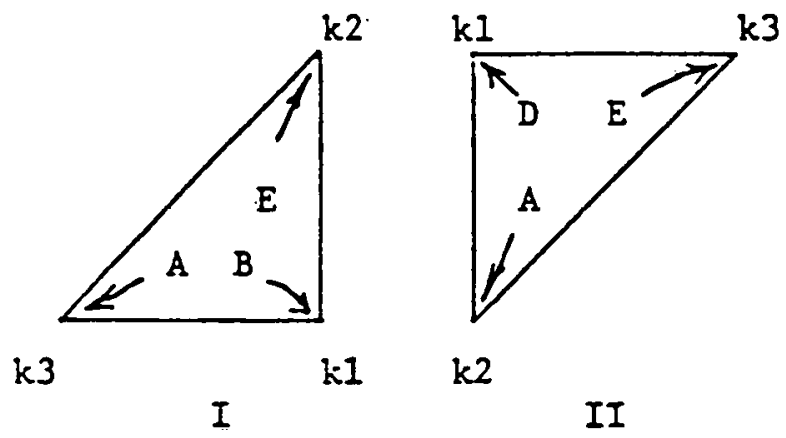

DIAGONAL \# 1
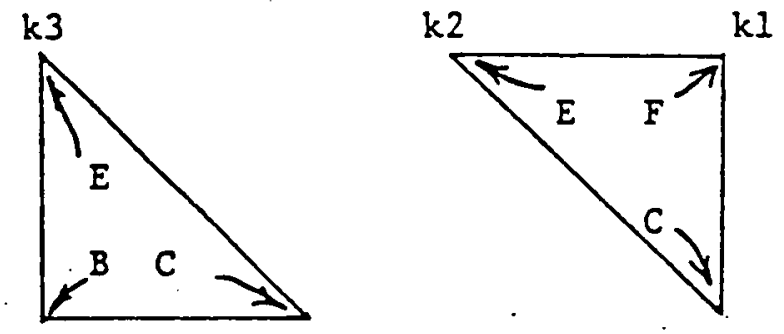

k1

I

II

ORIENTATION OF TRIANGLES

Figure III.B.5.2

\begin{tabular}{|c|c|c|c|c|c|}
\hline \multirow{2}{*}{$\begin{array}{l}\text { NODES } \\
\text { CONNECTED }\end{array}$} & \multicolumn{4}{|c|}{ ARRAYS' COLIMM NUMBER } & \multirow{2}{*}{$\begin{array}{l}\text { ARRAYS } \\
\text { ROW } \\
\text { NUMBER }\end{array}$} \\
\hline & $\begin{array}{c}\text { TRIANGLE } \\
\text { I }\end{array}$ & $\begin{array}{c}\text { TRIANGLE } \\
\text { II }\end{array}$ & $\underset{I}{\text { TR LANGLE }}$ & $\begin{array}{c}\text { TRIANGLE } \\
\text { II }\end{array}$ & \\
\hline$R_{1}, K_{2}$ & 7 & 3 & 5 & 1 & \multirow{2}{*}{ R } \\
\hline $\mathrm{KI}, \mathrm{K} 3$ & 1 & 5 & 7 & 3 & \\
\hline $\mathrm{K} 2, \mathrm{R} 1$ & 3 & 7 & 1 & 5 & \multirow{2}{*}{$\mathrm{R} 2$} \\
\hline $\mathrm{K} 2, \mathrm{~K} 3$ & 2 & 6 & 8 & 4 & \\
\hline $\mathrm{R} 3, \mathrm{R} 1$ & 5 & 1 & 3 & 7 & \multirow{2}{*}{$\mathrm{K} 3$} \\
\hline$R_{3}, R_{2}$ & 6 & 2 & 4 & 8 & \\
\hline & \multicolumn{2}{|c|}{ DIAGONAL \#1 1} & \multicolumn{2}{|c|}{ DIAGONAL \# 2} & \\
\hline
\end{tabular}

TABLE III.B.5.1

LOGIC ARRANGERENT OF THE POINTERS 


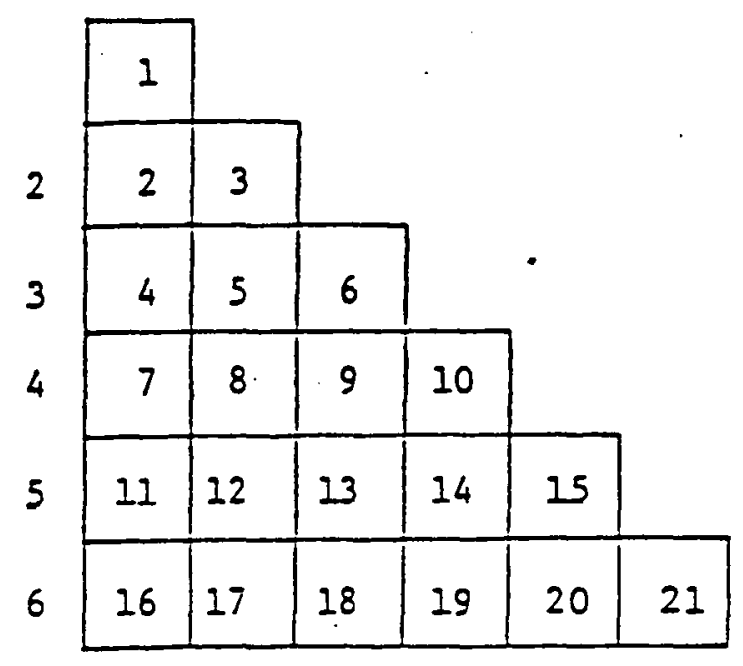

A)

Additional Admittances

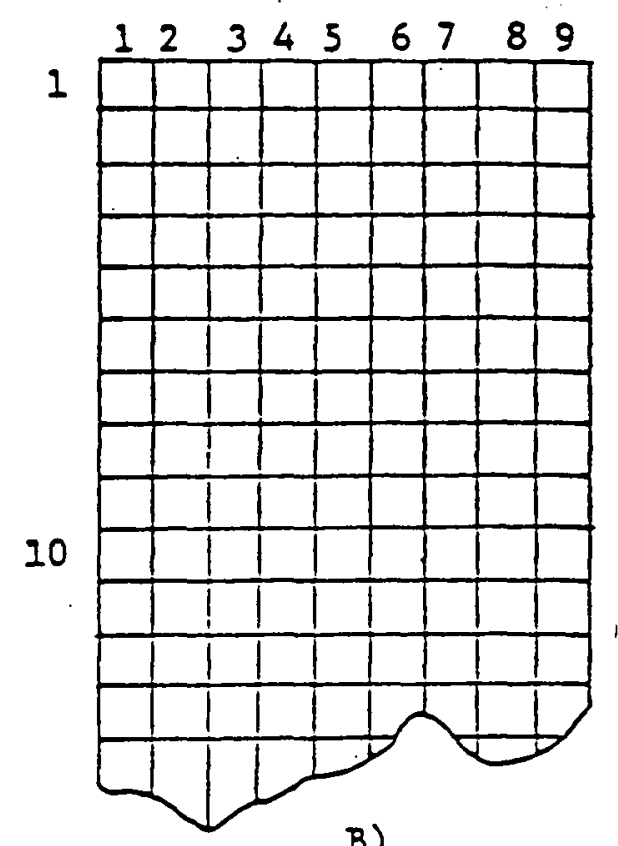

B)

Window Admittances

Equivalent window additional admittances for

Equivalent Window Boundary Nodes (Mutual) (Self) Node Node

\begin{tabular}{|c|c|c|c|}
\hline $\mathrm{J}$ & Node4(J) & $\operatorname{TEMP}(\mathrm{K})$ & \\
\hline 1 & 1 & $\mathrm{~K}=2,4,7,11,16$ & 1 \\
\hline 2 & 4 & $\mathrm{~K}=2,5,8,12,17$ & 3 \\
\hline 3 & 10 & $\mathrm{~K}=4,5,9,13,18$ & 6 \\
\hline 4 & 30 & $\mathrm{~K}=7,8,9,14,19$ & 10 \\
\hline 5 & 7 & $\mathrm{~K}=11,12,13,14,20$ & 15 \\
\hline
\end{tabular}

C)

Correlation Between Additional

Admittances and Boundary Nodes

Figure III.B.5.3 
inected to a given boundary node inside the array TEMP, by using $\mathrm{KI}=$ $(\mathrm{J}-1) * \mathrm{~J} / 2+1$ where the equivalent node number $1 \mathrm{~s} \mathrm{~J}$. This locates the first element of the row. The search for the remaining elements up to the diagonal is conducted column by column adding one to $\mathrm{Kl}$, and from the diagonal until the end of the row, adding the next colum number minus one to the last number obtained.

The rest of the nodes are processed in a conventional manner. The eight columns of ITRI are searched for the node number, and the elements in COEFF corresponding to the column scanned are multiplied by the proper potential.

\section{h. Field Strengths}

After the potential at every vertex is obtained the field strength inside each triangle is computed and the maximum for each permittivity is stored. Subroutine FSTR computes them. It is discussed in a separate paragraph.

\section{i. Printing of Potentials}

Finally the potential, grid position and co-ordinates of each vertex is written out in file WINOUT.

\section{Sub-Program PLOTY}

'Originally subroutine ELB was taken from the program FLD6. No modifications were made to the main algorithms. The changes were only on the calls to the plotting routines. The original calls were to "IBM CALCOMPLOTER". Their format was changed for use with "DYNAGRAPHICS" on IMLAC terminals.

To save necessary space, the array COEFF is used to store the information originally encountered in arrays SEGM, XA, YA, VERT $(1 \& 2)$. The correspondence is :

\begin{tabular}{|c|c|c|c|c|c|c|c|c|c|c|c|}
\hline & \multicolumn{1}{|c|}{ COEFF } & VOLTS & IVERT & PERM \\
\hline 1 & 2 & 3 & 4 & 5 & 6 & 7 & 8 & 9 & 1 & $1,2,3$ & 1 \\
\hline 1 & 2 & 3 & 4 & 5 & 1 & 1 & 1 & 1 & 3 & $1,2,3$ & 1 \\
\hline & \multicolumn{3}{|c|}{ SEGM } & X A & Y A & VERT & VERT & ITRI & TRI \\
\hline
\end{tabular}

Table III.B.6.1

Array Concordance Between ELB and PLOTY

The subroutine now plots the equipotential lines, problem identification, naximum potential, minimum potential and percent volts per line. 


\title{
7. Sub-Program PERTRI
}

The calling parameters for this subroutine are:

\author{
KIODG: kind of diagonal ( 1 or 2 ) \\ EPSI: permittivity \\ $M, N, L$ : grid node numbers of triangle vertices
}

The triangle vertex numbers are stored in a particular way so that they can be handled by subroutine PLOTY. IVERT is the array where this information resides. Fig. III.B.5.2 shows the four types of triangles, and Table III.B.7.1 shows the logic table for the assignment of the vertex numbers to the locations in ITRI.

Permittivity is stored in array PERM.

\begin{tabular}{|c|c|c|c|c|}
\hline \multirow{2}{*}{$\begin{array}{c}\text { Node } \\
\text { Number }\end{array}$} & \multicolumn{4}{|c|}{ Location in Array IVERT } \\
\cline { 2 - 5 } & Triangle I & Triangle II & Triangle I & Triangle II \\
\hline K1 & 2 & 3 & 2 & 2 \\
\hline K2 & 3 & 1 & 3 & 3 \\
\hline K3 & 1 & 2 & 1 & 1 \\
\hline & \multicolumn{2}{|c|}{ Diagona1 \#1 } & \multicolumn{2}{c|}{ Diagonal \#2 } \\
\hline
\end{tabular}

Table III.B.7.1

Logic Table for Array IVERT

I3 is the triangle number and is increased by one every time the subroutine is called.

\section{Sub-Program FSTR}

Th1s sub-program is taken from FLD6 (same name there).

It requests the triangle number, and returns the electric field in the $x$ direction, in the $y$ direction and the total electric field magnitude.

9. Sub-Program SUBD

This sub-program is taken from FLD6 (same name there).

It computes the area of a triangle when the co-ordinates are given. 
10. Sub-Program INTER

This sub-program is taken from FLD6 (same name there).

It determines whether a point is internal to a closed contour or not.

The call parameters are:

I1 : the number of points in the contour;

LPNT: pointer to the place in array LINAC where the coordinates of the II points start;

$\dot{X}: \quad X$ co-ordinate of the point in question;

$Y$ : Y co-ordinate of the point in question.

The return value is:

INTOR: code, 1 for internal, 0 for not internal.

11. Sub-Prugrall DIGIT

This sub-program is taken from program FLD6 (same name there).

It reads the $(x, y)$ co-ordinates for input points.

The call parameters are:

NPNTS: number of $x, y$ pairs to be read;

IN : FORTRAN logic unit number for input;

SORIG: scale of the co-ordinates being read.

\section{Function NODFT}

Computes the correct position of the $(i, j)$ element, when only the lower half of the matrix is stored as a linear array, proceeding by rows.

The call parameters are the row and column numbers of the element, ( $i$ and $j$ respectively).

The formula is:

$$
\text { POS }=(i-1) \star 1 / 2+j \text { for } i \geq j
$$

If $\mathrm{j}$ is greacer than 1 , the wrong element is chosen, then

$$
\operatorname{POS}=(j-1) * j / 2+1
$$

13. Function NBOUFT

Determines whether a grid point is on the boundary of the window.

Retums 0 if no, and 1 if yes. 
Call parameters are:

M: vertical line number defining the vertex;

$N$ : horizontal line number defining the vertex;

LHF, LHL, LVF and LVL: grid line numbers defining the window. 
Descriptions of Arrays

ARRAY

NAME

$\operatorname{ADMAB}(15)$

ADMAD (15)

$\operatorname{AREA}(4)$

$\operatorname{AUX}(500,2)$

$\operatorname{COEFF}(900,9)$

COEFF1(18145)

$\operatorname{DATLN}(70,3)$

$\operatorname{DIGLN}(140)$

IDENT (20)

$\operatorname{ILN}(70)$

$\operatorname{ITRI}(900,8)$

$\operatorname{IVERT}(2000,3)$

$\operatorname{JVERT}(6,4)$

$\operatorname{LINC}(800)$

$\operatorname{MAUX}(500)$
CONTENTS

GENERATED IN

CODING

CODING

SOLUTN

EQUIV

CODING

SOLUTN

PLOTY

EQUIV

CODING

DIGIT

CODING

CODING

SOLUTN

SOLUTN

SOLUTN

CODING

CODING
DESCRIPTION OF

CONTENTS

Standard, vertically connected admittances.

Standard, horizontally connected admittances.

Area of each one of the four possible triangles inside a box.

$(x, y)$ co-ordinates of vertices which have been moved.

Elements of the matrix representing the window. Later used for co-ordinates, and equipotential segments in PLOTY.

Elements of the matrix during computation of the equivalent.

Permittivity, potential and code of each contour.

Co-ordinates of the input lines and contour points.

Identification of the problem.

Accumulated number of input points for the contours.

Pointers indicating the connection of one node to others in the window.

Triangle vertices counterclockwise.

Pointer that locates the correct connecting node into ITRI.

Co-ordinates of the input points describing the contours.

Grid position number of the vertices which have been moved. 
..VERT (79)

CODING

$\operatorname{NCOD}(4)$

$\operatorname{NDATLN}(70,2)$

$\operatorname{NIRR(4)~}$

NOD (4)

NODE (900)

NODE4 (120)

$\operatorname{NTRI(8)}$

NZH (15)

NZON (4)

$\mathrm{NZV}(15)$

PCHH (16)

PCHV (16)

PERM(2000)

POINT (400)

$\operatorname{TEMP}(7260)$

VOLTS (904)
SOLUTN

EQUIV

EQUIV

SOLUTN

EQUIV

SOLUTN

EQUIV

EQUIV

SOLUTN

SOLUTN

INTER

CODING

SOLUTN

EQUIV

CODING

CODING

CODING

SOLUTN

CODING

SOLUTN

EQUIV SOLUTN
Vertex codes.

Special code used to identify the same electrodes in EQUIV and open floating conductors in SOLUTN where the admittances are computed.

Grid position of the first point encountered on a conductive contour.

Irregularity code for each corner of the grid boxes.

Electric node associated with each one of the four corners of a grid box.

In EQUIV, it contains the new node number of the matrix being built.

In SOLUTN, a code telling whe ther the node is an electrode or not.

Position in the equivalent matrix of the boundary nodes.

Codes for deciding whether a point is internal to a closed contour.

Last line number of a set of vertical lines equally spaced.

Contours to which each corner of a grid box belongs.

Last line number of a set of horizontal lines equally spaced.

Horizontal lines where new spacing begins.

Vertical lines where new spacing begins.

Triangle permittivity.

Grid position of input points for the contours.

Elements of the matrix representing the equivalent.

Potential at nodes in the window. 


\begin{tabular}{|c|c|c|}
\hline$x(4)$ & $\begin{array}{l}\text { SOLUTN } \\
\text { EQUIV }\end{array}$ & $\begin{array}{l}x \text { co-ordinate of each of the four corners } \\
\text { of a grid box. }\end{array}$ \\
\hline $\operatorname{XPOS}(70)$ & CODING & $X$ co-ordinates of the vertical grid lines. \\
\hline $\mathrm{Y}(4)$ & $\begin{array}{l}\text { SOLUTN } \\
\text { EQUIV }\end{array}$ & $\begin{array}{l}\text { Y co-ordinate of each of the four corners } \\
\text { of a grid block. }\end{array}$ \\
\hline YPOS (100) & CODING & $\begin{array}{l}\text { Y co-ordinates of the horizontal grid } \\
\text { lines. }\end{array}$ \\
\hline
\end{tabular}

Equivalence between arrays:

\begin{tabular}{|ccc|ccc|c|}
\hline TEMP 7260 & Positions & COEFF & 8100 & Positions & $\begin{array}{c}\text { Perm. } \\
2000 \\
\text { Positions }\end{array}$ \\
\hline COEFF1 & 18145 & Positions \\
\hline
\end{tabular}




\section{LIST OF VARIABLES}

AVEVOL: Initial estimate of the solution; later becomes dummy variable.

CODE : Indicates type of body.

DELX: Grid spacing in X-direction.

DELY: $\quad$ Grid spacing in Y-direction.

EJ: Dummy variable, indicates distance.

EPS: $\quad$ Permittivity of a given contour.

EPSO: $\quad$ Relative permittivity if not specified otherwise.

EQLIN: $\quad$ Number of equipotential lines desired in output plot.

FLAXI: $\quad$ Code indicating flat or axial symmetry.

GAMA: Acceleration factor in the iterative solution.

HLF: First horizontal line of the window.

HLL: Last horizontal line of the window.

IN : Logical unit for reading.

I6=ITOT: Number of vertices (grid points) on the grid.

JLAST: Highest electric node number reached.

JP: Number of points which no longer are at the original co-ordinates.

LINAC: Number of the contour in process.

LINTO: Total number of contours.

LNHOR: Number of horizontal lines in the grid.

LNVER: Number of vertical lines of the grid.

MAC: Dummy variable for the avallability code.

MAXI: Maximum number of iterations in solution.

MIR: Dummy variable for the irregularity code.

NOCOL: Number of columns in the grid. 
JLIN : Number of contours.

NOROW: Number of rows in the grid.

NPNTS: Number of points.

NZHT: Number of equi-spaced zones from bottom to top.

NZVT: Number of equi-spaced zones from left to right.

OUT: Logical unit for writing.

PI: $\quad 3.1416$

PI02: $\quad$ PI/2

POT: Potential of a given contour.

RMIN: $\quad$ Minimum radius of field.

RMIX: Minimum radius parallel to $\mathrm{X}$ axis.

RMIY: Minimum radius parallel to $Y$ axis.

SORIG: Scale of the original drawing.

TOL: $\quad$ Convergence criterion for the iterative solution.

TOLR: Tolerance allowed between input points describing the contours.

VLF : $\quad$ First vertical line of the window.

VLL: $\quad$ Last vertical line of the window.

WARN : Warning format number.

WINDAT: Name of the input file.

WINOUT: Name of the output file.

WITHN: $\quad$ Code indicating use of the equivalent or not.

XCORR: Spacing between axis of symmetry and the first grid line parallel to the $\mathrm{X}$-axis.

YCORR: $\quad$ Spacing between axis of symmetry and the first grid line parallel to the Y-axis. 


\section{Users' Manual}

\section{Introduction}

The program, WINDOW, computes electric potential distribution and maximum electric field stress in each one of the different permittivities present in a portion of the whole region representative of the problem.

The portion solved for is called the "window." It is a rectangular sub-region of the larger rectangular region representative of the problem.

An equivalent of the region outside the "window" at the boundary of the latter is computed to assure completeness of the solution.

The first run of the program is used to compute the equivalent and subsequent runs to compute the electric potential distribution within the "window", corresponding to different design alternatives.

Two sets of input data are prepared, corresponding to the "equivalent" and the "window" respectively. Both follow the same format and are differentiated by proper coding.

The program is written in FORTRAN IV. Information regarding size, loading mode, etc., is provided at the end of this users' manual.

\section{Input Data}

The list below shows the order in which input data are read. The first column is for the equivalent formation run. The second column is for the window solution run.

\section{Equivalent Formation}

IDENT

FIAXI, RMIN, SORIG

EQLIN, EPSO, WITHN, NOLIN

HLF, HLL, VLF, VLL

PCHV

$\operatorname{DIGLIN}(a)$

PCHH

$\operatorname{DIGLIN}(\mathrm{b})$

PNTS, EPS, POT, CODE

$\operatorname{DIGLIN}(c)$
Window Solution

IDENT

FLAXI, RMIN, SORIG

EQLIN, EPSO, WITHN, NOLIN

MAXI, TOL, GAMMA, AVEVOL

PCHV

$\operatorname{DIGLIN~(a)~}$

PCHH

DIGLIN (b)

PNTS, EPS, POT, CODE

$\operatorname{DIGLIN}(c)$
Format

$20 A 4$

$3 F 10.0$

4F 10.2

4F10.2

$8 \mathrm{~F} 10.0 / 8 \mathrm{~F} 10.0$

10F7.0 repeated

$8 F 10.0 / 8 F 10.0$

10F 7.0 repeated

$4 \mathrm{~F} 10.0$

10F7.0 repeated 
A brief description of each variable is given in the GLOSSARY which follows immediately. A fuller description is given in following sections.

3. Run identification and over-all geometry

(IDENT, FLAXI, RMIN, SORIG)

IDENT can have up to 78 alpha-numeric characters at the user's discretion. It is used as a run identifier for output.

FLAXI and RMIN - Electric field problems for flat two-dimensional geometry and for axi-symetric three-dimensional geometry can be solved. The distance from the edge of the region closer to the axis of symmetry is specified as the minimum radius. For flat geometries it is zero. Proper coding is used to indicate the type of geometry and the axis of symmetry. Table III.C.I indicates al.l the information needed.

\begin{tabular}{|c|c|c|c|c|}
\hline $\begin{array}{c}\text { Code/Variable } \\
\text { Name }\end{array}$ & $\begin{array}{l}\text { Possible } \\
\text { Values }\end{array}$ & Meaning & $\begin{array}{l}\text { Location on } \\
\text { Input Sheet }\end{array}$ & Format \\
\hline FLAXI & $\begin{array}{l}1.0 \\
2.0 \\
3.0\end{array}$ & $\begin{array}{c}\text { Flat } \\
\text { Geometry } \\
\text { X-Axis } \\
\text { Symmetry } \\
\text { Y-Axis } \\
\text { Symmetry }\end{array}$ & $\begin{array}{l}\text { 2nd Card } \\
\text { Ist Position }\end{array}$ & $\begin{array}{l}\text { FORTRAN } \\
\text { F } 10.0\end{array}$ \\
\hline RMIN & $\begin{array}{r}0.0 \\
\geq 0.0\end{array}$ & $\begin{array}{c}\text { Flat } \\
\text { Geometry } \\
\text { Symmetry }\end{array}$ & $\begin{array}{l}\text { 2nd Card } \\
\text { 2nd Position }\end{array}$ & $\begin{array}{l}\text { FORTRAN } \\
\text { F } 10.0\end{array}$ \\
\hline
\end{tabular}

Table III.C.I

FLAXI and RMIN

SORIG is a value which divides all dimensions read in during a run. It can be thought of as the scale of an original drawing from which dimensions in millimeters are measured to provide dimensional information. Thus if a drawing has a scale of $1 \mathrm{~cm}$ representing 1 meter so that its scale is 1 to 100 or .01 , then the program adjusts each given dimension by dividing it by .01 . Thus a drawing measurement of $30 \mathrm{~mm}$ will be adjusted to $30 / .01=3000 \mathrm{~mm}=3.0 \mathrm{~m}$.

Dimensions are treated as identical within 0.5 /SORIG during computer processing. That is, if two dimensions are given which are within 0.5 of the input data units, they will be treated as equal. 
IDENT (20): alphanumeric array where the run identification is stored.

FLAXI:

RMIN:

SORIG:

EQLIN:

EPSO:

WITHN :

NOLIN:

HLF :

HLL :

VLF :

VLL:

MAXI:

TOL :

ALPHA :

AVEVOL:

PCHV (16):

$\operatorname{PCHH}(16)$ :

PNTS:

EPS :

POT:

CODE:

DIGLN (140): index for specifying flat field or axi-symmetric field. distance from the axis of symetry to the closest grid edge. scale of the drawing.

index for specifying equivalent formation and number of equipotential lines.

permittivity if not specified otherwise.

index for use of the equivalent when solving for the potentials in the window.

total number of contours to be read.

lower horizontal line number of the window.

upper horizontal line number of the window.

left vertical line number of the window.

right vertical line number of the window.

maximum number of iterations to be used in window solution.

tolerance permissible in window solution.

acceleration factor for iterative window solution.

initial estimate of the potentials for the window solution.

vertical grid line numbers where grid density changes.

simflar for the horizontal lines.

number of points that describe the following contour.

permittivity of material inside the contour

known potential of an electrode $(0.0$ if code $\neq 2.0)$.

indicates whether the contour is a dielectric, an electrode or a floating conductor. (0., 2., 3.)

temporary storage for several pairs of $(x, y)$ co-ordinates. 


\begin{tabular}{|c|c|c|c|c|}
\hline $\begin{array}{c}\text { Code } \\
\text { Name }\end{array}$ & $\begin{array}{c}\text { Possible } \\
\text { Values }\end{array}$ & Meaning & $\begin{array}{c}\text { Location on } \\
\text { Input Sheet }\end{array}$ & Format \\
\hline SORIG & $>0$ & $\begin{array}{c}\text { Scale of the } \\
\text { drawing }\end{array}$ & $\begin{array}{c}\text { Card 2 } \\
\text { Position 3 }\end{array}$ & F 10.0 \\
\hline
\end{tabular}

4. EQLIN, EPSO, WITHN, NOLIN

EQLIN is an index which specifies the number of equi-potential lines to be plotted, if a window solution is being run. If it is zero, an equivalent formation is run.

EPSO is the base permittivity, assumed to apply outside all contours. It may be either absolute or relative permittivity.

WITHN is an index set to 0.0 if an equivalent formed previously is to be used in this run. It is set to 1.0 if a previously formed equivalent is not to be used.

NOLIN is the number of contours which will be read in as input data later.

\begin{tabular}{|c|c|c|c|c|}
\hline $\begin{array}{l}\text { Code } \\
\text { Name }\end{array}$ & $\begin{array}{l}\text { Possible } \\
\text { Values }\end{array}$ & Meaning & $\begin{array}{l}\text { Location on } \\
\text { Input Sheet }\end{array}$ & Format \\
\hline EQLIN & $\begin{array}{l}0.0 \\
>0 .\end{array}$ & \begin{tabular}{l}
\multicolumn{1}{c}{ Compute } \\
Equivalent \\
Solve Window \\
with EQLIN no. \\
of equipoten- \\
tial lines
\end{tabular} & $\begin{array}{c}\text { Card } 3 \\
\text { Position } 1\end{array}$ & F 10.0 \\
\hline EPSO & $\geq 0$ & $\begin{array}{c}\text { Base } \\
\text { permittivity }\end{array}$ & $\begin{array}{c}\text { Card } 3 \\
\text { Position } 2\end{array}$ & F 10.0 \\
\hline WITHN & $\begin{array}{l}0 . \\
1 .\end{array}$ & $\begin{array}{l}\text { Use previous } \\
\text { equivalent } \\
\text { Do not use } \\
\text { equivalent }\end{array}$ & $\begin{array}{c}\text { Card } 3 \\
\text { Position } 3\end{array}$ & F 10.0 \\
\hline NOLIN & 1. to 70. & $\begin{array}{l}\text { Number of } \\
\text { contours to } \\
\text { be entered }\end{array}$ & $\begin{array}{c}\text { Card } 3 \\
\text { Position } 4\end{array}$ & F 10.0 \\
\hline
\end{tabular}


5. Window location (for equivalent formation runs only) (HLF, HLL, VLF, VLL)

A regular grid must first be defined. See section 6. on Grid Definition.

Once the grid has been defined, the window is chosen, just by selecting the grid line numbers that frame it. These lines are two horizontal and two vertical. The window can be anywhere in the grid as long as the number of grid points in it does not exceed 900.

\begin{tabular}{|c|c|c|c|c|}
\hline $\begin{array}{c}\text { Variable } \\
\text { Name }\end{array}$ & $\begin{array}{l}\text { Possible } \\
\text { Values }\end{array}$ & Meaning & $\begin{array}{l}\text { Location on } \\
\text { Input Sheet }\end{array}$ & Format \\
\hline HLF & 1 to 100 & $\begin{array}{c}\text { Lower Horiz. } \\
\text { Line }\end{array}$ & $\begin{array}{c}\text { Card } 4 \\
\text { Position } 1\end{array}$ & F 10.0 \\
\hline HLL & 1 to 100 & $\begin{array}{l}\text { Upper Horiz. } \\
\text { Line }\end{array}$ & $\begin{array}{c}\text { Card } 4 \\
\text { Position } 2\end{array}$ & F 10.0 \\
\hline VLF & 1 to 70 & $\begin{array}{c}\text { Left Vertical } \\
\text { Line }\end{array}$ & $\begin{array}{c}\text { Card } 4 \\
\text { Position } 3\end{array}$ & F 10.0 \\
\hline VLL & 1 to 70 & $\begin{array}{c}\text { Right Vertical } \\
\text { Line }\end{array}$ & $\begin{array}{c}\text { Card } 4 \\
\text { Position } 4\end{array}$ & F 10.0 \\
\hline
\end{tabular}

The total number of nodes present at any one time during equivalent formation can not exceed 190, including those on the window boundaries. When the equivalent is finally formed, only 120 nodes may be included, divided into 116 on the window boundary $(30 \times 30$ window grid) and four electrodes outside the window.

\section{Grid definition} (PCHV (16), DIGLN, PCHH (16), DIGLN)

The whole region is overlaid with a uniform rectangular grid. The grid is made up of vertical and horizontal lines; the intersection of any two of such lines defines a "grid point" which may eventually be called a "node."

Spacing between the lines, in either direction, does not have to be equal; the spacing is determined by the number of lines in a given distance. Only the line number. where the new spacing begins has to be specified. Also the coordinates of those lines are specified (see the example at the end of this users' manual). 
A maximum of 70 vertical lines and of 100 horizontal lines is accepted. both can be used simultaneously, yielding a maximum of 7,000 grid points.

A maximum of 16 grid density changes in each direction is accepted.

How close the lines should be depends on the degree of accuracy desired. A spacing of 0.5 millimeters between consecutive lines is the minimum allowed.

The first line number is always 1 , and has to be specified. The last line number must also be specified.

In PCHV(16) and PCHH(16) there are 16 input fields (Format F 10.0) allotted to each set of line numbers defining the grid; those that are not needed must be filled out with zeros.

In DIGLN the co-ordinates of each line given in the grid definition are specified as an $x-y$ pair. The coordinate $x$ is irrelevant for the definition of horizontal lines and coordinate $y$ is irrelevant for vertical lines. However, their input fields must be filled out with zeros.

There are 32 input fields (Format F 7.0) allotted to each set of coordinates defining the lines. Co-ordinates are given only for the line numbers different from zero.

\begin{tabular}{|c|c|c|c|c|}
\hline $\begin{array}{l}\text { Array } \\
\text { Name }\end{array}$ & $\begin{array}{l}\text { Possible } \\
\text { Values }\end{array}$ & Meaning & $\begin{array}{l}\text { Location on } \\
\text { Input Sheet }\end{array}$ & Format \\
\hline PCHV (16) & 1 to 70 & $\begin{array}{c}\text { Vertical line numbers } \\
\text { where horizontal } \\
\text { spacing changes }\end{array}$ & $\begin{array}{l}\text { Cards } 5 \text { and } 6 \\
\text { Positions } 1 \text { to } 8\end{array}$ & F 10.0 \\
\hline $\operatorname{DIGLN}(140)$ & $\geq 0$. & $\begin{array}{l}\text { Co-ordinates of the } \\
\text { lines in the form } \\
(x, y)=(x, 0 .)\end{array}$ & Follows card 6 & F 7.0 \\
\hline PCHH (16) & 1 to 100 & $\begin{array}{l}\text { Horizontal line num- } \\
\text { bers where vertical } \\
\text { spacing changes }\end{array}$ & $\begin{array}{c}\text { Follows vertical } \\
\text { co-ordinates }\end{array}$ & F 10.0 \\
\hline DIGLN (140) & $\geq 0$. & $\begin{array}{l}\text { Co-ordinates of the } \\
\text { lines in the form } \\
(x, y)=(0 ., y)\end{array}$ & $\begin{array}{c}\text { Follows } \\
\text { horizontal } \\
\text { lines }\end{array}$ & F 7.0 \\
\hline
\end{tabular}

Table III.C.2

Grid Co-Ordinate Data 
7. Contour specification

(PNTS, EPS, POT, CODE, DIGLN)

The geometry is represented by two dimensional contours. The contours are formed piecewise by straight segments; the segments originate when joining a series of consecutive points that define a shape of interest.

To define a contour the necessary number of points (PNTS) and the coordinates (DIGLN) of each point are given.

To indicate a closed contour the first and last point defining it should be the same, otherwise it is considered open.

These contours can represent electrodes, floating conductors and bodies of different permittivities. They are selected by proper coding (CODE).

Open contours can represent only electrodes and floating conductors; a permittivity (EPS) other than 0.0 cannot be associated with them.

The potential (POT) and the permittivity (EPS) specified in the contour definition is assigned to all the points inside it only if it is closed.

A maximum of 70 contours, with up to 70 points per contour, is allowed. However, the total number of points may not exceed 400 .

If two points are spaced 0.5 millimeters or less they are considered to be physically the same.

Floating conductors that are a closed contour are specified as if they were a body with a relative permittivity of 9000 . The special code for floating conductors should be saved for open lines only unless the equivalent is to be computed, in which case it should be 3.0 for closed and open lines.

Points describing a contour cannot be closer than the local spacing of the grid, $1 . e$. , there must be at least as many grid points available as there are contour vertices in a region, otherwise the program aborts and an error message is printed.

Two different contours can have common lines. The order in which the contours are entered is important. Electrodes should be entered first; next, the floating conductors, and last the remaining type.

The information needed for each contour is:
a) number of points that describe it (PNTS);
b) relative permittivity ( 0.0 if contour is open or if describing an electrode)(EPS);
c) potential in volts ( 0.0 if other than electrode)(POT); 
d) code: 2.0 for electrodes

3.0 for floating conductors

0.0 for dielectric

e) co-ordinates for the points in a)(DIGLN)

Table III.C.3 gives information on items a) to d). Item e), the point coordinates are given in $x-y$ pairs, 5 pairs per line, in $10 F 7.0$ format. The dimensions are assumed to be in millimeters.

Figure III.C.l shows a rectangular dielectric shape with a poor approximation to a circle resting on one end. Input data required for these two shapes are:

$\begin{array}{lllll}5.0 & 2.0 & 0.0 & 0.0 \quad(4 \mathrm{~F} 10.0 \text { format })\end{array}$

0051. 0000.0071 .0000 .0071 .0051$.

0051.0051 .0051 .0000 .

All on one card

(10F7.0 format)

$\begin{array}{lllll}7.0 & 0.0 & 100.0 & 2.0 & \text { (4F10.0 format) }\end{array}$

0051. $0051 . \quad 0071.0051 .0081 .0068 .0071 .0086$.

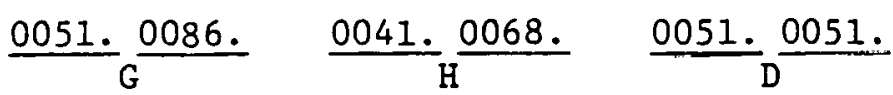

All on one card (10F7.0 format) 


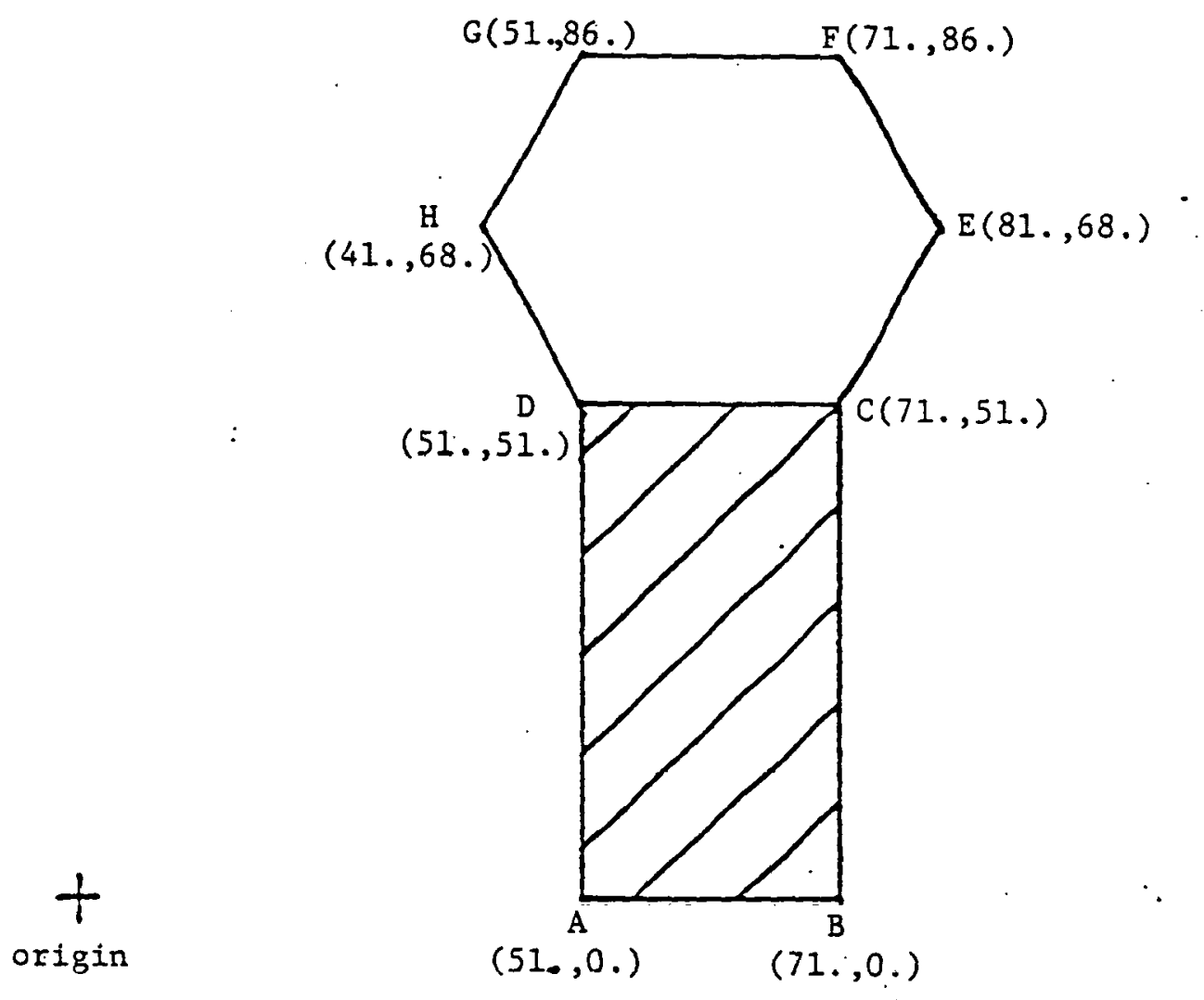

Figure III.C.I -

Input Vata Sample 


\begin{tabular}{|c|c|c|c|}
\hline $\begin{array}{c}\text { Code } \\
\text { Name }\end{array}$ & $\begin{array}{c}\text { Possible } \\
\text { Values }\end{array}$ & Meaning & Format \\
\hline NPTS & 1 to 70 & $\begin{array}{c}\text { Number of points } \\
\text { in a contour }\end{array}$ & $F 10.0$ \\
\hline EPSI & $\varepsilon_{\mathrm{R}}$ & $\begin{array}{c}\text { Relative permittivity } \\
\text { of material inside } \\
\text { the contour }\end{array}$ & F 10.0 \\
\hline PO'T & Any & $\begin{array}{c}\text { Potential of the } \\
\text { contour }\end{array}$ & F 10.0 \\
\hline CODE & 0 & $\begin{array}{c}\text { Dielectric } \\
\text { Electrode } \\
\text { Floating Conductor }\end{array}$ & F. 10.0 \\
\hline
\end{tabular}

Table III.C.3

8. Computation of the equivalent

Use of the proper code causes the program to compute the equivalent; the input data is that for the whole grid.

When computing the equivalent, each electrode or floating conductor is considered as one node.

The information regarding the equivalent is stored in two files which are opened automatically by the program.

The only out-put the user receives is in the file "WINOUT" and contains a repeat of the input data, and any error messages.

9. Computation of field strengths

New input data are produced; this time the window is considered the whole grid observing all the restrictions already mentioned. Use of the proper code will cause the program to compute the voltage distribution within the window.

Additional information regarding the solution of a system of equations must be specified. (MAXI, TOL, GAMMA, AVEVOL) 


\begin{tabular}{|c|c|c|c|c|}
\hline $\begin{array}{c}\text { Code/Variable } \\
\text { Name }\end{array}$ & $\begin{array}{c}\text { Possible } \\
\text { Values }\end{array}$ & Meaning & $\begin{array}{c}\text { Location on } \\
\text { Input Sheet }\end{array}$ & Format \\
\hline MAXI & $>0$ & $\begin{array}{c}\text { Maximum No. } \\
\text { of Iterations }\end{array}$ & $\begin{array}{c}\text { Card 4 } \\
\text { Position 1 }\end{array}$ & F 10.0 \\
\hline TOL & $>0$ & Tolerance & $\begin{array}{c}\text { Card 4 } \\
\text { Position 2 }\end{array}$ & F 10.0 \\
\hline GAMMA & $0 \rightarrow 2$ & $\begin{array}{c}\text { Acceleration } \\
\text { factor } \\
\text { Card 4 }\end{array}$ & Position 3 10.0 \\
\hline AVEVOL & $\varepsilon_{R}$ & $\begin{array}{c}\text { Initial } \\
\text { estimate }\end{array}$ & $\begin{array}{c}\text { Card 4 } \\
\text { Position 4 }\end{array}$ & F 10.0 \\
\hline
\end{tabular}

The solution of the linear system of equations is done by the successive overrelaxation (S.O.R.) method. The acceleration factor (GAMMA) is a number between 0 . and 2.; overrelaxation occurs when it is greater than one, and underrelaxation when less than one. The number of iterations needed for a certain convergence depends on the number of grid-points in the windows and the initial estimate of the solution. There is no definite way of best proceeding, but as a first approximation the maximum number of iterations (MAXI) should be equal to or larger than the number of grid points in the window, the acceleration factor (GAMMA) to 1.4 , or in any case, overrelaxed, and the initial voltage value (AVEVOL) to the weighted average of what the operator feels is going to be the final potential distribution. The average of the maximum and minimum potential will do if no better estimate can be provided. All of the above instructions are for a tolerance of $0.1 \%$, where tolerance (TOL) means the maximum change of potential for one given grid-point belween two consecutive iterations.

The output consists of two parts:

a) a graphic display;

b) a repetition of the input data, the maximum field strengths for each permittivity present and the potential at every grid-point.

A graphic display of the equipotentials is always part of the program's output. It is programmed to produce the largest picture possible and also shows the identification of the problem and the percent volts per line.

The graphics package is "Dynagraphics," as implemented on the "IMLAC" erminals. 
A file with the following items is provided:

1) identification;

2) grid line numbers and their co-ordinates;

3) repetition of the input data, regarding the contours (shapes);

4) warnings or errors if any occur during the execution of the program;

5) maximum field strength for each permittivity, and the co-ordinates and grid numbers of the vertices of the triangles where they happened;

6) potential in volts at every vertex, as well as their grid numbers and co-ordinates.

10. Input and Output files

The program was implemented in a "PRIME 500" computer system. Advantage was taken of its file management system, and the program is run interactively from a terminal.

The input data is written in a file by the name of "WINDAT." This file is automatically opened by the program and the information is read as it is requested. When the program is finished reading, this file is closed.

The output is handled in a similar way. When building the equivalent the program generates two output files, "DATA 1" and "DATA 2." "DATA 1" contains the grid number of the vertices on the window boundary that have connections to the equivalent, the assigned number of the electrodes that were on the equivalent and its potentials. "DATA 2 " contains the equivalent matrix, stored in a linear array.

These two files must exist when the solution in the window is required if the equivalent matrix is to be used. The program opens and closes them automatically.

When solving for the potentials in the window the output is written out in a file called "WINOUT" which is also opened and closed automatically.

Refer to the PRIME FTN MANUAL for instructions on how to get a hard-copy of the files.

11. Error messages

The program aborts and prints out one or more of the following error messages, if it is necessary to modify the input: 
1. The number of horizontal grid lines is more than 100; the number of vertical grid lines is more than 70 .

2. The number of nodes in the grid is more than 7000 ; the number of nodes in the window is more than 900 .

3. There are more than 70 contour Iines.

4. A contour line is described by more than 70 points.

5. The total number of contour points exceeds 400 .

6. The permittivity is given different from zero, and the last point on the line is not equal to the first.

7. The line fitting was interrupted for line segment-near-, (Coordinates define the line segment and the point where the line fitting got stuck.)

8. This point is too close to the preceding point-. (The point is defined by its co-ordinates.)

9. The program has moved vertex - from one line to another line which is too close. (The vertex point is defined by its number and its co-ordinates.)

10. The area came out negative or zero for triangle with-. (The triangle is defined by its vertex numbers and co-ordinates.) Change line sequence or move grid lines.

12. Compiling, loading and running the program

The program has the following memory requirements

for the compiled program: PROCEDURE 12010 words

for variables and array storage: DATA $\underline{67681}$

Total 79782

The program is compiled in the virtual mode (FTN WINDOW $-64 \mathrm{~V}$ ). It loads in the segmented mode (SEG). The Dynagraphic's Library and the FORTRAN library most be loaded also. The order is important and Dynagraphic's is first.

Once the program is properly loaded, it is run in the segmented (yirtual) mode. (SEG 非 WINDOW.)

The data files and the output files are opened and closed from within the program; to obtain a listing of these flles the comand "SPOOL" is used, i.e. for a listing of "WINOUT" we type:

SPOOL WINOUT - FTN. 
The FTN option tells the computer to execute FORTRAN carriage control commands. It should not be used for listing of data files. A typical session in one of the terminals would appear as follows; the user types the underlined words.

\section{Example}

The problem consists of the determination of the best shape of the end of a semiconducting sheath on a cable joint, as shown in Fig. III.C.2. It is desired to choose a shape so as to reduce the field stress on the surface of contact of the materials with permittivities $\varepsilon_{1}$ and $\varepsilon_{2}$.

The problem was simplified to an arrangement of electrodes and dielectrics, as shown in Fig. III.C.3.

The grid line changes for the whole problem and for the window are shown in Fig. III.C.4.

Fig. III.C.5.a shows the input data file for the computation of the equivalent and Fig. III.C.5.b shows the same for the solution in the window.

Fig. III.C.6 shows graphic output of the program in the window region. 
OR, LOGIN VARELA LAUBER

VARELA (23) LOGGED IN AT 14'12 D92179

ENTER LOGIN PASSWORD: 非非非非

THE MACHINE RESPONDS WITH SYSTEM IDENTIFICATION, TIME OF LOGIN AND DATE OF LAST LOGOUT.

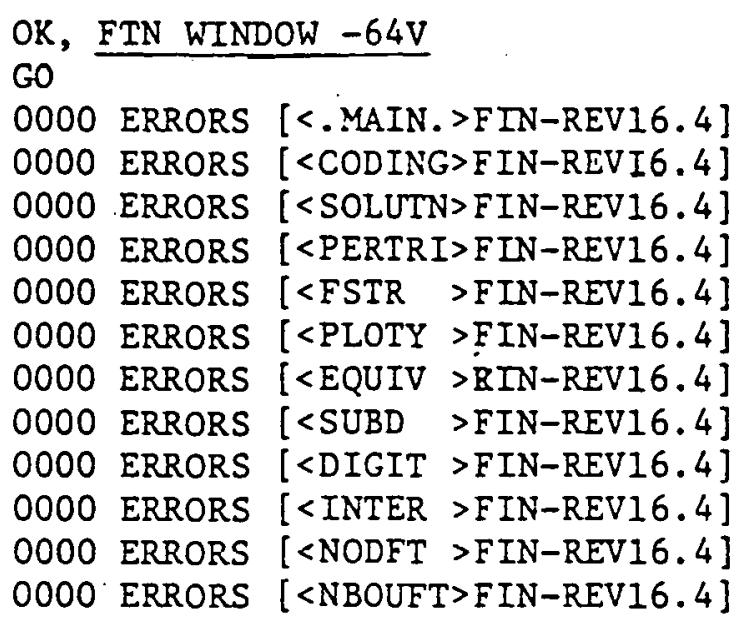

OK, SEG

GO

\# VLOAD \#WINDOW

$\$$ LO B-WINDOW

$\$$ LI. HGP1FV

$\$ \overline{L I}$

LOAD COMPLETE

$\$$ SAVE

$\$$ EXECUTE

Co

OR, SPOOL WINOUT -ETN 


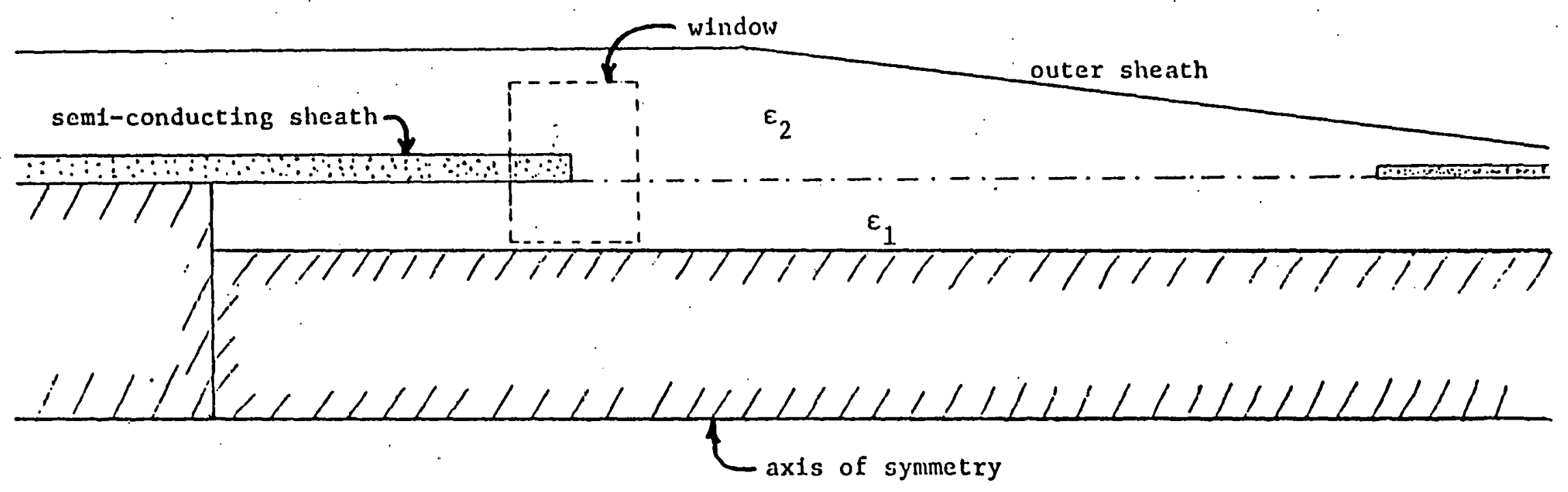

Cable Splice

F1gure III.C. 2 


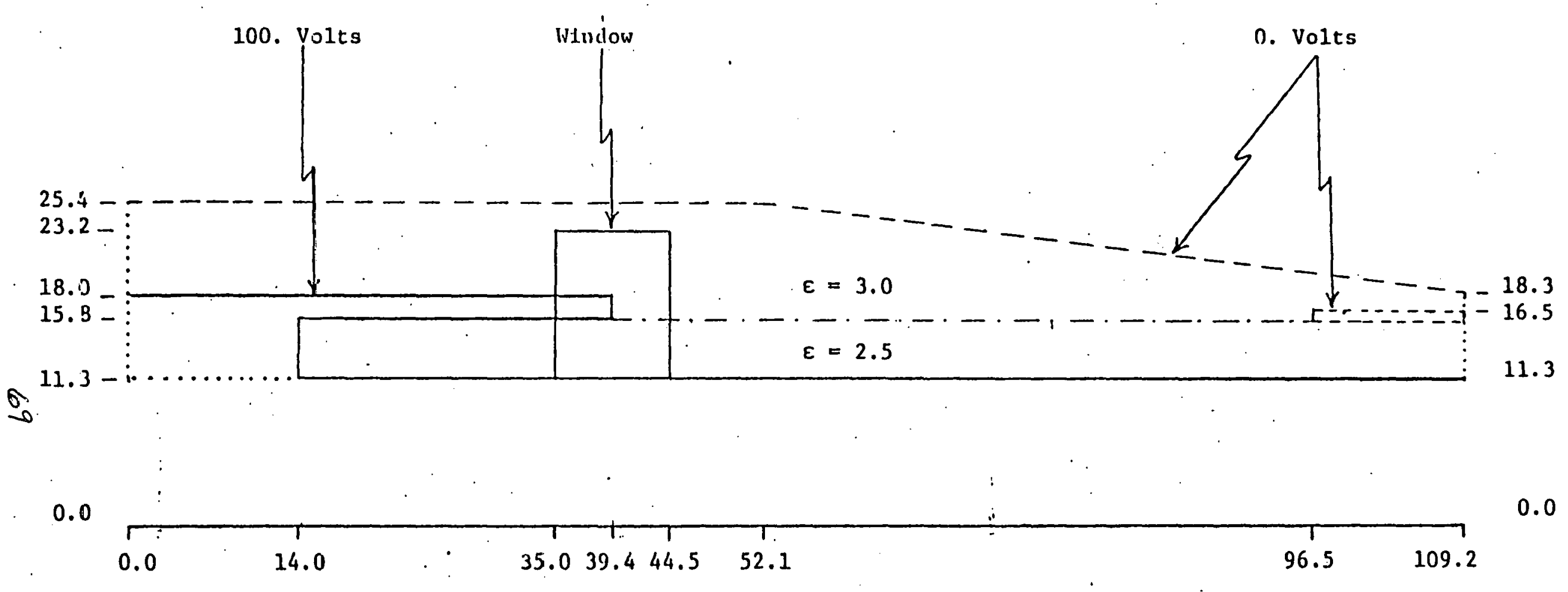

Schemat1c of the Problem (Dimenstons in Millimeters)

Figure III.C.3 


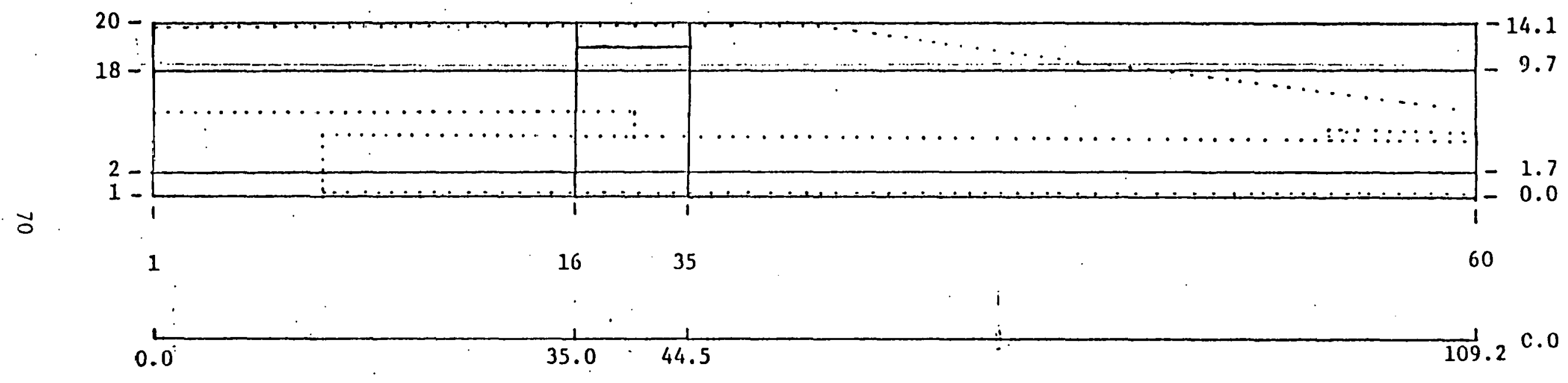

Lines Indicating Grid Density Changes and the Window (Dimensions in Milimeters)

Figure III.C.4 
CALLE SPLICE CONICAL EQUIVALEITT.

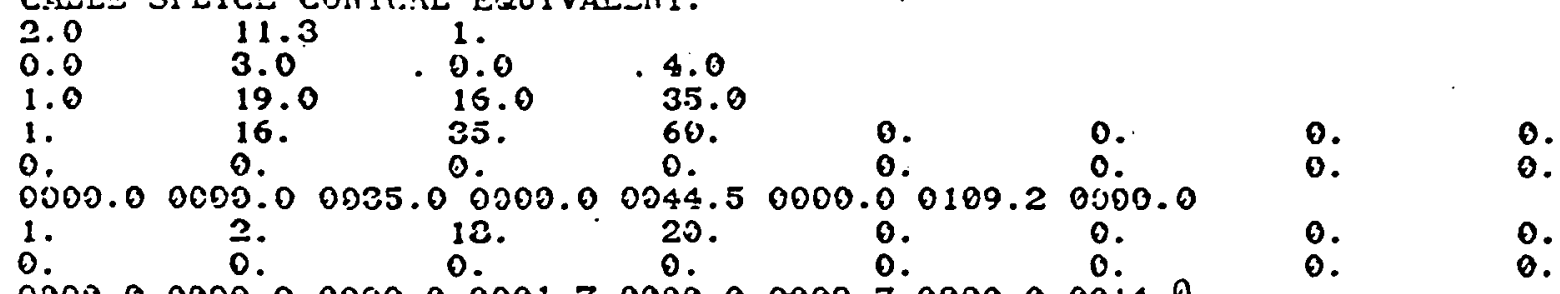

0000.00000 .00000 .00001 .70000 .00009 .70000 .00014 .0

6.0 . $\quad 100.2$

0000.00006 .70039 .40006 .70039 .40004 .50014 .00004 .50014 .00000 .0 0109.20003 .0

3.00 .20$.

0000:0 0014. 1 0052.10014.1 0109.20007 .0

$5.0 \quad 0.0 \quad 0.0 \quad 2.0$

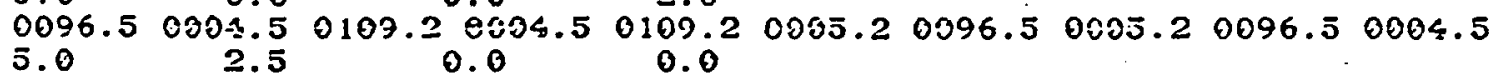

0014.00300 .00109 .20000 .00109 .20004 .50014 .00004 .5 .0014 .00000 .0

$-\therefore$

Equivalent Input Data

Figure III.C.5.a

VIET OF COPHID IN CABLE JOINT.

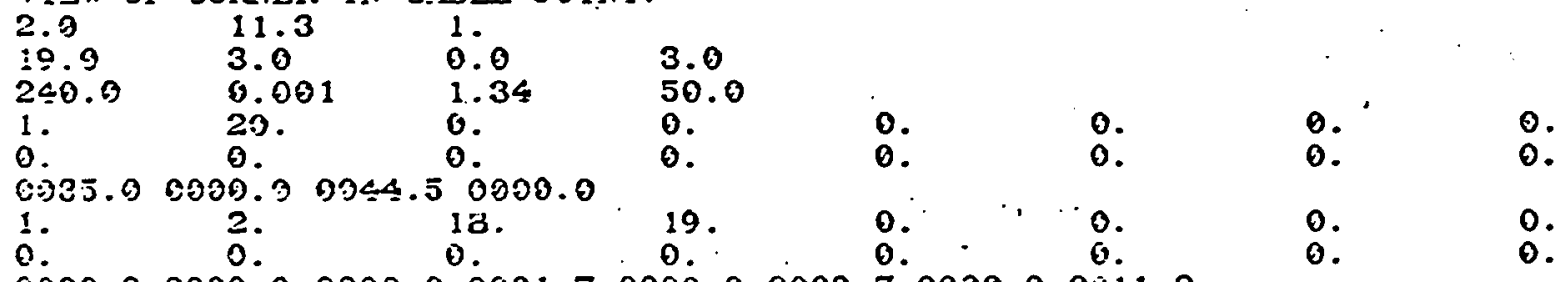

0009.00090 .00099 .00001 .70000 .00009 .70000 .00011 .9

$6.9 \quad 0.0 \quad 105.0 \quad 2.0$

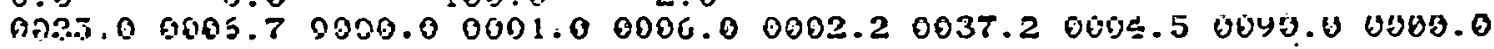

(1025.0 0004.5

2.0 .90

109.0

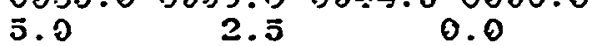

2.0

$0035.0 \quad 0033.00944 .50009 .00044 .50004 .50025 .00004 .50035 .00000 .0$

\section{Window Input Data}

Figure III.C.5.b 


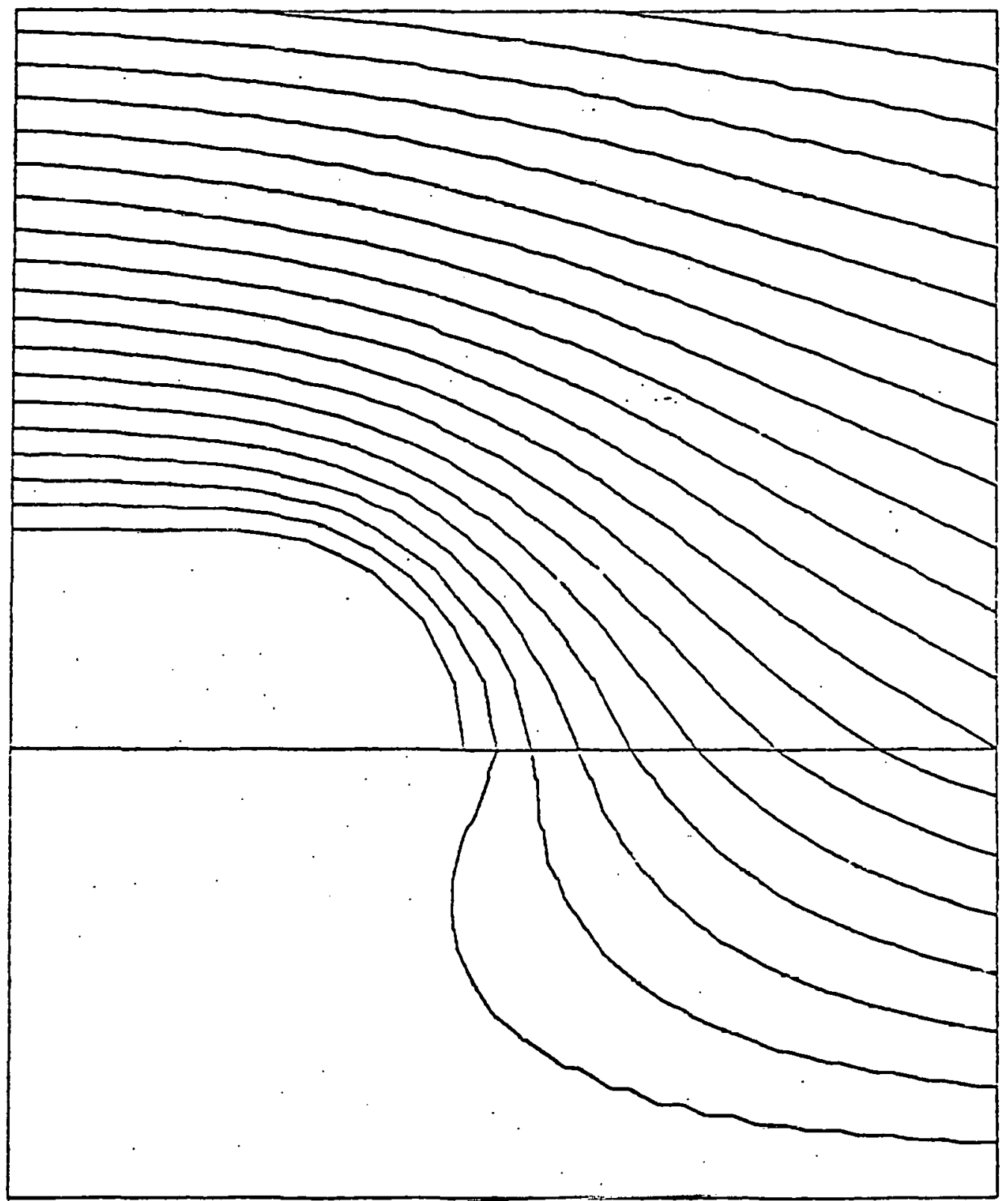

\section{Window Solution of Cable Joint}

Figure III.C.6 


\section{Program Verification}

\section{A. Summary}

Results for the electrostatic field in three different examples have been obtained.

1. a cable joint with two different radii and permittivities;

2. a shield for a bushing throat on an air blast circuit breaker;

3. a portion of a transformer winding.

The results were compared to those obtained using the Andersen program and found to be numerically the same. Cost of forming the equivalent matrix at the retained window surface was found to be comparable to the cost of the Andersen program result for the entire problem. Cost of each succeeding run for the retained window combined with the equivalent was significantly less than the Andersen program cost.

\section{A Cable Splice}

Figure IV.1 shows an axi-symmetric problem where a smaller conductor with insulation $\varepsilon_{1}$ and a semi-conducting outer sheath enter from the right.

A larger conductor enters from the left. It has an inner semi-conducting sheath and insulation $\varepsilon_{2}$ as well as an outer conducting sheath.

The outer sheath of the smaller conductor is shown cut back. The larger conductor is shown under-cut from its inner sheath. The two are then butted inside the large conductor, inner sheath. The splice is insulated by filling the conical space with insulation $\varepsilon_{2}$ and wrapping the entire joint with a conducting sheath.

The field problem is to determine maximum electric stresses in each of the dielectrics. Potential $=100 \%$ is specified on both conductor surfaces and on the inner semi-conducting layer of the large conductor. Potential $=0$ is specified on the outer conical wrapping and its extensions and also on the outer semi-cunducting sheach of the small conductor.

For illustrative purposes, the window was located over the end of the large conductor, inner sheath extension as indicated in Figure IV.1. Another possible location of large stress is at the end of the small conductor, outer sheath, but this case was not run for this report.

The question to be illustrated for this report is the effect of the shape of the end of the sheath extension, i.e. is the ramp cut shown optimal or would a square cut or quarter-round end be better?

The grid used was the same for two solutions: an Andersen program solution and the new window solutions. The entire problem had $20 \times 60$ grid lines giving L200 nodes. The window had $19 \times 20$ grid lines giving 380 nodes. 


\section{Figure IV.1. Cable Splice}

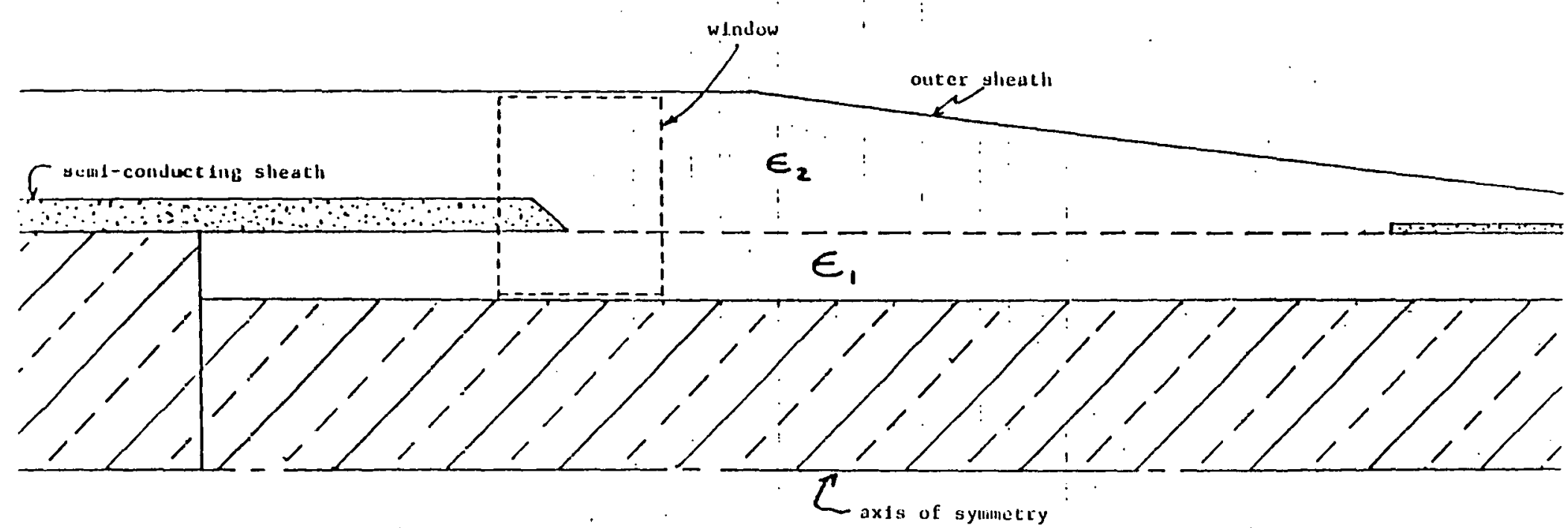


Figure IV.2 shows the Andersen program solution for this example. Note that right and left have been reversed and that the end of the inner semiconducting sheath has a quarter-round shape. Figure IV.3 is the solution of the window region using the new program. Figure IV. 4 is an enlargement of the Andersen solution in the area of the window so that a closer comparison can be made. It is evident that the solutions are the same.

Figure IV.5 shows two other runs made in the window region on the new program. They illustrate the fact that the window geometry can be varied without repeating the "first pass" run which forms the equivalent at the window surface.

\section{Circuit Breaker Bushing Throat Shield}

F1gure IV.6 is a picture taken from a manufacturer's instruction book illustrating an interrupter head for a circuit breaker. Figure IV.7 is a simplification of the throat region of the horizontal bushing. The field problem is to determine electric stress near the throat and, in particular, to determine the length of the shield located there (part 29).

Again, runs were made to compare the Andersen solution to the window solution. Figure IV.8 shows the complete Andersen solution. Figure IV.9 shows the window solution. The window was located over the end of the shield as indicated in Figure IV.7. Total grid was $64 \times 33=2112$ nodes. Window grid was $39 \times 23=897$ nodes. Figure IV.10 is an enlargement of the Andersen solution in the shield end region. Comparison of Figures 9 and 10 shows that the same result was obtained. Figure IV.11 shows two other runs of the window program, without repeating the first-pass equivalent formation used in Figure IV.9. This figure illustrates varying the shield end location within the window.

\section{Transformer Turns}

Figure IV.12 shows an approximation of a transformer winding which is the lower half of a high voltage winding wound symmetrically from the center to the ends. The left and bottom surfaces are at zero potential representing the low voltage winding and the bottom core yoke respectively. The upper surface is a cut surface representing symmetry with the upper half winding. The right surface is also a cut surface. The top turn, representing the line connection is held at $100 \%$ potential. All other conductors are floating. Thus, this solution is an approximation to impulse response. The top two sections are paper wrapped, and spaced farther than the other turns which are uniform.

Two solutions were obtained: the complete Andersen solution and the window solution. The window was located over the top three turns as shown in Figure IV.12. Total grid was $32 \times 17=544$ nodes. The Andersen solution of the complete problem is shown in Figure IV.13. Figure IV.14 shows the window solution. Figure IV.15 shows an enlargement of the Andersen solution. Again, the results are the same. 


\section{B. Cost Comparisons}

The table given below gives approximate costs of computer runs plus hard copy graphic results on the Prime 500 system.

\begin{tabular}{|l|c|c|c|}
\hline & Splice & Shield & Transformer \\
\hline $\begin{array}{l}\text { Andersen } \\
\text { Solution }\end{array}$ & $\$ 10.00$ & $\$ 12.50$ & $\$ 8.00$ \\
\hline $\begin{array}{l}\text { Equivalent } \\
\text { Formation }\end{array}$ & $\$ 5.00$ & $\$ 16.00$ & $\$ 2.20$ \\
\hline $\begin{array}{l}\text { Window } \\
\text { Solution }\end{array}$ & $\$ 4.00$ & $\$ 12.00$ & $\$ 5.00$ \\
\hline
\end{tabular}

The Andersen solutions were also run on the IBM3033. Costs were approximately $\$ 1.00$ less than the Prime 500 costs given in the table.

Costs for the splice and transformer examples are very favorable for the window solution versus the Andersen solution. For the shield example, difficult.ty was encountered in convergence of the matrix solutions. Thus extra cost was incurred. 


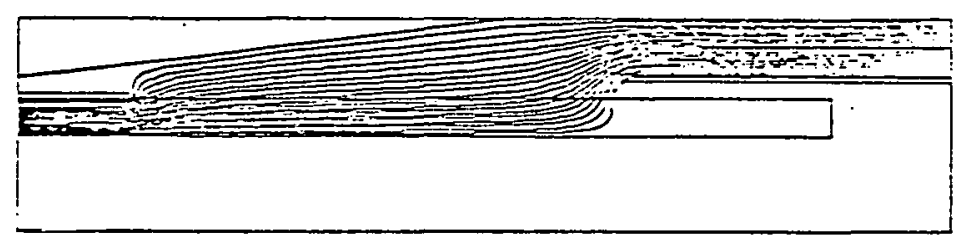

Figure IV.2 Andersen Solution of Cable Joint

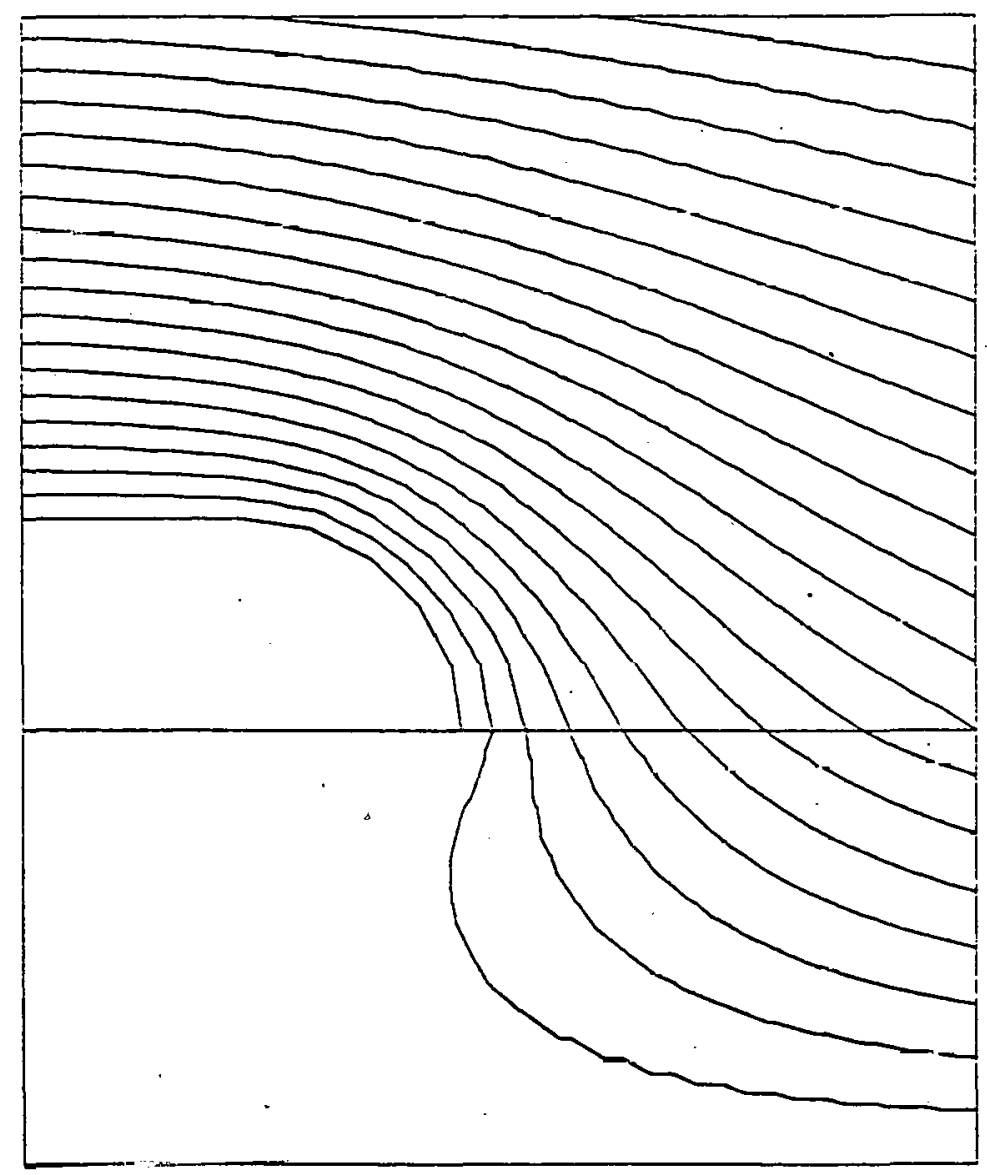

F1zure IV.3 Window Solution of Cable Joint 


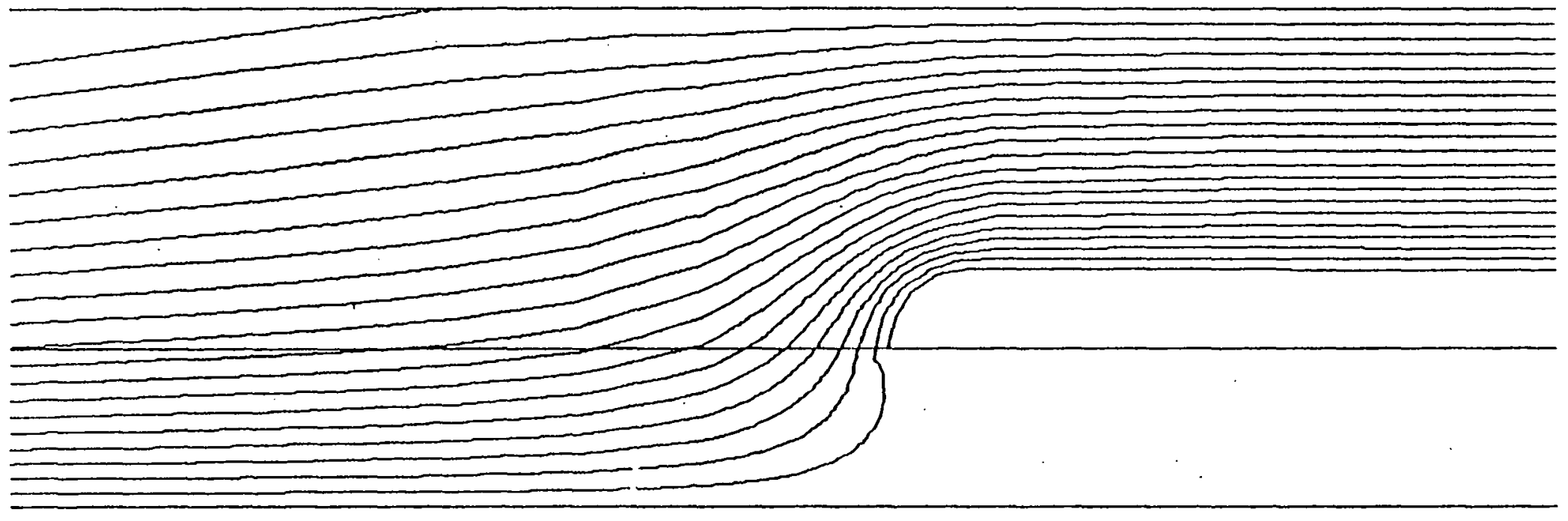

Flgure IV.4 Enlargement of Andersen Solution In Window Reglon of Cable splice 

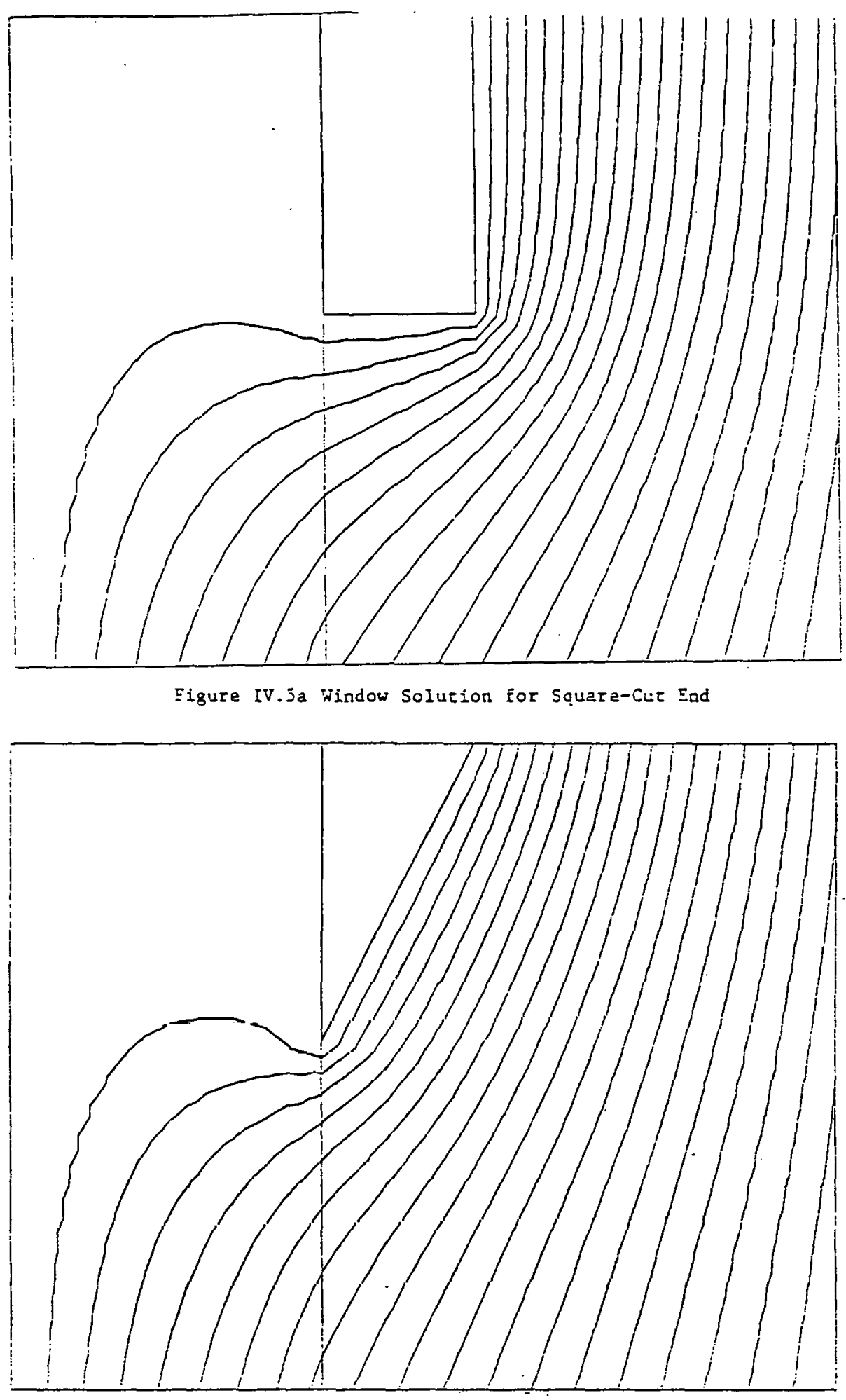

Foure IV.jb window Soiution for Ramp-Cut Ead 


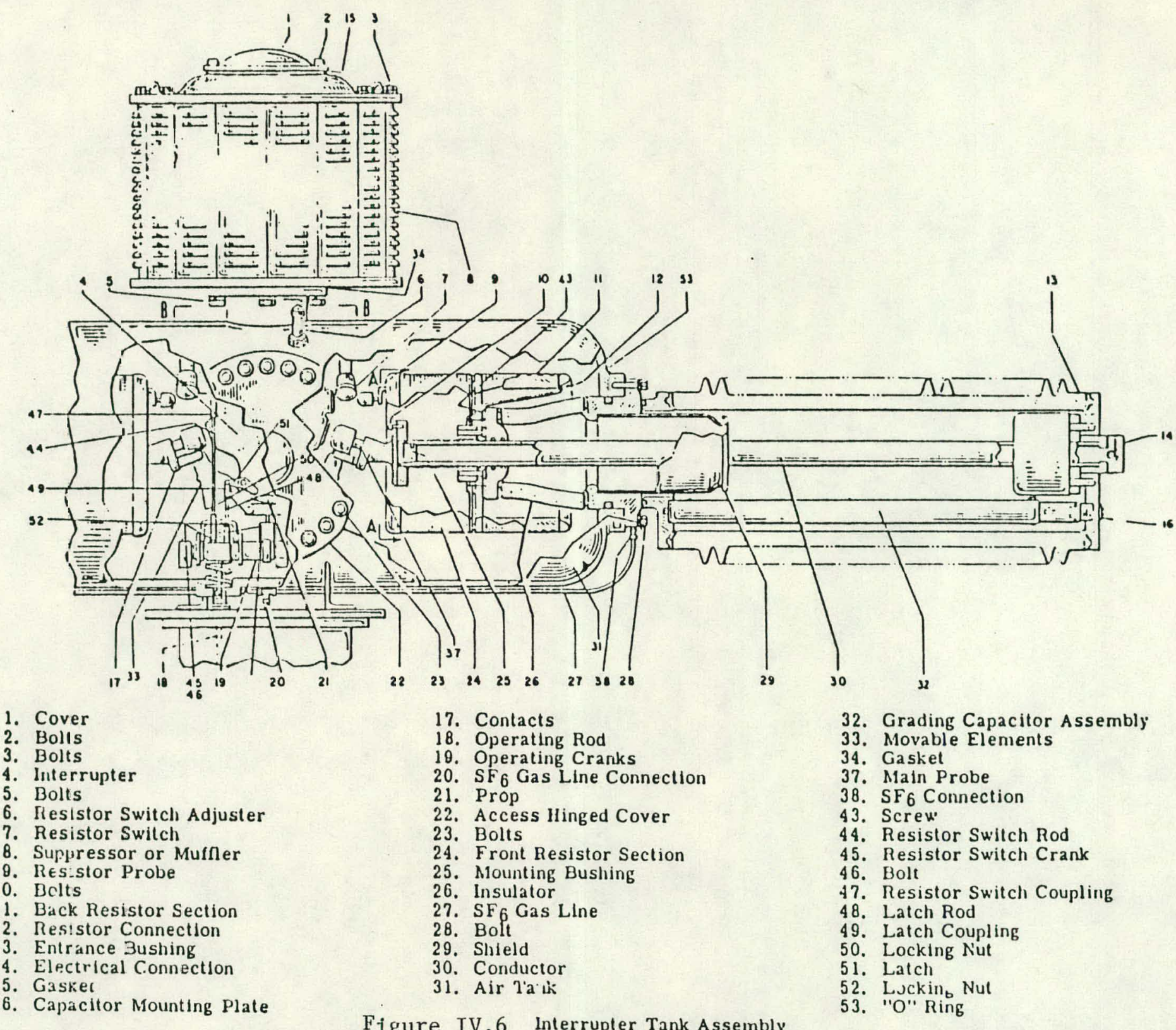




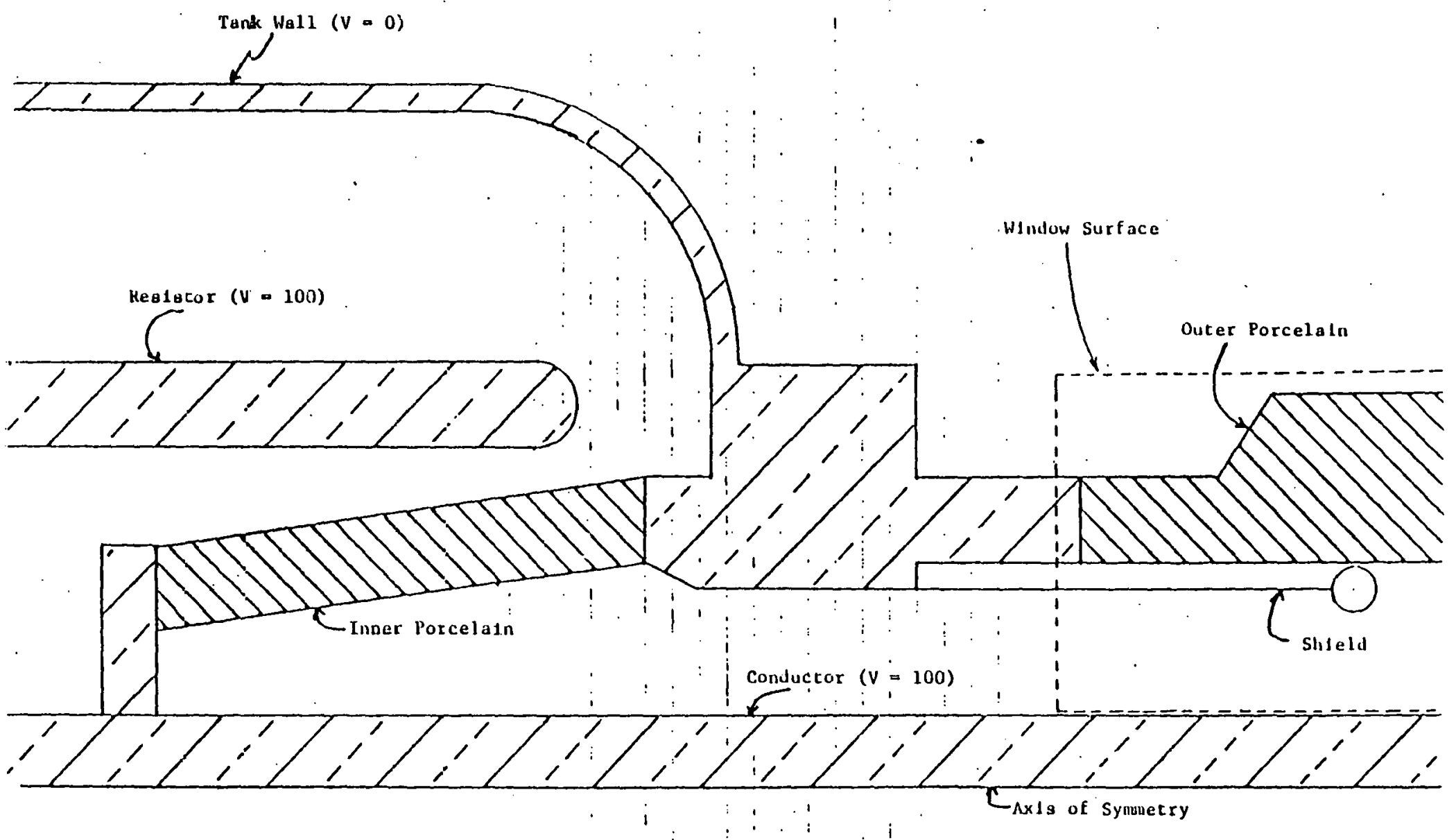

Pigure IV.7 C1rcult Breaker Busling Tiliroat Detall 


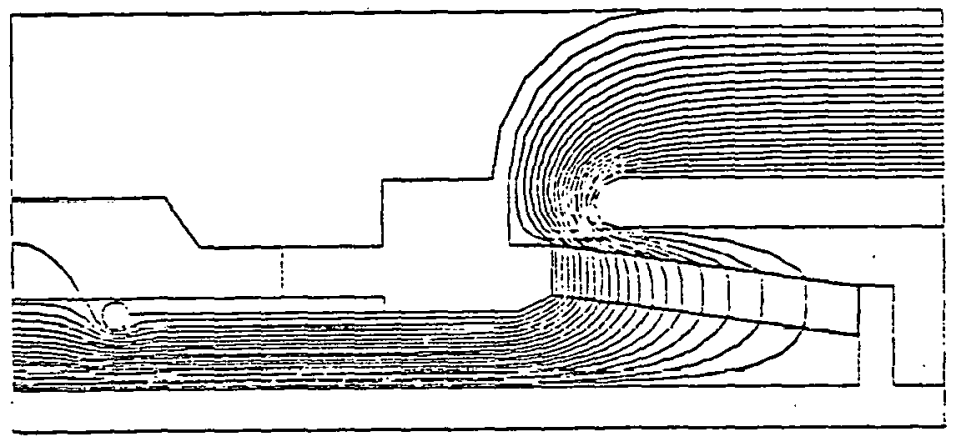

Figure IV. 3 Agdersen Solution of Circult Zregiker Busing Throat

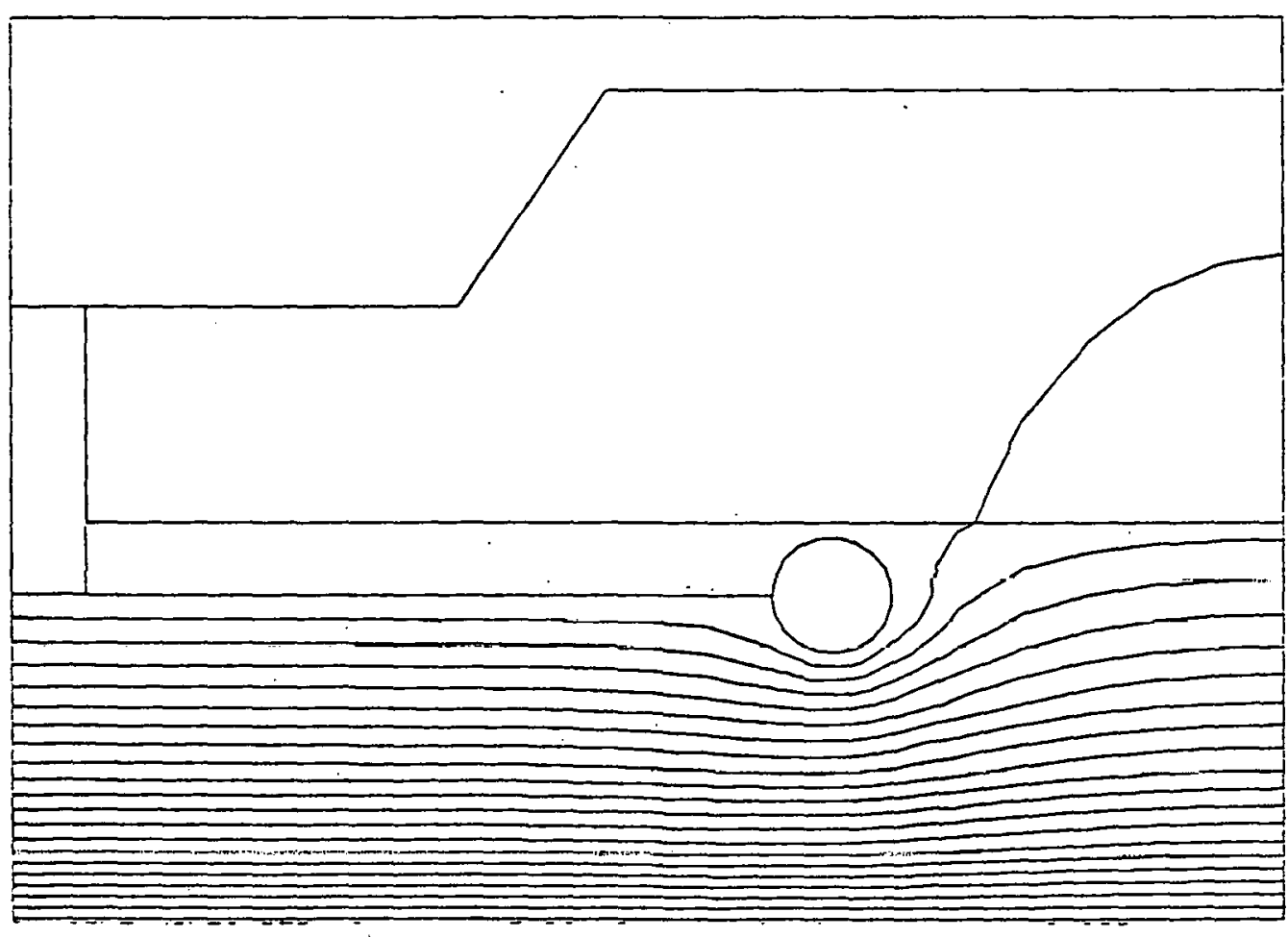

Figure IV.9 Wizdow Solution of C1rcuit Breaker Bushing Throat 
Flgure IV.10 Enlargenent of Andersen Solution in Window Region of Circutt Breaker Shield

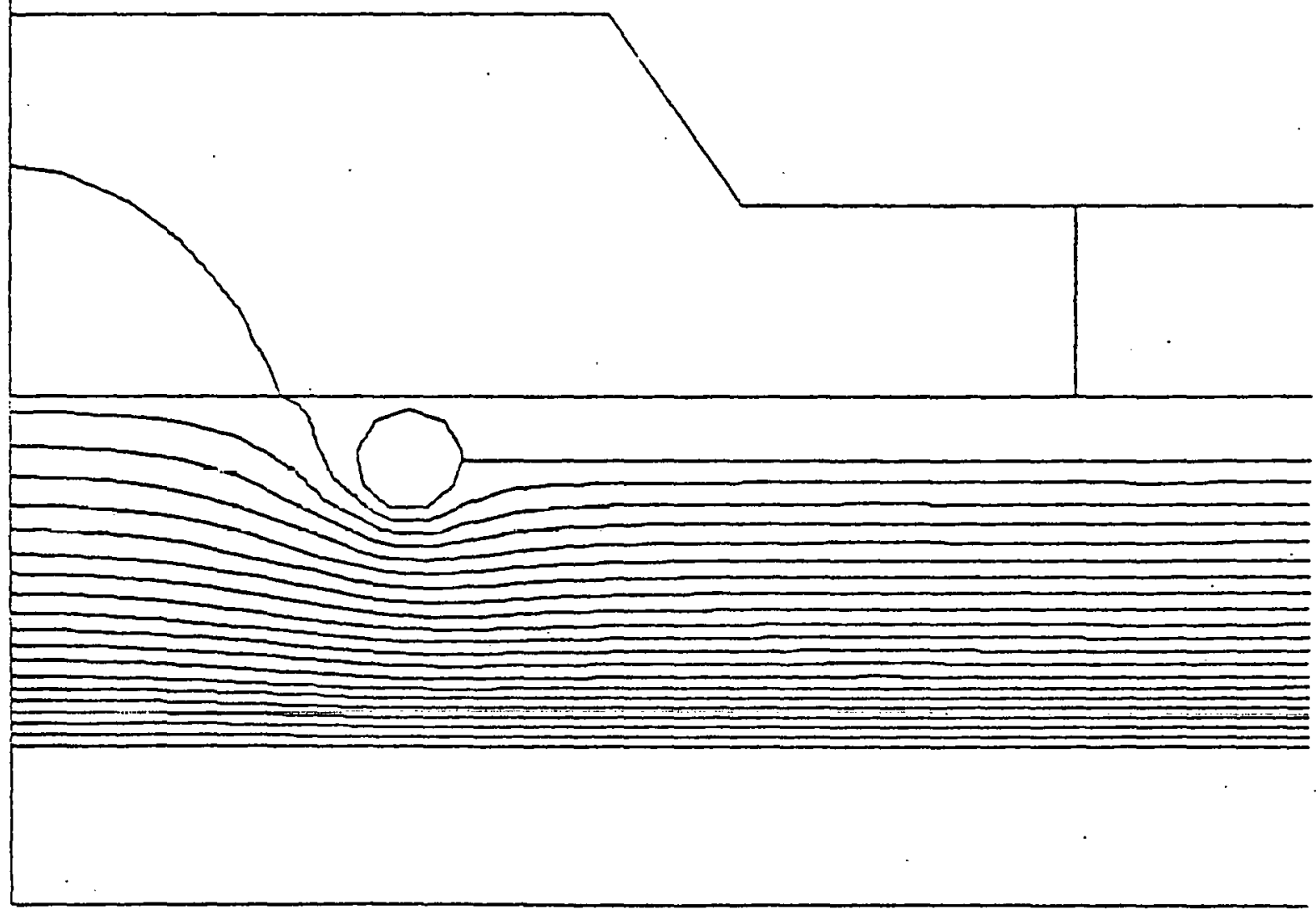



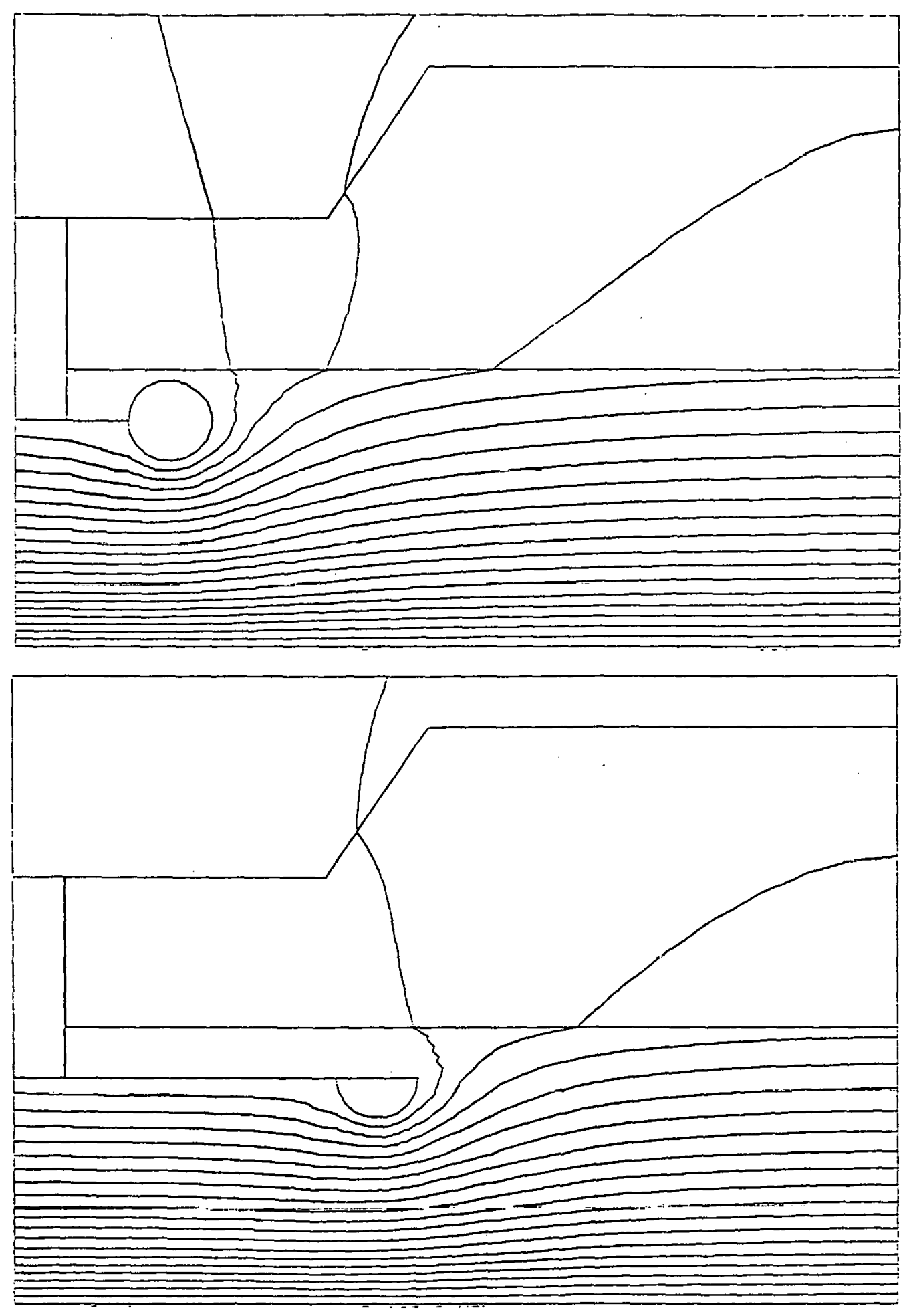

Figure IV.11 Shieid Paziaticos 


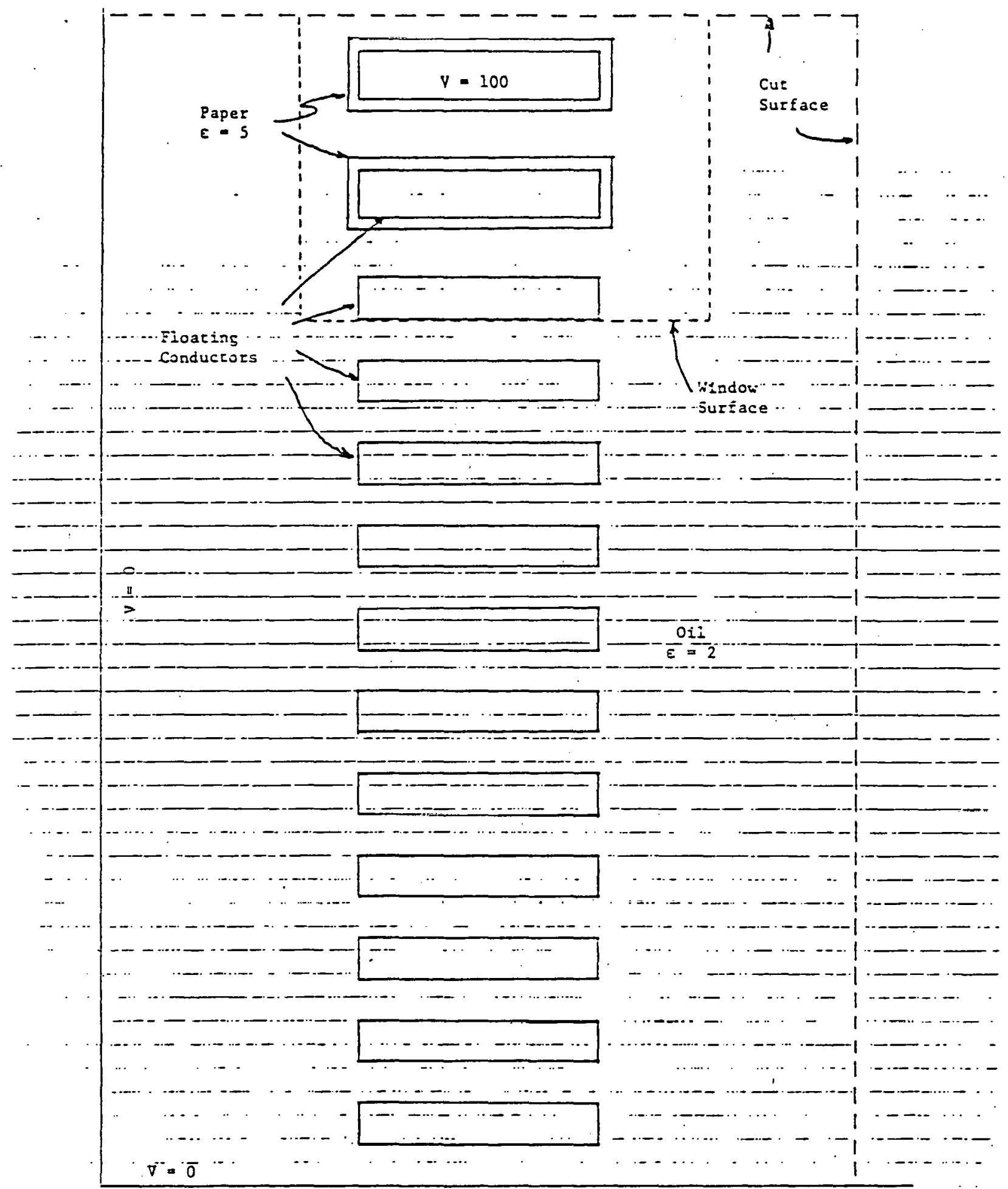

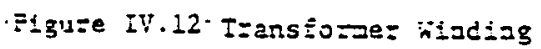




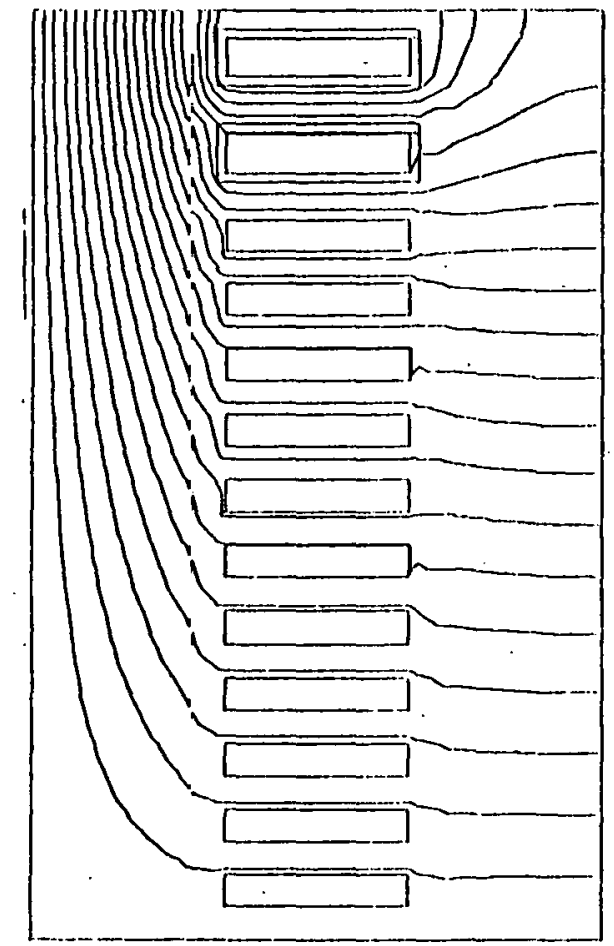

Figure IV.13 Andersen Solution for Transformer Wlinlling

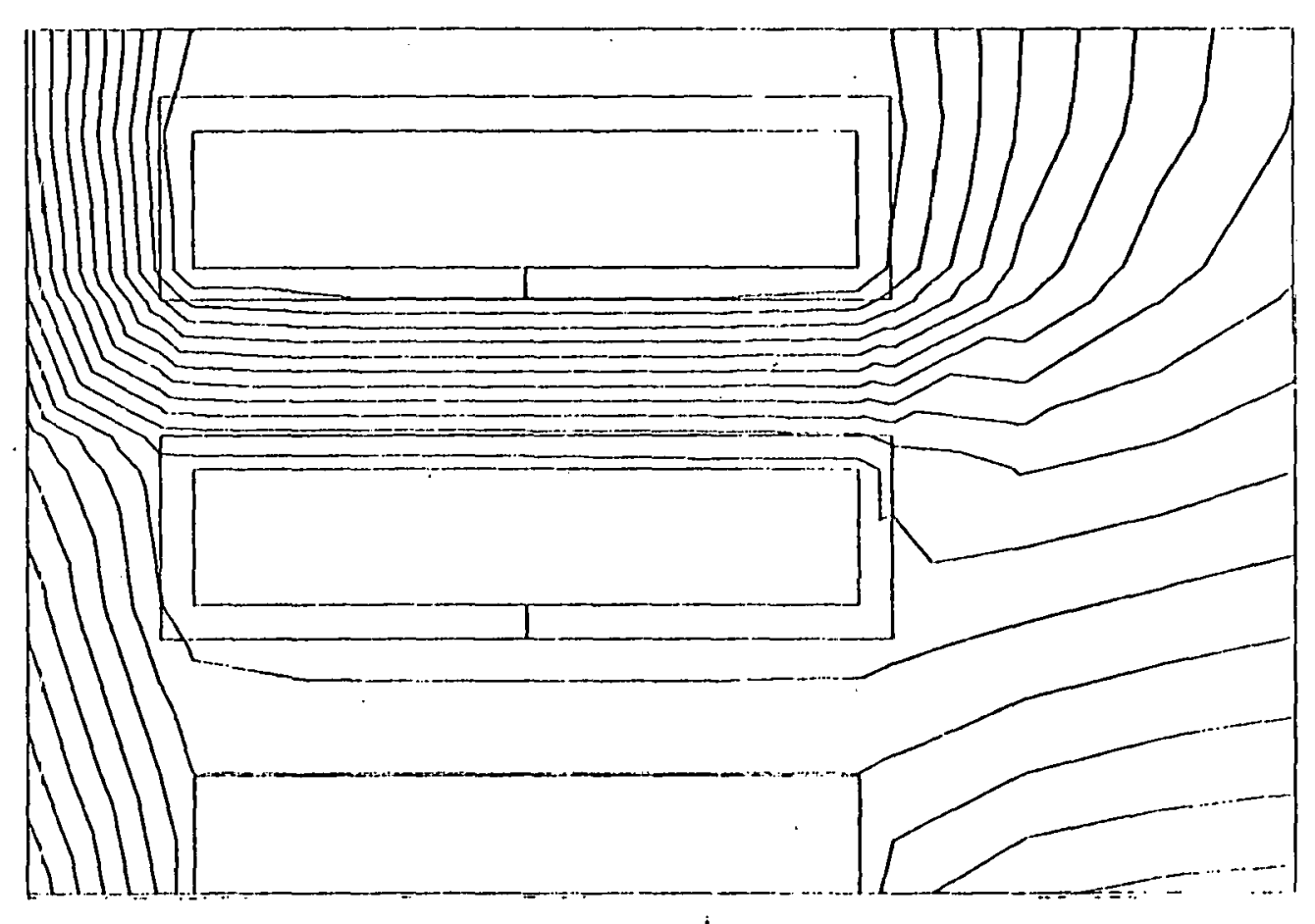

Higure IV.14 Window Solution for Trausforiner WInding End 


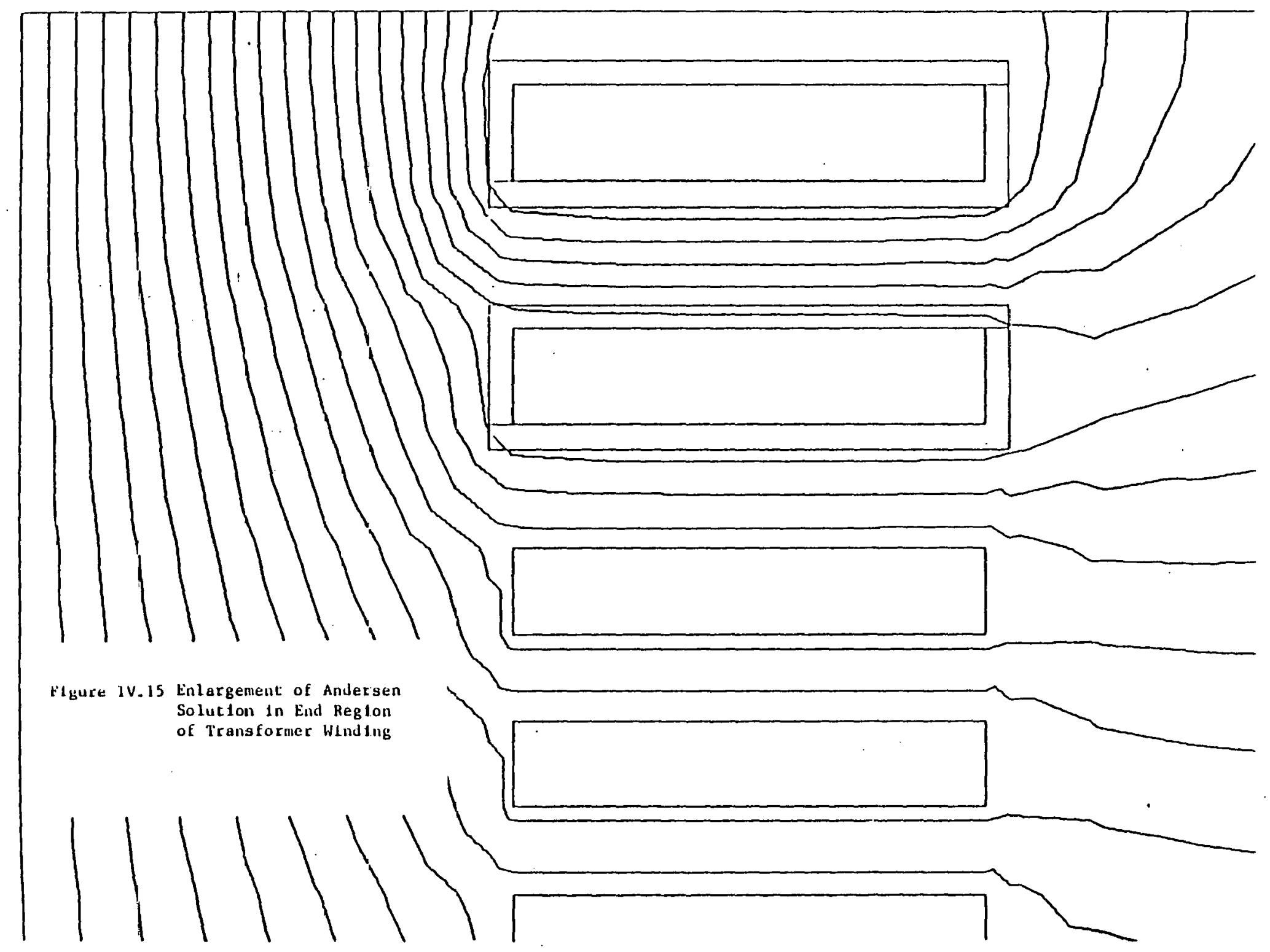




\section{Program Limitations}

A. Many of the limitations of the program given are due to the fact that the technique described was grafted onto an existing program (FLD6 due to 0 . W. Andersen). That program is commercially useful and can be applied in practical problems now.

On the other hand, it was developed in the late 1960's and early 1970's. Thus, it does not take advantage of the dramatic changes in computational technology in the last ten years. For example, the use of graphic input/output is rather cumbersome.

B. Grid size limitations as well as limits on numbers of curves and points are dictated by the computer installation at which the program will run. For example, when some of the sample problems were run on the Prime 500 system, they were found to require write-out and read-back from tape to accommodate large matrix processing. This was found to be a rather costly process on Prime. On the other hand, when the identical problem was run on the IBM3033, the fast access memory was large enough to accommodate the large matrix sizes and operational cost was reduced.

Compromise sizes of arrays are given in the program for use on the Prime system. They can be adjusted for any given installation.

C. Some limitations are due to the geometric technique introduced by Andersen and followed in this program. For example, the technique of describing contours as series of straight line segments by entering successive vertex coordinates, and then distorting a regular grid to fit these contours creates at least one limitation.

The problem occurs when a small acute angle exists in a contour. After grid distortion fits the vertex and after one side of the angle has been fitted by the line distortion process, it is sometimes found that attempts to fit the other side of the angle result in attempts to move grid nodes which have already been moved.

It was concluded that the difficulty arieeo when the angle is less than that of the aspect ratio of the regular grid definition near the vertex. Thus, when the program error message gives such an indication, the problem can be corrected by making the grid finer in the vertex region. Such a solution may not be feasible.

Another possibility is to blunt the acute angle to an appropriate value.

D. Inefficiencies in algorithm selection and programming can be identified. Unfortunately, they add to program run-time and storage requirements. For example, the Kron reduction process can make use of more efficient algorithms described by H. E. Brown.

Also, the technique of shifting data within matrices, rather than using a 
pointer system for empty axes, adds to run costs with no accompanying improvements.

E. Finally, it should be stated that this program was not intended as a polished result, useful in itself. It was intended solely to show that the "window" technique was feasible in that it gave the same results for much lower run costs. Thus, it was intended to be one step in the development of a three-dimensional program. 
$a$ b c Constants for Triangles

$\frac{1}{2 A}\left|\begin{array}{ccc}a_{i} & a_{j} & a_{k} \\ b_{i} & b_{j} & b_{k} \\ c_{i} & c_{j} & c_{k}\end{array}\right|=\begin{array}{lll}1 & x_{i} & y_{1} \\ 1 & x_{j} & y_{j} \\ 1 & x_{k} & y_{k}\end{array}$

$$
\begin{aligned}
& a_{i}=+\left|\begin{array}{cc}
x_{j} & y_{j} \\
x_{k} & y_{k}
\end{array}\right| \quad a_{j}=+\left|\begin{array}{cc}
x_{k} & y_{k} \\
x_{i} & y_{i}
\end{array}\right| \quad a_{k}=+\left|\begin{array}{cc}
x_{i} & y_{i} \\
x_{j} & y_{j}
\end{array}\right| \\
& b_{i}=-\left|\begin{array}{cc}
1 & y_{j} \\
1 & y_{k}
\end{array}\right| \quad b_{j}=-\left|\begin{array}{cc}
1 & y_{k} \\
1 & y_{i}
\end{array}\right| \quad b_{k}=-\left|\begin{array}{ll}
1 & y_{i} \\
1 & y_{j}
\end{array}\right| \\
& c_{i}=+\left|\begin{array}{cc}
1 & x_{j} \\
1 & x_{k}
\end{array}\right| \quad c_{j}=+\left|\begin{array}{cc}
1 & x_{k} \\
1 & x_{i}
\end{array}\right| \quad c_{k}=+\left|\begin{array}{cc}
1 & x_{i} \\
1 & x_{j}
\end{array}\right|
\end{aligned}
$$


Appendix 2

Minimization of the Functional

The functional to be minimized within the triangular area is equation (2.3) using potential in terms of the vertex potentials given by equation (2.10).

Denote the functional in the elementary tetrahedral volume by $U$. Then minimization with respect to $\mathrm{V}_{i}$ requires $\partial \mathrm{U}_{e} / \partial \mathrm{V}_{i}=0$. There are two other simultaneous relations, similar in form, for the potentials $v_{j}$ and $v_{k}$. These can be expressed in matrix form as

$$
\left|\begin{array}{l|l}
\partial u_{e} / \partial v_{i} \\
\partial u_{e} / \partial v_{j} \\
\partial u_{e} / \partial v_{k}
\end{array}\right|=\left[\begin{array}{c}
0 \\
0
\end{array} \mid\right.
$$

The partial derivative, $\partial U_{e} / \partial v_{i}$, can be found from equation (2.3) to be

$$
\frac{\partial U_{e}}{\partial V_{i}}=\iint_{A}\left[\varepsilon \frac{\partial V}{x} \frac{\partial}{\partial V_{i}}\left(\frac{\partial V}{\partial x}\right)+\varepsilon \frac{\partial V}{\partial y} \frac{\partial}{\partial V_{i}}\left(\frac{\partial V}{\partial y}\right)+\varepsilon \frac{\partial V}{z z} \frac{\partial}{\partial V_{i}}\left(\frac{\partial V}{\partial z}\right)\right] d A
$$

In matrix form

$$
\frac{\partial U_{e}}{\partial V_{i}}=\iiint_{A_{e}} \frac{\partial}{\partial V_{i}}\left(\overline{\frac{\partial V}{\partial x} \frac{\partial V}{\partial y}}\right)\left[\begin{array}{ll}
e_{x} & 0 \\
0 & e_{y} \\
\partial V / \partial y & d A
\end{array}\right.
$$

From equation (2.10), the partial derivatives are

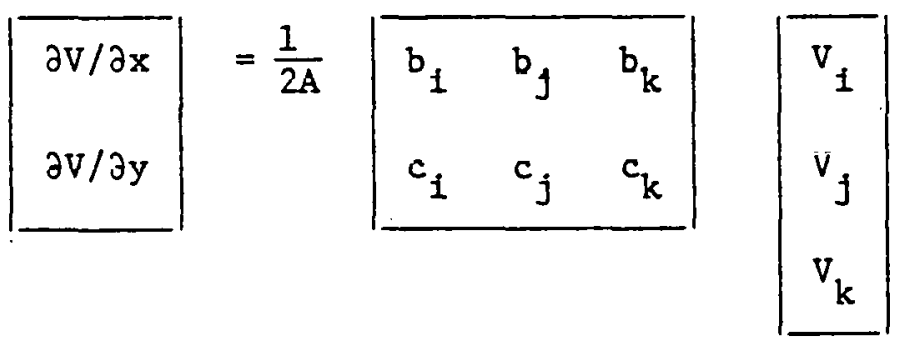


From (A2.3) it is seen that

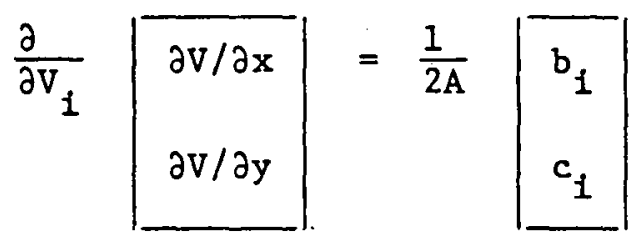

with similar results for $\partial / \partial v_{j}$, etc.

(A2.3) and (A2.4) are factors in the integrand of (A2.2). They are not functions of $x, y$ and $z$; the variables of integration. Therefore they can be moved outside the integral. Also when $\varepsilon_{x}=\varepsilon_{y}=\varepsilon_{z}=\varepsilon$, the isotropic case, a factor, $\varepsilon$, can be moved outside. That which remains is the area integral of the element. Thus these changes and use of (A2.3) and (A2.4) cause (A2.2) to become

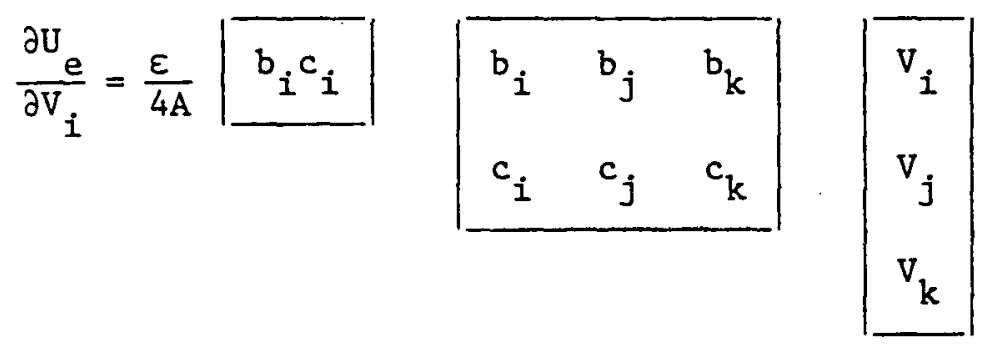

Results for $\partial U_{e} / \partial v_{j}$ and $\partial U_{e} / \partial v_{k}$ are similar except that the subscripts in the row matrix in $(\mathrm{A} 2.5)$ are, respectively; $j$ and $k$.

When partial derivatives with respect to each of the vertex potentials are assembled in an array, the matrix relation shown in equation (2.11) results. 
Appendix 3

Program Listing

A. 4 
C - WINDOW PROGRAM, PRIME 500. FORTRAN IV

C - MAIN CALL PROGRAM

C - - SUBROUTINES CODING AND PLOTY, MODIFIED BY C. VARELA

C - - SUBROUTINES SOLUTN AND PERTRI, ORIGINAL WORK OF C. VARELA

C - - SUBROUTINE EQUIVALENT, ORIGINAL WORK OF C. VARELA

C - FUNCTIONS NODFT AND NBOUJT, ORIGINAL WORK OF C. VARELA

C -- ALL OTHER SUBROUTINES , TAKEN FROM PROGRAM FIELD6 BY O. K. ANDERSEN. REAL LINC( 800), IDENT( 20), MLAXI

DIMENSION XPOS (70), YPOS $(100), \operatorname{ILN}(70), \operatorname{AUX}(500,2), \operatorname{MAUX}(500)$

$1, \operatorname{LINS}(4,4), \operatorname{NZV}(15), \operatorname{NZH}(15), \operatorname{ADMAB}(15,15), \operatorname{ADMLAD}(15,15)$

INTEGER*2 MVERT $(70,100)$

COMHION/BLOCK1/XPOS, YPOS, LIVER, LNHOR, IDENT, EQLIN,

$116, I 5, F L A X I$, EPSO/BLOCKO/LINC, NZV, NZH, ADMAB

2, ADMAD, DATLN $(70,3)$

CONION/BLOCK3/MVERT/BLOCK4/DIGLN (140)/BLOCK5/AUX, MAUX

COMMON/BLOCKG/NTRI ( 8)/BLOCKT/LINTO, ILN

COMTON /BLOCKB $/$ VOLTS $(904)$, NODE (900), JP, NZHT, NZVT

COMMION/BLOCIK9/COEFF $1(18145)$

COMION/BLOK1 1/ITRI $(900,8), \operatorname{IVERT}(2000,3)$

COMION/BLOK12/IFITEN, NLAXI, TOL, GAIMIA, AVEVOL, HLF, HLL

1, VLF, VLL

CALL CODING

IF (EQLIN.NE.O.) GO TO 10

CALL EQUIV

CALL EXIT

CALL SOLUTN

CALL PLOTY

CALL EXIT

END

SUBROUTINE CODING

SINSERT SYSCOMD KEYS.F

C -- WINDON PROGPAM, PRIME 500 FORTRAN IV, CODIFICATION

REAL LINC( 800), NOL IN, L INPR, IDENT( 20) , HAXI

INTEGER OUT, POINT (\$OO). WARN

DIMEINSION XPOS $(70)$, YPOS $(100), \operatorname{PCEV}(16), \operatorname{PCHH}(16), \operatorname{DIGLN}(140)$,

$1 \operatorname{ITTR} I(8), \operatorname{AUK}(500,2), \operatorname{ILN}(70), N Z V(15), N Z H(15), \operatorname{MVERT}(70,100)$

2, DATLN $(70,3), \operatorname{LIS}(4,4), \operatorname{MAUX}(500), \operatorname{ADMAB}(15,15), \operatorname{ADMAD}(15,15)$

COMTION / BLOCKI XPOS. YPOS, LITVER, LNEOR, IDENT, EQLIN,

$116,15, F L A X 1$, EPSU/BLOCKC LLINC, NZV, NZH, ADPAB

2, ADILAD, DATLN

COFIOH/BLOCK3/:TERT/BLOCK4/DIGLN/BLOCK5/AUX, ILAUK/BLOCK6/NTRI

COMTION/BLOCIK7/LINTO, ILH/BLCCIS/VOLTS (904), NODE (900), JP, NZHT

1, NZVT/BLOK12/KI THN, MLAXI , TOL, GANMIA, AVEVOL, BLF , HLL, VLF , VLL

FOMNAT (2OA4, $3 F 10.0)$

FOPULT(SF 10.0/SF 10.0)

FORMAT 4 F 10.2)

FORMAT ( 4 F 10.0)

FOPJIAT (33HIFEISSELAER POLYTECENIC INSTITUTE, $7 \%, 14$ HPROGRAM FINDOH,

17X, 29EL.APLACIAN ELECTROSTATIC FIELD/1H0, 20A4//)

FORILT(23日 FLAT, TTO DIIENS IONAL FIELD)

FORIAT(20A AYI-SYIRIETRIC FIELD/15G MINIMUN RADIUS, F7 . 1/

123日 AXIS OF SYTIETRI:- $X-)$

75

FORIAT (20B AXI-SYMTIETRIC FIELD/15E MINIMUN RADIUS,F7.1/

123B AXIS OF SYMIETRI:- Y -)

8 FORMAT 2AB SCALE, ORIGINAL DRAWING, F6.3/

126BOPOSITIONS, VERTICAL LINES) 
10 FORMAT (1B ,F6.1.,13,9(F7,1, 13)

11 FORMAT (28HOPOSTTIONS, HORIZONTAL LINES)

12 FORMATI $30 \mathrm{H}$ NURBER OF EQUIPOTENTIAL LINES, F5 . 1/

246H RELATIVE PERMITTIVITY, IF NOT GIVEN OTHERWISE,F7.2)

13 FORMAT 22HORELATIVE PERMITTIVITY,F7.2/17H POTENTIAL, VOLTS,F9.1/ $15 \mathrm{~B} \mathrm{CODE}, \mathrm{F} 4,1$ )

FORPAT $(4 X ; 1 \mathrm{EX}, 7 \mathrm{X}, 1 \mathrm{HY})$

FORMAT ( $1 \mathrm{H}, \mathrm{F6}, 1, \mathrm{~F} 8.1)$

FORPLAT( 16BOERRONEOUS INPUT)

FORLIAT (29HOTHERE ARE MORE THAN 70 LINES)

FORHAT (45 HOTEE LINE IS DESCRIBED BY MORE THAN 70 POINTS)

FORNIAT ( 39 HOTHE TOTAL NOTBBER OF POINTS EXCEEDS 400)

FORRIAT (104EOTHE PERMITTIVITY IS GIVEN DIFFERENT FROM ZERO, AND THE

1 LAST POINT ON THE LINE IS NOT EQUAL TO THE FIRST)

FORHLT 50 HOTHE LINE FITTING WAS INTERRUPTED FOR LINE SEGMENT!

$114 \mathrm{H} X \mathrm{Y} / 1 \mathrm{H}, \mathrm{F6} .1, \mathrm{FB} .1 / 1 \mathrm{H}, \mathrm{F6} .1, \mathrm{FB} .1 / 5 \mathrm{H} \mathrm{NEAR}$

$21 \mathrm{~B}, \mathrm{F6} \cdot 1, \mathrm{F8}, 1)$

51

FORIAT 47 HOTHIS POINT IS TOO CLOSE TO THE PRECEDING POINT/

$114 \mathrm{H} \quad \mathrm{Y} / 1 \mathrm{H}, \mathrm{F6}, 1, F 8.1)$

FORMAT( 13 H LONGEST SIDE,F9.2/15H SMALLEST DEPTH,F7.2)

FORFLTT (35H WARNING: THE RATIO IS MORE THAN 10)

FORHAT (87EOCHECK THE ACCURACY OF THE FIELD STRENGTHS BY COMPARING

1 VALUES I IN NE IGHBOR ING TRIAIIGLES)

FORMAT( 29EOTHE PROGRAM HAS MOVED VERTEX, 15)

FORIIAT ( 9 G FROM OINE LINE TO ANOTZER LINE WHICH IS TOO CLOSE)

FORIAT 56HOTHE NUTBER OF HORIZONTAL OR VERTICAL GRID LINES IS MORE

$1,4,44 \mathrm{H}$ TRAN ALLOWED. 100 BORIZONTAL . 700VERTICAL)

58 FORIAT( 50 BOTEE NUMPER OF NODES IN TEE GRID IS NOPE TZLAN 900)

585 FORMLT (50BOTHE NURBER OF. NODES IN THE GRID IS NORE TEAN 7000) WARV $=0$

$P I=3.1415927$

$\mathrm{PIO}=\mathrm{PI} / 2.0$

C --- LOGICAL UNIT ITUMBEPS

IN $=5$

OUT $=6$

C -- OPEN INPUT FILE "WINDAT"

CALI SRCESS (KSREAD,'WINDAT', 6, $1 ; 0$, NCOD)

C - OPEN OUTPUT FILF. "ININOTS"

CALL SRCE3S( KSTRIT, 'NIHOUT' , 6, 2, 6, NCOD)

C - - READ CARDS 1 TO 4

READ (II, 1) IDENT, FLAXI, RIIN, SORIG

READ (IN, 3) EOL IN, EPSO, WITHN, NOL IN

IF (EN IN. NE. O.) GO TO 1151

PEAD (IN , 3) BIF, HLL, VLF, VLL

GO TO 1152

1151 READ (IN, 3) MAXI, TOL, GATIA, AVEVOL

C - READ CARDS 5 TO 9

1152 READ $(I N, 2)$ PCHV

TOLR $=9.5 /$ SORIG

C --- ASSIGN THE PROPER VALUES TO RMIX AND RMIY RIIX $=0.0$

$R M I I Y=0.0$

IF (FLAXI . EQ.2.0) RMIY=RMIN IF ( FLAXI.EQ. 3.0) RMIX $=$ RHIIN

$C--$ VRITE FIRST PART OF INPUT

WRITE (OUT, 5) IDENT 


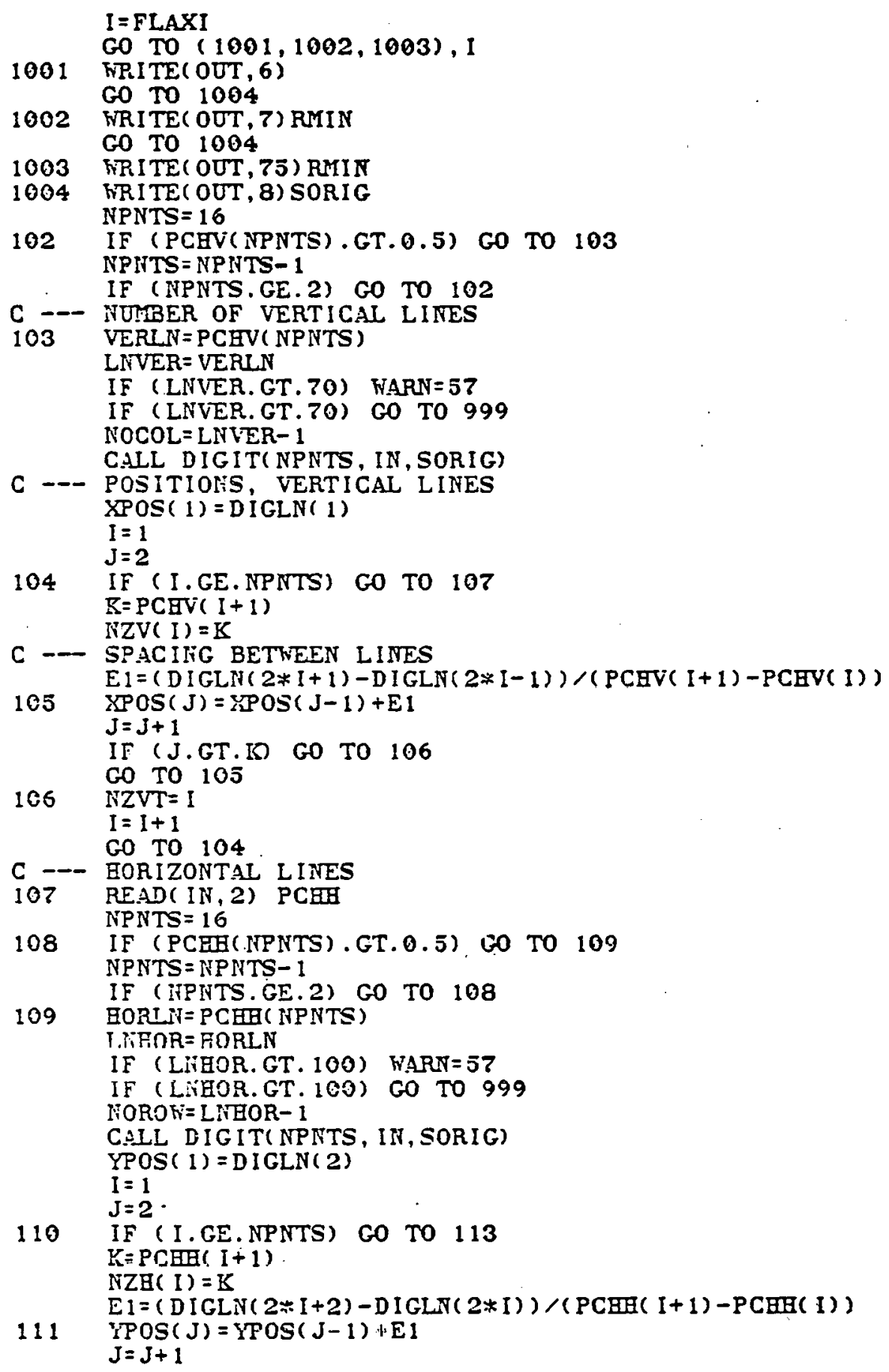




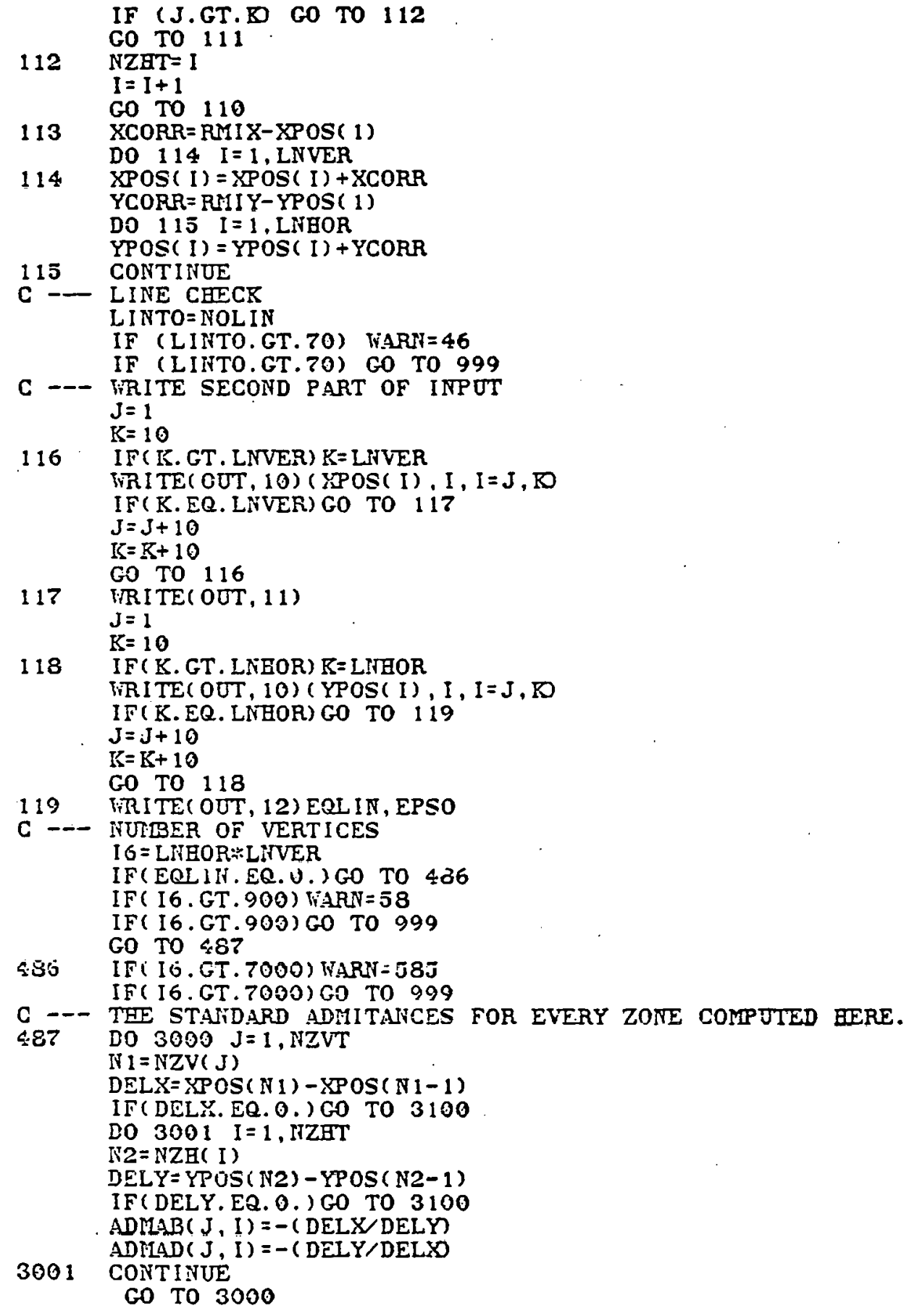




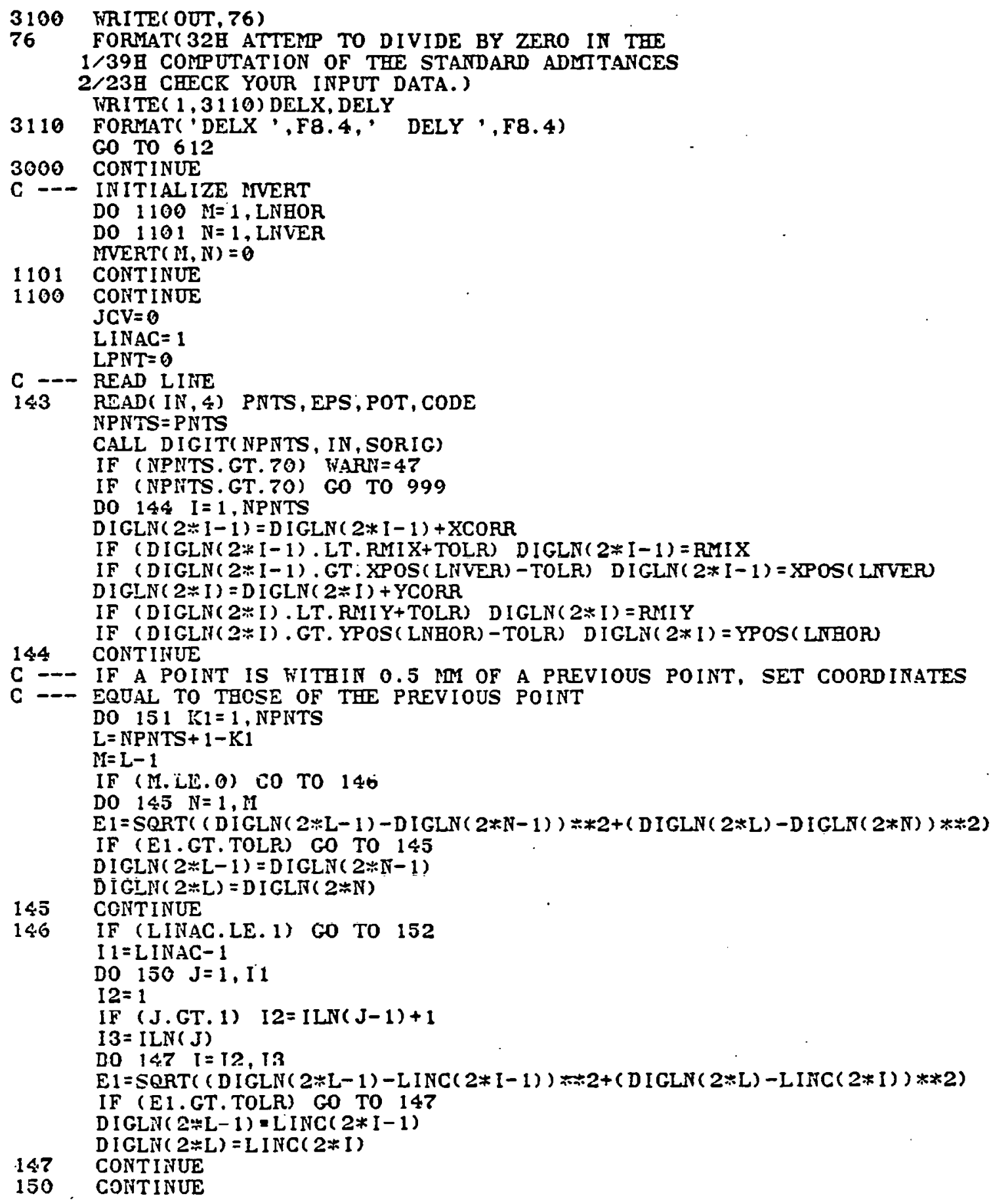




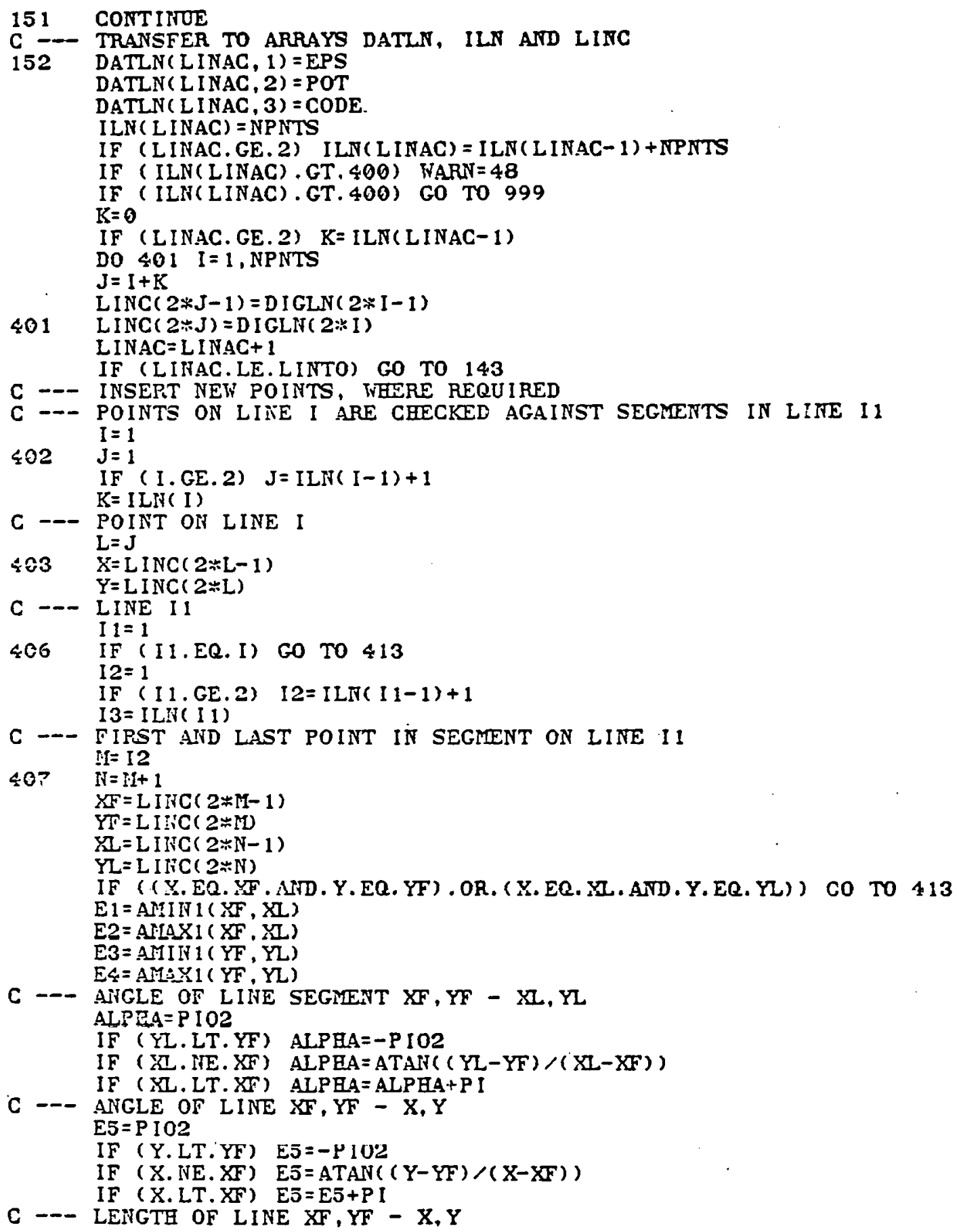




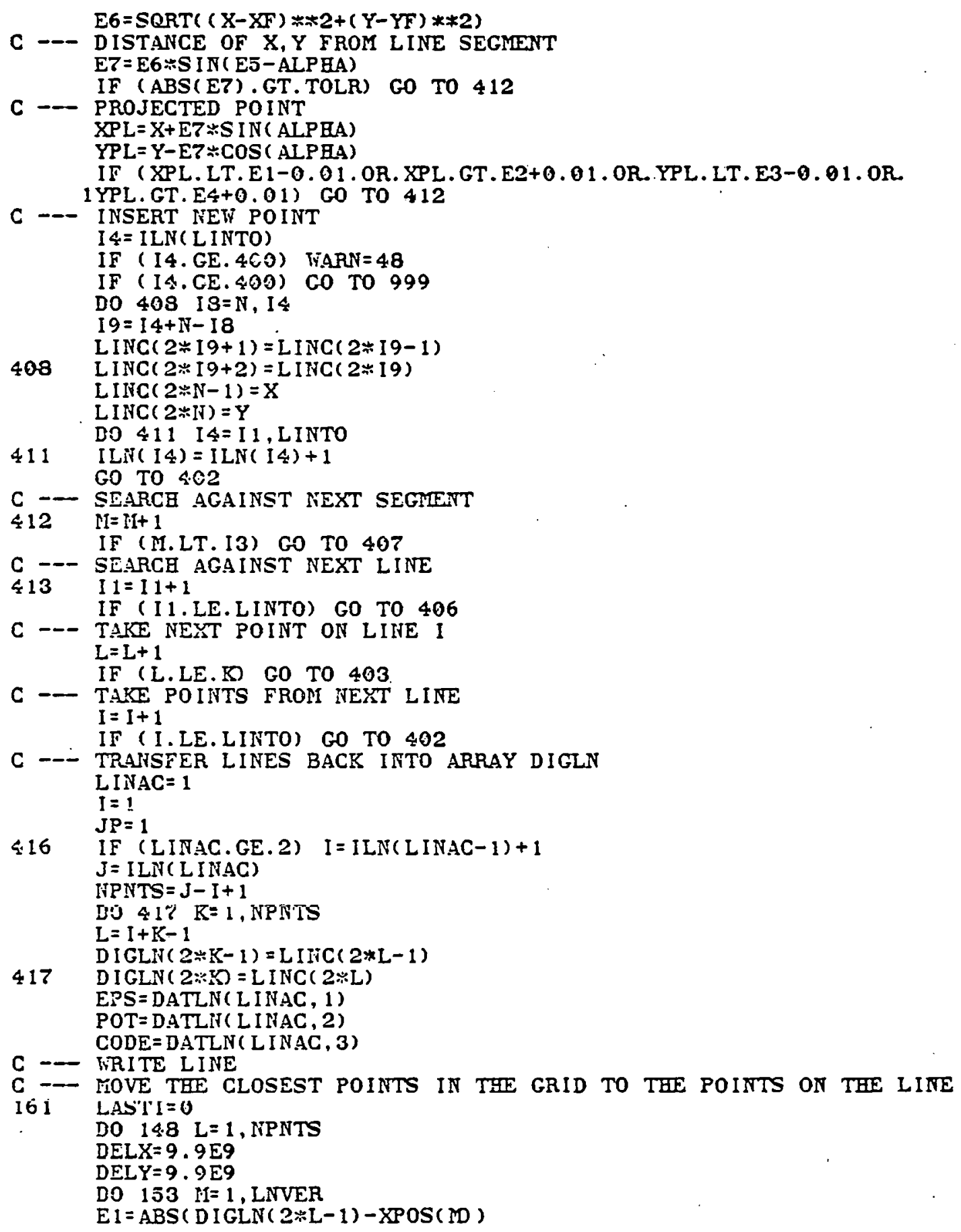


IF (E1.GT.DELX GO TO 154

DELX $=E 1$

153

IF (M. EQ. LNVER) GO TO 155

154

CONTINUE

155 DO $156 \mathrm{~N}=1, \mathrm{LNHOR}$

$E_{1}=\operatorname{ABS}(D I G L N(2 * L)-\operatorname{YPOS}(N))$

IF (E1.GT. DELY) GO TO 157

$D E I Y=E 1$

IF (N.EQ. LNEOR) GO TO 158

156

CONTINUE

$157 \quad \mathrm{~N}=\mathrm{N}-1$

$158 \quad \mathrm{I}=\mathrm{M}+\mathrm{LNVER} \div(\mathrm{N}-1)$

IF (I.EQ. LASTI) WARN $=51$

IF (I.EQ. LASTI) TRITE(OUT,51) DIGLT( $2 * L-1), D I G L T(2 * L)$

IF (I.EQ. LASTI) GO TO 1621

HAC $=$ MVERT $($ IN, M) $-($ INERT $(N, M D / 10) * 10$

IF (MAC.EQ. 1) GO TO 1621

$I F(X P C S(M) \cdot E Q \cdot D I G L N(2 * L-1), A N D \cdot \operatorname{YPOS}(N), E Q \cdot D I G L N(2 * L))$

1 GO TO 1622

WHARN $=\mathbf{5 5}$

VRITE (OUT, 55) I

ViR I TE ( OUT, 14)

WR ITE ( OUT, 16) IPOS ( $M$, YPOS(N)

IRITE (OUT, 56)

INERT $(\mathrm{Ii}, \mathrm{M})=\operatorname{INERT}(\mathrm{N}, \mathrm{M})+10$

$\operatorname{AUX}(J P, 1)=D \operatorname{IGLIT}(2 \div L-1)$

$A U X(J P, 2)=D I G L i N(2 * L)$

$\operatorname{IIAUX}(J P)=I$

$J P=J P+1$

1622 MVERT $N, M)=L$ I NAC $* 100+1+\operatorname{MVERT}(N$, II)

IF (MAC.EQ.2) MVERT(N, M = MVERT (N, M -1

IF (CODE. EQ.2 .0) RVERT $N, M)=$ RNERT $N, M D+10000$

1621 LASTI $=1$

JGPO $1=L P I T T+L$

14.8 POIITT $($ JBPO1) = I

C-D FIT GRID TO LIHE SEGRINTS

IF (IPNTS.LE. 1) GO TO 185

$I 1=$ LINAC- 1

$12=$ NNPNS -1

Lo $173 \quad I=1,12$

$X F=D I G L i N(2=1-1)$

$Y F=D I G L N(2 * I)$

YI $=\operatorname{DIGLiN}(2 \% 1+1)$

$\mathrm{YL}=\mathrm{DIGLIi}(2 \div 1+2)$

IF (LIHAC.LE. 1) GO TO 166

C --- CEECK IF XF, YF AND XI. YL ARE EQUAL TO SUCCESSIVE PREVIOUS POINTS DO $165 \mathrm{~J}=1$, I 1

$13=1$

IF (J.GT. 1) I3 $=\operatorname{ILN}(J-1)+1$

$I 4=\operatorname{ILIN}(\mathrm{J})$

DO $164 \mathrm{~K}=13,14$

IF (YF. NE. LINC ( $2 * K-1)$. OR. YF. NE. LINC ( $2 *$ D ) GO TO 164

IF (K.LE. I3) GO TO 163

IF (XL. EQ. LINC $(2 * K-3)$.AND. YL.EQ. $\operatorname{LINC}(2 * \mathrm{~K}-2)$ ) GO TO 173

IF (K.GE. I4) GO TO 164 


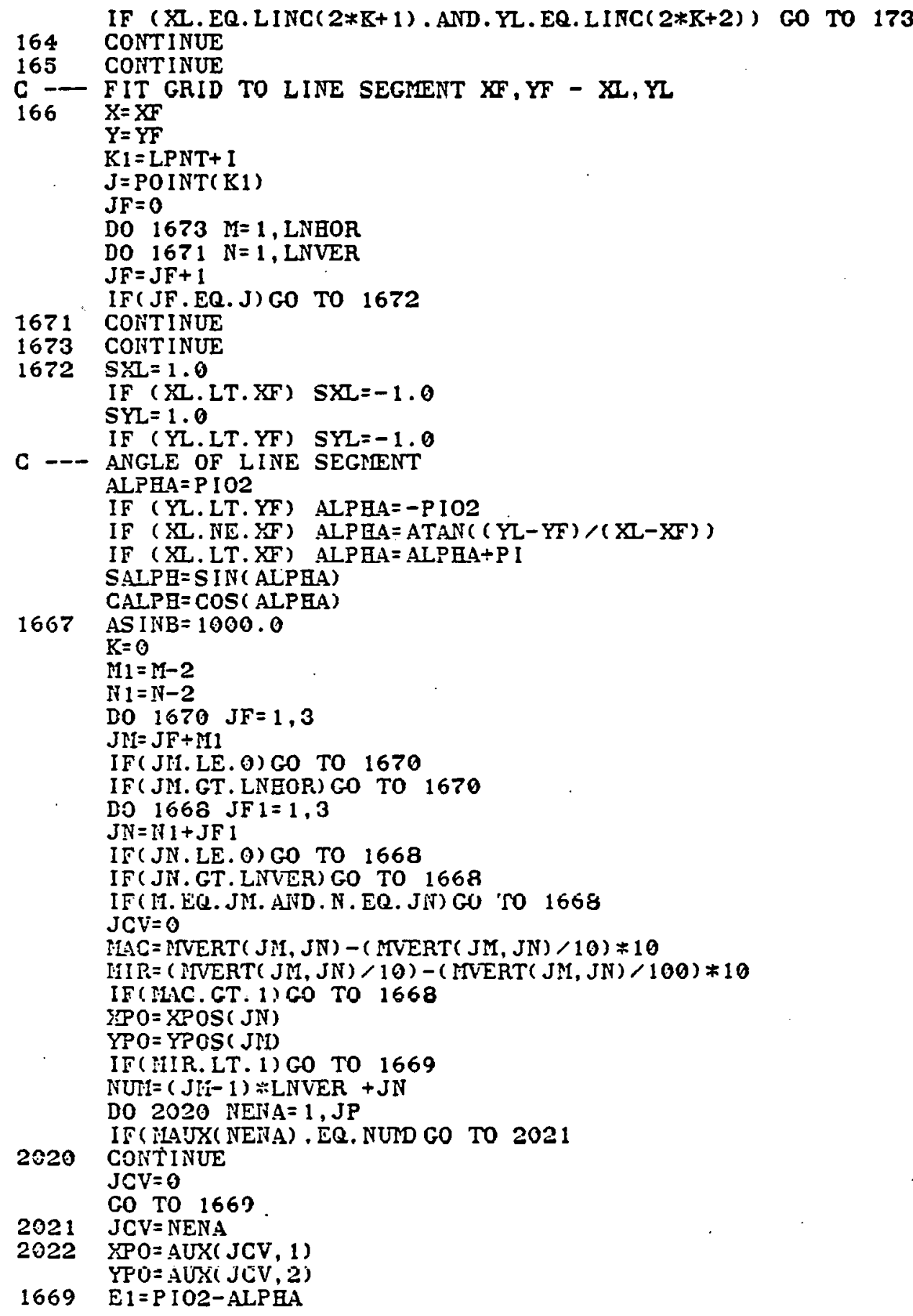


IF (YPO. LT. Y) EI $=$ E1-PI

C -- ANGLE BETTEEN LINE SEGMENT AND ADJOINING POINT (BETA) IF (XPO.NE.X) E1 =ATAN ( $(Y P O-Y) /(X P O-X))-A L P H A$

IF (XPO.LT.XO EI=ELPI

IF (COS(E1).LT.0.001) GO TO 1668

IF (XPO.EQ.X. AND. YPO.EQ. Y) GO TO 1668

C - DISTANCE TO ADJOINING POINT

$E 2=\operatorname{SQRT}((\mathrm{YPO}-\mathrm{Y}) * \div 2+(\mathrm{XPO}-\mathrm{X}) * * 2)$

$E 3=E 2 * S I N(E 1)$

IF (ABS (E3).GT. ABS (ASINB)) GO TO 1668

$X P L=X P O+E 3=S A L P B$

$Y P L=Y P O-E 3=C A L P B$

IF $((X P L-X I) * S X I . G T .0 .01)$ GO TO 1668

If $((Y P L-Y L) \approx S Y L$. GT. 0.01) GO TO 1668

AS INB $=E 3$

$\mathrm{JS}=\mathrm{JCV}$

IMIAC = IIAC

$\mathrm{KMI}=\mathrm{JM}$

$\mathrm{KCT}=\mathrm{JN}$

$\mathrm{K}=1$

1668 CONTINUE

1670 CONTINUE

IF (K.EQ. O) WART $=50$

IF (K. EQ. O) WRITE (OUT, 50) XF, YF, XI, YL, X, Y

$172 \quad \mathrm{~K} 1=\mathrm{LPNT}+\mathrm{I}+1$

NOS $=($ KNI 1 1) $\div$ LNVER $+K N$

IF (NOS. EQ.POINT(K1)) GO TO 173

IF (KSIAC. LE. O) GO TO 1720

THAPN $=55$

WRITE (OUT, 55) NOS

IRI I TE (OUT, 14)

FRITE (OUT, 16) YPOS ( KN), YPOS (KON

FRITE(OUT, 56)

C --- IOVE POIITT SHORTEST DISTANCE TO LINE

1720 IF(JS.EQ. O) GO TO 1721

$\operatorname{AUX}(J S, 1)=A U X(j S, 1)+A S I N B * S A L P H$

$A U X(J S, 2)=\operatorname{AUX}(J S, 2)-A S$ I NUSCALPB

GO TO 1722

1721 ASSAL $=A B S(A S I N B * S A L P H)$

$\triangle S C A L=A B S(A S I N B=C A L P H)$

IF (ABS (AS INB

1GT. 0.01$)$ GO TO 1723

MVERT ( GTi, IGN) = MVERT ( KM, KN ) + L INAC $\div 100+2$

IF ( CODE. EQ . 2.0) MVERT ( KM, KN) = INERT ( KM, KN $)+10000$

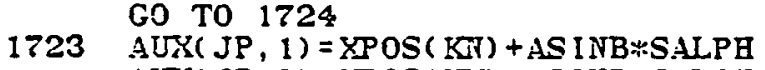

$A U X(J P, 2)=Y P O S(K D D-A S$ I INB $\div C A L P H$

$\operatorname{MAUZZ(JP})=$ NOS

$1722 \begin{aligned} & \mathrm{JP}=\mathrm{JP}+1 \\ & \text { MVERT }(\mathrm{MT}, \mathrm{KN})=0\end{aligned}$

MTERT IDI, IN $)=12+$ LINAC $* 100$

IF (CODE. EQ. 2.0) MVERT $(\mathrm{KI}, \mathrm{KN})=\operatorname{MVERT}(\mathrm{KM}, \mathrm{KN})+10000$

1724 $\mathrm{JPH}=\mathrm{JP}-1$

$\mathrm{MI}=\mathrm{KOI}$

$\mathrm{N}=\mathrm{I}$ IN

GO TO 1667 


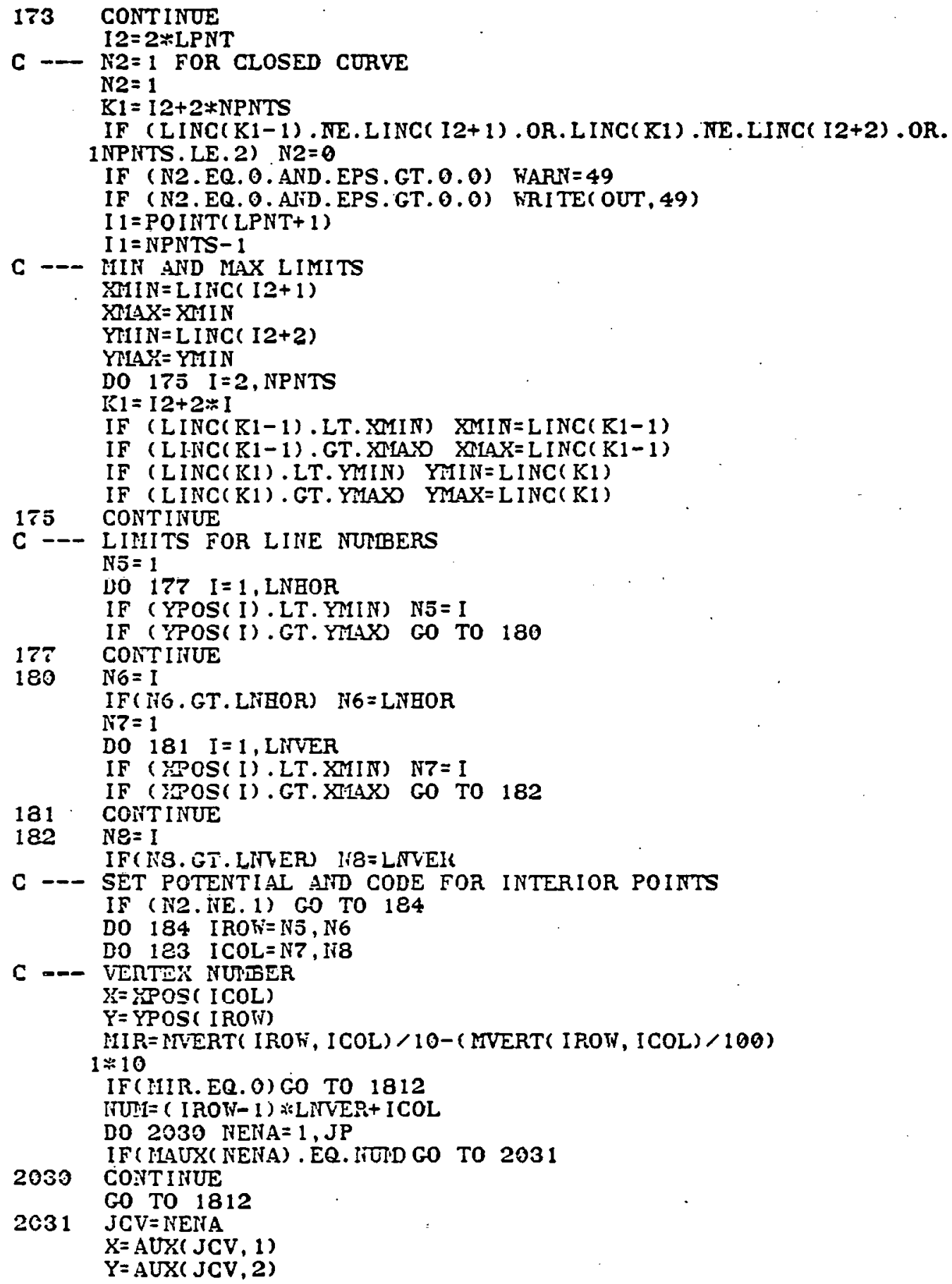


1812 CALL INTER( INTOR, I 1, LPNT, X, Y

IF (INTOR. EQ. O) GO TO 183

INERT (IROW, ICOL) = MVERT ( IROW, ICOL $)+L I N A C * 100$

183 IF (CODE. EQ, 2.0) MVERT(IROW, ICOL) $=$ RVERT( IROW, ICOL) + 10000

CONTINUE

184 CONTINUE

C --- TAIKE NEXT IINE

185 IINAC $=$ LINAC +1

LPNT $=$ LPNT+NPNTS

IF (LINAC.LE.LINTO) GO TO 416

C --- ABORT

999 TiRITE( OUT, 45)

IF (WARN. EQ. S.6) IRIT TE( OUT, 46)

IF ( NARN. EQ . 47) WRITE( OUT, 47)

IF (WARN. EQ. 48) IVR ITE (OUT, 48)

IF ( WAPN. EQ. 57) WRITE( OUT, 37)

IF ( WARN. EQ. 58) WR I TE ( OUT, 58)

IF (WARN. EQ. 585) VRI TE ( OUT, 585)

612 PETURH

END

SUEROUTINE SOLUTIN

SIHSERT SYSCOID KEYS.F

DIPENS ION VOLTS (904), NODE (900), NIRR( 4), COEFF $1(18145)$

1, NZOIN (4), NDATLN ( 70,2), NOD (4), X(4), $Y(4), \operatorname{AREA}(4), \operatorname{ILN}(70)$

$2, X P O S(70), Y P O S(100), A U X(500,2), \operatorname{MUUX}(500), \operatorname{NCOD}(4), \operatorname{ITRI}(900,8)$

3, TERPP(7260), JVERT (6, 4), NODE4( 120), IVERT( 2000, 3), PERT( 2000).

4. $\operatorname{COEFF}(900,9)$

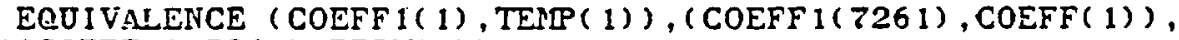

$1($ COEFF $1(15361)$, PERM( 1$))$

REAL L INC ( 800), IDENT( 20), NIAXI

INTEGER $\div 2$ NIVERT $(30,100)$, OUT

CORON/RLOCK1 / XPOS, YPOS, LNVER, LNEOR, IDENT, EQL IN,

1 ITOT, ISQ, FLAXI, EPSO/BLOCK2/LINC, NZV (15), NZB( 15),

$1 A D M A B(15,15), A D I A D(15,15), \operatorname{DATLN}(70,3)$

COMTON/BLOCK3/MVERT/BLOCK4/DIGLN/BLOCK5/AUX, MAUX/BLOCK6/NTRI CONMIOI/BLOCIK /LINTO, ILN/BLOCKB/VOLTS, NODE, JP, IZZAT, HZVT

CORTSON/3LC:CKO/COETF1, 3LOI:1 1/ITRI, ITERT

COMHON/RLOK12/ $\mathrm{WITHN}$, HLAXI, TOL, ALPEA, AVEVOL, BLF, BLL, VLF, VLL

DATA JVERT $(1,1), \operatorname{JVERT}(1,2), \operatorname{JVERT}(1,3), \operatorname{JVERT}(1,4) / 7,3,5,1 /$

DATA JVERT (2,1), JVERT $(2,2), \operatorname{JVERT}(2,3), \operatorname{JVERT}(2,4) / 1,5,7,3 /$

DATA JVERT $(3,1)$, JVERT $(3,2), \operatorname{JVERT}(3,3), \operatorname{JVERT}(3,4) / 3,7,1,5 /$

DATA JVERT $(4,1)$, JVERT $(4,2)$, JVERT $(4,3), \operatorname{JVERT}(4,4), 2,6,3,4 /$

DATA JVERT (5, 1), JVERT $(5,2), \operatorname{JVERT}(5,3), \operatorname{JVERT}(5,4), 5,1,3,7 /$

DATA JVRRT $(6,1), J \operatorname{JVRT}(6,2), \operatorname{JVERT}(6,3), \operatorname{JVERT}(6,4) / 6,2,4,8$,

ICRPTS (IV MG) $=($ HG -1$) \cdots L$ LVER + MG

C -- THE NURER OF COLUINS AND RONSS IS COMPUTED.

IN $=5$

OUT $=6$

NOCOL $=$ LNVER -1

NORD W $=$ LIYHOR- 1

ITTRI = NOCOL $*$ NORON $\div 2$

I TOT $=$ LIVPOR $L$ LNVER

NMAX = MLAYI

OMLPLE $=1.0-A L P B A$

C --- TIE ARRAY ITRI IS INITIALIZED 
DO $6010 \mathrm{I}=1$, ITOT

DO $6011 \mathrm{~J}=1,8$

$\operatorname{ITRI}(I, J)=0$

6011 CONTINUE

6010 CONTINUE

C --- THE ARRAY COEFF. IS INITIAIIZED

DO $6012 I=1$, ITOT

DO $6013 \mathrm{~J}=1,9$

$\operatorname{COEFF}(I, J)=0.0$

6013 CONTINUE

6012 CONTINUE

C -- THE NUIRER OF SQUARES "ISQ" IS ITTIALIZED. ISQ $=0$

C -- THE PROCESSING IS DONE ONE COLOTN AT A TIME FOR EVERY ROW.

6020 DO $9001 \mathrm{~N}=1$, NOROW

DO $9000 M=1$, NOCOL

HIRT $=0$

ISQ $=I S Q+1$

DO $20 \mathrm{~K}=1,4$

$\mathrm{NCOD}(\mathrm{K})=-\mathrm{K}$

GO TO $(30,40,50,60), \mathrm{K}$

$30 \quad \mathrm{NG}=\mathrm{N}$

$\mathrm{MG}=\mathrm{M}$

GO TO 70

ING $=\mathrm{N}$

$\mathrm{MG}=\mathrm{HI}+1$

GO TO 70

$\mathrm{ISG}=\mathrm{IN}+1$

$\mathrm{MG}=\mathrm{M}+1$

GO TO 70

$N G=N+1$

$M G=M$

C - AFTER THE PROPER GRID POSITION IS FOUND,

C - - THE NODE CUALITIES ARE COIPUTED.

70 IIPR $(K)=$ MVERT $(N G, M G) / 10-(\operatorname{MVERT}(N G, M G) / 100) * 10$ NZON $(K)=$ IVERT $(N G, M G) / 100-($ HVERT $(N C, M G), 10000) 2100$

C - THE RESEMBLANZE OF. GRID POINTS AND ELEC.NODES IS ESTABLISHED HERE $I=I G R P T S(N G, M G)$

IF(NZCN (I) E. EQ.0) GO TO 71

ID $=\mathrm{NZON}(\mathrm{K})$

IF(DATLNi ID,3) .NE.2.0)GO TO $\overline{7} 1$

$\operatorname{VOLTS}(I)=\operatorname{DATLIN}(I D, 2)$

$\operatorname{NOD}(\mathrm{K})=1$

$\operatorname{NODE}(I)=1$

GO TO 73

71 VOLTS $(I)=$ AVEVOL

$\operatorname{NOD}(I S)=I$

$\operatorname{NODE}(I)=0$

IF ( DATLN $(I D, 3) \cdot E Q .3 .0) N C O D(K O=I D$

$73 \quad$ HC NIRR(K).EQ.O)GO TO 80

DO $90 \mathrm{~J}=1$, JP

IF (I. FR. MATYY .I) IGO TO 100

90 CONTINUE

$160 \quad X(\mathrm{IO}=\triangle \mathrm{AUX}(\mathrm{J}, \mathrm{i})$

$Y(K)=A U X(J, 2)$

GO TO 19 


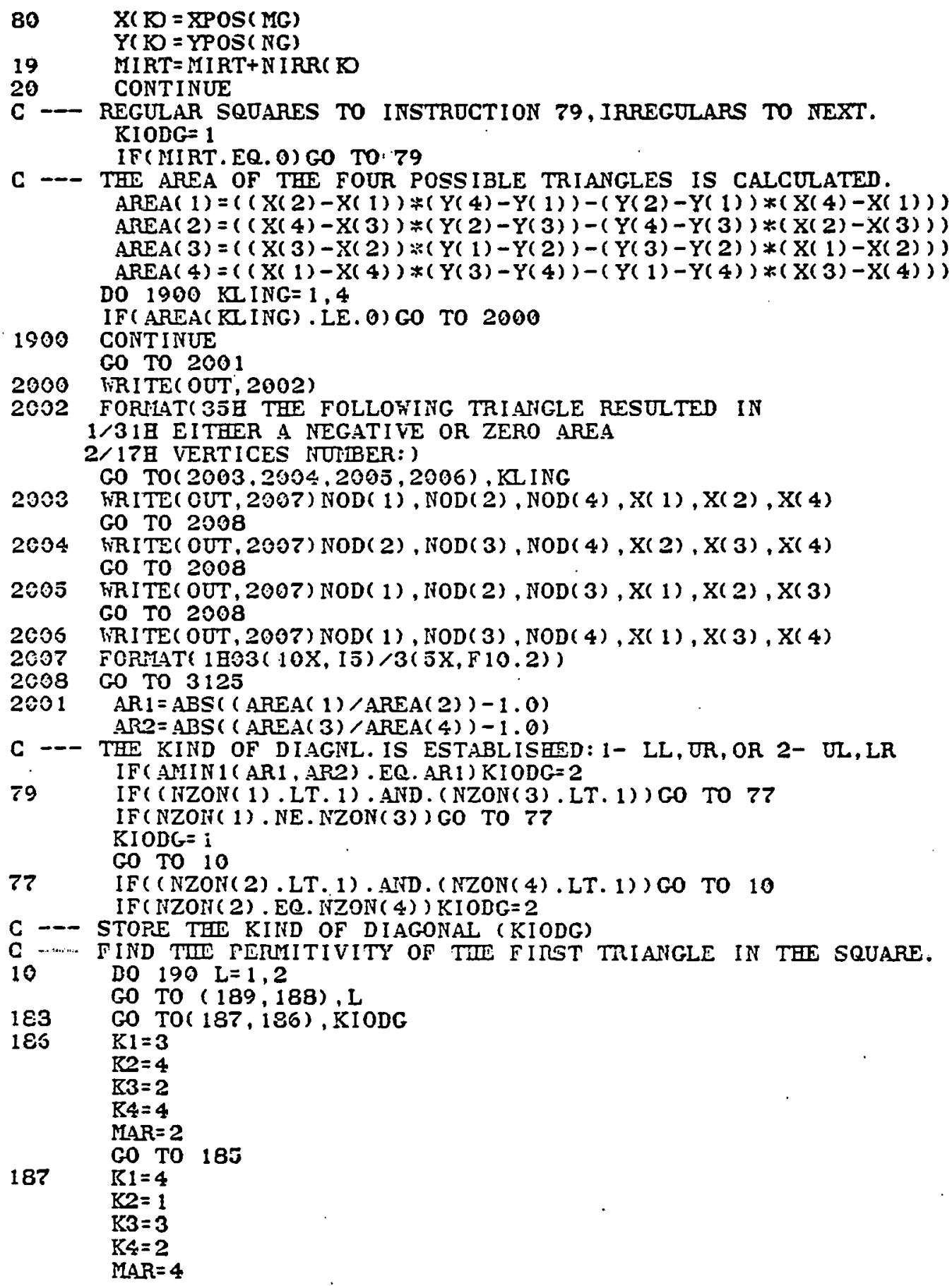




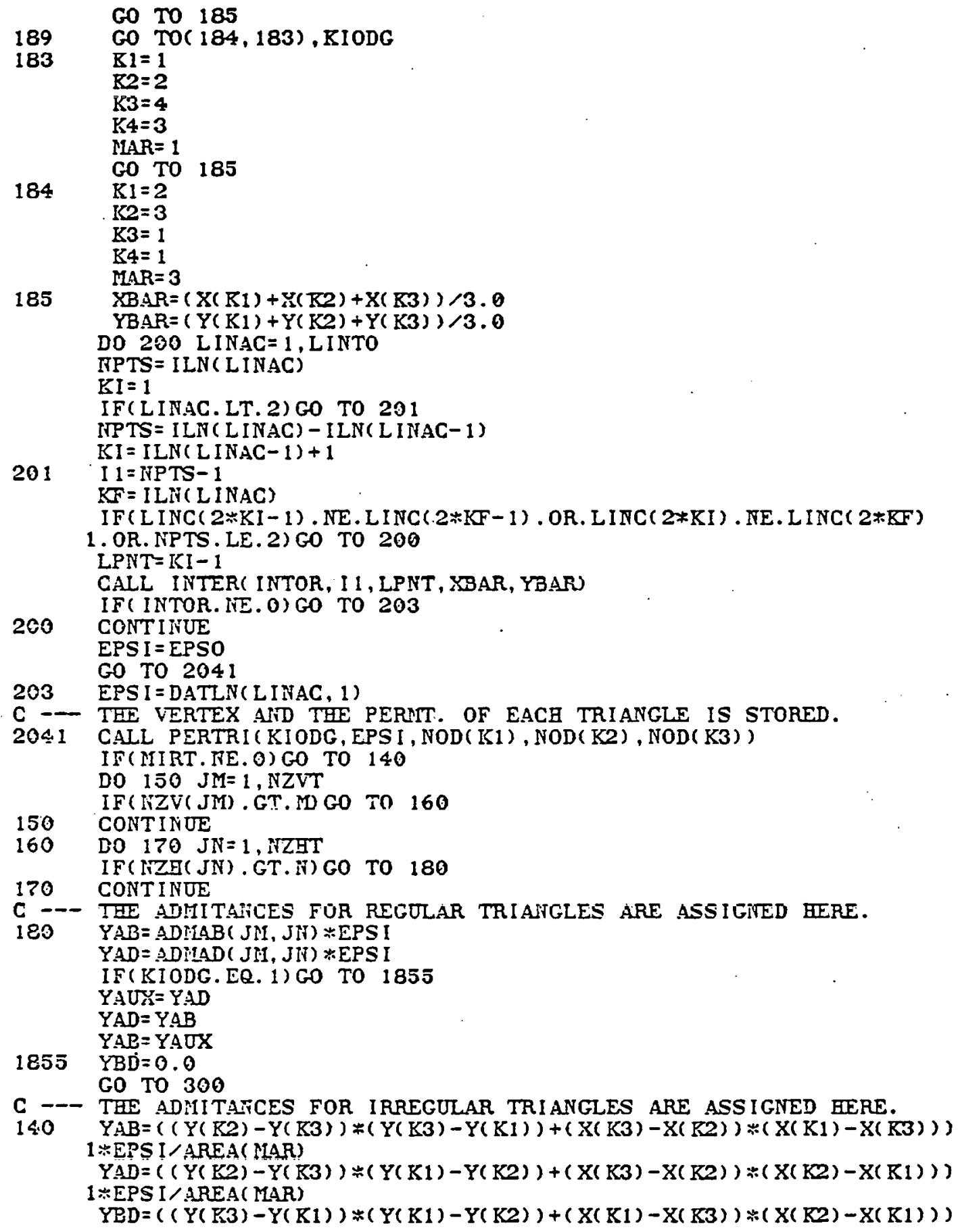




\section{$1 \div$ EPS I/AREA( MAR)}

C -- FOR FLOATING CONDUCTORS OF ZERO THICRNESS CHANGE Y'S

300 IF (NCOD $(K 1) . E Q$. NCOD $(K 2)) Y A B=(Y A B / E P S I) * 9000$. IF (NCOD (K1) . EQ. NCOD $(K 3)) Y A D=(Y A D / E P S I) * 9000$. IF (NCOD ( K2) , EQ. NCOD ( K3) ) YBD $=(\mathrm{YBD} / \mathrm{EPSI}) * 9000$.

C - IF AXIAL SIITETRY IS WITH RESPECT TO $Y$ GO TO IF (FLAXI. LT . 2.) GO TO 310

C - AXI-SYIDITRIC FIELDS IF (FLAYI.GT.2.0) GO TO 311 $Y A B=Y A B * Y B A R$

$Y A D=Y A D \div Y B A R$ $Y B D=Y B D * K B A R$ GO TO 310

C - - AYI-SYMIETRIC FIELDS

$311 \quad \mathrm{YAB}=\mathrm{YAB} * \mathrm{XBAR}$ $Y A D=Y A D \div X B A R$ $Y B D=Y B D * X B A R$.

C - - BOTH TYPES

$310 \quad \operatorname{NOD} 1=\operatorname{NOD}(\mathrm{K} 1)$ NOD2 $=$ NOD $(\mathrm{K} 2)$ NOD3 $=$ NOD $(\mathrm{K} 3)$

C -- THE COEFFICIENTS OF TBE ' $Y$ ' MATRIX ARE FORMED HERE. $\operatorname{COEFF}(\operatorname{NOD} 1,9)=\operatorname{COEFF}($ NOD 1,9$)-Y A B-Y A D$ COEFF $($ NOD2, 9$)=$ COEFF $($ NOD2, 9$)-$ YAB-YBD COEFF $($ IOD 3,9$)=\operatorname{COEFF}($ NOD, 9$)-$ YAD - YBD $\mathrm{J}_{1}=\mathrm{JVERT}(1, \mathrm{~K} 4)$

$\operatorname{ITRI}(\operatorname{NOD} 1, \mathrm{~J} 1)=$ NOD2

$\operatorname{COEFF}(\operatorname{NOD} 1, J 1)=\operatorname{COEFF}\left(\operatorname{NOD} 1, J_{1}\right)+Y A B$

$J 1=J \operatorname{VERT}(2, K 4)$

I TRI $($ NOD $1, \mathrm{~J} 1)=$ NOD3

$\operatorname{COEFF}\left(\operatorname{NOD} 1, J_{1}\right)=\operatorname{COEFF}\left(\operatorname{NOD} 1, J_{1}\right)+Y A D$

$\mathrm{J} 1=\mathrm{JVERT}(3, \mathrm{~K} 4)$

ITRI $\left(\right.$ IOD2, $\left.J_{1}\right)=$ NOD 1

$\operatorname{COEFF}(\mathrm{NOD2}, \mathrm{J} 1)=\operatorname{COEFF}(\mathrm{NOD} 2, \mathrm{~J} 1)+\mathrm{YAB}$

$J 1=J V E R T(4, K 4)$

ITRI ( NOD2, J1) = NOL3

$\operatorname{COEFF}(\operatorname{NOD} 2, J 1)=\operatorname{COEFF}(\operatorname{NOD} 2, J 1)+\mathrm{YBD}$

$J_{1}=J V E R T\left(5, K S_{5}\right)$

ITRI (NOD3, J 1$)=$ NOD 1

COEFF $($ NOD3,$J 1)=\operatorname{COEFF}($ NOL3,$J 1)+J_{1}$

$J 1=J V E R T(6, K 4)$

ITRI $($ NOD3,$J 1)=$ NOD2

$\operatorname{COEFF}($ HOD $3, J 1)=\operatorname{COEFF}(\operatorname{NOD} 3, \mathrm{~J} 1)+\mathrm{YBD}$

CONT INUE

9003 COHTINUE

\$OO1 CONTINUE

ITOT $1=1$ TOT

JF IN $=1$

INODE $4(1)=1$

IF ( NITHN. NE. O.) GO TO 3060

CALL SRCESS(KGREAD, 'DATA1', 5, 3,0, NCOD)

$\operatorname{READ}(7,3061)$ JF IN

3061 FORMAT( I5)

DO $3062 \mathrm{~J}=1, \mathrm{JF}$ IN

$\operatorname{READ}(7,3061)$ NODE 4 ( J)

3062

CONT INUE 
DO $3063 \mathrm{~J}=1$, JF IN

$\operatorname{NOD} 1=\operatorname{NODEA}(\mathrm{J})$

IF (NOD 1.GT.0) GO TO 3064

NOD $1=-\operatorname{NODES}(\mathrm{J})$

IF (NODE (NOD 1) .EQ. 1) NODE $4(J)=$ NOD 1

IF (NODE (NOD 1) , EQ. O) NODE (NOD 1$)=2$

GO TO 3063

3064 ITOT $1=$ ITOT $1+1$

READ ( 7,3065) VOLTS(NOD 1)

3065 FORNLAT(E12.5)

3063 CONTINUE

CALL SRCHSS (KSCLOS, 'DATA1', 5, 3, 0, NCOD)

CALL SRCESS (KSREAD, 'DATA2', $5, \overline{5}, 0$, NCOD)

NOD2 $=($ JFIN + 1) $\div$ JF IN $/ 2$

DO $3073 \mathrm{~K}=1$, NOD3

PEAD $(9,3074)$ TEIPP ( I

3074 FORNAT(E12.5)

3073 CONTINUE

CALL SRCHSS(KSCLOS,'DATA2', 5, 5, 0, NCOD)

$\mathrm{K} 4=\mathrm{JF} I \mathrm{IN}-1$

DO $3000 \quad I=1$, NMAX

$D I F F=0.0$

DO $3070 \mathrm{~J}=1, \mathrm{JF}$ IN

IF (NODES(J).GT.0) GO TO 3070

INOD $1=-\operatorname{NODE} \&(\mathrm{~J})$

NOD $3=0$

$\mathrm{K} 1=(\mathrm{J}-1) \div \mathrm{J} / 2$

$\mathrm{K} 2=\mathrm{J}-1$

SAVE $=$ VOLTS (NOD 1$)$

RES $=0$.

IF (J.EQ. 1) GO TO 3076

DO $3071 \mathrm{~K}=1, \mathrm{~K} 2$

NOD2 $=$ I ABS (NODE $4(K)$

$\mathrm{NOD} 3=\mathrm{K} 1+\mathrm{K}$

RES = RES + TEIP ( NOD3) $\div$ VOLTS (NOD2)

\section{CONTIINUE}

$307:$ NODS $=$ NCDS $\div 1$

NOL $3=$ NOD 4

IF ( J.EQ. JF IN) GO TO 3077

DO $3075 \mathrm{~K}=\mathrm{J}, \mathrm{K} 4$

THOD3 $=$ NOD $3+\mathrm{K}$

IOD2 = I ABS $(\operatorname{NODE} 4(\mathrm{~K}+1))$

RES $=R E S+T E I P($ HOD 3 ) $\div$ VOLTS (NOD2)

3075 COITTINUE

3077 DO $3072 \mathrm{~K}=1,8$

NOD2 $=$ ITRI ( NOD $1, K$

IF ( IOD2. EQ.0) GO TO 3072

RES $=$ RES + COEFF (NOD $1, K) * \operatorname{VOLTS}($ NOD2)

3072 CONTINUE

AVEVOL = TERIP ( NOD1 $)+\operatorname{COEFF~}($ NOD 1,9$)$

VOLTS (NOD 1) = VOLTS (NOD 1) \%ONLAPLE-( ALPHA AVEVOL) *RES

TOL $1=D I F F-A B S($ VOLTS $($ NOD 1$)-S A V E)$

IF (TOL1.LT. O.) D IFF = ABS ( VOLTS ( NOD 1) -SAVE)

3070 CONTINUE

DO $3020 \mathrm{~J}=1$, ITOT

$\operatorname{IF}(\operatorname{NODE}(\mathrm{J}), \mathrm{GT} .0)$ GO TO 3020 
$\operatorname{SAVE}=\operatorname{VOLTS}(\mathrm{J})$

RES $=0.0$

Do $3021 \mathrm{~K}=1,8$

$\mathrm{J} I=I \operatorname{TRI}(\mathrm{J}, \mathrm{K})$

IF (J1.EQ. B) GO TO 3021

3021 RES $=$ RES + COEFF $(J, N) * \operatorname{VOLTS}(\mathrm{J} 1)$

CONTIIUE

$\operatorname{VOLTS}(J)=O$ OMAPLH$: \operatorname{VOLTS}(J)-(\operatorname{ALPHA} / \operatorname{COEFF}(J, 9)) * \operatorname{RES}$

TOL $1=D I F F-A B S($ VOLTS $(J)-S A V E)$

IF( TOL 1. LT. O.) D IFF = ABS (VOLTS $(\mathrm{J})-\mathrm{SAVE})$

3020 CONTINUE

3000 IF((TOL-DIFF).GE.0.) GO TO 3040

WRI TE( OUT, 3050) TOL, NMAX

3050 FORMAT('TOLERANCE OF', E12.5, 'WAS NOT MET AFTER', I4,' TTERATIONS')

C - PRINT THE MINIMUN DIFF. REACHED

3040 WRITE (OUT, 305 1) DIFF, I

3051 FORMAT('MIN. DIFF. OF: ',E12.5,' AFTER', I4,' ITERATIONS')

C - - TRANSFER THE COORD INATES TO COEFF ARRAY.

$\mathrm{K} 1=0$

DO $3101 \mathrm{~J}=1$, LITHOR

DO $3102 \mathrm{~K}=1$, LNVER

$\mathrm{K} 1=\mathrm{K} 1+1$

$\operatorname{COEFF}(\mathrm{K} 1,8)=\mathrm{XPOS}(\mathrm{K})$

$\operatorname{COEFF}(K 1,9)=\operatorname{YPOS}(J)$

3102 CONTINUE

3101 CONTINUE

C --- TRANSFER ARRAYS AUX. 182 TO COEFF. $J P=J P-1$

IF ( JP. LE. O) GO TO 3104

DO $3103 \mathrm{~J}=1$, JP

$\mathrm{K} 1=\operatorname{MAUM}(\mathrm{J})$

$\operatorname{COEFF}(\mathrm{K} 1,8)=\operatorname{AUX}(J, 1)$

$\operatorname{COEFF}(K 1,9)=\operatorname{AUX}(J, 2)$

3103 CONTINUE

C --- EMPTY THE REMAINING OF THE ARRAY COEFF.

3104 DO $3105 \mathrm{~J}=1$, ITOT

DO $3106 \quad K=1,7$

$\operatorname{COEFF}(\mathrm{J}, \mathrm{K})=0$.

3106 CONTINUE

3105 CONTINUE

C --- CALCMATE ILAX. FIELD STRENGH. FON EACH PERMT. ISQ $=$ ISE $* 2$

$\mathrm{K} 1=\mathrm{L}[\mathrm{KT} \mathrm{T}+1$

$\operatorname{DATLIT}(K 1,1)=$ EPSO

DO $3041 \mathrm{~J}=1, \mathrm{~K} 1$

EPS I = DATLN $(J, 1)$

IF( (EPSI.LT.0.001).OR. (EPSI.GT. 1000.0)) CO TO 3041

ENIAXY $=0$.

DO $304.2 \mathrm{~K}=1$, ISQ

IF( EPS I. NE. PERM( $K$ ) CO TO 3042

CALL FSTR( $\mathrm{K}, \mathrm{EX}, \mathrm{EY}, \mathrm{E}, \mathrm{D})$

IF (E. LT. EMAX) GO TO 3042

EMAX $=E$

$$
\mathrm{K} 2=\mathrm{K}
$$

CONTINUE 
WRI TE( OUT, 3043) EPS I, EMAX

3043 FORMAT( 40BOFOR MATERIAL WITH RELATIVE PERMITIVITTY, F7.2, 137H THE MAXINTUN FIELD STRENGTE, VOLTS/MI,F9,2/

224.H OCCURS AT TRI ANGLE WITH)

IF (FLAXI . GT . 1.5) WR I TE (OUT, 304.4)

IF (FLAXI. LT . 1.5) WRITE( OUT, 3045)

3044 FORIIAT( 15H VERTEX NUNRERS, $7 \mathrm{X}, 1 \mathrm{HZ}, 8 \mathrm{X}, 1 \mathrm{HR}$ )

3045 FORMAT( 15 H VERTEX NUNBERS, $7 \mathrm{X}, 1 \mathrm{EX}, 8 \mathrm{X}, 1 \mathrm{HY})$

NOD $1=$ I VERT $(K 2,1)$

NOD2 = I VERT $(K 2,2)$

NOD3 = I VERT $(K 2,3)$

FRI TE( OUT, 3046) NOD2, COEFF (NOD2, 8), COEFF (NOD2, 9)

FRI TE ( OUT, 3046) NOD3, COEFF ( NOD3, 8), COEFF ( NOD3, 9)

FRI IE (OUT, 3046) NOD 1, COEFF( NOD 1, 8), COEFF (NOD 1,9)

3046 FORPLT ( $6 \times, I 4, F 15,1, F 9.1)$

3041 CONTINUE

C --- PRINTOUT OF THE POTENTIALS.

FRITE( OUT, 3100)

3100 FORILAT (27HIVERTEX POTENTIALS IN VOLTS)

$\mathrm{K} 1=1$

$\mathrm{K} 2=10$

3126 IF (K2.GT. ITOT) IK2 = ITOT

FRITE (OUT, 3111$)(\mathrm{K} 3, \mathrm{~K} 3=\mathrm{K} 1, \mathrm{~K} 2)$

FRITE( OUT, 3112$)(\operatorname{COEFF}(\mathrm{K} 3,8), \mathrm{K} 3=\mathrm{K} 1, \mathrm{~K} 2)$

FRITE (OUT, 3113$)(\operatorname{COEFF}(K 3,9), K 3=\mathrm{K} 1, \mathrm{~K} 2)$

VRITE (OUT, 3114 ) (VOLTS (K3), K3= K1 , K2)

3111 FORMAT( 9EOVERTEX : , I4,9I12)

3112 FORMAT $4 \mathrm{~B} X:, \mathrm{F} 9.1,9(2 \mathrm{X}, \mathrm{F} 10.1))$

3113 FORNIAT ( S. Y Y : F9.1, $9(2 \times, F 10.1))$

3114 FORMAT(2H ,E11.3,9(1X,E11.3))

$\mathrm{K} 1=\mathrm{K} 2+1$

IF (KI.GT. ITOT) GO TO 3125

$\mathrm{K} 2=\mathrm{K} 2+10$

GO TO 3126

3125 CALL SRCEES( KSCLOS, 'WINOITT', 6, 2,0, NCOD)

RETURN

EITD

SURROUTINE PERTRI (KIODG, EPS I, MI, N, L)

DIMENS I ON I VERT $(2000,3)$, PERRI 2000$), \operatorname{ITRI}(900,8)$

COTIOIO / BLOCES / COEFF $1(18145)$

COIETON/BLOK11/ITRI, I VERT

E@U I VALENCE (COEFF 1(15361), PERM( 1))

DATA I $2,13 / 0,0$

$12=12+1$

$13=13 \div 1$

GO TO $(10,20)$, KIODG

10 GO TO $(40,50), 12$

4. $\quad \operatorname{IVERT}(13,1)=\mathrm{L}$

IVERT $(13,2)=M$

IVERT $(3,3)=N$

GO TO 60

$50 \quad \operatorname{IVERT}(13,1)=\mathrm{N}$

I VERT $(13,2)=L$

$I \operatorname{VERT}(I 3,3)=$ II

GO TO 60

20 GO TO $(70,80), 12$ 
IVERT $(13,1)=\mathrm{L}$

IVERT $(13,2)=M$

IVERT $(13,3)=N$

GO TO 60

80 IVERT $(13,1)=\mathrm{L}$

IVERT $(13,2)=M$

IVERT $(13,3)=\mathrm{N}$

$60 \quad \operatorname{IF}(12 . \mathrm{GE} .2) 12=0$

PERH $I 3$ ) $=$ EPS I

RETURIT

END

SUBROUTINE FSTR( I, EX; EY, E, D)

DINENS ION COEFF $(900,9)$. PERM( 2000), COEFFI ( 18145)

COMION/BLOCIS8/VOLTS (904), NODE(900), JP, NZHT, NZVT

COMMON/BLOCK9/COEFF 1/BLOK1 I/ITRI $(900,8)$, IVERT $(2000,3)$

EQU I VALENCE ( COEFF $1(7261), \operatorname{COEFF}(1)),(\operatorname{COEFF} 1(15361), \operatorname{PERM}(1))$

$L=I$ VERT $(I, 1)$

$\mathrm{H}=$ IVERT $(I, 2)$

li $=I V E R T(I, 3)$

$\mathrm{UL}=\operatorname{COEFF}(\mathrm{L}, 8)$

YL $=\operatorname{COEFF}(\mathrm{L}, 9)$

$X M=\operatorname{COEFF}(M, 8)$

$Y M=\operatorname{CCEFF}(M, 9)$

ZIN $=\operatorname{COEFF}(\mathrm{N}, 8)$

$Y N=\operatorname{COEFF}(N, 9)$

CALL SUBD ( D, XM, YM, XIN, YT, XI, YL)

$E X=(\operatorname{VOLTS}(L) *(Y T-Y T D+\operatorname{VOLTS}(M) \div(Y L-Y N)+\operatorname{VOLTS}(N) *(Y M-Y L)) / D$

$E Y=-($ VOLTS $(L)=(X I N-X N D+\operatorname{VOLTS}(M) *(X I-X I Y)+\operatorname{VOLTS}(N) *(X M I-X I)) / D$

$E=\operatorname{SaRT}(E X * E X+E Y * E Y)$

RETURN

END

SUBROUTINE PLOTY

C -.- LAPLACI - ELECTRJST/TIC I IL:D, PFIME 500 FORTRAN IV, PART E

DINEISION XPOS $(70)$, YPOS $(100), \operatorname{ILN}(70), \operatorname{IVZV}(15), N Z H(15)$

1, $A D N A B(15,15), \operatorname{ADHAD}(15,15), \operatorname{DATLI}(70,3), \operatorname{TENP}(7260), \operatorname{COEFF}(900,9)$

2, PERII 2000), COEFF I ( 18145$)$

REAL IDENT( 20$)$, LIINC ( 800$)$

INTEGER $\div 2$ IVERT $(2000,3)$, IPRCV( 4$)$

CONI:ON /BLOCKI / YPOS, YPOS, LNVER, LNHOR, IDENT, EQL IN, ITOT

1, ISQ, FLAXI , EPSO

COMRIOIY/BLOCK2/LINC, NZV, KZB, ADMAB, ADMAD, DATLN

COPMON/BLOCKT/LINTO, ILN

COMLION/BLOCK8/VOLTS ( 904$)$, NODE( 900), JP , NZHT, NZVT

COIDION/BLOCK9/COEFF 1

COMIOH/BLOK11/ITRI $(900,8)$, IVERT

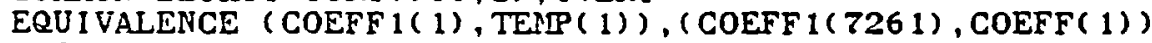

1, ( COEFF 1 (15361), PERY( 1))

DATA BLANK', ',

C - DETERMINE THE VALUES OF POTMX AND POTMT

331 POTTEK $=-1000$.

POTMTI $=1000$

DO $332 \mathrm{~J}=1$, ITOT

IF (VOLTS $(J)$. GT. POTMX) POTIX $=\operatorname{VOLTS}(J)$

332 CONTINUE

-- DETERMINE IF OPTIONAL PLOT IS DESIRED... 
IF (EQLIN. LE. 0.0) GO TO 999 C - DETERMINE SIZE OF REGION TO PLOT... $E 2=Y P O S(L N B O R)-Y P O S(1)$ $\mathrm{E} 5=9.0 / \mathrm{E} 2$

IF (E1.GT.E2) E5 $=10.0 / E 1$

C --- SELF-DETERHIN IMG SCAL ITG FACTOR...

C --- PERCEITT VOLTS PER LINE PERCV $=0$

IF (EQL IN.GT.0.5) PERCV $=100.0 /(E @ I N+1.0)$

C -- ENTER INTO GRAPHICS MODE...

CALL GRESET

C -- DALA ENTGRA $\mathrm{N}=4$

DO $141 \quad M=2,20$

15.1 IF (IDENT (N) . NE. BLANK $\mathbb{N}=\mathrm{N}+4$

15:1 CONTINUT

C.ALL SLTRZ(0)

CALL TEXT( IDENT, $N$ )

CAIL MOVE $(-\overline{5} .0,-4.7)$

CALL TEXT('PERCENT VOLTS PER LINE:', 23)

10 ENCODE ( 8, 10,

PRCV) PERCV

CALL MOVE $(-1.5,-4.7)$

CALL TEXT (IPRCV, 8)

ENCODE ( $B, 10$, IPRCV) POTTXX

CALL TEXT(' P. MAX:', 7)

CALL TEXT( IPRCV, 8)

ENCODE ( 3, 10, IPRCV) POTT

CALL TEXT(? P. MIIN:, 7$)$

CALL TEXT( IPRCV, 8)

C --- SECTION BOUNDARIES

$143 \quad E I=X P O S(1)$

E2= YPOS ( LIVVER)

$E 3=Y P O S\{1$ :

$\mathrm{E} 4=$ YPOS ( LTHOR)

$\mathrm{E} G=-4.5$

$\operatorname{COEFF}(1,6)=-5.0$

$\operatorname{COEFF}(1,7)= \pm 6$

$\operatorname{COEFF}(2,6)=-5.0$

$\operatorname{COEFF}(2,7)=E 5 \div(E 4-E 3)+E 6$

$\operatorname{COEFF}(3,6)=E 5 \div(E 2-E 1)-5.0$

$\operatorname{COEFF}(3,7)=\operatorname{COEFF}(2,7)$

$\operatorname{COEFF}(4,6)=\operatorname{COEFF}(3,6)$

$\operatorname{COEFF}(4,7)=\operatorname{E} 6$

$\operatorname{COEFF}(5,6)=-5.0$

$\operatorname{COEFF}(5,7)=E 5$

CALL MOVE $(\operatorname{COEFF}(1,6), \operatorname{COEFF}(1,7))$

DO $1001 \mathrm{JP}=2,5$

ICO1 CALL DRAN $\operatorname{COEFF}(J P, 6), \operatorname{COEFF}(J P, 7)$ )

C -- ELECTRODES NND DIELECTRIC MATERIALS

143 DO $242 \quad \mathrm{I}=1$, LINTO

LPNT $=0$

IF (I.GT.1) LPNT $=\operatorname{ILN}(I-1)$ 
$N=\operatorname{ILN}(I)-\operatorname{LPNT}$

IF (N.LE. 1) GO TO 242

DO $241 \mathrm{~J}=1, N$

$N 1=2 *(L P N T+J)$

$\operatorname{COEFF}(J, 6)=E 5 \div\left(\operatorname{LINC}\left(N_{1}-1\right)-E 1\right)-5.0$

$241 \operatorname{COEFF}(\mathrm{J}, 7)=\mathrm{E5} *(\mathrm{~L}$ INC (NI) $-\mathrm{E} 3)+\mathrm{E} 6$

$\operatorname{COEFF}(N+1,6)=-5.0$

$\operatorname{COEFF}(N+1,7)=-4.5$

$\operatorname{COEFF}(\mathrm{N}+2,6)=-\mathbf{5} .0$

$\operatorname{COEFF}(N+2,7)=-4.5$

CALL MOVE( $\operatorname{COEFF}(1,6), \operatorname{COEFF}(1,7))$

DO 1002 JP=2, N

$1002 \operatorname{CALL}$ DRAF $(\operatorname{COEFF}(J P, 6) ; \operatorname{COEFF}(J P, 7))$

242 CONTIITUE

C - - CHAIIGE COORDINATES

DO $243 \mathrm{I}=1$, ITOT

$\operatorname{COEFF}(1,8)=\operatorname{E} 5 \div(\operatorname{COEFF}(1,8)-\mathrm{E} 1)-5.0$

$243 \operatorname{COEFF}(1,9)=\operatorname{E5} *(\operatorname{COEFF}(1,9)-E 3)+E 6$

C - - EQUIPOTENTIAL LINES

INL INE $=E Q L I$ iN

XEND $=0$

YEND $=0$

$E I=($ EQL $I N+1.0) /($ POTHX-POTMN $)$

DO $602 I=1, I$ TOT

602 VOLTS $(1)=E i \neq($ VOLTS $(1)-$ POTNN)

DO 610 N1 $=1$, NLINE

$\mathrm{J}=0$

$\mathrm{E} 1=$ FLOAT N 1 ;

DO $609 \quad I=1$. ISQ

$110=0$

IT $=I \operatorname{VERT}(I, 1)$

$L=I$ VERT $(1,2)$

$M=1$

603 IF (VOLTS(K).GT.VOLTS (L)) GO TO 604

IMIN $=\mathrm{K}$

$I M A X=L$

POTII $=$ VOLTS $(\mathrm{R})$
POTIIX $=$ VOLTS $(I$.

604 GO TO 605

IMIII $=\mathrm{L}$

I $M 4 Y_{2}=\mathrm{K}$

POTIN $=$ VOLTS $(L)$

POTTY = VOLTSC IO

605 IF (EI.LT.POTITY.OR.E1.GT.POTINO GO TO 607 $E 2=0$

IF (POTIN.LT.POTHED E2 $=(E 1-$ POTMN) $/$ (POTMX-POTMN)

IF (I 10.EQ. O) $\mathrm{J}=\mathrm{J}+1$

DO 606 I11 $=8,9$

$\mathrm{K}_{1}=110+111-7$

$606 \operatorname{COEFF}(J, K 1)=\operatorname{COEFF}(\operatorname{IMIN}, I 11)+\operatorname{E2} *(\operatorname{COEFF}(\operatorname{IMAX}, I 11)-\operatorname{COEFF}(\operatorname{IMIR}, I 11))$

$\operatorname{COEFF}(\mathrm{J}, 5)=0$

607 IF (M.GE.2) GO TO 608

$\mathrm{I}=\operatorname{IVERT}(1,2)$

$L=1$ VERT $(1,3)$

$M=2$ 


\section{GO TO 603}

608 IF (M.EQ.3) GO TO 609

$\mathrm{K}=1 \operatorname{VERT}(1,3)$

$L=I \operatorname{VERT}(1,1)$

$\mathrm{M}=3$

GO TO 603

609 CONTINUE

IF (J.EQ.0) GO TO 610

INV $=0$

C --- FIRST LINE SEGMENT INTO ARRAYS XA AND YA

DO $701 \quad 1=1,2$

$\operatorname{COEFF}(1,6)=\operatorname{COEFF}(1,2 * I-1)$

$701 \operatorname{COEFF}(I, 7)=\operatorname{COEFF}(1,2 \div I)$

$\mathrm{N}=2$

IF (J.EQ. 1) GO TO 708

C --- LOOK FOR CONNECTING LINE SEGMENT

702 DO $766 I=2, J$ J $(\operatorname{COEFF}(I, 5) . G T .0 .5)$ GO TO 706

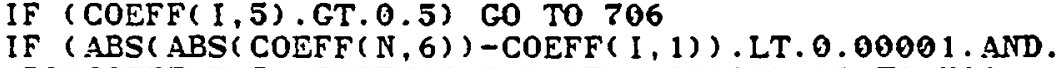

$1 A B S(\operatorname{COEFF}(N, 7)-\operatorname{COEFF}(1,2))$. LT. 0.00001$)$ GO T0 703

IF (ABS (ABS ( $\operatorname{COEFF}(N, 6))-\operatorname{COEFF}(1,3))$. LT. 0.00001 . AND.

$1 \mathrm{ABS}(\operatorname{COEFF}(N, 7)-\operatorname{COEFF}(1,4))$. LT. 0.00001$)$ GO TO 704

GO TO 706

$303 \quad \mathrm{~N}=\mathrm{N}+1$

$\operatorname{COEFF}(N, 6)=\operatorname{COFFF}(1,3)$

$\operatorname{COEFF}(N, 7)=\operatorname{COEFF}(1,4)$

$\operatorname{COEFF}(I, 5)=1$

GO TO 705

$704 \quad \mathrm{H}=\mathrm{N}+1$

$\operatorname{COEFF}(1,6)=\operatorname{COEFF}(1,1)$

$\operatorname{COEFF}(N, Z)=\operatorname{COEFF}(1,2)$

$\operatorname{COEFF}(1,5)=1$

705 IF (N.LE.J) GO TO 702

GO TO 708

706 CONTINUE

C - IIVERT LINE AND TRY AGAIN

IF ( IIVV.EQ. 1) GO TO 708

IEXIT $=1$

GO TO 714

12 IIIV $=1$

GO TO 702

C - DRAW LINE

$703 \quad I I V=0$

IEXIT=2

$\operatorname{IF}((\operatorname{ABS}(\operatorname{COEFF}(1,6))-\mathrm{XEND}) * 2 \div(\operatorname{COEFF}(1,7)-Y E N D) \div 2 . \mathrm{GT} .(\operatorname{ABS}(\operatorname{COEFF}(\pi$

$1,6))-X E$ IND $): 2+(\operatorname{COEFF}(N, 7)-Y E N D) * * 2)$ GO TO 714

713 XEND = ABS $(\operatorname{COEFF}(N, 6))$

YEID $=\operatorname{COEFF~}(\mathrm{N}, \mathrm{T})$

$\operatorname{COEFF}(\mathrm{N}+1,6)=-5$.

$\operatorname{COEFF}(\mathrm{iN}+1,7)=-5$

$\operatorname{COEFF}(N+2,6)=-4$.

$\operatorname{COEFF}(N+2,7)=-4$.

CAIL HOVE $(\operatorname{COEFF}(1,6), \operatorname{COEFF}(1,7))$

Dก 1003 JP $=2, N$

$1603 \operatorname{CALL} \operatorname{DRAW}(\operatorname{COEFF}(J P, 6), \operatorname{COEFF}(J P, 7))$

IF (J.GE.2) GO TO 709 


\section{GO TO 610}

C - - REMAINING LINE SEGMENTS

$709 \quad M=0$

DO $711 \mathrm{I}=2, \mathrm{~J}$

IF (COEFF $(I, 5), G T .0 .5)$ GO TO 711

$\mathrm{I}=\mathbb{N 1}+1$

DO $710 \mathrm{~K}=1,5$

$710 \operatorname{COEFF}(M, I)=\operatorname{COEFF}(I, K)$

711 CONTINUE

$\mathrm{J}=\mathbf{M}$

IF ( J.GE. 1) GO TO 200

GO TO 610

C -- INVERT LINE

714 $\quad M=N / 2$

no $707 \quad I=1, M$

$E 1=\operatorname{COEFF}(1,6)$

$E 2=\operatorname{COEFF}(1,7)$

$\mathrm{K}=\mathrm{N}-\mathrm{I}+1$

$\operatorname{COEFF}(I, 6)=\operatorname{COEFF}(\mathrm{K}, 6)$

$\operatorname{COEFF}(I, 7)=\operatorname{COEFF}(\mathrm{K}, \mathrm{T})$

$\operatorname{COEFF}(\mathrm{K}, 6)=\mathrm{E} 1$

$707 \operatorname{COEFF}(K, 7)=E 2$

610 GO TO $(712,713)$, IEXIT

C RETURN TO ALPEA MODE...

CALL EXITGR

999 RETURN

END

SUBROUTINE EQUIV

SINSERT SYSCOND IKEYS. F

C -- THIS SUBROUTIITE CALCULATES THE MATRIX THAT REPRESENTS

C -- THE BOUIDARY CONDITIONS FOR THOSE GRID POINTS ON THE

C -- BORDER LINE OF THE PEG ION NAERE CHANGES ARE TO BE DONE. DIRENS ION VOLTS $(904), \operatorname{NODE}(900)$, NIRP( 4$), \operatorname{COEFFI(13145)}$

1, NZON( 4$), \operatorname{NDATLN}(70,2), \operatorname{NOD}(4), X(4), Y(4), \operatorname{AREA}(4), I \operatorname{LN}(70)$

?, XPCS (70), YPCS $(100)$, UU: 305,2$), \operatorname{MAUi}(500)$

REAI LINC( 800$)$, MAAXI, IDENT (20)

IHTEGER 2 MVERT $(70,100)$, STEP, OUT

COMTION / BLOCK1 / YPOS, YPOS, LIVVER, LNHOR, IDEITT, EQL IN,

$116,15, F L A X I$, EPSO, BLOCKO, L I INC, NZV (15), NZH( 15),

$1 \triangle D H A B(15,15), A D M L D(15,15), D A T L N(70,3)$

COFUSH/BLOCK3/TVERT/BLOCR4/D IGLN/BLOCK5/AUX, MLAUX/BLOCK6/NTRI

CONDON/BLOCKZ/LINTO, ILN/BLOCKB/VOLTS, NODE, JP, NZHT, NZVT

CORTON $/$ BICCK9 / COEFF 1

COMMON/BLOK12/WITHN, MAXI, TOL, ALPHA, AVEVOL, BLF, HLL, VLF, VLL

IGRPTS (NG, MG) $=(N G-1) \div$ LNVER + WG

C - - THE - HUTBER OF COLUTIS AIND ROVIS IS COMPUTED.

I I $=5$

OUT $=6$

ICCOL $=$ ITVER -1

INORO W = LTEOR -1

C --- THE WINDOW LITE NOTBERS ARE DEFINED.

LEF $=$ BLIF

$\mathrm{LEL}=\mathrm{BLL}$

$\mathrm{LVF}=\mathrm{VLF}$

$\mathrm{LVL}=\mathrm{VLL}$ 
C --- THE NUMBER OF RETAINED NODES IS INITIALIZED.

JLAST $=1$

C --- THE PROCESSING IS DONE ONE COLUMN AT A TIRE FOR EVERY ROW. DO $9001 \mathrm{~N}=1$, NOROW

DO $9000 \mathrm{M}=1$, NOCOL

C --- IF THE SQOARE IS INSIDE THE KEPT REGION, IT IS SKIPPED.

IF ( ( (N.GE. LHF ) . AND. (N.LT.LHL)) . AND . ( (M.GE.LVF) . AND. (M.LT.LVL))

*) CO TO 9000

C -- THE ELERENT OF AREA IS ANALIZED

Do $20 \mathrm{~K}=1,4$

GO TO $(30,40,50,60), K$

$30 \quad \mathrm{NG}=\mathrm{N}$

MG $=\mathrm{M}$

GO TO 70

$40 . \quad N G=N$

$M G=M+1$

GO TO 70

$50 \quad N G=N+1$

$M G=M+1$

GO TO 70

$60 \quad \mathrm{NG}=\mathrm{N}+1$

$M G=M$

C --- AFTER THE PROPER CRID POSITION IS FOUND,

C -- THE NODE CUALITIES ARE CALCULATED.

30 NIRR ( KD = MNERT (NG, MG) $/ 10$-(INERT (NG, MG) $/ 100) \div 10$

HZON $($ ID $=$ HVERT (NG, MG) $/ 100-($ MVERT $($ NG, MG $) / 10000) * 100$

C --- THE RESEIBLLAIZE OF GRID POINTS AND ELEC. NODES IS ESTABLISHED HERE $I D=N Z O N(K O$

ID $1=$ NBOUFT $(M G, N G, L E F, L E I, L V F, L V L)$

IF( ID I.EQ. 1) GO TO 721

IF (NZON (K).EQ.O) GO TO 71

IF( DATLN(ID,3).LT.2.0) GO TO 71

IF (NDATLN (ID, 1). NE.0) GO TO 72

TDATLN $(I D, 1)=$ ING

NDATLN $(I D, 2)=$ MIG

NODE ( JLAST) = IGRPTS ( NG, NG)

VOLTS $(J L A S T)=$ VATLM $(I,, \angle)$

$\operatorname{NOD}(K)=J L A S T$

JLAST $=$ JLAST $\div 1$

GO TO 73

$72 I$ I 1 GRPTS(NDATIT (ID , 1), NDATLIT ID , 2)

GO TO 76

$721 I=-((N G-L E F) *(L V L-L V F+1)+M G-L V F+1)$

GO TO 76

$I=I$ GRPTS $(N G, M G)$

$\mathrm{JF}=\mathrm{JLAST}-1$

DO $74 \mathrm{~J}=1, \mathrm{JF}$

IF(NOLE (J).EQ. I) GO TO 75

CONTIINUE

TODE ( JLAST) $=$ I

$\operatorname{VOLTS}(\mathrm{JLAST})=0.0$

$J=J L A S T$

$\mathrm{JLAST}=\mathrm{JLAST}+1$

$\operatorname{NOD}(K)=J$

IF(NIRR(K).EQ.0)GO TO 80

$I=I G R P T S(N G, I G)$ 
DO $90 \mathrm{~J}=1, \mathrm{JP}$

IF (I.EQ. MAUX( J) ) GO TO 100

CONTINUE

$\mathrm{X}(\mathrm{K})=\operatorname{AUX}(\mathrm{J}, 1)$

$Y(K)=\operatorname{AUX}(J, 2)$

GO TO 19

90
100

$80 \quad \begin{aligned} & X(K)=X P O S(M G) \\ & Y(K)=Y P O S(N G)\end{aligned}$

19 MIRT $=$ MIRT + NIRRC BO

20 CONTINUE

C - REGULAR SQUARES TO INSTRUCTION 79, IRREGULARS TO NEXT.

KIODG $=1$

IF (MIRT.EQ. O) GO TO. 79

C - - THE AREA OF THE FOUR POSSIBLE TRIANGLES IS CALCULATED.

$\triangle \operatorname{AREA}(1)=((X(2)-X(1)) *(Y(4)-Y(1))-(Y(2)-Y(1)) *(X(4)-X(1)))$

AREA(2) $=((X(4)-X(3)) *(Y(2)-Y(3))-(Y(4)-Y(3)) *(X(2)-X(3)))$

AREA $(3)=((X(3)-X(2)) *(Y(1)-Y(2))-(Y(3)-Y(2)) *(X(1)-X(2)))$

AREA $(4)=((X(1)-X(4)) *(Y(3)-Y(4))-(Y(1)-Y(4)) *(X(3)-X(4)))$

DO $1900 \mathrm{KLING}=1,4$

IF ( AREA( KL IITG) . EQ.0) GO TO 2000

1900 CONTINUE

GO TO 2001

2000 FRITE( 1,2002$)$ YL ING, AREA(IL ING)

$2 \mathrm{CO2}$ FORMAT('AREA(', I4,',', E12.5)

PAOSE 1

$2001 \quad A R 1=A B S(A R E A(1)-A Z E A(2))$

$A P 2=A P S(\operatorname{AREA}(3)-\operatorname{AREA}(4))$

C -- THE KIITD OF DIAGNL. IS ESTABLISHED: 1- LL, UR, OR 2- UL, LR IF (AR1. LT. AR2) IKIODG =2

$79 \quad \operatorname{IF}((N Z O N(1) . L T .1)$.AND. (NZON (3).LT.1)) GO TO 77

IF (NZON( 1$)$. NE. NZON (3)) GO TO 77

KIODG $=1$

GO TO 10

$77 \quad$ IF ( (NZON (2) .LT. 1).AND. (NZON(4).LT.1)) CO TO 10

IF (NZON (2) . EQ. NZON ( 4$)$ ) KIODG $=2$

C - FIND THE PERIITIVITY OF THE FIRST TRIANGLE IN TEE SQUARE.

10 DO $190 \quad \mathrm{~L}=1.2$

GO TO $(189,183), \mathrm{L}$

$1 \varepsilon 3 \quad$ GO TO $(137,186)$, KIODG

$186 \quad \mathrm{~K} 1=3$

$\mathrm{K} 2=4$

$\mathrm{K} 3=2$

MAR $=2$

GO TO 185

$187 \quad \mathrm{~K} 1=4$

$\mathrm{K} 2=1$

$\mathrm{K} 3=3$

$M A R=4$

GO TO 135

189

GO TO $(134,183)$, KIODG

$\mathrm{K} I=1$

$\mathrm{K} 2=2$

II $3=4$

$\mathrm{MAR}=1$

GO TO 185

124 $\mathrm{K} 1=2$ 


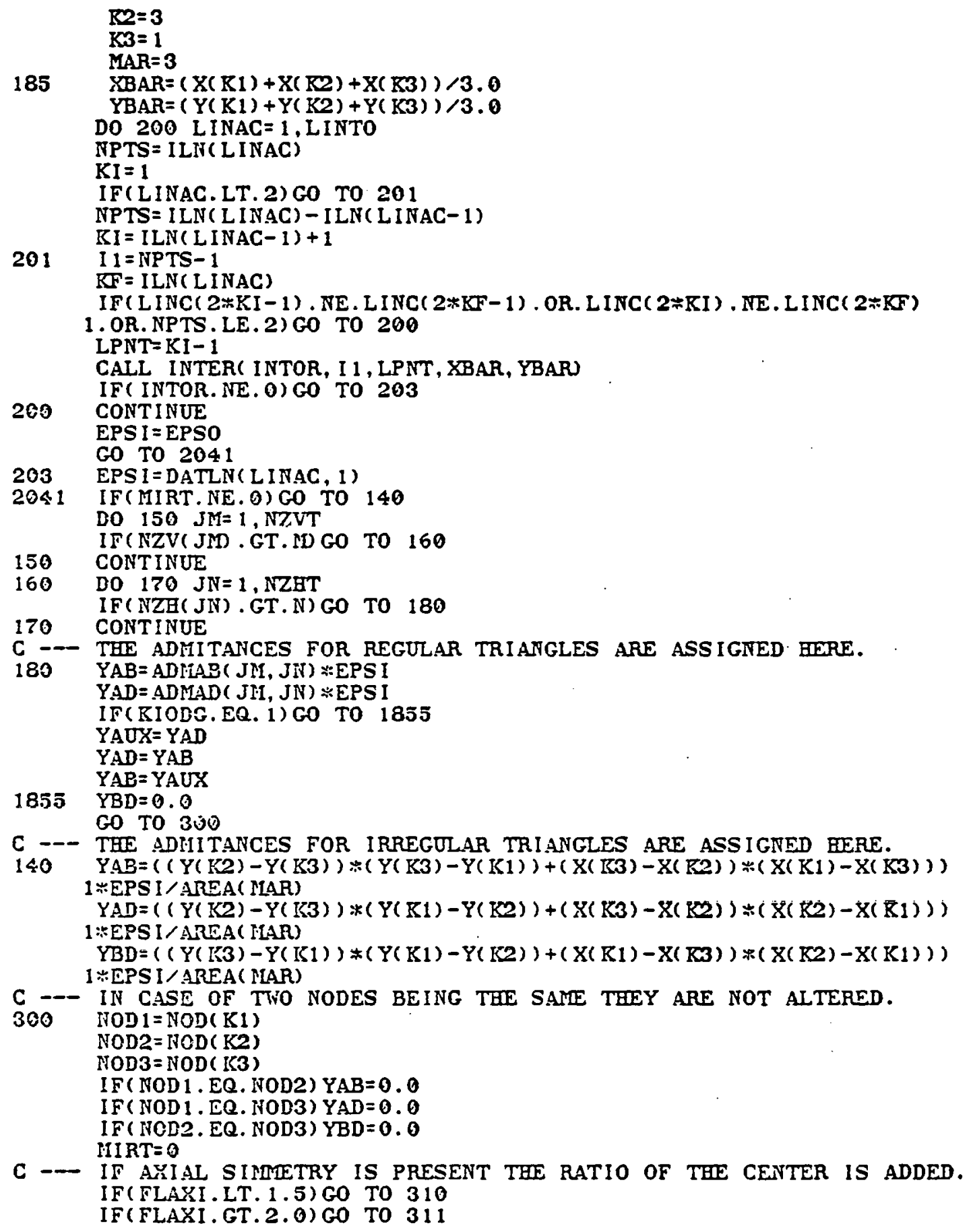




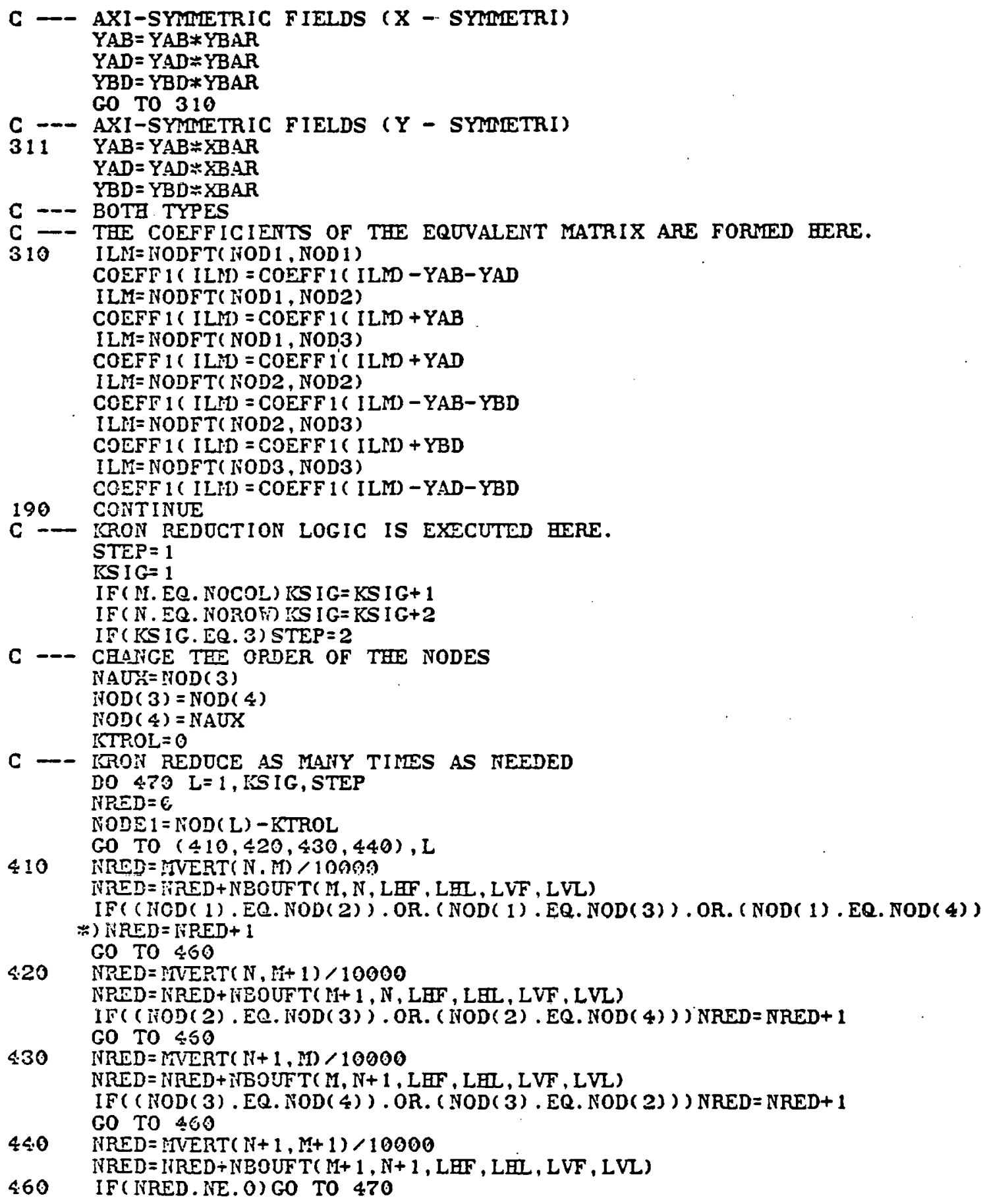


C -- EXECUTE THE XRON REDUCTION

JLAST $=$ JLAST -1

ILM= NODFT ( NODE 1 , NODE 1 )

IF ( COEFF I ( ILN) . NE.0.) GO TO 4000

WRITE (OUT, 4001 ) L, JLAST, KS I G, M, N, NODE 1, ( NOD ( KLMD , KLM=1, 4)

SEO 1 FORMAT ( COEFF $1(', 13, ')$ ', WHEN L =', 13,

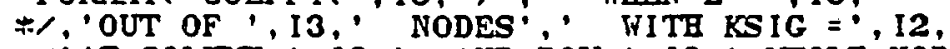

$\because \therefore$ AT COLUTN , $12,{ }^{\prime}$ AND ROW, 12, WHILE NODE $1^{\prime}=, 14$

$\because,,^{\prime}$ AND NOD $1,2,3,84=\cdot, 413$ ) RETURN

4000 DO $204 \mathrm{~J}=1$, JLAST

IF (J.EQ. NODE 1) GO TO 204

ILFP $=$ NODFT $($ NODE $1, \mathrm{~J})$

DO $205 \mathrm{I}=1, \mathrm{~J}$

IF( I.EQ. NODE I) GO TO 205

ILM3 $=$ NODFT $($ NODE 1, I $)$

ILIIS = NODFT $(\mathrm{J}, \mathrm{I})$

COEFF 1 ( ILN1 ) $=$ COEFF $1($ ILM4) $-($ COEFF $1($ ILME) / COEFF 1 (ILPD $)$

$1 \%$ COEFF 1 ( ILNB )

205 CONTINUE

204 CONTINUE

C --- AFTER ELIMINATING ONE TODE ALL THE REMAINIG ARE READJUSTED

C - - COEFF. ARE IIOVED FROM RIGTH TO LEFT.

KODE $2=$ NODE $1+1$

DO 208 I = NODE2, JLAST

I LMI = IYODFT (NODE 1, I)

BO 207 J =NODE2, I

ILH2 = ILMS 1

COEFF 1 ( ILID = COEFF 1 (ILIR)

COEFF I ( ILN 12$)=0$.

ILM= ILII2

207 CONTINUE

208 CONTINUE

C - THE COEFF. ARE MOVED FROM BELON THE REDUCED AXIS.

$J F I R=J L A S T-1$

ILF $=$ NODFT (NODE $1-1$, NODE $1-1$ )

DO 211 I = NODE $1, J F I N$

DO $212 \mathrm{~J}=1, \mathrm{I}$

ILMI $=1$ Llit 1

$I L M 2=I L I I+I$

COEFF 1 ( ILII) $=$ COEFF 1 ( ILFE)

COEFF I ( ILHZ) $=0.0$

212

CONTINUE

211 CONTINUE

C - THE NODES NUMBER ARE BACSPACED, AS WELL AS THE VOLTAGE VALUES DO $210 \mathrm{~J}=$ HODE 1, JF IN

$\operatorname{NODE}(J)=\operatorname{NODE}(\mathrm{J}+1)$

$\operatorname{VOLTS}(J)=\operatorname{VOLTS}(J+1)$

210 CONTINUE

KTROL $=$ KTROL +1

470 CONTINUE

9000 CONTINUE

9001 CONTINUE

C --- PRINTING OF THE REDUCED MATRIX.

JF IN $=$ JLAST -1

CALL SRCESS(RSIRIT, 'DATA1', 5, 4, 0, NCOD) 


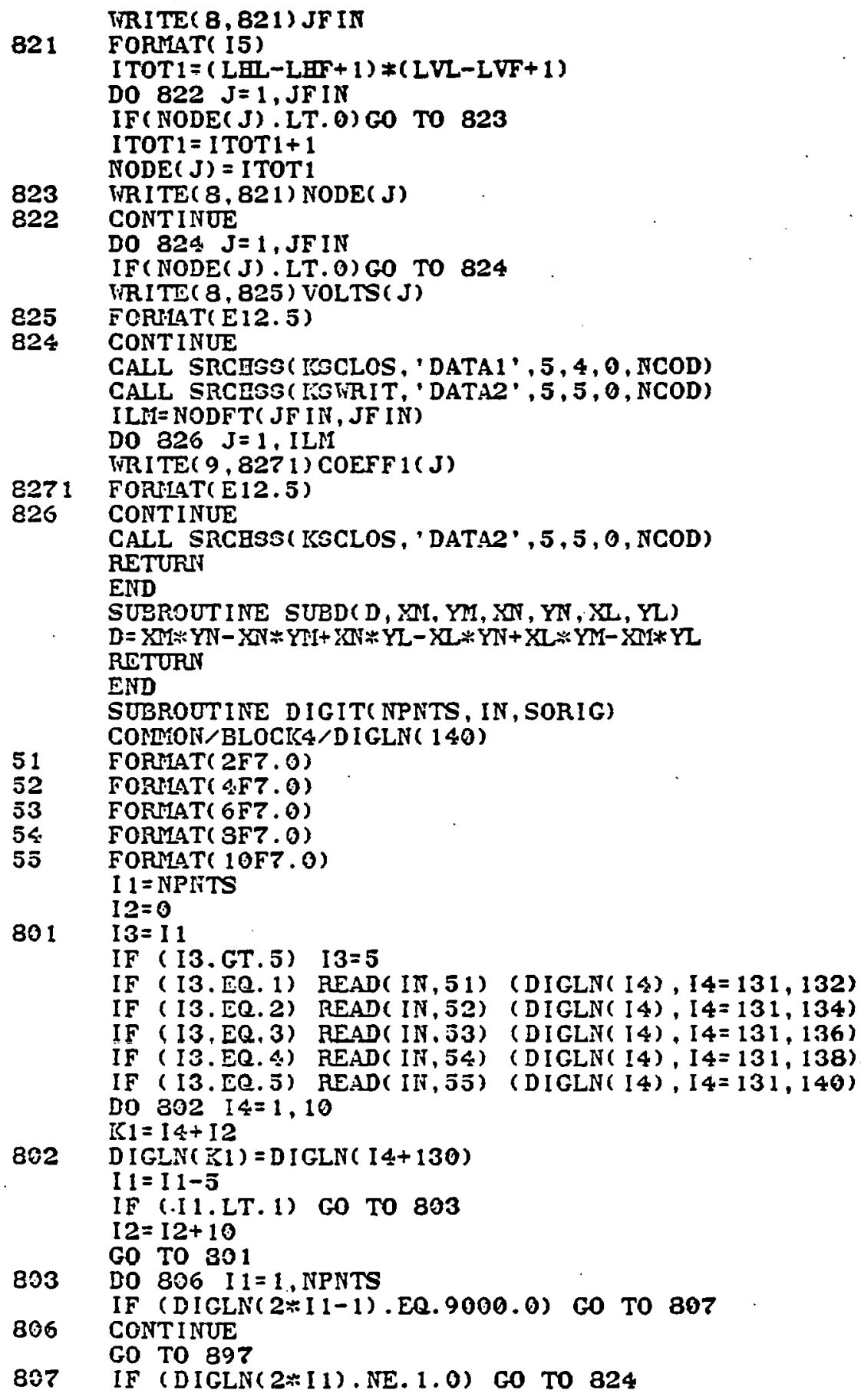




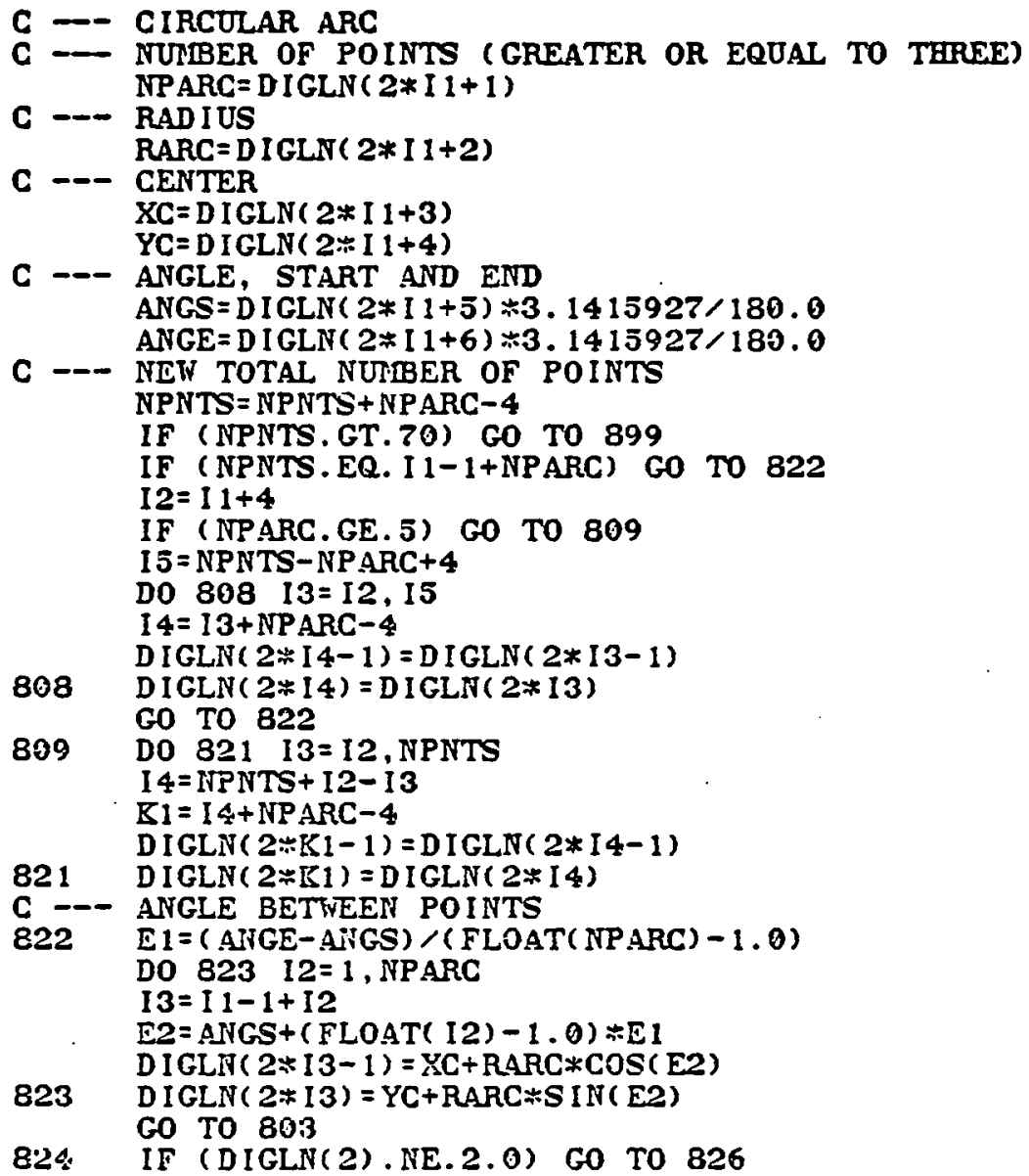


REAL LINC( 800$)$

CONOMON /BLOCK2/L INC, NZV, NZB, ADMAB, ADMAD/BLOCK6/TTRI ( 8)

INTOR $=0$

811

DO $811 \quad[=1,4$

NTRI $(I)=0$

DO $815 \quad I=1, I 1$

$N 1=2 *(L P N T+1)$

$X 1=\operatorname{LINC}(N 1-1)$

$Y 1=\operatorname{LINC}(N 1)$

$X 2=\operatorname{LINC}(N 1+1)$

$Y 2=\operatorname{LINC}(N 1+2)$

IF (Y.LT.AMIN1 $(Y 1, Y 2) . O R . Y . G T$. AMAX1 (Y1,Y2).OR.Y1.EQ.Y2) CO TO 812

$\mathrm{X} 3=(\mathrm{Y}-\mathrm{Y} 1) \div(\mathrm{Y} 2-\mathrm{X} 1))(\mathrm{Y} 2-\mathrm{Y} 1)+\mathrm{X} 1$

IF (X.GT.X3-0.01.AND.X.LT.X3+0.01) G0 TO 816

IF (Y.EQ. Y1) GO TO 812

IF (YS.LT.X) IFTRI $(1)=\operatorname{NTRI}(1)+1$

IF ( X3.GT.X) NTRI ( 2$)=\operatorname{NTRI}(2)+1$

812 IF (X.LT.AHIN $1(X 1, X 2), O R . X . G T . A M A X 1(X 1, X 2) . O R . X 1 . E Q . X 2)$ GO TO 813 $Y 3=\left(X-X_{1}\right) *(Y 2-Y 1) /(X 2-X 1)+Y 1$

IF (Y.GT. Y3-0.01.AND.Y.LT. Y3+0.01) GO TO 816

IF (X.EQ.X1) Go TO 813

IF (Y3.LT.Y) NTRI (3) $=\operatorname{NTRI}(3)+1$

IF (Y3.GT.Y) NTRI $(4)=\operatorname{NTRI}(4)+1$

813 DO $314 \mathrm{N1}=1,4$

IF (NTRI (N1).EQ.2) NTRI $(N 1)=0$

814 CONTIIUE

Q15 CONTINUE

$\mathrm{N} I=\operatorname{NTRI}(1)+\mathrm{NTRI}(2)+N \operatorname{TRI}(3)+\operatorname{NTRI}(4)$

IF (N I.GE.3) INTOR=1

816 RETURH

END

FUNCTION NODFT (NODF, NODL)

NODFT $=($ NODL -1$) \div$ NODL $/ 2+$ NODF

IF (NODF. GT. NODL) NODFT $=($ NODF -1$) \div N O D F / 2+$ NODL

RETURY

END

FUNCTION NBOUFT( M, N, LEF, LEL, LVF, LVL)

NBOUFT $=0$

C - - CHECK TPAT YOU ARE THT CI :NY BOTNDARY

IF ( (N.EQ. LEF) . AND. ((I. GE.LVF) . AND. (M. LE.LVL))) GO TO 10

IF ( (N. EQ. LEII). AND. ((N.GE.LVF). AND. (M.LE.LVL)) ) GO TO 10

IF ( (M.EQ. LVF) . AND. ( (N.GE.LEF) . AND. (N.LE.LHR) )) GO TO 10

IF ( (M. EQ.LVL). AND. ((N,GE.LAF). AND. (N.LE.LHL))) CO TO 10 RETURi'

10 NBOUFT $=1$

RETURT

END 


\section{Appendix 4 - Flow Charts}

Table of Key-to-Program-Line* Correspondence

III.B.3.I (CODING) Standard Admittances Computation
III.B. 4.1
III.B. 4.2
III.B. 4.3
III. B. 4.4
III. B. 4.5
III.B. 4.6
III.B. 4.7
III.B. 4.8
III.B. 4.9
III.B.4.10
III.B. 4.11
(EQUIV) Block Action of EQUIV
(EOUIV) Subdivision of Action Block A of EQUIV
(EQUIV) Code Decomposition - Block A1
(EQUIV) Electric Node Assignation - Block A2
(EOUIV) Permittivity Assignation - Blocks A3 and A4
(EQUIV) Computation of Admittances - Block A5
(EQUIV) Admittance Addition - Block B
(EQUIV) Kron Reduction Logic - Block C1
(EQUIV) Node Elimination - Block C2
(EOUIV) Writing Nodal Information - Block D1
(EQUIV) Writing Node Voltages - Block D2
III.B.5.1 (SOLUTN) Potential Code Assignation
III.B.5.4 (SOLUTN) Window Admittance Creation
III.B.5.5 (SOLUTN) Reading Equivalent Matrix
III.B.5.6 (SOLUTN) Solution of System of Equations
III.B.5.7. (SOLUTN) Field Strength
III.B.5.8 (SOLUTN) Writing of Potentials
III.B.6 Subroutine PLOTY
III.B. 7 Subroutine PERTRI
III.B. 8 Subroutine FSTR
III.B.13 Function NBOUFT

* Program lines are numbered from 1 to 56 for each program page (from 1 to 32) as given in Appendix 3. 
Table of Key-to-Program-Line Correspondence

\begin{tabular}{|c|c|c|c|}
\hline \multirow[b]{2}{*}{ Subroutine } & \multirow[b]{2}{*}{ Rey } & \multicolumn{2}{|c|}{ Program } \\
\hline & & Page & Line \\
\hline CODING & $\begin{array}{l}\text { A } \\
\text { B }\end{array}$ & $\begin{array}{l}4 \\
5\end{array}$ & $\begin{array}{r}45 \\
8\end{array}$ \\
\hline EQUIV & $\begin{array}{l}\text { C } \\
\text { D } \\
\text { E } \\
\text { F } \\
\text { G } \\
\text { H } \\
\text { I } \\
\text { J } \\
\text { K }\end{array}$ & $\begin{array}{l}25 \\
25 \\
26 \\
27 \\
28 \\
28 \\
29 \\
29 \\
30\end{array}$ & $\begin{array}{r}27 \\
27 \\
11 \\
23 \\
12 \\
26 \\
2 \\
55 \\
10\end{array}$ \\
\hline SOLUTN & $\begin{array}{l}\mathrm{L} \\
\mathrm{M} \\
\mathrm{N} \\
0 \\
\mathrm{P} \\
\mathrm{Q} \\
\mathrm{R} \\
\mathrm{S}\end{array}$ & $\begin{array}{l}13 \\
14 \\
13 \\
16 \\
16 \\
17 \\
18 \\
19\end{array}$ & $\begin{array}{r}37 \\
6 \\
17 \\
19 \\
47 \\
20 \\
17 \\
18\end{array}$ \\
\hline
\end{tabular}




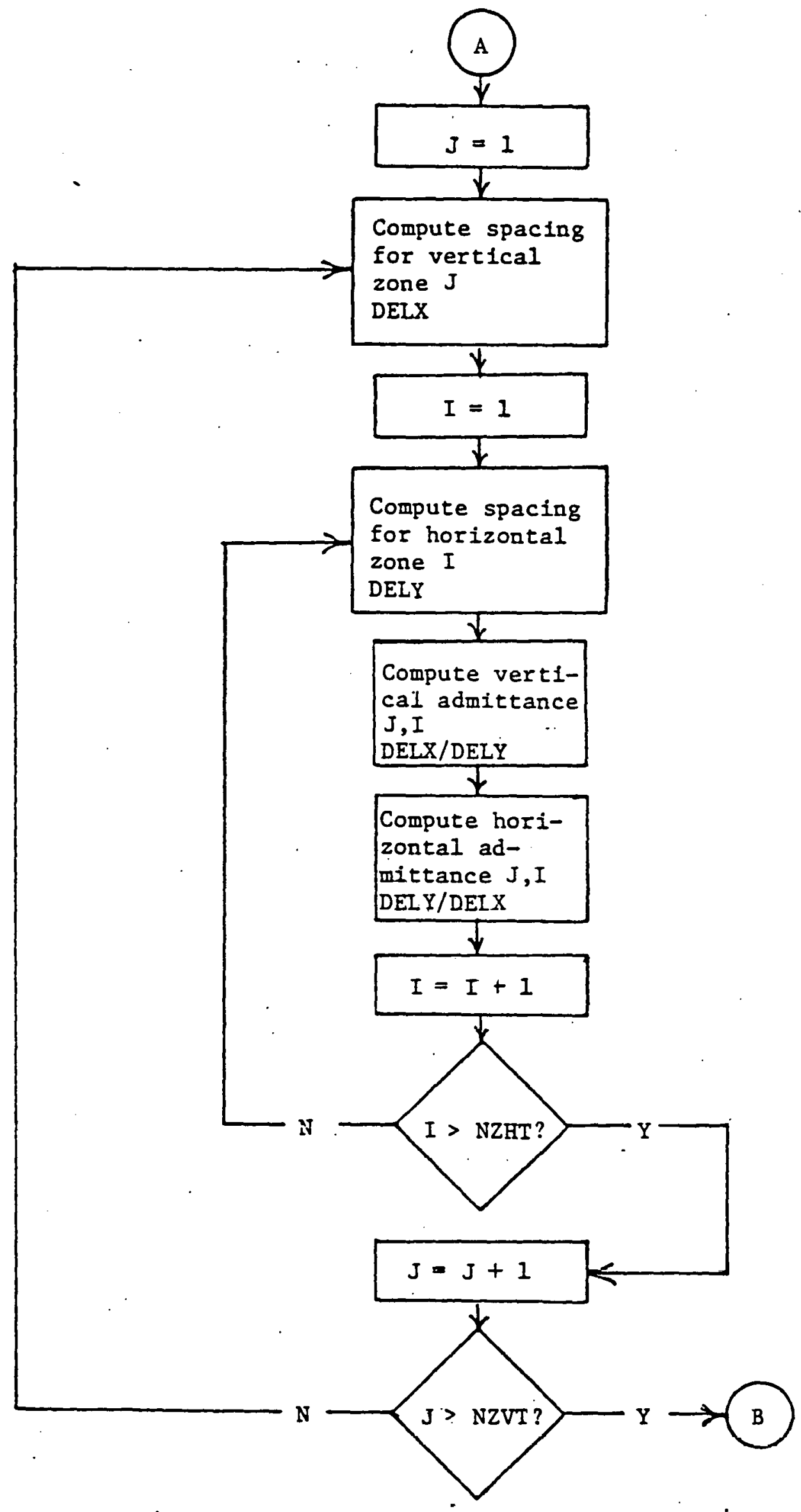

- F1gure III.B.3.1

Standard Admittances Computation Flowchart (CODING)

A. 39 


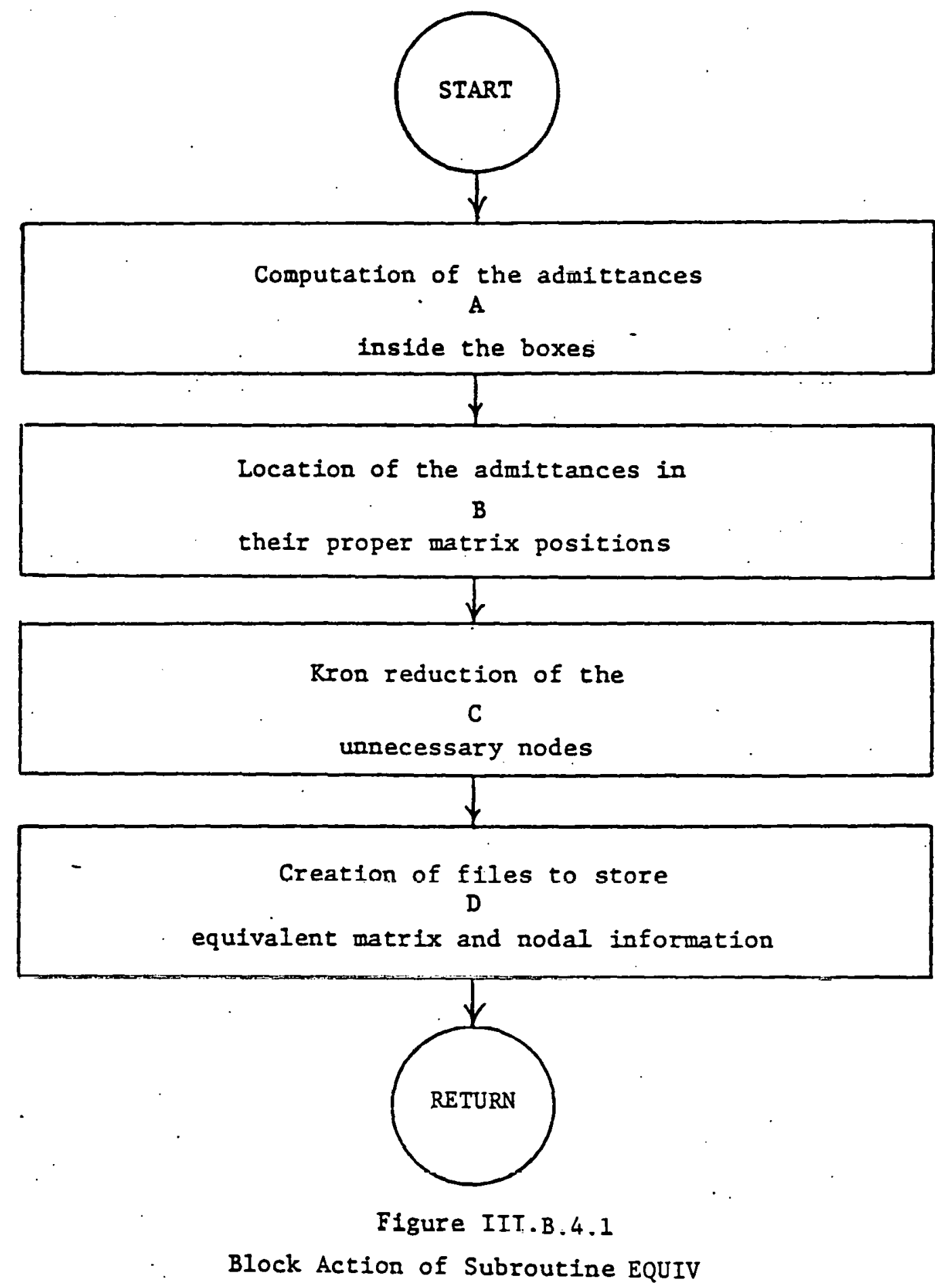




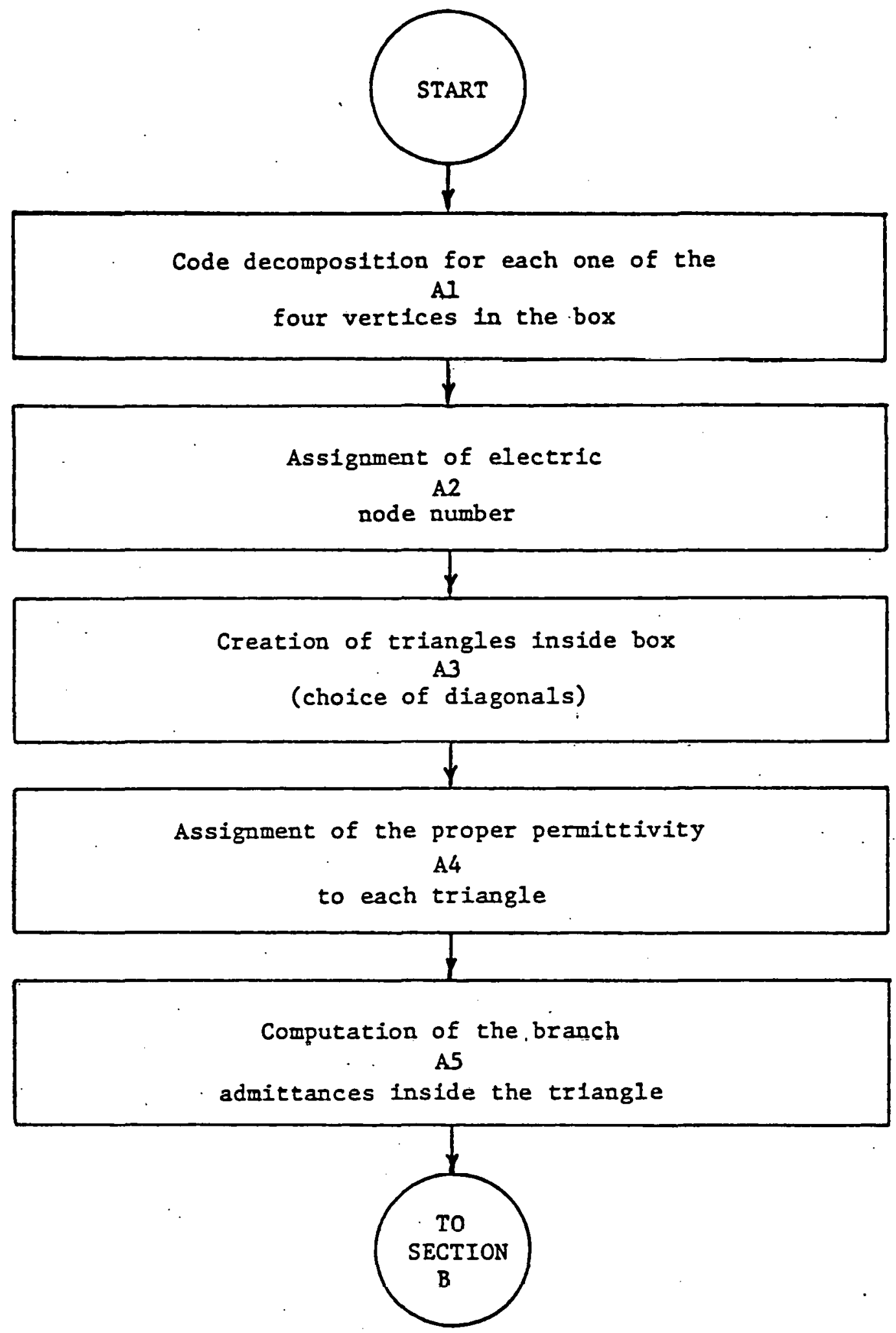

Figure III.B.4.2

Subdivision of Action Blocks of Block A of EQUIV 


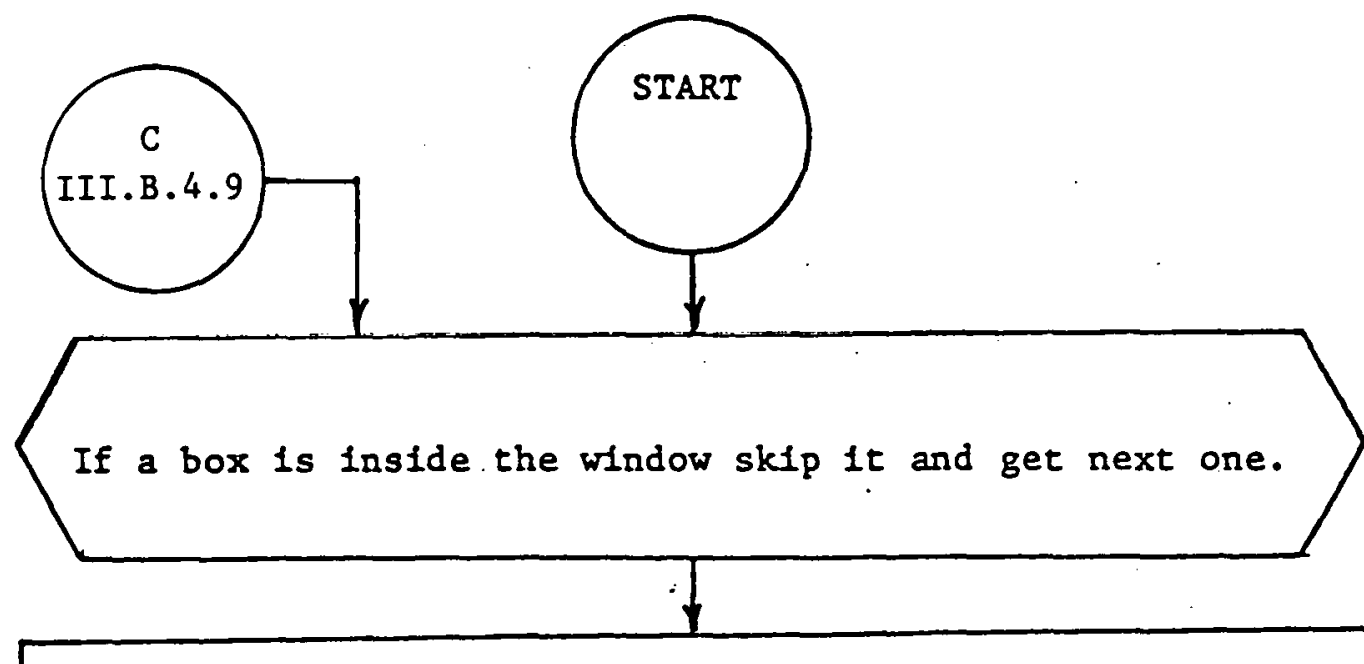

For each corner of the box repeat steps to E

Find the horizontal (N) and vertical (M) lines defining the corner.

Compute the irregularity code: NIRR

Compute the contour zone: NZON

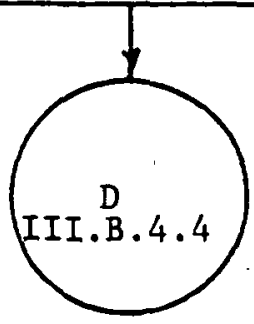

Figure III.B.4.3

Code Decomposition Flow Chart

Subroutine EQUIV

Block AI 


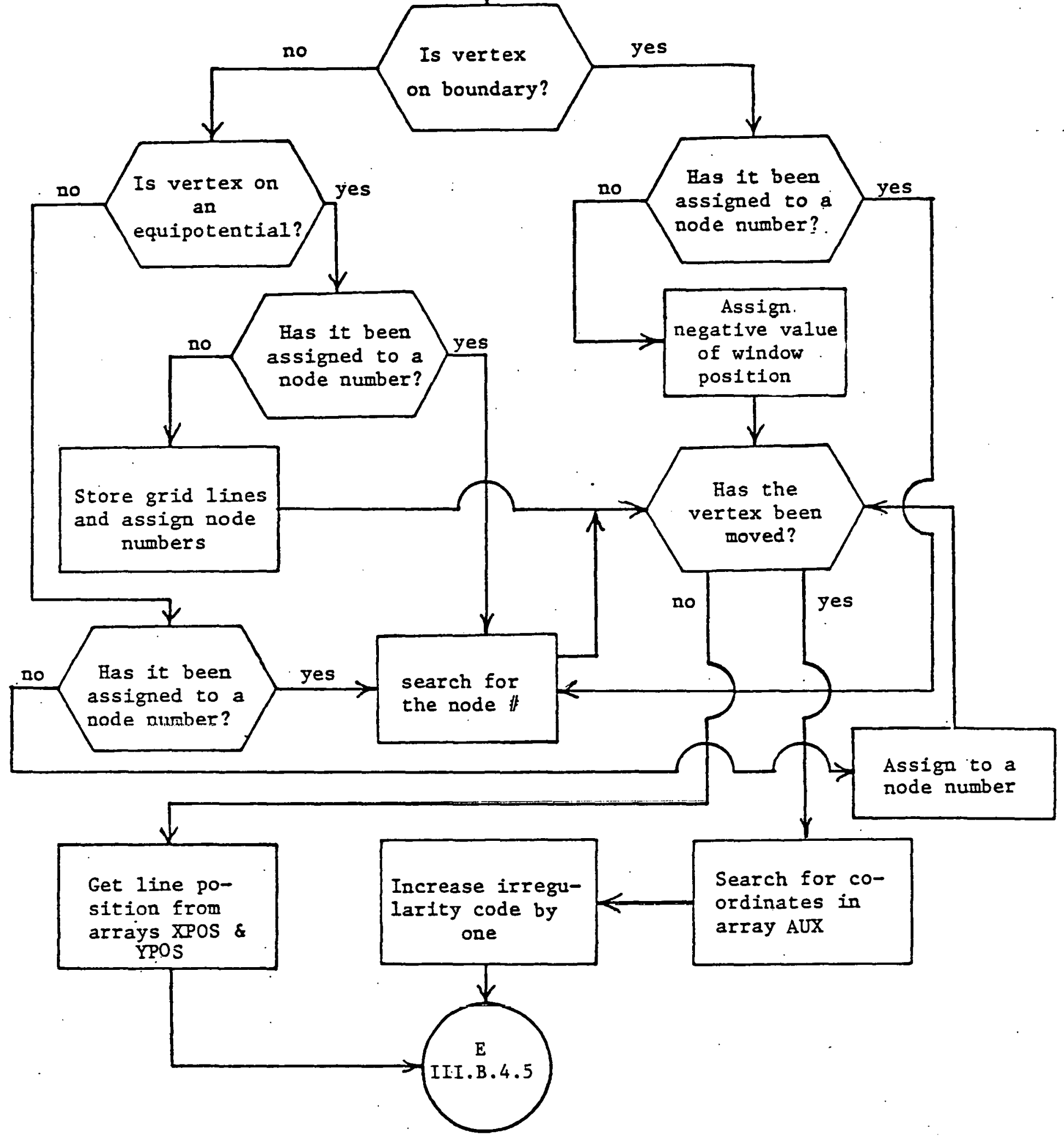

\section{FIgure III.B.4.4}

-Electric Node Number Assignatinn Flow Chart

Subroutine EQUIV, Block A2 


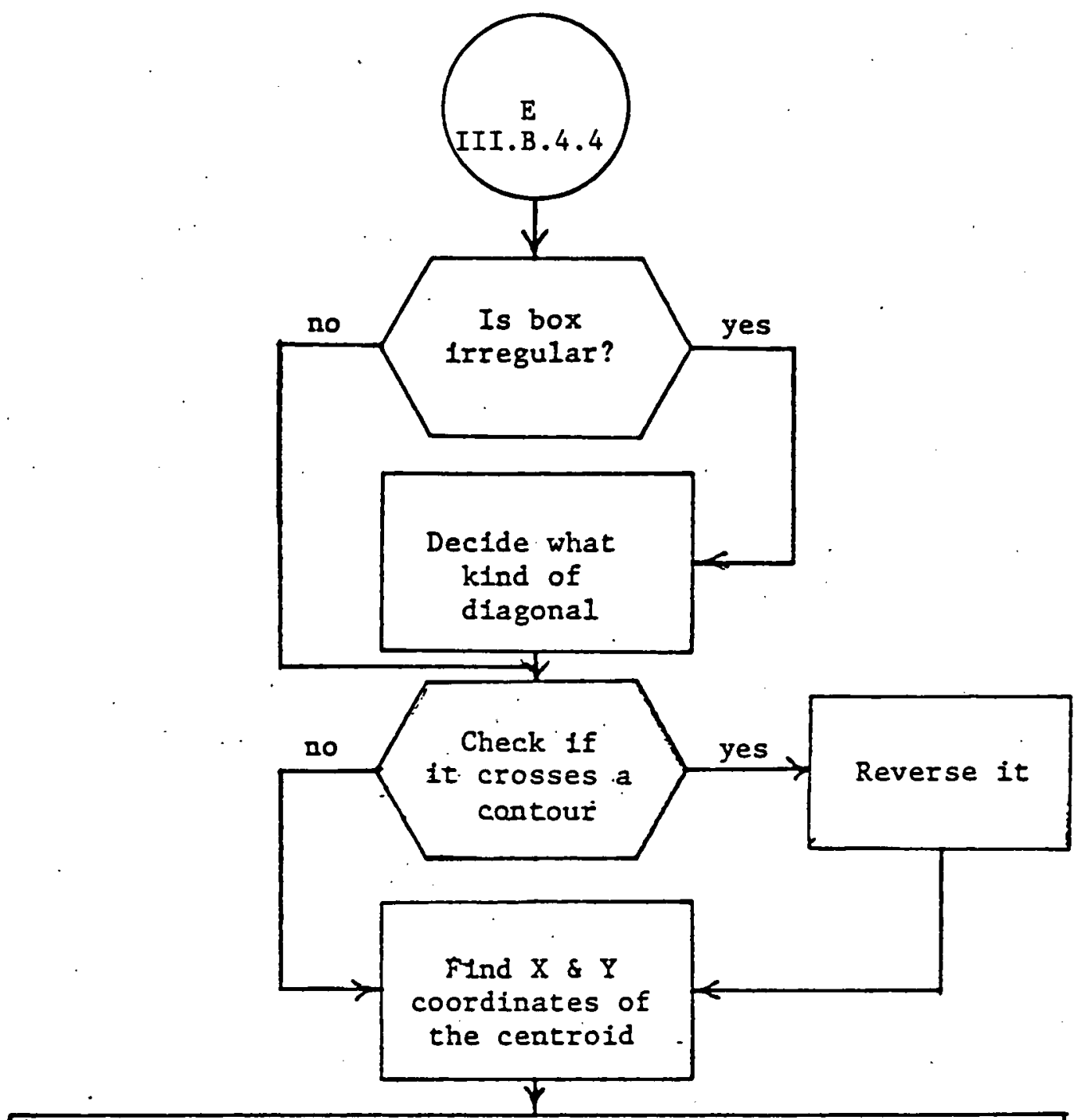

Subroutine INTER is called

Returns the contour to which the centroid is internal, if none returns a zero

Assign permittivity of the indicated contour,

if INTOR $=0$ equals zero assign

default permittivity

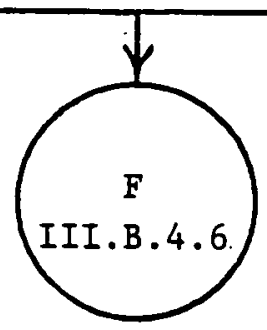

Figure III.B.4.5

Permittivity Assignation Flow Chart

Subroutine EQUIV, Blocks $A 3$ and $A 4$ 


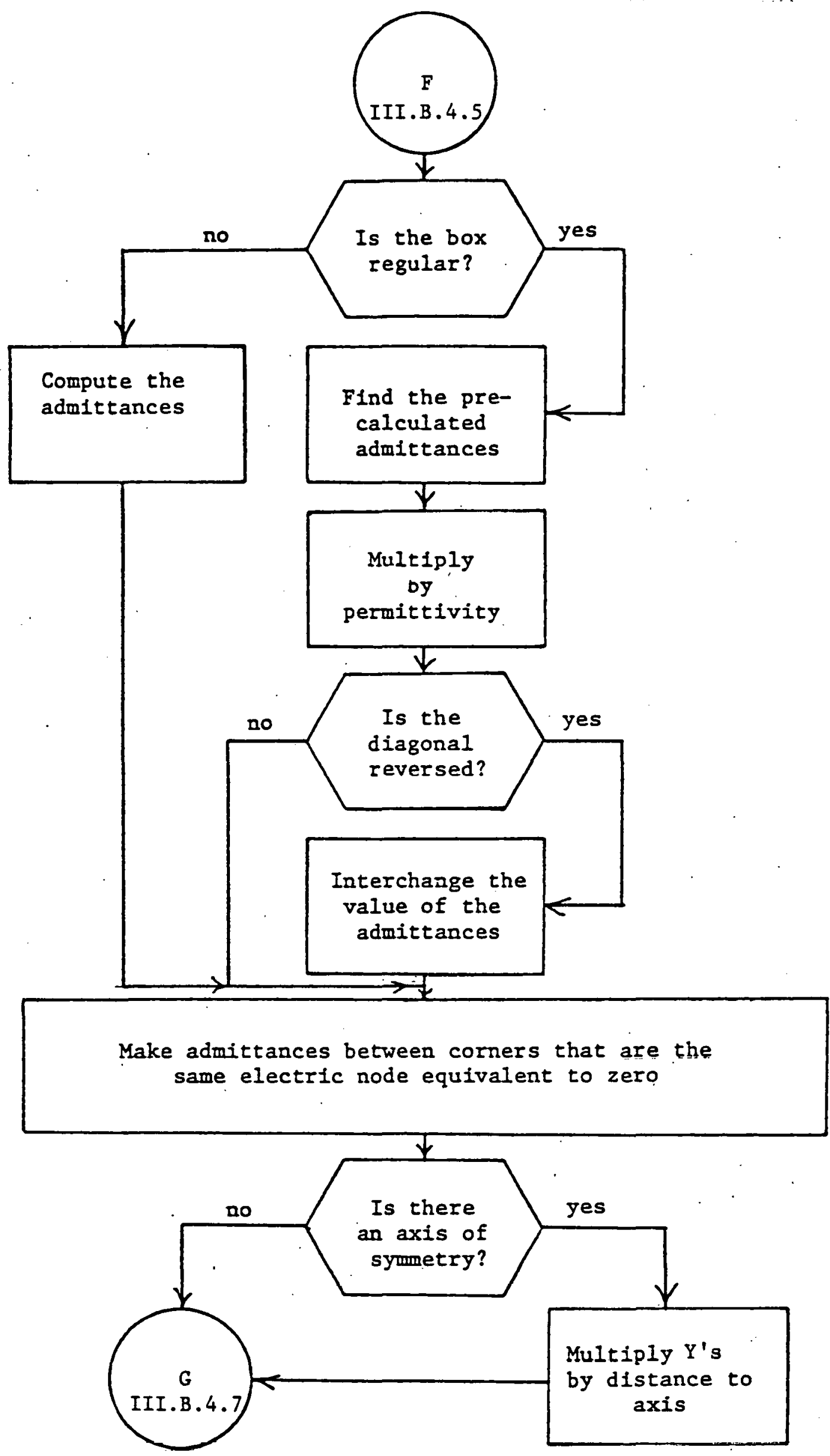

Figure III.B.4.6

Computation of Admittances Flow Chart Subroutine EQUIV, Block AS 


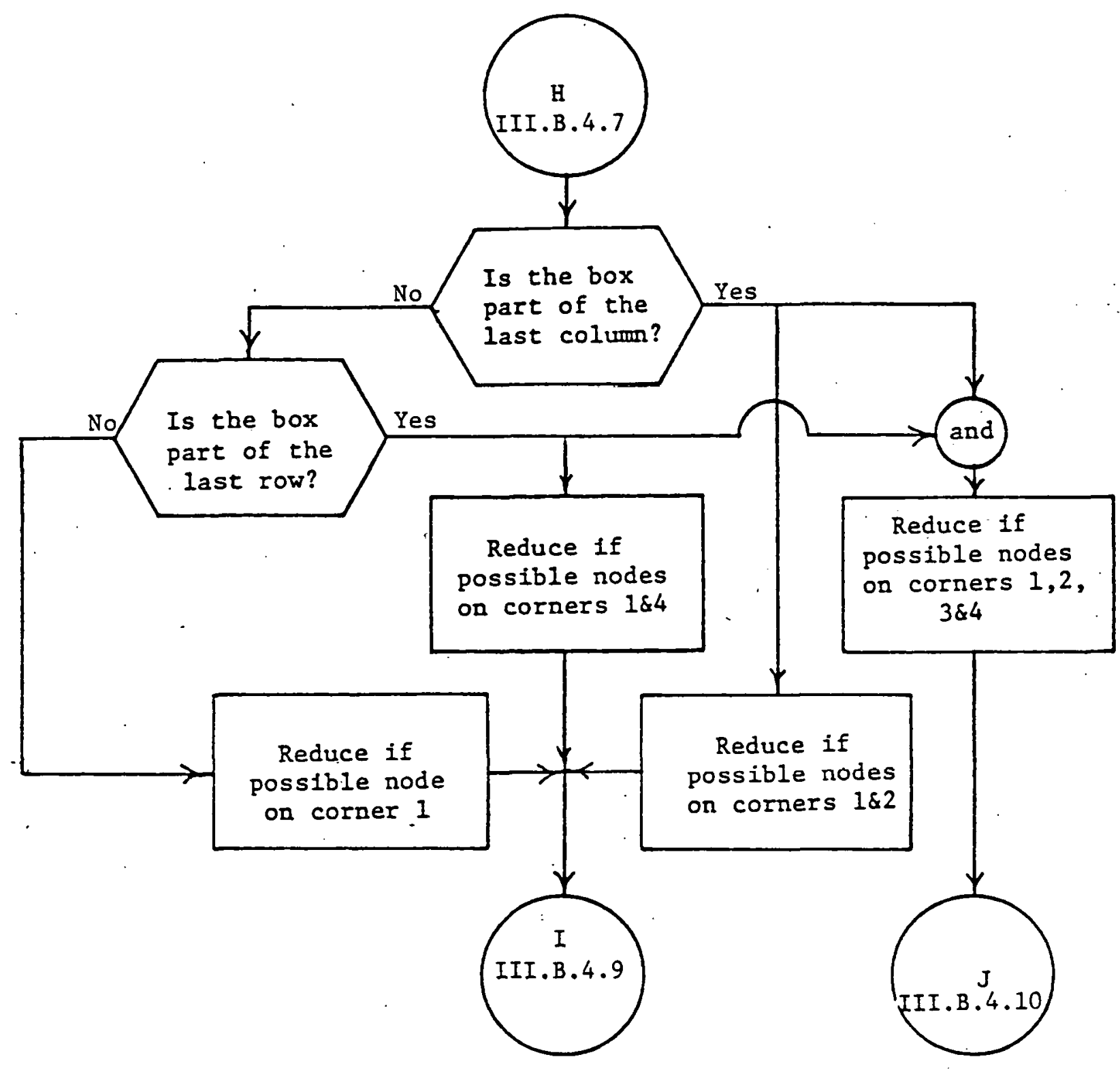

F1gure III.B.4.8

Kron Reduction Logic Flow Chart

Subroutine EQUIV, Block Cl 


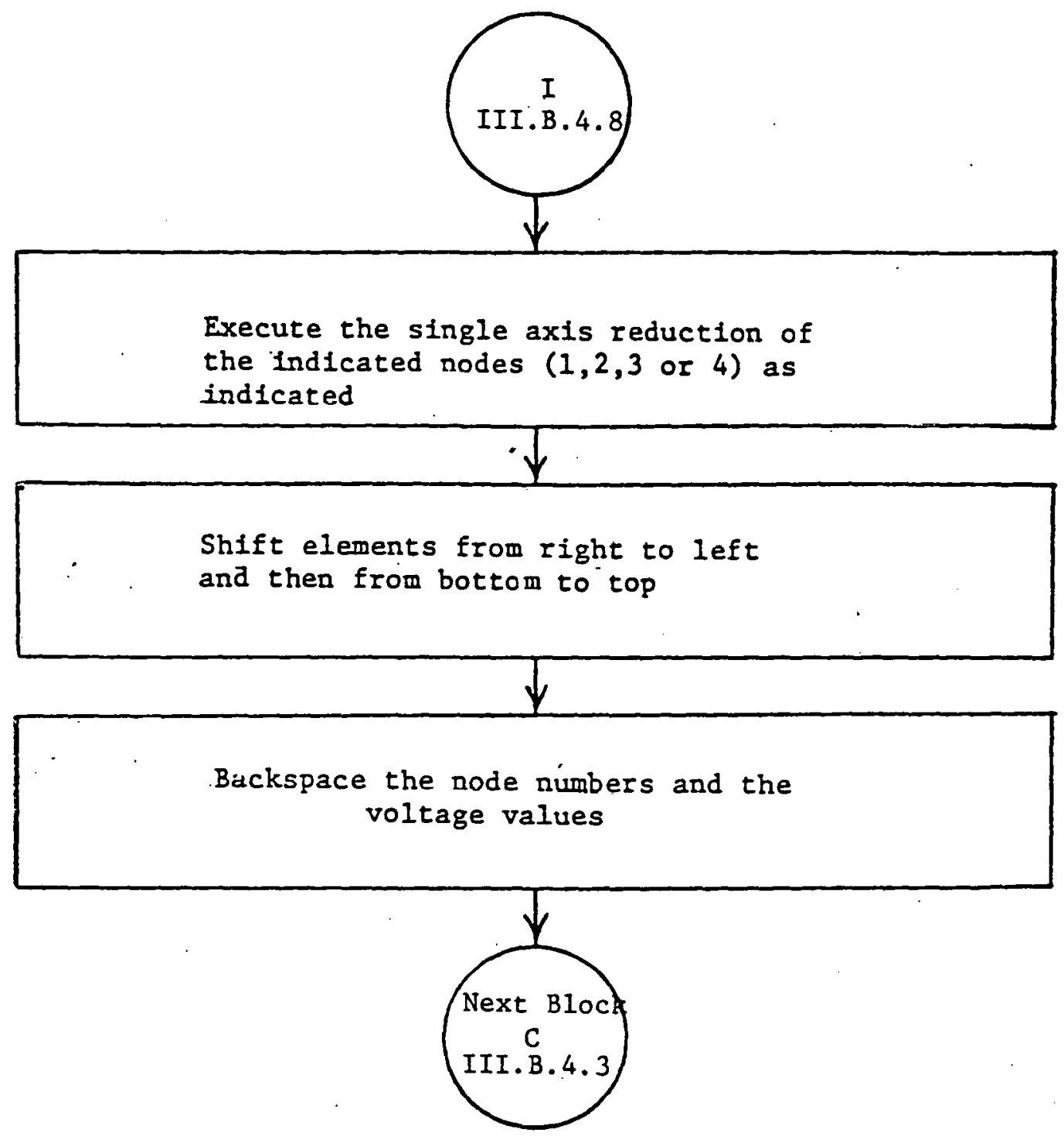

Figure III.B.4.9

Block action for node elimination

Subroutine EQUIV, Block C2 


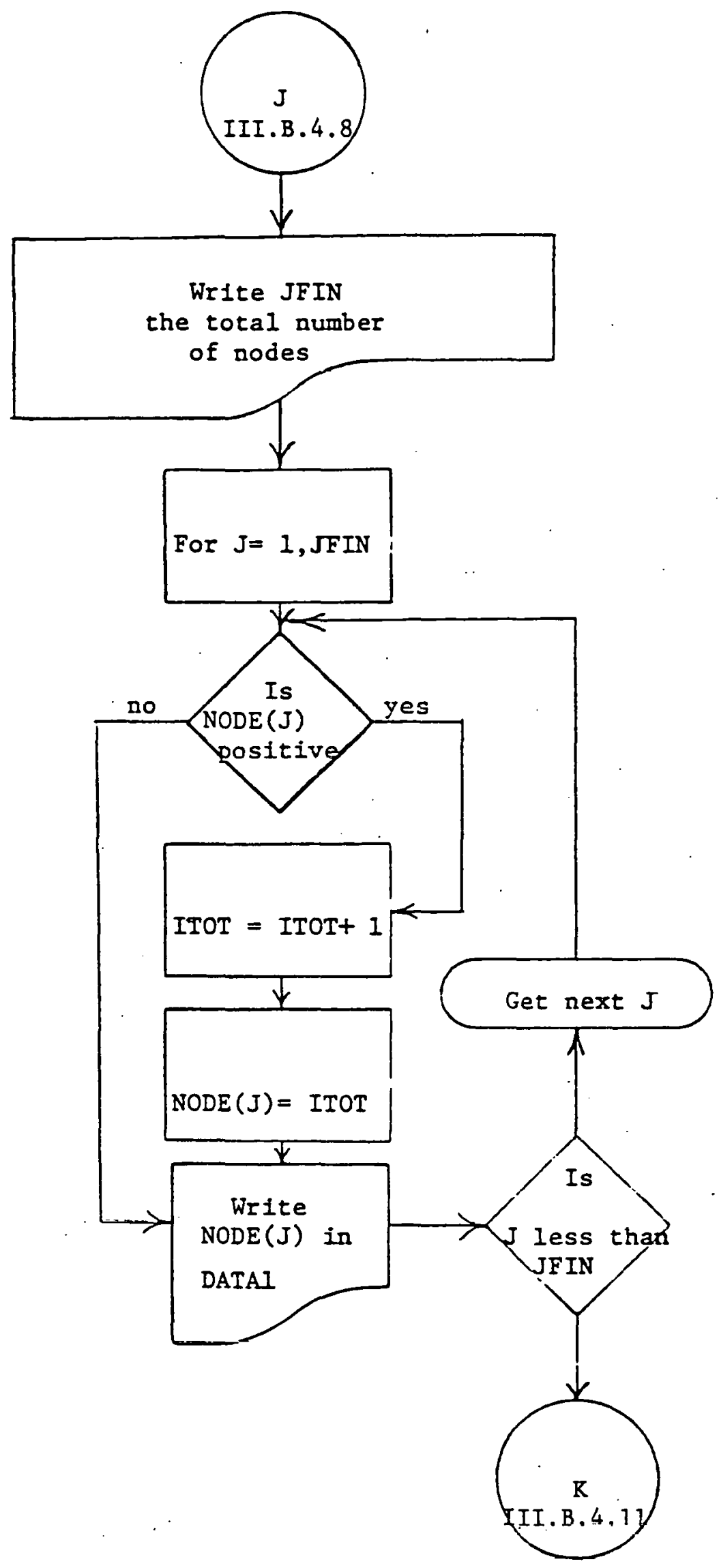

Figure III. B.1.10

Writing of nodal information

Subroutine EQUIV, Block D 1 


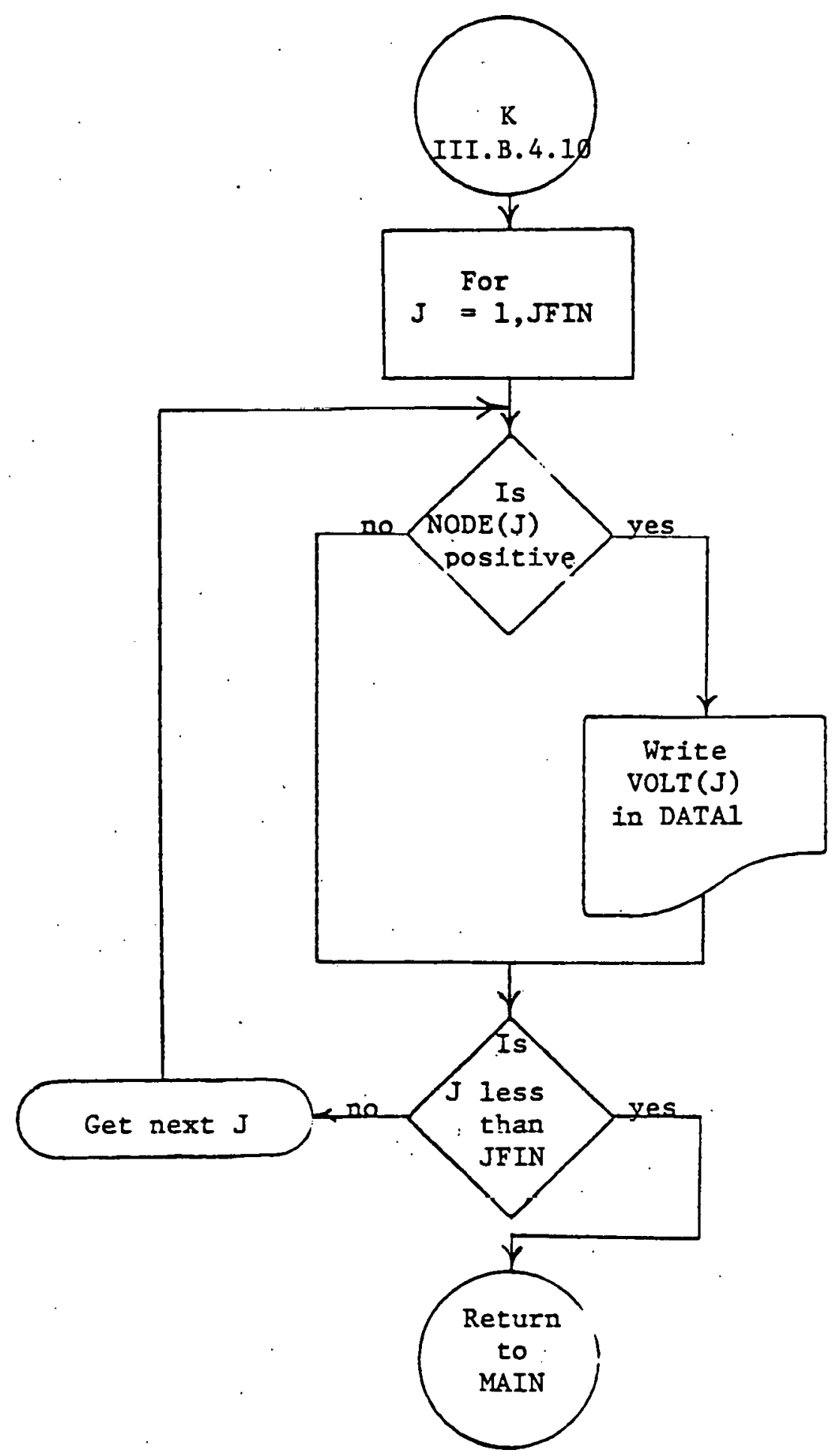

Figure III.B.4.11

Writing of the node's voltage

Subroutine EQUIV, B1ock. D2 


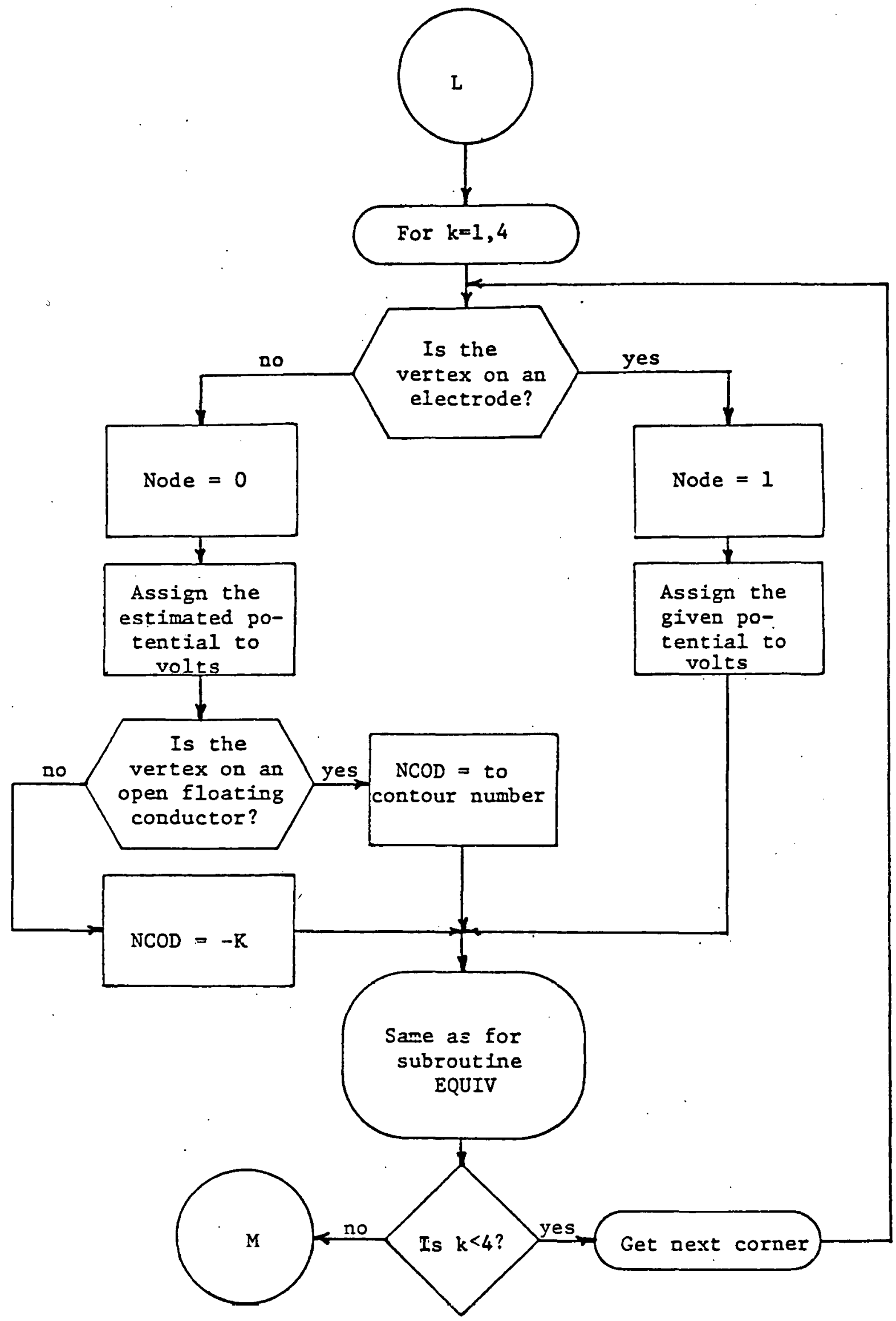

Figure III.B.5.1

Potential Code Assignation Flow Chart Subroutine SOLUTN

\section{A. 51}




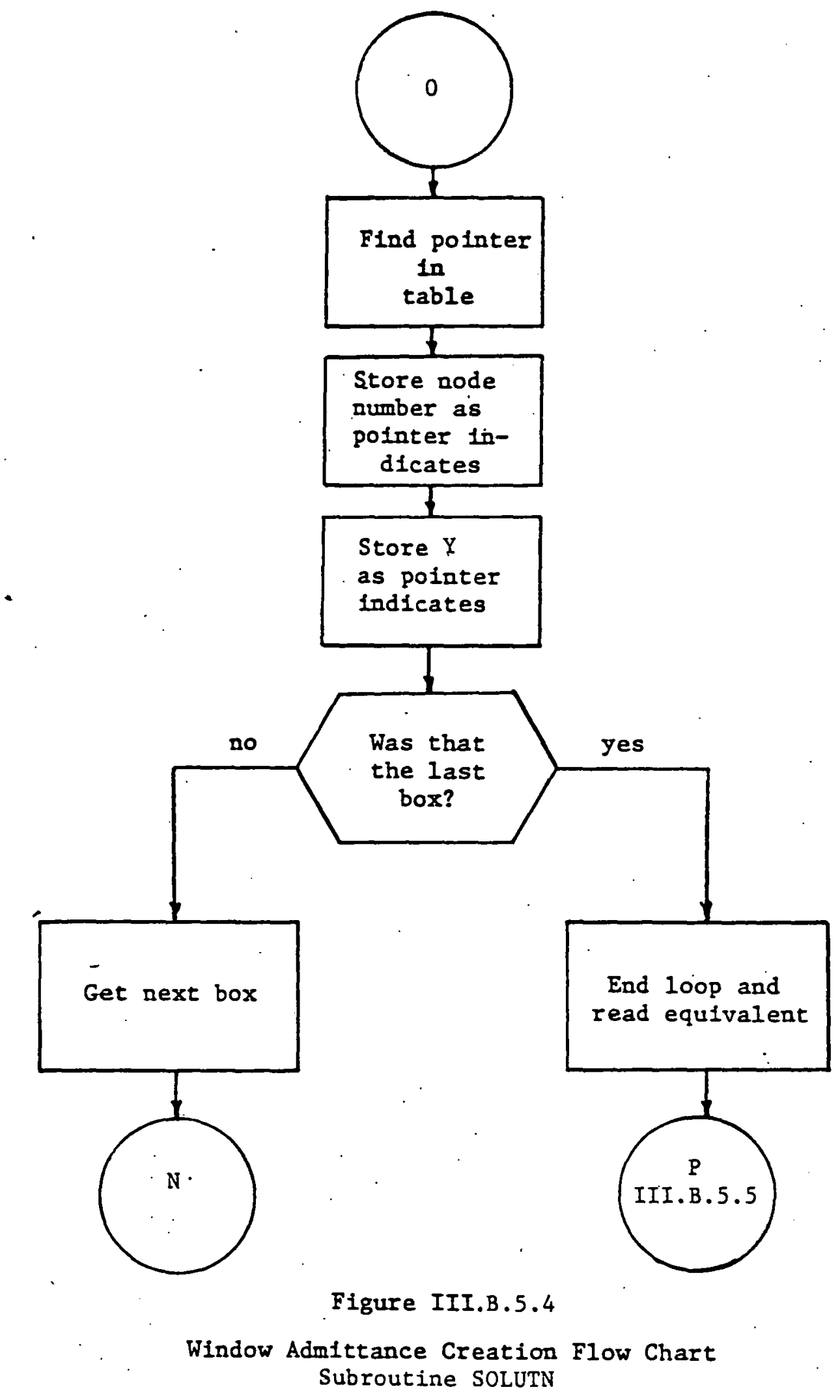




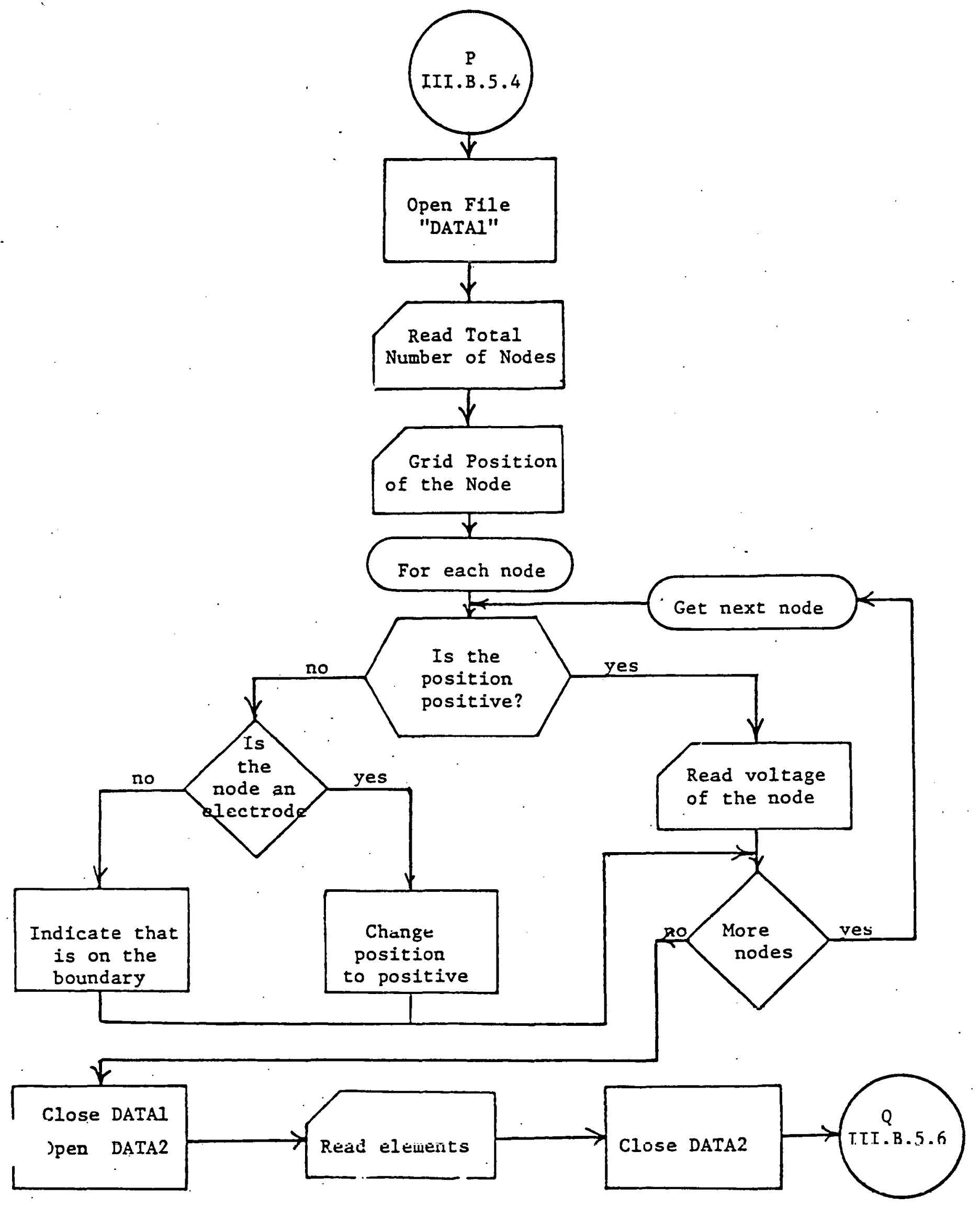

Figure III.B.5.5

Reading of the equivalent matrix, Flowchart (SOLUTN) 


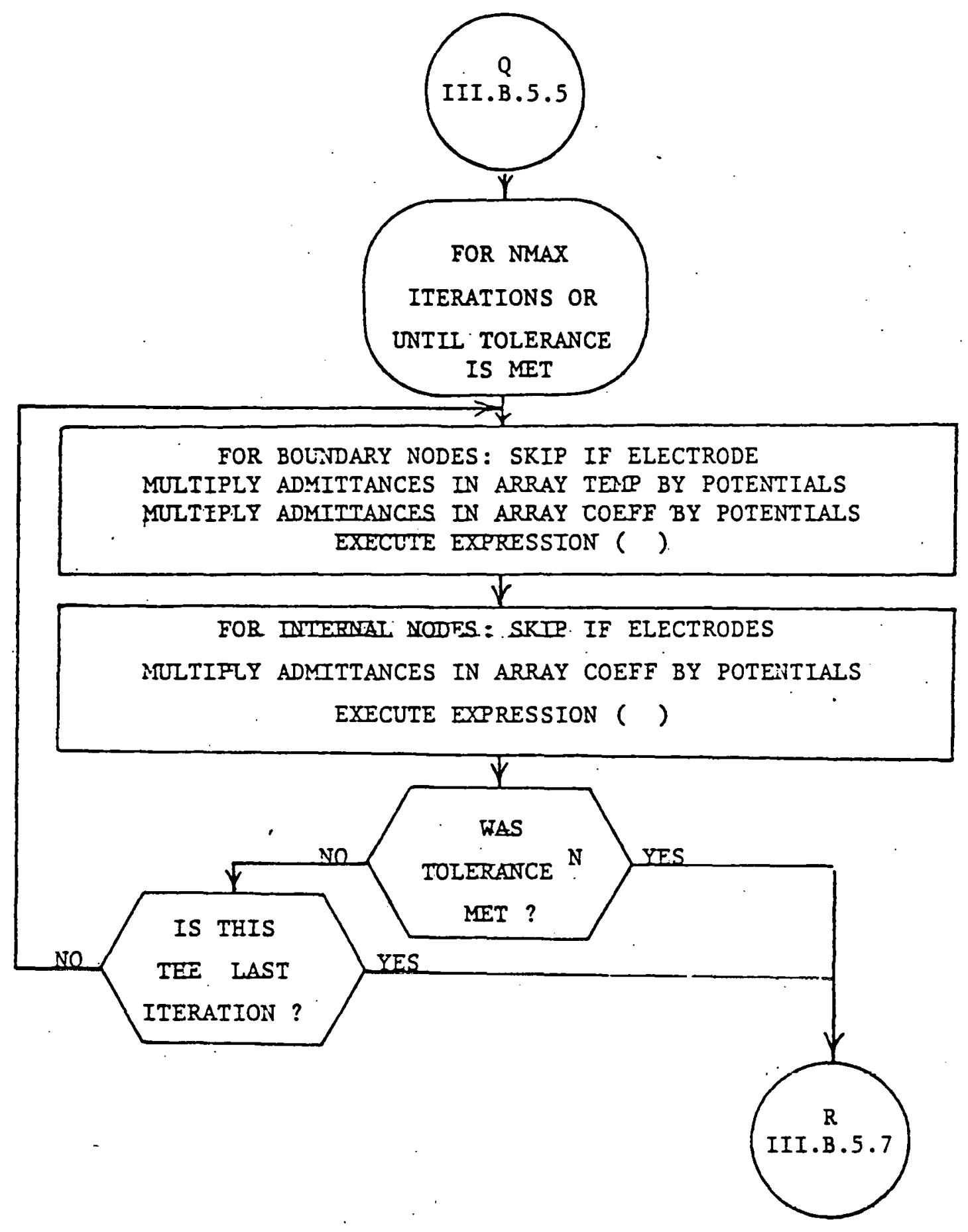

Figure III.B.5.6

Solution of the System of Equations Flow Chart Subroutine SOLUTN 


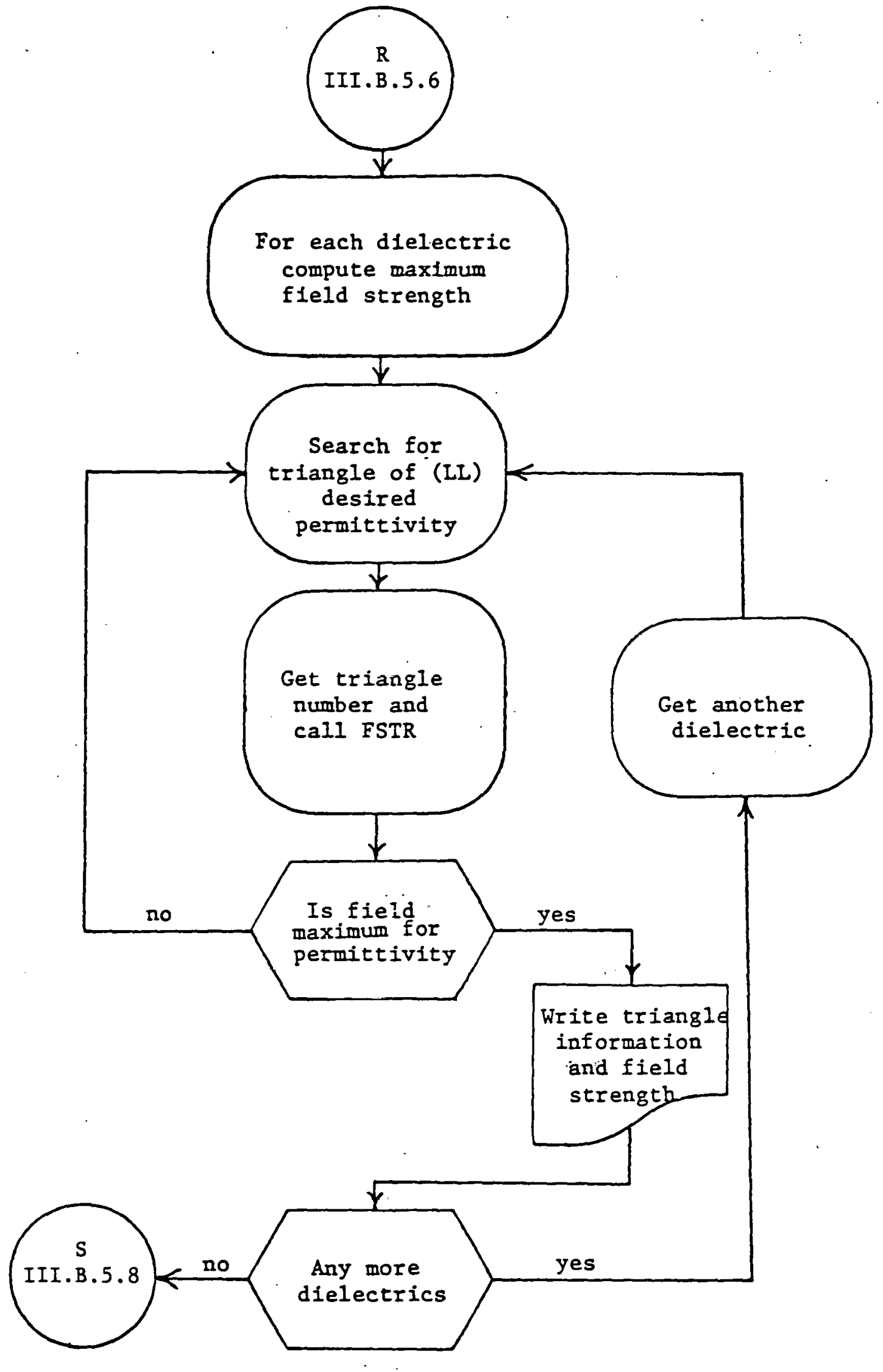

Figure III.B.5.7

Field Strength Flow Chart (SOLUTN) 


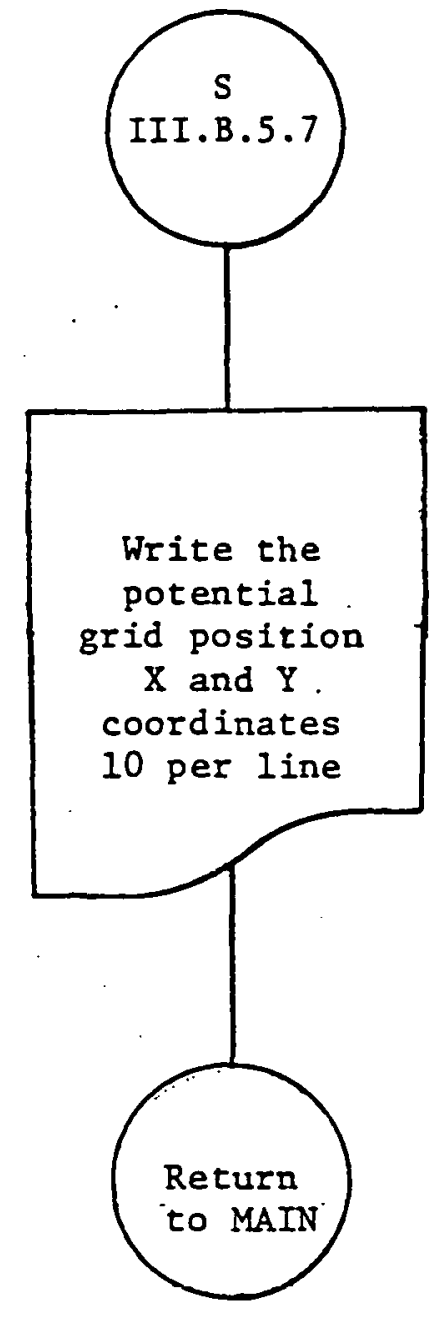

Figure III.B.5.8

Wriling of the Potentials

Subroutine SOLUTN 


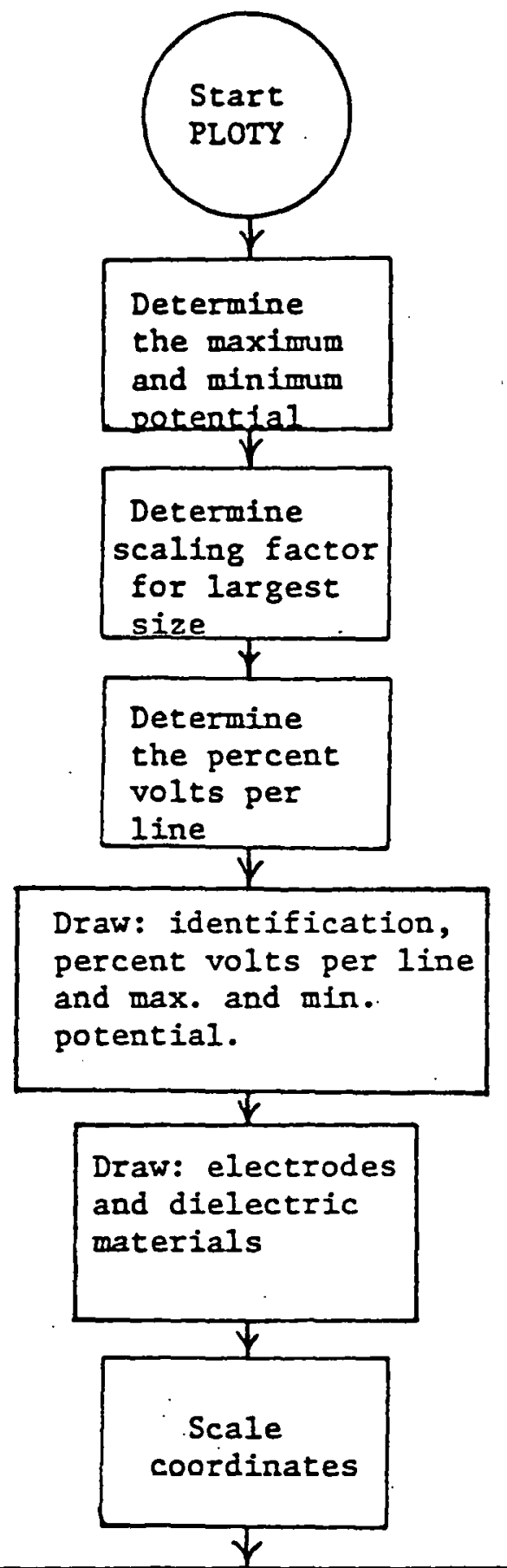

For each percent increase, search each triangle. When applicable join sides of required potential by a segment and draw the concatenation of segments defining the equipotential line corresponding to the percent increase

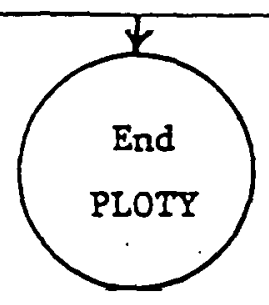

Figure III.B.6

Subroutine PLOTY, Flowchart 


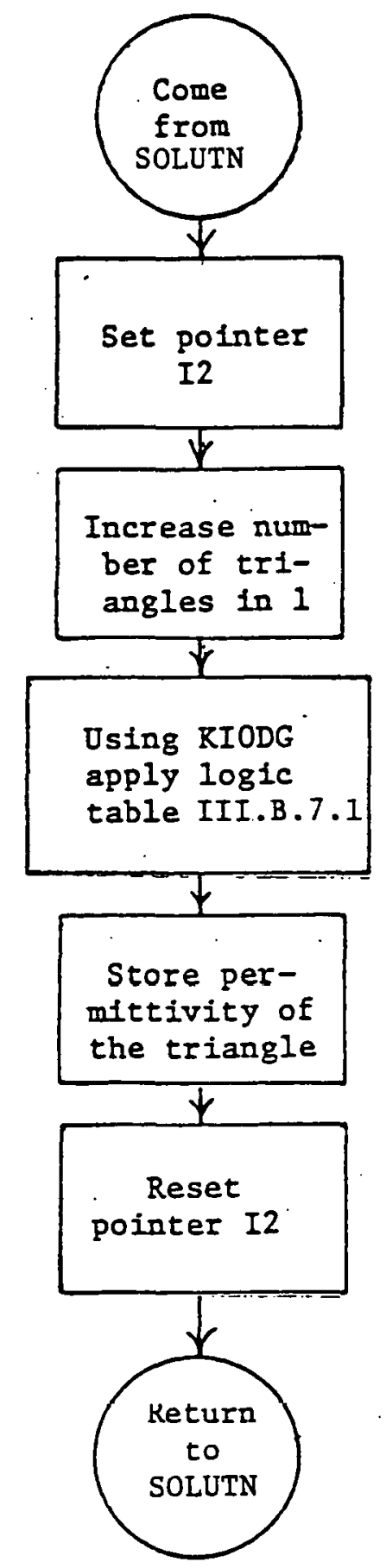

Figure III.B.7

Subroutine PERTRI Flow Chart 


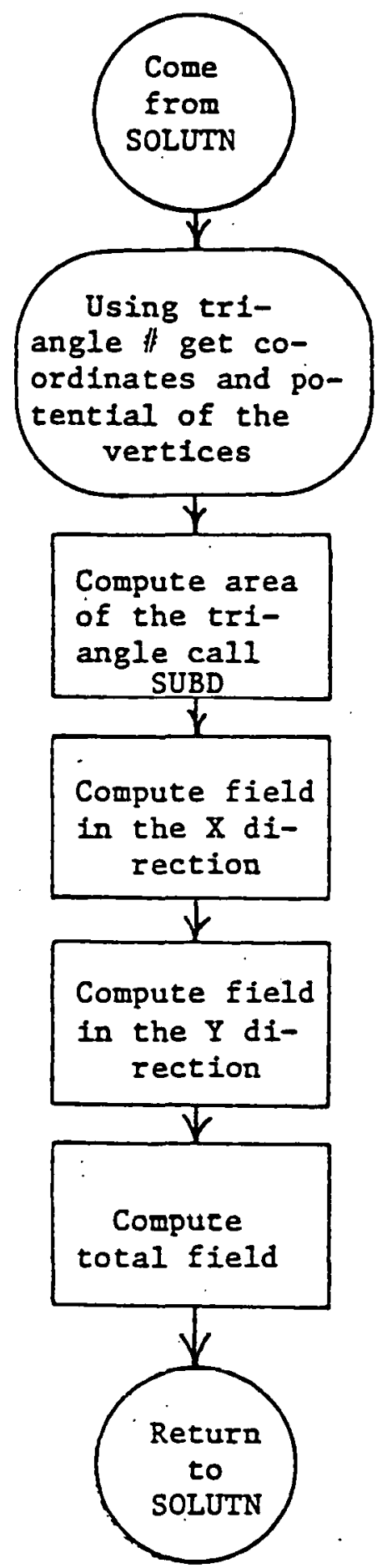

Figure III.B. 8

Subroutine FSTR Flow Chart 


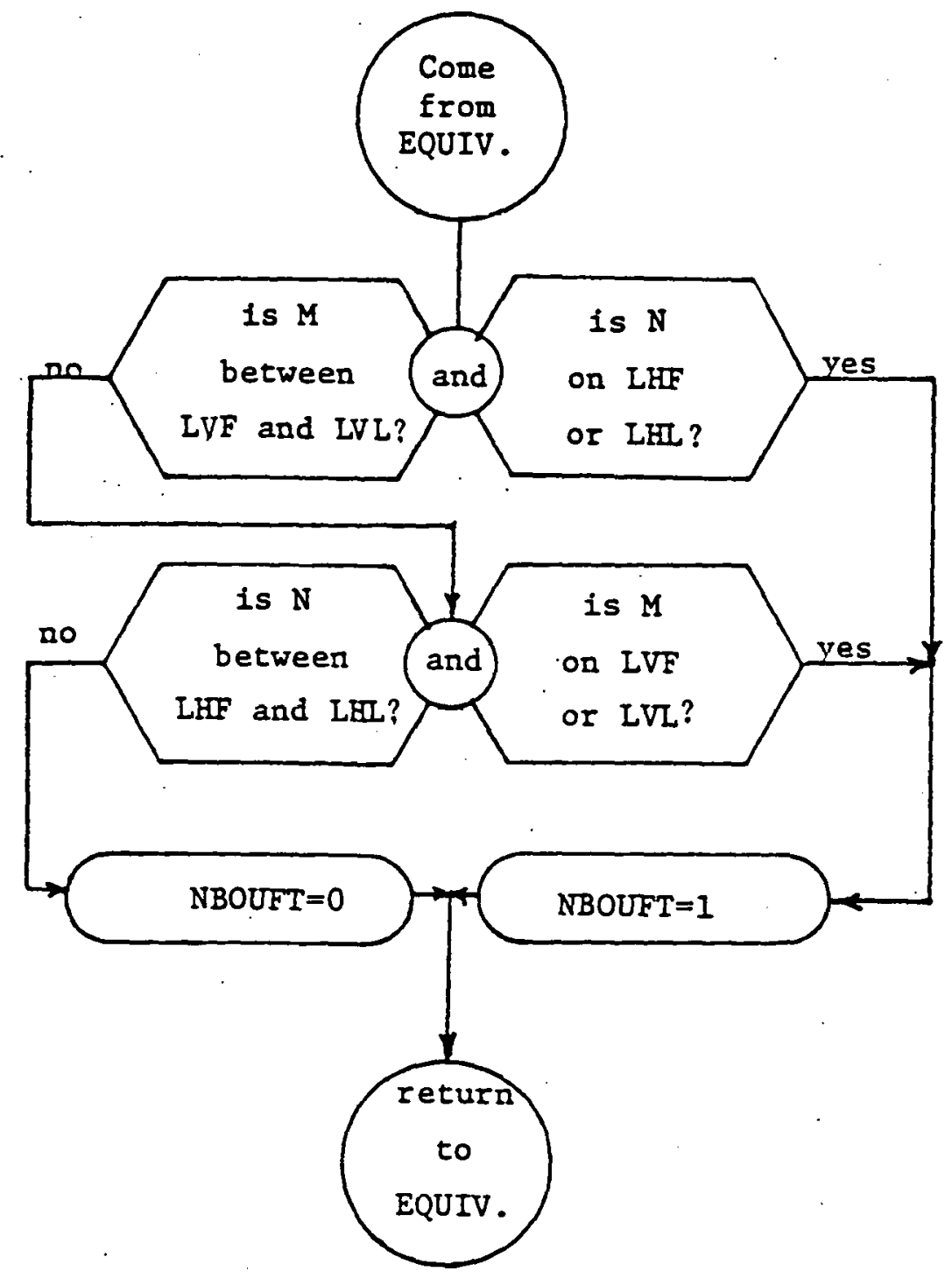

Figure III.B.13

Function NBOUFT Flowchart. 